\title{
LINUX-SMART: \\ Melhoria de Desempenho para Aplicações Real-Time Soft em Ambiente LINUX.
}

Jorge Euler Vieira

DISSERTAÇAO APRESENTADA

$\mathrm{AO}$

INSTITUTO DE MATEMÁTICA E ESTATÍSTICA

$\mathrm{DA}$

UNIVERSIDADE DE SÃO PAULO

PARA OBTENÇÃO DO GRAU

$\mathrm{DE}$

MESTRE EM CIÊNCIA DA COMPUTAÇĀO

Area de Concentração: Sistemas Operacionais Orientadora: Profa. Dra. Dilma Menezes da Silva

- São Paulo, 21 de outubro de 1999 - 


\title{
LINUX-SMART: Melhoria de Desempenho para Aplicações Real-Time Soft em Ambiente LINUX
}

\begin{abstract}
Este exemplar corresponde à redução final devidamente corrigida e defendida por Jorge Euler Vieira e aprovada pela comissão julgadora
\end{abstract}

São Paulo, 21 de Outubro de 1999.

Banca examinadora:

- Profa. Dra. Dilma Menezes da Silva - Orientadora

- Prof. Dr. Marco Dimas Gubitoso

- Prof. Dr. Rômulo Silva de Oliveira 


\section{Agradecimentos}

A Deus, que concedeu-me a vida e a inspiração para este trabalho e deu-me tranqüilidade nos momentos difícieis para superá-los.

Sou grato a minha orientadora, Profa. Dilma, pela excelente orientação e apoio durante todo o curso de Mestrado, desenvolvimento desta dissertação e principalmente, por ela ter aceito esta parada:-))).

Agradeço aos meus colegas de trabalho, principalmente aos meus chefes: Arnalberto, Roberto e Tarifa por compreenderem a necessidade de me ausentar por várias ocasiões no trabalho para assistir as aulas no IME ou em função de reuniōes com minha orientadora.

A Liliane, Euler, Jorge e Silvia (futura esposa e filhos :-))) pelo apoio técnico, pelo carinho, estímulo, paciência, compreensão e incentivo em todos os momentos desta tese, principalmente nos momentos difíceis.

Agradeço aos professores do IME pelo oportunidade de melhorar meus conhecimentos e minha formação acadêmica. Especialmente ao Prof. José Augusto por ter me guiado nos passos iniciais deste Mestrado.

Também agradeço aos professores Gubi e Rômulo por aceitarem compor minha banca examinadora. E ao Prof. Endler por participar do meu Exame de Qualificação.

Aos colegas do curso no I.ME pelos vários momentos que estivemos juntos dando risadas, tomando cafezinho e estudando seriamente ... afinal de contas estamos aqui para isto:-)).

Aos colegas:

Marco Cesati < cesati@gollum.ce.uniroma2.it >

Rik van Riel < riel@nl.linux.org >

Brian Gerst < bgerst@quark.vpplus.com >

Tigran Aivazian < tigran@sco.com >

Mike Galbraith < mikeg@weiden.de $>$

Andrzej Krzysztofowicz < ankry@pg.gda.pl >

Pavel Machek < pavel@bug.ucw.cz>

Mike Galbraith < mikeg@weiden.de >

Sam Roberts < sam@cogent.ca >

Richard B. Johnson < root@chaos.analogic.com >

demais integrantes da lista de discussãolinux - kernel@vger.rutgers.edu

e principalmente ao Ralf Baechle < ralf@uni-koblenz.de > (respondeu todas as minhas dúvidas sem perder a paciência :- )) ) pelas valiosas sugestões e discussões em grande parte deste trabalho.

Finalmente, aos meus pais e minhas irmãs, pelo amor e constante apoio, e porque mais do que ninguém torceram e sofreram comigo nos momentos difíceis desta fase da minha formação. A eles dedico este trabalho... a eles dedico a minha vida. 


\section{Resumo}

Nos sistemas operacionais atuais não há um escalonador adequado para tratar aplicações de tempo real soft. Estas tarefas se caracterizam pela co-existência com outras aplicações de tempo real ou convencionais.

No âmbito das políticas de escalonamento existentes, adotou-se nesta dissertação o SMART (Scheduling Multimedia Applications Real-Time) como solução para o problema mencionado. Esta política foi analisada, projetada e implementada como escalonador do sistema operacional LINUX. O objetivo da implementação realizada foi analisar o desempenho deste escalonador, bem como o desempenho de uma aplicação multimídia neste sistema em uma situação de sobrecarga.

A aplicação de tempo real construída em TK/TCL foi entitulada "Controle de Aproximação de Aeronaves em Aeroportos". Os testes foram realizados com a aplicação executando sozinha, a aplicação com mais 41 processos (20 processos que consumiam memória, 20 processos que gastavam CPU e 1 processo gráfico), a aplicação com 10 processos (todos gráficos) e a aplicação com um processo de compilação do processador de texto emacs versão 20.2. Isto no sistema LINUX com o SMART e com seus escalonadores padrão, realizando-se uma análise comparativa dos resultados obtidos e dos custos de escalonamento.

Esta dissertação também apresenta uma pequena resenha dos escalonadores de tempo real, os quais foram classificados sob alguns paradigmas que os caracterizam. Adicionalmente, exibe-se os esforços atuais na comunidade LINUX, comparando-se os sistemas estudados com o LINUX modificado pela inclusão do escalonador SMART. 


\begin{abstract}
In current operating systems there is no scheduler appropriated to support soft realtime applications. These tasks are caracterized by co-existing with others conventional and real-time applications.

In the context of contemporary scheduling politics, we chose SMART (Scheduling Multimedia Applications Real-Time) as an approach to solve the above mentioned problem. This scheduling policy has been analyzed, designed and implemented as the LINUX scheduler. We analyzed the performance of the scheduler and the behavior of a real time graphic application in an overloaded system scenario.

The real-time application was built in TK/TCL and entitled "Airplane Approximation Control in Airports". Our tests were performed with the application running alone, the application with more 41 processes (20 processes using memory, 20 wasting CPU and 1 ghaphics process), the application with 10 graphics processes and the application with the version 20.2 emacs compiling. The experiments were carried out in both systems, the standard LINUX and LINUX with the SMART scheduler. We also compared the results obtained and the scheduling costs.

This dissertation also presents a short survey of real-time schedulings, which was classified under some paradigms caracterizing these politicies. In addition, we showed current efforts in the LINUX community, comparing them with the LINUX modified by the SMART scheduler.
\end{abstract}




\section{Sumário}

1 Introdução 1

1.1 Motivação e Objetivos . . . . . . . . . . . . . . . . . . . 3

1.2 Organização da Dissertação $\ldots \ldots \ldots \ldots$. . . . . . . . . . . 4

2 SMART - Uma Política de Escalonamento 5

2.1 Fundamentos do SMART . . . . . . . . . . . . . . . . . 5

2.2 Biased Virtual Finishing Time . . . . . . . . . . . . . . . 6

2.3 Princípios de Operação . . . . . . . . . . . . . . . . . . . . . . . 8

2.4 Construtores de Programação . . . . . . . . . . . . . . . . . . . . . . 9

2.5 O Algoritmo de Escalonamento . . . . . . . . . . . . . . . . . 11

2.6 Resultados dos Experimentos _ . . . . . . . . . . . . . . . 13

2.6.1 Características das Aplicações e Métricas de Qualidade . . . . . . 14

2.6.2 Programação com Restrições de Tempo . . . . . . . . . . . . . 16

2.6.2.1 Video Player . . . . . . . . . . . . . . . . 16

2.6.2.2 Audio Player . . . . . . . . . . . . . . . 17

2.6.3 Características dos Escalonadores . . . . . . . . . . . 17

2.7 Comparação entre Escalonadores . . . . . . . . . . . . . . . . . . 18

3 Implementação do Escalonador LINUX-SMART 24

3.1 O escalonador LINUX-SMART . . . . . . . . . . . . . 25

3.1 .1 O escalonamento no LINUX-PADRÃO . . . . . . . . . . . . 37

3.1 .2 As modificações do LINUX-SMART . . . . . . . . . . . . 39

4 Análise Comparativa entre LINUX-SMART e LINUX-PADRÃO 52 
4.1 Descrição da Aplicação Principal . . . . . . . . . . . . . . . . . . . . 52

4.2 Ambiente ............................... 54

4.3 Testes . . . . . . . . . . . . . . . . . . . . . 54

4.3.1 Cenário com a Aplicação Principal sem Processos Concorrentes . . 57

4.3.2 Cenário com a Aplicação Principal e 10 Processos Gráficos Concorrentes . . . . . . . . . . . . . . . . . . . 5 59

4.3.3 Cenário com a Aplicação Principal Concorrente com 41 Processos . 66

4.3.4 Cenário com a Aplicação Principal e a Compilação do emacs . . . . 71

4.4 Custos de Escalonamento. . . . . . . . . . . . . . . . . . . 74

4.5 Considerações Finais . . . . . . . . . . . . . . . . . . . 75

5 Trabalhos Relacionados $\quad 78$

5.1 Técnicas Empregadas . . . . . . . . . . . . . . . . . . 78

5.1 .1 Paradigma Baseado em Prioridade . . . . . . . . . . . . . . . 79

5.1 .2 Paradigma Baseado em Qualidade de Serviço . . . . . . . . . . . 80

5.1.3 Paradigma Baseado em Reserva de Recursos . . . . . . . . . . . . . 88

5.1.4 Paradigma Baseado em Fatias (shares) Proporcionais . . . . . . . . 95

5.1 .5 Paradigma do Enfileiramento Justo . . . . . . . . . . . . . . . . . . 101

5.1 .6 Paradigma Baseado em Hierarquia . . . . . . . . . . . . . . . . 108

5.1.7 Paradigma Baseado em Feedback . . . . . . . . . . . . . . . . 111

5.2 Esforços na Comunidade Linux . . . . . . . . . . . . . . . . . 118

5.2 .1 KU Real-Time Linux . . . . . . . . . . . . . . . . . . . . . . 119

5.2.1.1 Modelo de Programação . . . . . . . . . . . . . . 120

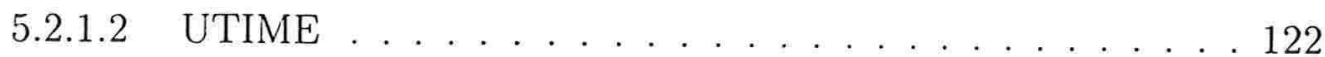

5.2.1.3 Chamadas de Sistema no Core do KURT . . . . . . . . . 122

5.2.1.4 Chamadas de Sistema no Módulo Processo . . . . . . . . 124

5.2 .2 RT-LINUX . . . . . . . . . . . . . . . . . . . . 126

5.2 .2 .1 Interfaces . . . . . . . . . . . . . . . . . . 128

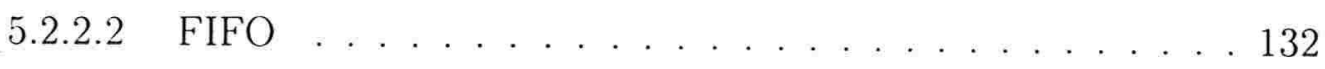

5.2 .2 .3 O Escalonador . . . . . . . . . . . . . . . . 133

5.2 .3 Consideraçōes Finais . . . . . . . . . . . . . . . . . . . 136 
6 Conclusões e Trabalhos Futuros

6.1 O LINLX-SMART e Outros Escalonadores de Tempo Real . . . . . . . . 138

6.2 Contribuições . . . . . . . . . . . . . . . . . . . . . 140

6.3 Trabalhos Futuros . . . . . . . . . . . . . . . . . . 141

A Custos de Escalonamento no LINUX-SMART e no LINUX-PADRÃO 149 


\section{Lista de Figuras}

2.1 Comparação do Desempenho das aplicações nos Escalonadores . . . . . . . 19

2.2 Distribuições de Métricas de Qualidade . . . . . . . . . . . . . . . . . . . 21

3.1 Diagrama representando a relação entre task_struct e smart_struct . . . . . 26

3.2 Implementação da Função copy_sm . . . . . . . . . . . . . . . . . . . 30

3.3 Implementação da Função _.exit_sm . . . . . . . . . . . . . . . . . . . . . . 32

3.4 Implementação da Chamada ao Sistema setdeadline . . . . . . . . . . . . . 33

3.5 Implementação da Chamada ao Sistema setprio . . . . . . . . . . . . . 35

3.6 Alterações no arquivo unistd.h . . . . . . . . . . . . . . . . . 36

3.7 Alterações no arquivo entry.S . . . . . . . . . . . . . . . . 36

3.8 Core do Escalonador LINUX-SMART . . . . . . . . . . . . . . . . . . . . 39

3.9 Implementação da Função goodness_smart . . . . . . . . . . . . . . . . . . 40

3.10 Implementação da Função build_cand . . . . . . . . . . . . . . . . . . . . . 42

3.11 Código da Construção de W na Função Best-effort. . . . . . . . . . . . . . 43

3.12 Implementação da Função feasibility . . . . . . . . . . . . . . . . . . . . 44

3.13 Implementação da Função insertion_do_not_loose_deadline . . . . . . . . . 45

3.14 Instante da Escolha do Processo a Executar . . . . . . . . . . . . . . . . 45

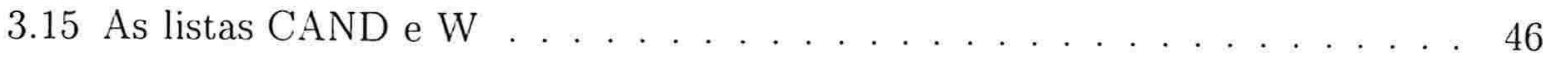

3.16 Implementação da Função evaluate_virtual_time . . . . . . . . . . . . . 47

3.17 Implementação da Função evaluate_bvft_quantum . . . . . . . . . . . . . 47

3.18 Implementação da Função evaluate_bvft_blocked. . . . . . . . . . . . . . . . 48

3.19 Implementação da Função evaluate_delta . . . . . . . . . . . . . . . . . . 48

3.20 Emulando os Escalonadores do LINUX-PADRÃO . . . . . . . . . . . . j1 
4.1 Tela da aplicação principal . . . . . . . . . . . . . . . . . . 53

4.2 Análise Estatística com vmstat na inicialização do LINUX-SMART . . . . 57

4.3 Análise Estatística com vmstat na inicialização do LINUX-PADRÃO . . . 57

4.4 Gráfico smart e linux TS com 0 processos. . . . . . . . . . . . . . . 58

4.5 Gráfico smart e linux $\mathrm{RR}$ com 0 processos. . . . . . . . . . . . . . 58

4.6 Gráfico smart e linux FF com 0 processos. . . . . . . . . . . . . . . . . . 59

4.7 Gráficos do smart com 0 processos nos ambientes A e B. . . . . . . . . . 60

4.8 Gráfico smart e linux-Other com 10 processos. . . . . . . . . . . . . . 60

4.9 Gráfico smart e linux-RR com 10 processos. . . . . . . . . . . . . . . . 61

4.10 Gráfico smart e linux-FIFO com 10 processos. . . . . . . . . . . . . . . 61

4.11 Análise Estatística utilizando strace - $C$ no cenário com 10 processos no LINUX-PADRÃO . . . . . . . . . . . . . . . . . . 63

4.12 Análise Estatística utilizando strace $-C$ no cenário com 10 processos no LINUX-SMART . . . . . . . . . . . . . . . . . . . . 64

4.13 Análise Estatística utilizando vmstat no cenário com 10 processos no LINUXSMART

4.14 Análise Estatística utilizando vmstat no cenário com 10 processos no LINUXPADRÃO com escalonador Time-sharing . . . . . . . . . . . . . 65

4.15 Gráficos do smart com 10 processos nos Ambientes A e B. . . . . . . . . 66

4.16 Gráfico smart e linux-Other com 41 processos. . . . . . . . . . . . . . 67

4.17 Gráfico smart e linux-RR com 41 processos. . . . . . . . . . . . . . 67

4.18 Gráfico smart e linux-FIFO com 41 processos. . . . . . . . . . . . . 68

4.19 Análise Estatística utilizando strace $-C$ no cenário com 41 processos no LINUX-SMART . . . . . . . . . . . . . . . . . . . . . 69

4.20 Gráficos do smart com 41 processos nos ambientes A e B. . . . . . . . . 70

4.21 Análise de Tempo das Chamadas ao Sistema utilizando strace - T no cenário com 41 processos no LINUX-SMART . . . . . . . . . . . . . . . . . . 70

4.22 Gráfico smart e linux-Other com emacs. . . . . . . . . . . . . . . 71

4.23 Gráfico smart e linux-RR com emacs. . . . . . . . . . . . . . . . . . 72

4.24 Gráfico smart e linux-FIFO com emacs. . . . . . . . . . . . . . . . 72

4.25 Análise Estatística utilizando vmstat no cenário com a compilação do emacs no LINUX-SMART 
4.26 Análise Estatística utilizando vmstat no cenário com a compilação do emacs no LINUX-PADRÃO . . . . . . . . . . . . . . . . . . . . 73

4.27 Análise Estatística com vmstat no cenário com a compilação do emacs. . 76

5.1 Programação com restrição de tempo . . . . . . . . . . . . . . . . . 90

5.2 Grafo de Escalonamento com um Período Base de $10 \mathrm{~ms}$. . . . . . . 92

5.3 Exemplo da Loteria. . . . . . . . . . . . . . . . . . . . . . . 101

5.4 Algoritmo de Escalonamento Stride Básico. Código ANSI C para escalonar um conjunto estático de clientes. . . . . . . . . . . . . 102

5.5 Algoritmo de Escalonamento Stride Dinâmico. Código ANSI C para operações de escalonamento stride. . . . . . . . . . . . . . . 106

5.6 Modificação Dinâmica de tickets . . . . . . . . . . . . . . . . . 107

5.7 Um Exemplo da Estrutura de Escalonamento . . . . . . . . . . . . . 110

5.8 Arquitetura em Alto Nível . . . . . . . . . . . . . . . . . . . . 113

5.9 Arquitetura do Sistema KURT . . . . . . . . . . . . . . . . . . 120

5.10 Estrutura de um Processo KURT . . . . . . . . . . . . . . . . . . . 121

5.11 Um Processo Executivo no KURT . . . . . . . . . . . . . . . . . 121

5.12 RT-Linux . . . . . . . . . . . . . . . . . . 127

5.13 Interrupções em RT-Linux . . . . . . . . . . . . . . . . . . 128

5.14 Função rtl_schedule do RT-LINUX . . . . . . . . . . . . . . . . . 136 


\section{Lista de Tabelas}

2.1 Tempo Virtual versus Tempo Virtual da Fila . . . . . . . . . . . . . . 7

2.2 Tempo de Execução das Aplicações . . . . . . . . . . . . . . . . . . 15

2.3 Métricas de Qualidade de Desempenho das Aplicações . . . . . . . . . . . . 16

5.1 Tabela de Atividades . . . . . . . . . . . . . . . . . . . . . 91

5.2 Restrições de Tempo . . . . . . . . . . . . . . . . . . . . . . . . 93

5.3 Atribuições de Intervalos . . . . . . . . . . . . . . . . . . . . . . . 93 


\section{Capítulo 1}

\section{Introdução}

Enfocando a evolução do hardware dos computadores, constata-se que inicialmente as máquinas eram lentas e caras. As aplicações eram simples e tinham a finalidade de automatizar tarefas repetitivas. Existindo a necessidade de uma tarefa mais específica, um hardware especial devia ser adquirido, geralmente trazendo grandes custos para o usuário.

Atualmente, o crescente desenvolvimento do hardware em escala e custos cada vez menores gerando processadores cada vez mais rápidos, as novas técnicas de multiprogramação e o barateamento das máquinas sendo utilizadas têm motivado uma grande escalada no desenvolvimento de software mais complexos.

Aplicações como as de multimídia, gráficas e de videoconferência vêm surgindo com uma grande demanda. Nestes tipos de aplicações, não é apenas importante que os resultados sejam logicamente corretos; devem ser levados em conta aspectos como uniformidade na taxa de progresso da aplicação, eficácia no uso de recursos disponíveis e garantias mínimas de desempenho. Estas aplicações têm restrições de tempo, mas aceitam que estas sejam violadas dentro de certos limites estatísticos. Esta característica as classificam como aplicações de tempo real, cujos aspectos principais são [NL97b]:

- Requisitos de Tempo - Dependendo da conseqüência da perda do deadline, processos de tempo real são divididos em duas classes:

1. Hard - um processo é dito tempo real hard se o término de uma computação após seu deadline causar conseqüências catastróficas;

2. Soft - um processo é dito tempo real soft se a perda do deadline decrementa a performance do sistema mas não gera conseqüências catastróficas.

As aplicações de multimídia e gráficas, que motivam esta dissertação, são de tempo real soft porque a perda do deadline provoca apenas a degradação da qualidade de serviço, em geral não descaracterizando aspectos de corretude funcional da aplicação. 
- Características Dinâmicas - Nas estações de trabalho usuais a carga do sistema é altamente dinâmica, e o comportamento das aplicações também. Por exemplo, o tempo de processamento para descomprimir um vídeo codificado em MPEG ou JPEG pode variar substancialmente entre diferentes frames do vídeo.

- Características Adaptativas - Esta classe de aplicações, geralmente, consome grande quantidade de recursos da máquina. É natural que, algumas vezes, o sistema não tenha recursos suficientes para as aplicações. Estas, porém, são tolerantes a perda de algumas informações de forma a adaptar-se à carga do sistema. Por exemplo, uma aplicação de vídeo pode ser capaz de reduzir a qualidade da imagem de cada frame para reduzir os requisitos de processamento.

- Co-existência com aplicações convencionais - devem compartilhar o ambiente de processamento com aplicações convencionais já existentes (compiladores, processadores de texto, etc). Além do mais, os usuários gostariam de combinar tempo real e convencional em aplicações como documento em multimídia que mistura texto, gráfico, audio e vídeo.

- Preferências dos usuários - Diferentes usuários podem ter diferentes preferências quanto a como priorizar o uso dos recursos entre as suas várias aplicações.

Nesta crescente demanda por software mais complexos, vários problemas foram detectados devido à falta de suporte dos atuais sistemas operacionais. Particularmente, problemas de gerenciamento de recursos foram percebidos rapidamente quando aplicações de tempo real soft executavam, em razão do grande consumo de recursos geralmente imposto por estas aplicações [NHNW93].

É altamente desejável que esta nova classe de aplicações opere em uma estação de trabalho co-existindo com as demais classes. Restringir o potencial de computação de uma estação de trabalho a um única função é inaceitável nos ambientes computacionais usualmente disponíveis; o que se deve fazer é gerenciar melhor os recursos. Tentativas de solucionar estes problemas utilizando simples mecanismos de alteração de prioridade, como o nice no $U N I X$, têm se revelado ineficientes e ineficazes.

O desafio é projetar um escalonador para alocação de recursos entre as diversas aplicações das várias classes de forma a preservar as características de desempenho esperadas para cada classe. Quando um processador tem que executar um conjunto de tarefas concorrentes, a CPU tem que ser atribuída para as várias tarefas de acordo com um critério pré-definido, chamado política de escalonamento. O conjunto de regras que, em qualquer instante, determina a ordem na qual as tarefas serão executadas é chamado algoritmo de escalonamento. A operação de alocar a CPU para uma tarefa selecionada por um algoritmo de escalonamento é referenciada como dispatching [NSSH95].

A política adotada por um escalonador pode gerar um enorme impacto no throughput e no tempo de resposta, podendo favorecer aplicações genéricas em detrimento das que 
apresentam restrições como as da classe de tempo real soft. Determinar quando e como alocar os recursos disponíveis para os processos existentes de forma justa e flexível não é uma tarefa fácil.

Esta dissertação propõe um ambiente para alocação de CPU que trata convenientemente aplicações complexas que exigem uma alta taxa de computação e throughput, como aquelas de multimídia, gráficas e de videoconferência entre outras.

A Sec. 1.1 descreve os objetivos desta dissertacão.

\subsection{Motivação e Objetivos}

O tema principal desta dissertação é o estudo do escalonamento de processos e seu impacto na qualidade de serviço garantida às aplicações. O interesse é na análise, desenvolvimento e utilização de algoritmos que suportem aplicações como de multimídia, gráficas, iterativas e batch.

A motivação para este trabalho está na falta de adequação dos atuais escalonadores para aplicações de tempo real soft e nos resultados apresentados por Nieh et. al [NHNW93] no caso de aplicações multimídia em ambiente SVR4 UNIX. Em conseqüência, elaborou-se um ambiente para alocação de CPU que trata convenientemente as aplicações de tempo real soft em uma situação em que a carga usual do sistema não possa ser controlada a priori.

Como cenário para experimentos de avaliação, foi implementada uma aplicação de controle de aproximação de aeronaves em aeroportos. Esta foi desenvolvida em ambiente LINUX [HP96, BBD ${ }^{+}$98, CDM97, Ben96. Rus97], utilizando a linguagem TK/TCL [Joh97, Ous94]. Desta implementação [VNdS99b], foram extraídos testes de desempenho do sistema baseados nas seguintes configurações de execução: a aplicação executando sozinha, a aplicação com mais 41 processos (20 processos que consumiam memória, 20 processos que gastavam CPU e 1 processo gráfico), a aplicação com 10 processos (todos gráficos) e a aplicação com um processo de compilação do processador de texto emacs versão 20.2. Ressalta-se que os testes também foram efetuados com a aplicação principal na classe de escalonamento de tempo real, com política round robin e FIFO (conforme oferecido pelo Linux).

É importante ressaltar que destes testes foi possível concluir que mesmo no caso extremo de somente a aplicação principal executando em classe de escalonamento de tempo real e os demais processos na classe timesharing, os recursos não foram gerenciados apropriadamente: a aplicação principal teve um desempenho pobre por não ter sua demanda de recursos atendida.

Na busca de soluçōes, foi estudada a política de escalonamento SMART (Scheduling Multimedia Applications Real-Time), a qual serviu de base para o ambiente proposto. Outras abordagens presentes na literatura foram analisadas de forma a verificar quais 
características poderiam/deveriam ser acrescentadas ao SMART para obter/garantir um melhor desempenho. Os esforços foram concentrados na operacionalização das características do SMART, ficando os aspectos das demais técnicas abordadas que se mostraram compatíveis para inclusão na implementação realizada indicados para trabalhos futuros.

Um objetivo a longo prazo é empregar em um ambiente de produção real (por exemplo, redes Linux operando em universidades) os resultados mais recentes da área de escalonamento de forma a possibilitar que aplicações de interesse do usuário, uma vez iniciadas, possam ter alguma garantia da alocação de recursos esperada ao longo de toda a execução.

\subsection{Organização da Dissertação}

Adicionalmente a esta introdução, compõem esta dissertação os seguintes capítulos:

- Capítulo 2:

Devido a sua relevância nesta dissertação, dedica-se este capítulo à descrição da política de escalonamento SMART.

- Capítulo 3:

A implementação da política SMART como novo escalonador do LINUX é detalhada neste capítulo. Relata-se os problemas encontrados e os procedimentos adotados para solucioná-los.

- Capítulo 4:

São exibidos os testes de desempenho da aplicação "Controle de Aproximação de Aeronaves em Aeroportos" no LINUX-SMART, que são comparados com aqueles realizados no LINUX-PADRÃO [VNdS99b]. Também aborda-se os custos de escalonamento em ambos sistemas operacionais.

- Capítulo 5:

Exibe-se o estado da arte dos escalonadores de tempo real, sob a perspectiva de alguns paradigmas comumente referenciados na literatura. Entre eles, cita-se: os baseados em prioridade, os baseados em qualidade de serviço, os de reserva de recursos, os de alocação proporcional ao share, os de enfileiramento justo, os hierárquicos e os baseados em feedback.

Adicionalmente, são apresentados os esforços atuais na comunidade LINUX discutindose os escalonadores RT-LINUX e KU RT-LINLX.

- Capítulo 6:

Neste capítulo enumera-se as contribuiçōes, os trabalhos futuros e realiza-se uma análise comparativa entre o LINUX-SMART e alguns escalonadores de tempo real comentados no Cap. 5. 


\section{Capítulo 2}

\section{SMART - Uma Política de Escalonamento}

O SMART [NL97b, NL97a, NHNW93, NL95], Scheduling Multimedia Applications RealTime, surgiu para suprir a ausência de políticas de escalonamento que tratassem as informações necessárias e tivessem uma interface apropriada para atender aplicações com requisitos de tempo real dinâmicos e adaptativos. Neste contexto, a alocação de recursos não pode ser controlada pela aplicação e portanto nem sempre esta obtém a quantidade de recursos que deseja. Em conseqüência, as aplicações devem se adaptar aos recursos disponíveis e garantidos às mesmas pela política de escalonamento do sistema.

A política de escalonamento do SMART permite a co-existência da classe de aplicações de tempo real soft com as aplicações convencionais. O escalonador provê um feedback dinâmico às aplicações para que estas possam se adaptar a carga do sistema. Isto permite que as aplicações possam decidir o que fazer quando suas restrições de tempo não puderem ser cumpridas. O SMART utiliza o critério de urgência e importância na escolha pelo escalonador da aplicação que executará. A urgência é baseada no deadline da aplicação e a importância na prioridade que o usuário associa à aplicação.

As próximas seções detalham os fundamentos, os princípios de operação, os construtores de programação, o próprio algoritmo de escalonamento e a interface de programação da aplicação do SMART.

\subsection{Fundamentos do SMART}

O fundamental no projeto SMART é a separação do conceito de importância (expressa pelas preferências dos usuários) da urgência (expressa pelas restrições de tempo).

Importância e urgência são dois parâmetros utilizados pelo escalonador para escolher a próxima aplicação que irá executar. A importância é aplicada a todos os processos. O 
processo com mais alta prioridade é aquele com mais alta importância. Se dois processos tiverem as mesmas prioridades irá executar aquele que, proporcionalmente, executou menos. Urgência é específico para aplicações real-time. A aplicação com menor deadline é aquela mais urgente. O escalonador primeiro identifica todos os processos que são considerados mais importantes para executar e depois escolhe um deles baseado na urgência. A idéia principal do SMART é não confundir urgência com importância.

A importância é medida pelo par ordenado (prioridade,BVFT). Prioridade é um valor estático enquanto BVFT, Biased Virtual Finishing Time, é um valor dinâmico que o sistema usa para medir o grau da fatia (share) proporcional dos recursos que tem sido consumida por cada processo. Pode-se dizer que uma aplicação A tem mais alto valor de par do que uma aplicação B se A tem prioridade maior que B ou A e B têm a mesma prioridade mas A tem um menor BVFT.

Vista a utilidade do parâmetro BVFT na política SMART, é oportuna uma descrição formal do termo mencionado.

\subsection{Biased Virtual Finishing Time}

A proposta do VFT, Virtual Finishing Time, é medir o grau do share proporcional dos recursos que tem sido consumido por cada processo e foi previamente utilizada na descrição dos algoritmos baseados em enfileiramento justo [SAWJ97, Wal95, BZ96, DKS89, PG93]. A esta idéia básica foram acrescentadas prioridades diferentes e um bias que é um deslocamento limitado usado para medir a capacidade de processos convencionais de tolerar atrasos de serviço maioreș e mais variados. Ressalta-se que os algoritmos baseados em enfileiramento justo executam o processo com menor VFT para prover um compartilhamento justo; SMART usa a prioridade, o BVFT e os deadlines dos processos para escolher o candidato que irá executar. As aplicações são colocadas em filas, de acordo com sua prioridade, em ordem crescente de seus valores BVFT. Cada processo tem um tempo virtual que avança em uma taxa proporcional à soma do tempo de processamento que ele consome, dividido por seu share (que foi especificado pelo usuário). As modificações efetuadas no SMART em relação a proposta do VFT, permitem o tratamento de aplicações não periódicas com restrições de tempo e condições de sobrecarga.

Suponha que o processo corrente tenha share $S$, tempo inicial $\tau$ e tempo virtual $V(\tau)$ no tempo $\tau$. Então, o tempo virtual $V(t)$ do processo no corrente tempo $t$ é:

$$
V(t)=V(\tau)+\frac{(t-\tau)}{S}
$$

Da mesma maneira que os processos, cada fila tem um tempo virtual que avança somente se qualquer de seus componentes está executando. O avanço é proporcional a quantidade de tempo de processamento gasto na tarefa dividido pela soma total de share de todos os processos na fila. 


\begin{tabular}{|c|c|}
\hline Comparação & Resultado \\
\hline \hline$V(t)=V_{P}(t)$ & alocação proporcional recebida \\
\hline$V(t)<V_{P}(t)$ & alocação proporcional inferior \\
\hline$V(t)>V_{P}(t)$ & alocação proporcional superior \\
\hline
\end{tabular}

Tabela 2.1: Tempo Virtual versus Tempo Virtual da Fila

Suponha que o processo corrente sendo executado tenha prioridade $P$, tempo inicial $\tau$ e tempo virtual $V_{P}(\tau)$ da fila com prioridade $P$ no tempo $\tau$. Então, o tempo virtual da fila $V_{P}(t)$ com prioridade $P$ no tempo corrente $t$ é:

$$
V_{P}(t)=V_{P}(\tau)+(t-\tau) / \Sigma_{a \in A_{P}} S_{a}
$$

onde $S_{a}$ representa o share da aplicação $a$ e $A_{P}$ é o conjunto de aplicações com prioridade $P$.

A relação entre o tempo virtual e o tempo virtual da fila é usada para medir se a respectiva tarefa consumiu sua alocação proporcional de recursos, como exibido na Tab. 2.1. O embasamento teórico foi apresentado por A. Demers [DKS89].

A seguir descreve-se como são realizados os ajustes do BVFT de um processo, os quais baseiam-se nos seguintes aspectos: tempo de criação do processo, consumo do quantum, bloqueio por I/O ou eventos e reatribuição de parâmetros do usuário.

Sejam $P$ e $S$ a prioridade e o share do processo, respectivamente. Definimos $\beta(t)$ (o BVFT do processo no tempo t) através das seguintes regras:

- Momento de Criação dos Processos - No momento inicial $\tau_{0}$, o processo adquire como seu tempo virtual o tempo virtual da sua respectiva fila. Supondo que o processo tenha quantum $Q$, então seu BVFT é :

$$
\beta\left(\tau_{0}\right)=V_{P}\left(\tau_{0}\right)+\frac{Q}{S}
$$

- Consumo do quantum - Quando um processo gasta seu quantum, um noro quantum $\mathrm{Q}$ é devidamente atribuído e um novo BVFT é calculado para atualizar o valor do par ordenado. E se um processo convencional acumula tempo de execução, um bias é adicionado ao seu BVFT quando ele obtem o referido quantum $Q$. Formalmente, seja $b$ o valor do bias ${ }^{1}$ incrementado e $\tau$ o instante da última modificação do BVFT do processo, então temos:

$$
\beta(t)=\beta(\tau)+\frac{Q}{S}+\frac{b}{S}
$$

\footnotetext{
${ }^{1} \mathrm{O}$ bias tem valor inicial igual a zero.
} 
O bias é usado para atrasar um batch longo fazendo com que os processos iterativos e real-time obtenham um melhor tempo de resposta. O bias é incrementado de maneira similar à maneira como prioridades são ajustadas no UNIX SVR4 para implementar time-sharing.

- Bloqueio por I/O ou Eventos - No SMART um processo que está esperando um evento permanece em sua fila de prioridade por um período igual ao menor deadline do processo ou um valor default do sistema. Ao final deste período, um processo bloqueado deve sair da fila e registra-se a diferença entre o tempo virtual do processo e da fila. No momento que o processo se torna executável e retorna a fila de processos, este valor é rearmazenado.

Sejam $E$ a fatia do quantum $Q$ já consumida pelo processo, $B$ o bias atual, e $v(t)$ o tempo virtual da tarefa. Então, a diferença $\Delta$ é:

$$
\begin{aligned}
\Delta & =v(t)-V_{P}(t), \quad(5) \\
\text { ondev }(t) & =\beta(t)-\frac{Q-E}{S}-\frac{B}{S} .
\end{aligned}
$$

Após o retorno à fila, o bias é zero e o BVFT é

$$
\beta(t)=V_{P}(t)+\Delta+\frac{Q}{S}
$$

- Reatribuição de Parâmetros do Usuário - Se um processo recebe uma nova prioridade, este é alocado na fila do correspondente valor atribuído e seu BVFT é calculado pela Eq. (3). No caso de um novo share, o cálculo do BVFT é efetuado segundo os velhos parâmetros usados na Eq. (6) para calcular $\Delta$ e os novos parâmetros usados na Eq. (7).

\subsection{Princípios de Operação}

Listados os conceitos e expressões usados no escalonamento, destacam-se a seguir os princípios de operação usados no projeto do SMART:

- Prioridade - o sistema não deve degradar o desempenho de uma aplicação de alta prioridade na presença de uma com baixa prioridade;

- Compartilhamento proporcional dos recursos entre aplicações de tempo real e convencionais pertencentes a mesma classe de prioridade - utilizado quando não houver recursos suficientes para atender todas as solicitaçōes de recursos. O sistema atenderá todos os pedidos menores do que a quantia de share proporcional, os recursos disponíveis após esta alocação serão distribuídos entre a tarefas que podem usar este excesso. 
- Transições transparentes durante as flutuações da carga do sistema - a carga do sistema varia dinamicamente e a demanda de recursos de cada aplicação pode igualmente variar, cabendo ao sistema gerenciar estas flutuaçōes transparentemente.

- Satisfação das restrições de tempo das aplicações de tempo real e tempo de resposta rápido para tarefas interativas na presença de baixa carga no sistema - quando as solicitações de recursos são menores do que o share proporcional em ambos tipos de aplicação, as restrições de tempo devem ser respeitadas e o tempo de resposta deve ser curto.

- Negociação da justiça instantânea na alocação de recursos para melhor atender aplicações de tempo real e de tempo de resposta interativo - abdicar da condição de alocação justa instantaneamente, tendo em vista o favorecimento de tarefas curtas e buscando uma alocação justa na média.

- Notificação sobre a disponibilidade de recursos - SMART permite que as aplicações especifiquem se e quando desejam ser notificadas do não término de suas computações antes dos seus respectivos deadlines.

\subsection{Construtores de Programação}

SMART pode ser usado tanto por desenvolvedores quanto por usuários das aplicações. Para os desenvolvedores, SMART provê três construtores de programação:

- Restrição de Tempo - para que a aplicação possa informar ao escalonador sobre as restrições de tempo. Estas restrições consistem de dois parâmetros:

- deadline - é o tempo exigido pela aplicação para a computação de um bloco de código.

- Estimativa da CPU - é uma estimativa da quantidade de tempo de processamento exigida para o bloco de código.

Por default, se o deadline não é especificado, a restrição de tempo é simplesmente ignorada e se a estimativa da CPU não for especificada, o sistema assume que a aplicação requer qualquer tempo de processamento disponível até o seu deadline.

- Notificação - para que o escalonador possa enviar informes às aplicações quando suas restrições de tempo não puderem ser satisfeitas. Uma notificação consiste de dois parâmetros:

- Tempo da Notificação - é o intervalo de tempo em que o escalonador deve informar a respectiva aplicação que é improvável que se complete sua computação antes do seu deadline; 
- Tratador de Notificação - é uma função que a aplicação registra com o escalonador. Através desta função o escalonador notifica a aplicação que o seu deadline não foi satisfeito.

Pela combinação da notificação com o tratador de notificação, a aplicação não necessita interagir com o sistema para verificação do seu deadline, bem como, pode escolher suas próprias políticas para decidir o que fazer quando suas restrições de tempo não puderem ser satisfeitas. Dentre as políticas utilizadas cita-se: descartar a atual computação, executar somente uma parte da computação ou modificar as restrições de tempo.

É necessário que os parâmetros mencionados sejam especificados conjuntamente, pois a ausência de algum deles implica na não utilização do outro.

- Disponibilidade - para indicar o tempo de processamento disponível, sendo expressa por dois parâmetros:

- Razão de Consumo, que é a percentagem do processador que está sendo consumida pela aplicação.

- Razão de Alocação, que é a percentagem do processador que a aplicação pode usar como determinado pelo escalonador baseado na prioridade e share da aplicação. Se a razão de alocação é maior que a razão de consumo significa que a aplicação está usando menos do que alocou. Se a razão de alocação é menor do que a razão de consumo, a aplicação está usando mais que sua alocação do processador.

Ao permitir que aplicações informem ao escalonador o limite de tempo, este pode otimizar a distribuição dos recursos requisitados pelas diferentes aplicações. Ele pode usar o conhecimento dos requisitos de tempo de cada aplicação para estimar a carga do sistema e determinar quais restrições de tempo podem e quais não podem ser satisfeitas.

Fornecendo notificadores, o escalonador libera a aplicação de ter que adivinhar se suas restrições de tempo podem ser satisfeitas.

Se há informação sobre a disponibilidade de recursos para aplicações, uma aplicação de tempo real adaptativa pode ajustar a sua taxa de execução quando seus requisitos de tempo não puderem ser satisfeitos.

No caso dos usuários, existem as seguintes construções de programação:

- Prioridade - quando há disputa por recursos, a aplicação com maior prioridade será favorecida;

- share - entre aplicaçōes que têm a mesma prioridade, quando há disputa por recursos estas receberão os recursos proporcionalmente ao seu share. 


\subsection{O Algoritmo de Escalonamento}

Nesta seção, apresenta-se o algoritmo SMART propriamente dito. Além disto, para completa compreensão do mecanismo, também define-se o escalonamento Best-effort Realtime.

- Escalonamento Best-effort Real-time

SMART seleciona os processos do conjunto de candidados em ordem decrescente do valor da dupla ordenada e os insere em uma classificação de trabalho inicialmente vazia em ordem crescente de deadline. Esta classificação define a ordem de execução para o serviço de requisição de recursos de tempo real e é denominada factível, se o conjunto de requisitos de recursos do processo pode ser atendido antes dos seus respectivos deadlines. Observe que os requisitos de recursos de um processo de tempo real periódico inclui uma estimativa de tempo de processamento exigida nas suas futuras requisições.

A página a seguir apresenta o algoritmo Best-effort Real-time para o SMART. Este utiliza o deadline dado e estimativas de tempo de serviço para encontrar o processo com o menor deadline cuja execução não cause a perda de deadline para qualquer processo com par ordenado mais alto. Para isto o algoritmo considera cada candidato, começando com aquele de maior par ordenado. O Best-effort tenta escolher o candidato em uma classificação de trabalho, a qual é inicialmente vazia. O candidato é inserido na ordem do deadline nesta classificação, desde que sua execução não faça nenhum processo na classificação perder seu deadline. 


\section{Algoritmo Best-effort Real-time para o SMART}

1. Defina:

(a) $Q_{j}$, o tempo de CPU requerido pelo processo $j$ para alcançar seu deadline;

(b) $E_{j}$, o tempo de execução já gasto pelo processo $j$.

(c) $F_{j}$, a fração do processador solicitada por um processo real-time periódico ${ }^{2}$.

(d) $D_{j}$, o deadline do processo.

(e) a requisição $R_{j}(t)$ de recurso estimada do processo $j$ no tempo $t, t \geq D_{j}$, como:

$$
R_{j}(t)=Q_{j}-E_{j}+F_{j} \times\left(t-D_{j}\right)
$$

(f) $W$, uma classificação de trabalho inicialmente vazia e Cand o conjunto de processos candidatos.

2. Escolha $i \in$ Cand com maior valor de par ordenado e faça $T$ Cand $=\mid$ Cand $\mid-1$. ${ }^{*}$ Onde $\mid$ Cand $\mid$ denota a cardinalidade de Cand. */

3. Enquanto $T C a n d \geq 0$ faça

(a) $V=0$

(b) Para cada $j \in\{i \cup W\}$ faça

i. Se $D_{j} \geq t+\sum_{k \in W, D_{k} \leq D_{j}} R_{k}\left(D_{j}\right)$ então $V=V+1 /^{*}$ Variável que contabiliza quantos processos satisfazem a inequação ${ }^{3} * /$

(c) Se $V=|W|+1$ então

i. Se $i$ é um processo de tempo real periódico então calcule a estimativa de requisições para processamentos futuros.

ii. Se $i$ possui um par ordenado menor do que algum elemento em $W$ então

A. Se sua inserção não causa a perda de deadline de processos com maior valor de par ordenado de $W$ então $W=W \cup i$.

iii. senão $W=W \cup i$.

(d) Se TCand $>0$ então escolha $i \in$ Cand e faça TCand $=$ TCand -1

i. senão $T C$ and $=$ TCand -1 .

4. Se $|W| \neq 0$ então

(a) Execute o processo com menor deadline.

(b) Senão execute o processo de tempo real executável com maior valor de par

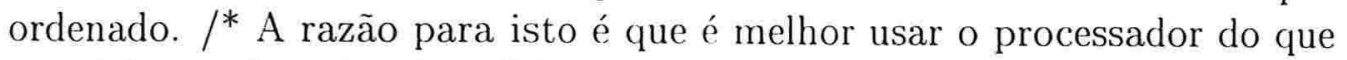
permitir que fique inativo. */

\section{Fim_do_Algoritmo}

\footnotetext{
${ }^{2}$ Então $F_{j}$ é simplesmente a razão do tempo de serviço do processo por seu deadline se for um processo de tempo real e zero se não for.

${ }^{3}$ Esta inequação é um teste de viabilidade que verifica se as solicitações de recursos da classificação existente $W$ mais a tarefa a ser inserida $i$ podem ser completadas antes dos seus respectivos deadlines, quando atendidas na ordem definida pela classificaçào $W^{*} \cup i$.
} 
Apresentado o escalonamento Best-effort Real-time, exibe-se a seguir, o algoritmo SMART.

\section{Algoritmo de Escalonamento SMART}

1. Se o processo com mais alto valor do par ordenado é um processo convencional (uma aplicação sem um deadline), escolha aquela aplicação;

2. Caso contrário, crie um conjunto de candidatos constituído de todos os processos de tempo real com valor do par ordenado maior que o maior par ordenado dos processos convencionais;

3. Aplique o algoritmo de escalonamento Best-effort Real-time no conjunto de candidatos, usando o valor do par ordenado como a prioridade no algoritmo original.

4. Se o processo não pode completar sua computação antes do seu deadline, envie uma notificação para informar à respectiva aplicação que seu deadline não pode ser satisfeito.

\section{Fim_do_Algoritmo}

Destacados os aspectos que caracterizam o SMART, aborda-se a seguir os experimentos e resultados desta política de escalonamento presentes na literatura, comparando-os com aqueles obtidos nos escalonadores UNIX SVR4 e WFQ (Enfileiramento Justo com Pesos).

\subsection{Resultados dos Experimentos}

Nieh et. al [NL97b] realizaram testes com um grupo de aplicações de tempo real, interativas e batch em uma estação de trabalho comparando o SMART com o escalonador do UNIX SVR4 e com um escalonador WFQ (Enfileiramento Justo com Pesos). Estes foram efetuados nas políticas de tempo real e timesharing.

Três aplicações foram usadas para representar computações batch, interativas e de tempo real:

- Dhrystone (batch) - Esta é o benchmark Dhrystone, versão 1.1, que mede a performance da CPU.

- Typing (interativa) - Esta aplicação emula um usuário utilizando um editor de texto através do recebimento de uma série de caracteres de um dispositivo de entrada serial e do uso do servidor de janelas para exibí-las. Para simular uma seqüência realística e repetitiva de teclas digitadas para aplicaçōes interativas, um hardware para o simulador de teclado foi construído e conectado através de uma linha serial com a estaçào de trabalho sendo testada. 
- Integrated Media Streams Player (tempo real) - O IMS Player da Sun Microsystems é um sistema capaz de tratar dados de áudio e vídeo sincronizadamente. Esta aplicação se adapta ao ambiente do sistema através de ajustes da qualidade de playback baseados na carga do sistema. O IMS Player foi desenvolvido para o escalonador timesharing do UNIX SVR4 no sistema operacional Solaris. Para o experimento com o SMART, inseriu-se algumas chamadas ao sistema para a aplicação usufruir das vantagens de características fornecidas pelo SMART. Utilizou-se a aplicação em dois modos diferentes:

- News (tempo real) - Esta aplicação exibe dados de áudio e vídeo sincronizados de um dispositivo de armazenamento local. Cada fonte de dado de mídia flui sob o gerenciamento de uma thread de controle independente. As threads de áudio e vídeo se comunicam através de uma memória compartilhada e usam intervalos de tempos para sincronizar a exibição dos dados de mídia. A fonte de dados de vídeo contém frames com resolução de 320x240 pixels em formato JPEG compactado a uma razão de 15 frames/segundo. Os dados capturados são de um satélite de uma rede de notícias.

- Entertain (tempo real) - Esta aplicação processa vídeo de um dispositivo de armazenamento local. A fonte de dados de entrada de vídeo contém frames com resolução de 320x240 pixels em formato JPEG compactado a uma razão de 15 frames/segundo. A aplicação exibe o vídeo com uma resolução de 640x480 pixels. O dado capturado contém informações sobre a programação de uma emissora de TV.

Descritas as aplicações utilizadas, são apresentadas as características e métricas de qualidade das aplicações.

\subsubsection{Características das Aplicações e Métricas de Qualidade}

Representando diferentes classes de aplicações, Typing, Dhrystone, News e Entertain têm muitas características e métricas de qualidade distintas. Por exemplo, para tarefas interativas o aspecto relevante é o tempo de resposta, no caso das tarefas batch preocupa-se com o throughput e o número de deadlines respeitados é o parâmetro importante para tarefas de tempo real.

A Tab. 2.2 mostra o tempo de execução de cada aplicação usando o escalonador L'NIX SVR4 em um intervalo de tempo de 300 segundos. O tempo de execução inclui o tempo no modo usuário e no modo sistema. A aplicação Dhrystone pode executar quando o processador está disponível e pode assim utilizar completamente o processador. Observouse que não existe diferença significativa entre o desempenho dos diferentes escalonadores quando executando somente uma aplicação.

Como mencionado, a métrica de qualidade das aplicações utilizadas nos experimentos são bem distintas. Para Typing, é desejável minimizar o tempo entre a entrada do usuário 


\begin{tabular}{|c|c|c|c|}
\hline \hline Nome & Base de Medida & No. de Medidas & Tempo médio de CPL \\
\hline \hline News audio & por segmento & 4700 & $1.54 \mathrm{~ms}$ \\
\hline News video & por frame & 4481 & $28.35 \mathrm{~ms}$ \\
\hline Entertain & por frame & 4487 & $39.16 \mathrm{~ms}$ \\
\hline Typing & por caracter & 1314 & $1.96 \mathrm{~ms}$ \\
\hline Dhrystone & por execução & 1 & $298.73 \mathrm{~s}$ \\
\hline \hline
\end{tabular}

\begin{tabular}{|c|c|c|}
\hline \hline Nome & Desvio Padrão do tempo de CPU & \% médio da CPU \\
\hline \hline News audio & $0.79 \mathrm{~ms}$ & $2.42 \%$ \\
\hline News video & $2.19 \mathrm{~ms}$ & $42.34 \%$ \\
\hline Entertain & $2.71 \mathrm{~ms}$ & $58.55 \%$ \\
\hline Typing & $0.17 \mathrm{~ms}$ & $0.86 \%$ \\
\hline Dhrystone & N/A & $99.63 \%$ \\
\hline \hline
\end{tabular}

Tabela 2.2: Tempo de Execução das Aplicações

e a resposta do sistema para um nível que é mais rápido do que a percepção humana pode detectar. Isto significa que para tarefas simples como digitar, mover o cursor ou selecionar o mouse, o tempo de resposta deveria ser em torno de 50-150ms [Shn92]. Desta maneira [NL97b], mediu-se a latência para caracteres digitados na aplicação Typing e determinou-se o percentual dos caracteres processados com latência menor do que $50 \mathrm{~ms}$, com latência entre $50-150 \mathrm{~ms}$ e com latência maior do que $150 \mathrm{~ms}$. No caso do áudio da News, é desejável não ter qualquer artefato na saída do áudio. Assim, mediu-se o número de áudios descartados na News. Para o vídeo da News e o Entertain, é desejável minimizar a diferença entre o instante de exibição desejado e o instante de exibição real, enquanto maximizando o número de frames que são exibidos dentro de suas restrições de tempo. Desta forma, mediu-se o percentual de frames de vídeo da News e da Entertain que foram mostrados no instante correto, anterior e atrasadamente, bem como, o percentual de frames descartados. Finalmente, para aplicações batch como o Dhrystone, é desejável maximizar o tempo de processamento dedicado à aplicação para garantir um progresso tão rápido quanto possível. Neste caso, mediu-se o tempo de CPU acumulado pela Dhrystone.

Para estabelecer uma base de desempenho. a Tab. 2.3 mostra o desempenho de cada aplicação quando foi executada.

Comentadas as características e as métricas de qualidade das aplicações, exibe-se a seguir como se programa com restrições de tempo no SMART. 


\begin{tabular}{|c|l|c|c|}
\hline \hline Nome & Métrica de Qualidade & Tempo correto & Adiantado \\
\hline \hline News audio & Número de dropouts de áudio & $100.00 \%$ & $0.00 \%$ \\
\hline News video & instante de exibição real menos aquele desejado & $99.75 \%$ & $0.09 \%$ \\
\hline Entertain & instante de exibição real menos aquele desejado & $99.58 \%$ & $0.22 \%$ \\
\hline Typing & Intervalo entre a entrada do caracter e sua exibição & $100.00 \%$ & N/A \\
\hline Dhrystone & Tempo de CPU acumulado & N/A & N/A \\
\hline \hline
\end{tabular}

\begin{tabular}{|c|c|c|c|c|}
\hline \hline Nome & Atrasado & Descartado & Média & Desvio Padrão \\
\hline \hline News audio & $0.00 \%$ & $0.00 \%$ & 0 & 0 \\
\hline News video & $0.13 \%$ & $0.02 \%$ & $1.50 \mathrm{~ms}$ & $2.54 \mathrm{~ms}$ \\
\hline Entertain & $0.13 \%$ & $0.07 \%$ & $1.95 \mathrm{~ms}$ & $3.61 \mathrm{~ms}$ \\
\hline Typing & $0 \%$ & N/A & $26.40 \mathrm{~ms}$ & $4.12 \mathrm{~ms}$ \\
\hline Dhrystone & N/A & N/A & $298.73 \mathrm{~s}$ & N/A \\
\hline \hline
\end{tabular}

Tábela 2.3: Métricas de Qualidade de Desempenho das Aplicações

\subsubsection{Programação com Restrições de Tempo}

Esta seção exibe as modificações realizadas no IMS Player para ilustrar como a API do SMART possibilita que restrições de escalonamento possam ser informadas ao sistema pelo desenvolvedor de aplicações e o sistema execute como esperado.

\subsubsection{Video Player}

Esta aplicação lê de uma fonte de entrada de vídeo JPEG timestamped a partir de um dispositivo de armazenamento local, descompacta o dado, modifica-o para 8-bit pseudocolor e o envia para um buffer de frames. Quando o Video Player não é usado em sincronia com o Audio Player, como no caso da Entertain, o player utiliza o timestamp sobre a fonte de entrada de vídeo para determinar quando exibir cada frame e se um dado frame está adiantado ou atrasado. Quando usado em conjunto com o Audio Player, como em News, o Video Player tenta sincronizar sua saída com o dispositivo de áudio.

Se o Video Player está pronto para exibir seu frame antecipadamente, então o frame é atrasado até o momento adequado, mas se o frame está atrasado, o frame atual é descartado na suposição de que a continuação do processamento causaria futuros atrasos. A aplicação define adiantado ou atrasado quando um frame chega $20 \mathrm{~ms}$ antes ou depois do áudio respectivamente. Para LNIX SVR4, o Video Player deve determinar a possibilidade de cada frame ser impresso no momento correto. Isto é executado medindo-se a quantidade de tempo de clock consumida durante o processamento de cada frame de vídeo. Uma média exponencial do tempo de clock consumido pelos frames exibidos anteriormente é usada como estimativa para a duração do procesamento do frame atual. Se a estimativa indica 
que o frame se adiantará, o Video Player é bloqueado por uma quantidade de tempo necessária para permitir que o frame seja exibido no momento certo. Se a estimativa indica que o frame está atrasado, então o frame é descartado.

A aplicação adaptada para executar no SMART usa o mesmo mecanismo do UNIX SVR4 para atrasar os frames completados antes do instante correto. Já o procedimento de descartar frames em situação de atrasos na aplicação adaptada foi substituído por uma chamada ao sistema para informar ao SMART as restrições de tempo para um bloco de código da aplicação e por um tratador de sinal para processar notificações de restrições de tempo perdidas. Uma restrição de tempo no SMART é o deadline para a execução de um bloco de código que processa um frame de vídeo. O deadline, neste caso, é o tempo em que um frame é considerado atrasado, isto é, $20 \mathrm{~ms}$ após o instante correto para chegada. A aplicação também fornece uma estimativa da quantidade de tempo de execução do código, calculada de maneira similar a estimativa efetuada no UNIX SVR4. Em particular, uma média exponencial dos tempos de execução dos frames anteriormente exibidos normalizados em $10 \%$ é usada como estimativa. Conhecida a restrição de tempo dada, a aplicação solicita que o SMART a envie uma notificação indicando que a restrição não será cumprida. Quando a notificação é recebida pelo tratador de sinal, este registra o recebimento e se a notificação chegou no instante em que a aplicação começa a computação para processar e exibir o respectivo frame de vídeo, este é descartado. Caso contrário, a aplicação simplesmente permite o atraso na exibição do frame.

\subsubsection{Audio Player}

Esta aplicação lê uma fonte de entrada de áudio timestamped a partir de um dispositivo de armazenamento local e envia o dado processado para o dispositivo de áudio. Para evitar dropouts de áudio, o Audio Player aproveita o mecanismo de buffer disponível no dispositivo de áudio, para continuar sua computação quando existem ciclos de processador disponíveis. No máximo, 1 segundo de trabalho adiantado é permitido. Para cada bloco de código que processa um segmento de áudio (512 bytes), o Audio Player esforça-se para completar o segmento antes que o dispositivo de áudio exiba os frames armazenados no seu buffer. O deadline informado ao SMART é o instante em que o último frame no buffer será exibido. A estimativa é calculada como no caso do Video Player e segmentos de áudio que não podem ser processados antes dos seus respectivos deadlines são simplesmente exibidos mais tarde.

A próxima seção comenta as características dos escalonadores.

\subsubsection{Características dos Escalonadores}

Para fornecer uma caracterização da sobrecarga de escalonamento mediu-se os tempos das trocas de contexto para o UNIX SRV4, WFQ e o SMART. Os tempos médios das trocas foram 27, 42 e 47 microsegundos, respectivamente. Estas medidas foram obtidas 
executando as aplicações descritas anteriormente. Resultados semelhantes foram obtidos quando se aumentou o número de aplicações multimídia de tempo real até o ponto de consumir toda a memória.

O tempo de troca de contexto no UNIX SVR4, essencialmente mede o overhead da troca para um escalonador que gasta quase nenhum tempo para decidir qual tarefa precisa executar. O escalonador simplesmente seleciona aquela com maior prioridade, com todas as tarefas já ordenadas por prioridade. Observe que esta medida não contabiliza o processamento periódico realizado pela política timesharing do UNIX SVR4 para ajustar os níveis de prioridade de todas tarefas. Este processamento periódico não é exigido pelo SMART nem pelo WFQ (Enfileiramento Justo com Pesos), o qual faz as comparações de sobrecarga baseando-se nos tempo de trocas de contexto mais favoráveis para o UNIX SVR4. Contudo, como tarefas são tipicamente escalonadas por quanta de tempo de muitos milissegundos, os tempos de trocas de contexto medidos para todos os escalonadores não tiveram um impacto significativo no desempenho da aplicação.

Para o SMART, mediu-se o custo para uma aplicação determinar os parâmetros de escalonamento tais como restrições de tempo ou ler informações de escalonamento. O custo da atribuição de parâmetros é 20 microsegundos enquanto o custo de leitura das informações de escalonamento é somente 10 microsegundos.

A próxima seção exibe a comparação entre o desempenho das aplicações descritas anteriormente nos escalonadores SMART, UNIX SVR4 e WFQ.

\subsection{Comparação entre Escalonadores}

Os experimentos foram realizados em um ambiente composto de $10 x$-terminals e uma estação com um único processador hyperSPARC de $150 \mathrm{MHz}, 64 \mathrm{MB}$ de memória principal e $3 \mathrm{~GB}$ de espaço em disco. O sistema testado incluiu um controlador padrão de buffer de frames pseudo-color de 8-bit, por exemplo, um GX. A impressão na tela foi gerenciada pelo Servidor de Janelas. O sistema operacional Solaris 2.5.1 foi utilizado como base para os experimentos efetuados.

O ambiente de escalonamento UNIX SVR4 padrão sob o qual o sistema operacional Solaris foi utilizado teve o tick de clock modificado de $10 \mathrm{~ms}$ para $1 \mathrm{~ms}$. As medidas foram realizadas interferindo o mínimo possível no desempenho das aplicações. Estas medições foram realizadas periodicamente e criou-se um $\log$ na memória. O custo destas medidas foi de 2-4 microsegundos por evento.

Todas as medidas foram realizadas em um sistema completamente funcional ${ }^{4}$ para representar um ambiente de estação de trabalho realístico. Ao mesmo tempo, o sistema foi reinicializado antes de cada experimento ser executado.

\footnotetext{
${ }^{4}$ Todos os experimentos foram efetuados com todas as funçōes do sistema e o sistema de janelas executando, e o sistema conectado a uma rede.
} 

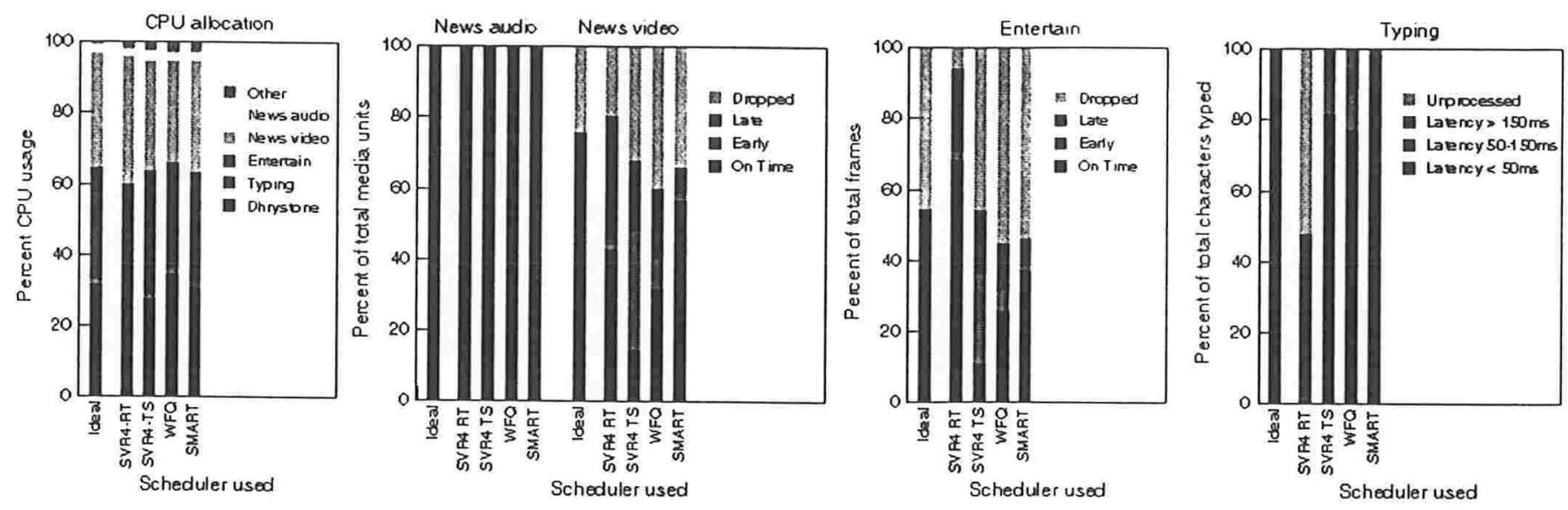

Figura 2.1: Comparação do Desempenho das aplicações nos Escalonadores

No primeiro experimento executou-se as quatro aplicações (News, Entertain, Typing e Dhrystone) com parâmetros do usuário defaults para cada escalonador:

- SVR4-RT: As aplicações News e Entertain são colocadas nas classes de tempo real, enquanto typing e Dhrystone são localizadas na classe timesharing.

- SVR4-TS: Todas as aplicações são executadas no modo timesharing. Também foi testada a aplicação Typing na classe de aplicações interativas e obteve-se uma performance sutilmente pior.

- WFQ: Todas as aplicações executam com mesmo share.

- SMART: Todas as aplicações executam com mesma prioridade e share.

A Fig. 2.1 apresenta a alocação de CPU para as diferentes aplicações utilizando escalonadores distintos. Esta inclui o percentual de CPU usado para executar outras funções do sistema tais como o sistema de janelas, rotulado Other. A figura também contém o resultado esperado de um escalonador ideal para efeito de comparação. Para aplicaçōes de tempo real, a figura também exibe o percentual de unidades de mídia que são mostradas no tempo certo, adiantadas, atrasadas ou descartadas. Para a aplicação interativa Typing, a figura apresenta o número de caracteres que gastam menos do que $50 \mathrm{~ms}$, entre $50-150 \mathrm{~ms}$ e mais do que $150 \mathrm{~ms}$ para serem exibidas. 
A figura 2.2 apresenta mais detalhes exibindo as distribuições dos pontos de dados. Também foram incluídas as medidas para cada uma das aplicações executando sozinha (rotulado Standalone) na figura. Observou-se que todo escalonador trata bem a aplicação News audio sem a ocorrência de dropouts. Desta maneira, concentra-se as discussões posteriores na qualidade das demais aplicações.

Ao contrário dos outros escalonadores, o escalonador SVR4-RT concede maior prioridade para aplicações na classe de tempo real. Este escalonador dedica mais tempo da CPU para aplicações de vídeo, e assim perde um menor número de frames. Contudo, SMART é capaz de distribuir mais frames em tempo do que o SVR4-RT para a aplicação News video, usando para isto menos recursos. Infelizmente, SVR4-RT executa as aplicações de tempo real quase excluindo as aplicações convencionais. Dhrystone consegue apenas $1.6 \%$ do tempo de CPU. Mais drasticamente, a aplicação interativa Typing não obtém nem mesmo o mínimo de processamento solicitado, recebendo somente $0.24 \%$ do tempo de CPU. Apenas 635 dos 1314 caracteres digitados são processados dentro do período de 300 segundos, e quase todos os caracteres processados têm uma latência inaceitável de mais do que $150 \mathrm{~ms}$. Note que colocar Typing na classe de tempo real não alivia este problema, uma vez que os processamentos de I/O exigidos pela aplicação não conseguem ser executados por executarem em um nível de prioridade menor do que aquele das tarefas de tempo real. Claramente, é inaceitável utilizar o escalonador SVR4-RT.

Todos os outros escalonadores distribuem igualmente as demandas de recursos das aplicações. O escalonador SVR4-RT tem menos controle sobre a distribuição de recursos do que os escalonadores WFQ e SMART, resultando em uma sutil penalização da Entertain em relação a Dhrystone. Os princípios básicos usados para ser justo com as solicitações das aplicações são as mesmas no WFQ e no SMART. Contudo, observou-se que o escalonador WFQ dedica sutilmente mais tempo de CPU (3.8\%) para Dhrystone em detrimento da aplicação News video. Este efeito pode ser atribuído à implementação padrão do WFQ, visto que o share proporcional do processador obtido por uma tarefa é baseado apenas no tempo em que a tarefa está pronta para executar e não inclui qualquer tempo em que a tarefa esteja bloqueada.

Os escalonadores são distingüidos pela sua habilidade em satisfazer as restrições de tempo dos frames processados. O SMART satisfaz um número significativamente grande de restrições em relação aos outros escalonadores, distribuindo mais do que $250 \%$ frames de vídeo a mais do que o SVR4-TS e mais do que $60 \%$ frames de vídeo em tempo a mais do que aqueles exibidos pelo IVFQ. Além disto, como mostrado na Fig. 2.2, os frames atrasados são tratados logo depois dos deadlines, ao contrário dos outros escalonadores. Como o SMART possui um comportamneto mais previsível, as aplicações conseguem se ajustar melhor sobre o tempo em que precisam estar bloqueadas para evitar exibições de frames adiantados. Em conseqüência, há um menor número de frames adiantados. O SMART distribui em tempo $57 \%$ e $37 \%$ do número total de frames na News video e Entertain, respectivamente. Isto representa respectivamente, $86 \%$ e $81 \%$ dos frames exibidos. 

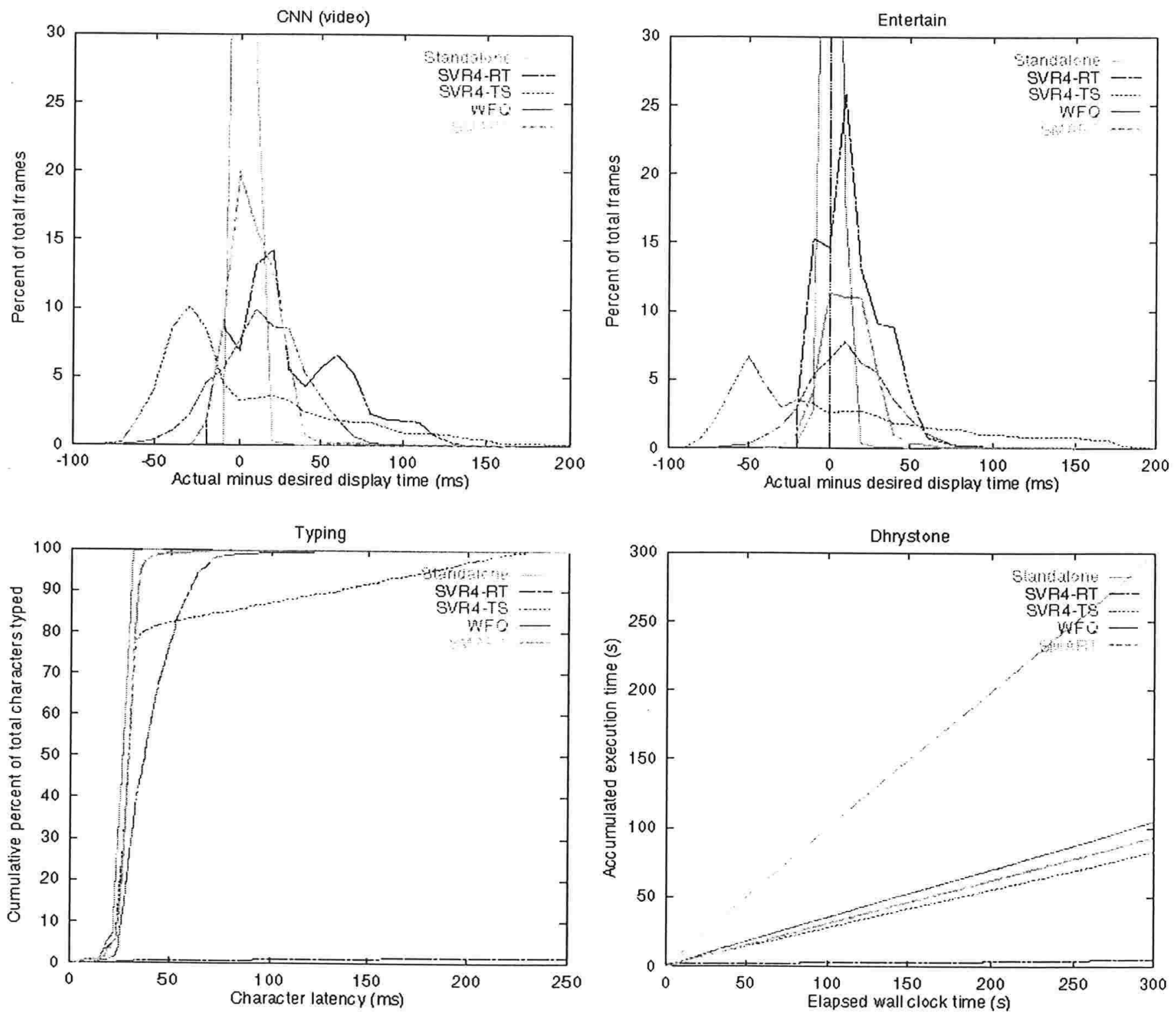

Figura 2.2: Distribuições de Métricas de Qualidade 
Para entender a significância do bias apresentado para melhorar o desempenho das aplicações de tempo real e iterativas, executou-se os mesmos experimentos com todos os bias com valor igual a zero. O uso do bias produz uma melhoria relativa de $10 \%$ na distribuição pelo escalonador de frames em tempo da Entertain.

Em contraste, o WFQ distribui $32 \%$ e $26 \%$ do total de frames em tempo, o que representa apenas $53 \%$ e $58 \%$ dos frames processados. Existem muito mais frames atrasados no WFQ do que no SMART. O atraso faz com que as aplicações iniciem o processamento mais cedo, resultando em um maior número de frames antecipados. O SVR4-TS executa mais pobremente, distribuindo $15 \%$ e $11 \%$ do total de frames, representando somente $22 \%$ e $21 \%$ dos frames processados. Alguns dos frames tratados pelo SVR4-TS são extremamente atrasados, causando um processamento antecipado de muitos frames, resultando em uma variância enorme no tempo de exibição dos frames.

Finalmente, como mostrado na Fig. 2.2, SMART é superior a SVR4-TS e WFQ no tratamento da aplicação Typing. SMART tem a menor média e desvio padrão em latência de caracteres e completa o maior número de caracteres em menos do que $50 \mathrm{~ms}$.

Embora SMART e WFQ apresentem um desempenho interativo aceitável, no caso da Typing o WFQ exibe um comportamento pior porque a tarefa não acumula qualquer crédito quando está bloqueada. Motivando-se neste fato, executou-se um experimento onde o WFQ foi modificado para permitir que tarefas bloqueadas acumulem um número limitado de créditos exatamente como acontece no SMART. O resultado é que Typing melhorou significativamente, e a aplicação de vídeo conseguiu um compartilhamento mais justo dos recursos. Entretanto, apesar da redução no número de frames de vídeo perdidos, o WFQ modificado teve o mesmo desempenho pobre anteriormente detectado no caso dos frames distribuídos em tempo.

Os experimentos realizados, no contexto dos sistemas operacionais de propósito geral, comerciais e bem estruturados, mostram que o SMART:

1. reduz o ônus de escrita de aplicações de tempo real adaptativas;

2. tem a habilidade de cooperar com aplicações no gerenciamento dos recursos para satisfazer suas restrições de tempo dinâmicas;

3. fornece compartilhamento de recursos para aplicações de tempo real e convencionais;

4. apresenta um desempenho de tempo real e interativo melhor do que aqueles exibidos pelos outros escalonadores sem nenhuma necessidade de reserva de recursos, ajuste dos parâmetros de escalonamento ou conhecimento dos requisitos das aplicações por parte do usuário;

5. fornece controles flexíveis e previsíveis para permitir que usuários gerenciem as alocações de recursos de acordo com suas preferências. 
O SMART atinge este comportamento diferenciando importância e urgência para aplicações de tempo real e convencionais. Isto é realizado integrando prioridades e enfileirameto justo com pesos para importância, então usando urgência para otimizar a ordem na qual as tarefas são atendidas baseando-se em um escalonamento EDF (Seção 5.1.1). Os resultados das medidas de desempenho demonstraram a eficiência do SMART sobre os outros escalonadores no suporte de aplicações multimídia em um ambiente de estações de trabalho realístico.

No capítulo a seguir exibimos como implementamos as idéias do SMART no ambiente LINUX. 


\section{Capítulo 3}

\section{Implementação do Escalonador LINUX-SMART}

É sabido o grande interesse da comunidade de sistemas operacionais quanto ao estudo e desenvolvimento do LINUX, que também vem sendo mais utilizado por corporações [Lin98, Lin99a, Lin99b], acarretando para este sistema uma notoriedade crescente nos últimos anos. Este fato e o interesse na melhoria do comportamento de aplicações de multimídia nos sistemas operacionais existentes, motivaram os estudos desenvolvidos e relatados nesta dissertação.

A etapa inicial da pesquisa objetivou determinar o grau de tratamento que o LINUX oferece para as aplicações de multimídia. Para tanto desenvolveu-se uma aplicação gráfica entitulada "Controle de Aproximação de Aeronaves em Aeroportos" e realizaram-se vários testes para medir o seu desempenho em diversos cenários que caracterizavam o sistema na presença e na ausência de sobrecarga. Os resultados obtidos podem ser encontrados em trabalho publicado [VNdS99b] no Workshop de Tempo Real da SBRC - Simpósio Brasileiro de Rede de Computadores, ou mais detalhadamente em [VNdS99a].

Constatando-se um comprometimento da performance da aplicação desenvolvida e utilizada nos testes, optou-se pela busca de outras políticas de escalonamento que tratassem aplicações de multimídia convenientemente e pela análise de viabilidade da implementação das mesmas no LINUX. Entre as políticas analisadas escolheu-se aquela desenvolvida por Nieh et. al [NL97b, NL97a, NL95] chamada SMART. Destaca-se que durante este relato utiliza-se a denominação LINUX-SMART para a nossa implementação da política de escalonamento SMART e LINLX-PADRÃO para o sistema LINUX original. Destaca-se que sistemas multi-processadores (SMP) não foram considerados neste trabalho. A nova versão procura também emular os escalonadores do LINUX original.

A idéia central deste capítulo é justamente registrar os procedimentos usados na implementação do escalonador LINUX-SMART, descrito na próxima seção. 


\subsection{O escalonador LINUX-SMART}

Um dos mais importantes conceitos em um sistema multi-tarefa tal como LINUX é o processo. As estruturas de dados e os algoritmos para gerenciamento de dados formam a parte central do LINUX-PADRÃO.

A descrição das características de um processo [CDM97] é dada na estrutura task_struct. Os primeiros componentes da estrutura são acessados por rotinas assembler e o seu acesso é realizado via offset e não pelos nomes dos campos. Todo processo ocupa exatamente uma entrada na tabela de processos task. Esta tabela no LINUX-PADR ÃO é estaticamente organizada e restrita ao tamanho $N R_{-} T A S K S$ que é definido no arquivo param. $h$, o qual tem valor igual a 512 e é mantido no LINUX-SMART. A definição de task no arquivo sched.h é exibida a seguir.

extern struct task_struct *task [NR_TASKS];

É importante ressaltar que o valor máximo para a constante NR_TASKS é de 8192 para arquitetura Intel. Este valor é obtido dividindo-se o tamanho máximo que a tabela pode atingir $(64 \mathrm{~kb})$ pelo limite mínimo por entrada (8 bytes) na tabela de descritores globais (GDT). Entre outras coisas esta tabela tem entradas para cada ${ }^{1}$ thread_struct dos processos. A entrada consiste de um ponteiro para aquela thread_struct e algumas informações adicionais (por exemplo, tipo de entrada), por este motivo é 8 bytes e não 4 bytes. O limite disponível é um pouco mais baixo uma vez que o LINUX usa algumas entradas para si próprio.

As estruturas task_struct estão conectadas em uma lista circular duplamente ligada, onde o início desta lista é representado pela variável externa init_task que é inicializada com INIT_TASK. Esta variável ocupa a posição task[0], além de ser chamada apenas quando não existe nenhuma outra tarefa para executar. Uma característica importante é que a init_task não pode ser morta e não pode ter o estado SLEEP.

A estrutura mencionada não era adequada para descrever um processo no LINUXSMART e desta forma foi necessário o acréscimo de mais componentes. Como solução foi definida uma nova estrutura chamada smart_struct e acrescentada na struct task_struct um campo ponteiro do tipo smart_struct.

As novas estruturas smart_struct complementam a tabela de processos task existente e são organizadas na tabela smart, sendo que neste nível do LINUX-SMART cada entrada relativa a um processo é classificada de acordo com a prioridade do mesmo, a qual varia de 0 a $N R_{-} P R I O-1$ e as correspondentes posições no array smart identificam estas filas de prioridade $^{2}$. A constante $N R_{-} P R I O$ especifica o número máximo de prioridades permitido

\footnotetext{
${ }^{1}$ A definição desta estrutura pode ser encontrada no arquivo include/asm-i386/processor.h.

${ }^{2}$ Onde 0 é a mais alta prioridade e conseqüentemente $N R \_P R I O-1$ a menor delas.
} 
e nesta implementação tem valor ${ }^{3} 5$. Uma observação importante é que todas as inserções na tabela smart são efetuadas no início de cada fila de prioridade com a finalidade de diminuir o custo de cada operação de inserção. A relação entre as estruturas mencionadas é apresentada na Fig. 3.1.

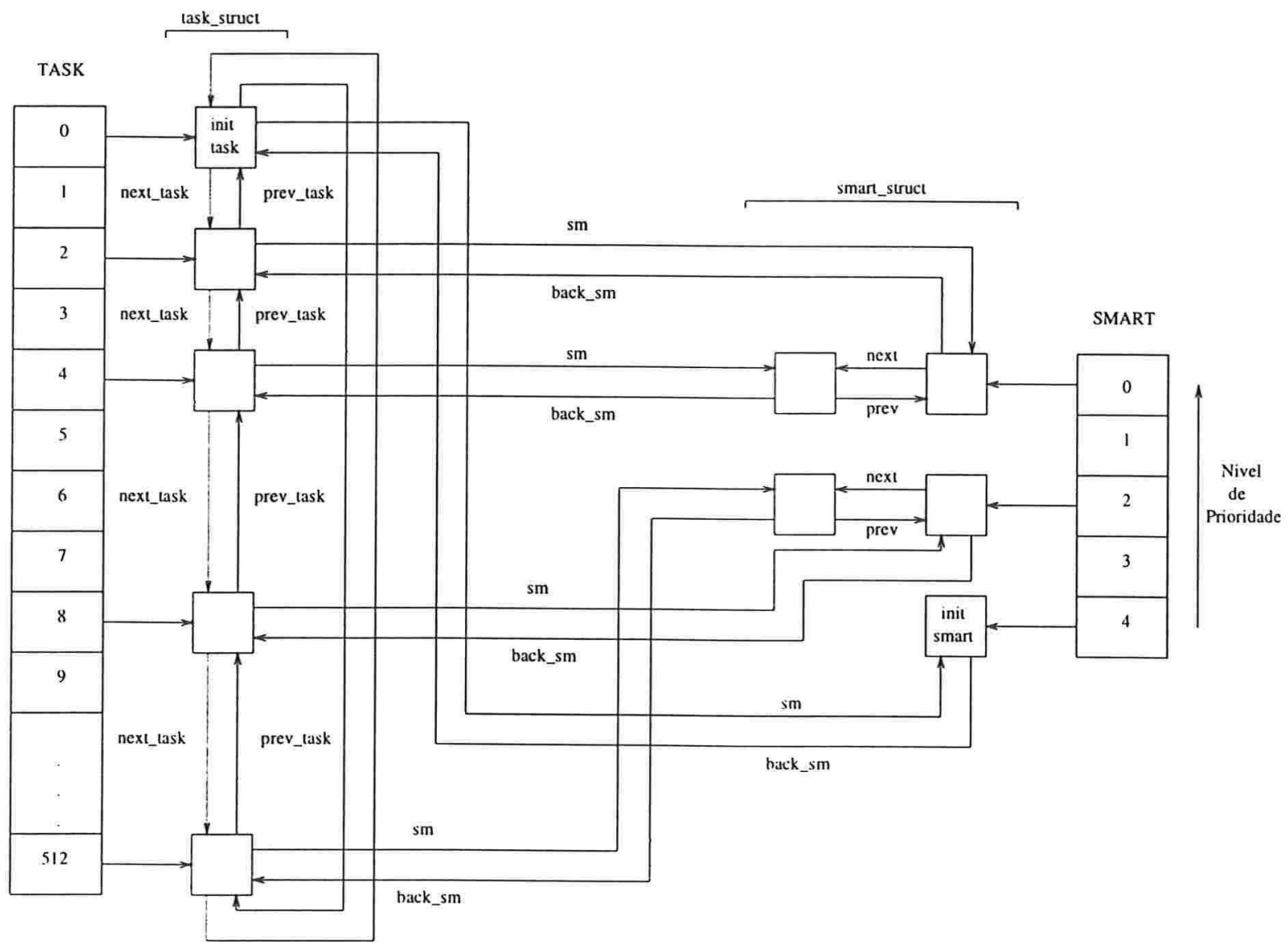

Figura 3.1: Diagrama representando a relação entre task_struct e smart_struct

A estrutura smart_struct que define os processos de tempo real e convencionais do LINUX-SMART é constituída dos seguintes campos:

- prio : um valor inteiro estático ${ }^{4}$ atribuído a cada processo.

- bias : um valor unsigned long atribuído apenas a processos convencionais.

- share: um valor unsigned long que determina a fração de recursos destinada a cada processo de mesma prioridade quando estes disputam recursos.

\footnotetext{
${ }^{3}$ Para alterar este valor modifica-se a constante NR_PRIO definida no arquivo tasks.h. Também é necessário redefinir as constantes que identificam cada prioridade no arquivo sched.h

${ }^{4}$ Estático no sentido que o escalonador não o altera, mas este valor pode ser alterado pelo usuário.
} 
- bvft: um valor unsigned long dinâmico que o sistema usa para medir o grau do share proporcional dos recursos que tem sido consumido por cada processo.

- tvirtual: um valor unsigned long que representa o tempo virtual de cada processo e que avança em uma taxa proporcional à soma de processamento que ele consome dividida pelo seu share.

- tvf_start : um valor unsigned long que expressa o valor do tempo virtual da fila de prioridade de um processo no instante em que foi criado.

- deadline: um valor unsigned long que expressa o deadline de cada processo de tempo real.

- quantum : um valor unsigned long que determina o tempo de processamento para cada processo.

- delta : um valor unsigned long que registra a diferença entre o tempo virtual do processo e aquele da fila a qual pertence.

- tblocked: um valor unsigned long que assume o valor da variável jiffies ${ }^{5}$ no instante em que o processo é bloqueado.

- next : um ponteiro para uma estrutura smart_struct que aponta para o próximo elemento da lista de processos.

- prev : um ponteiro para uma estrutura smart_struct que aponta para o elemento anterior da lista de processos.

- next_cand: um ponteiro para uma estrutura smart_struct que aponta para o próximo elemento da lista de processos de tempo real candidatos à execução.

- next_cand_w : um ponteiro para uma estrutura smart_struct que aponta para o próximo elemento de uma lista $W$ de processos, a qual representa um subconjunto da lista de candidatos.

- back_sm : um ponteiro para uma estrutura task_struct que contém os dados suplementares à estrutura smart_struct e juntas definem um processo linux.

Um problema enfrentado na definição da nova estrutura smart_struct foi a restrição no tamanho da pilha do kernel. É sabido que no LINUX-PADRÃO cada processo tem alocado $4 \mathrm{~K}$ da memória do kernel. este sendo o local onde reside a task_struct e a pilha do kernel do processo ${ }^{6}$. Assim, se o tamanho da struct task_struct cresce muito, como

\footnotetext{
${ }^{5}$ Jiffies é uma variável global que armazena o número de ticks de clock consumidos desde que o sistema foi inicializado.

${ }^{6}$ Enquanto o processador está no modo kernel, o restante da memória do kernel, $4 K-$ sizeof (task_struct), é ocupada com a pilha do kernel do processo. A partir da versão 2.2.x do kernel a área por processo passou a ser $8 \mathrm{~K}$ (2 páginas consecutivas na arquitetura i386).
} 
em muitas arquiteturas a task_struct está sendo alocada no final da pilha, pode ocorrer colisão com a pilha real. Tendo em vista esta restrição, optou-se pela organização dos dados como discutido acima. Anteriormente a área ocupada com a struct task_struct era 996 bytes. Após as modificações efetuadas este tamanho passou a ser 1000 bytes devido ao acréscimo de 4 bytes do ponteiro para struct smart_struct, com esta última estrutura consumindo 60 bytes. Desta maneira não foi superado o limite de $4 \mathrm{~K}$ nem o tamanho da pilha do kernel foi restringido problematicamente.

Outro problema encontrado foi o não suporte para tipos float e double dentro do kernel. A razão é que o estado da FPU é indefinida dentro do kernel. Descrevendo melhor a situação, tem-se que dois valores de pontos flutuantes são usados inicialmente durante a inicialização de um ix86 para testar a resposta em ponto flutuante. Daquele momento em diante, o estado da unidade de ponto flutuante é indefinida dentro do kernel. O estado da unidade de ponto flutuante é salvo/armazenado nas trocas de contexto de forma que códigos de usuários podem usar a unidade de ponto flutuante. O problema em utilizar a unidade de ponto flutuante é que uma chamada ao sistema é tipicamente executada dentro do contexto de uma tarefa. Em outras palavras, uma troca de contexto não ocorre normalmente quando alguém interrompe o kernel para serviços. Contudo, quando esperando por alguns serviços do sistema (I/O por exemplo), é provável que a tarefa possa voluntariamente liberar a CPU. Se a unidade de ponto flutuante é usada neste momento, seu estado deveria ser salvo e rearmazenado. Isto adiciona overhead ao sistema, o que não é necessário. Então decretou-se que a unidade de ponto flutuante não seria usada em código do kernel. Alternativamente é possível representar pontos flutuantes como pontos fixos, como a razão de dois inteiros ou seguir procedimentos como:

\section{Bloquear o kernel.}

2. Salvar o estado atual da unidade de ponto flutuante.

3. Fazer a computação solicitada.

4. Rearmazenar o estado da unidade de ponto flutuante.

5. Desbloquear o kernel

A desvantagem de esquemas como o exibido acima é o custo envolvido. Cerca de 130 clocks $^{7}$ para salvar o estado da unidade de ponto flutuante e um pouco menos de tempo para rearmazená-lo. Neste tempo gasto, muitos cálculos com inteiros poderiam ser executados.

No caso do LINUX-SMART optou-se pela representação em ponto fixo de alguns campos da struct smart_struct. Por exemplo, os campos share e buft, entre outros.

\footnotetext{
${ }^{7}$ Por exemplo, para uma máquina de $100 \mathrm{MHz}$ tem-se $1 / 100 \mathrm{MHz}=10$ ns. Assim 130 clocks são 1.3 microsegundos.
} 
Complementando a init_task foi definida a estrutura init_smart, a qual herda as mesmas características da init_task mencionadas anteriormente. A init_smart possui no LINUXSMART a mais baixa prioridade, ou seja, é localizada na fila cujo indíce do array smart é NR_PRIO - 1 .

Para implementar os algoritmos que caracterizam a política LINUX-SMART foram alterados os seguintes arquivos: fork.c, exit.c,sched.c,sys.c,vmscan.c,param.h,sched.h, unistd.h, entry.S e tasks.h.

No arquivo sched.h foram definidas as seguintes prioridades para os processos:

$\begin{array}{ll}\text { \#define HIGH } & 0 \\ \text { \#define MIDDLE1 } & 1 \\ \text { \#define MIDDLE2 } & 2 \\ \text { \#define NORMAL } & 3 \\ \text { \#define LOW } & 4\end{array}$

A variação de valores de prioridade permitidas e que também definem o tamanho do array smart é especificada pela constante $N R_{-} P R I O$, a qual é definida no arquivo tasks.h e nesta implementação tem valor 5 .

Os valores iniciais da variável init_smart e do array smart, também definidos no sched.h, são apresentados a seguir:

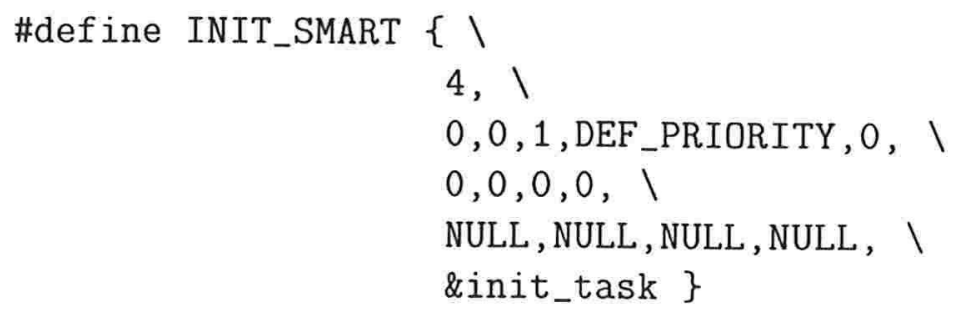

As demais definições e inicializações efetuadas no arquivo sched.h serão referenciadas no decorrer desta seção quando se tornarem necessárias para a compreensão desta implementação do LINUX-SMART.

As alterações relativas ao fork.c são direcionadas à criação e inicialização das estruturas smart_struct. Na função do_fork aloca-se espaço e inicializa-se toda estrutura smart_struct através da função copy_sm exibida na Fig. 3.2, onde tsk é o processo sendo criado. 


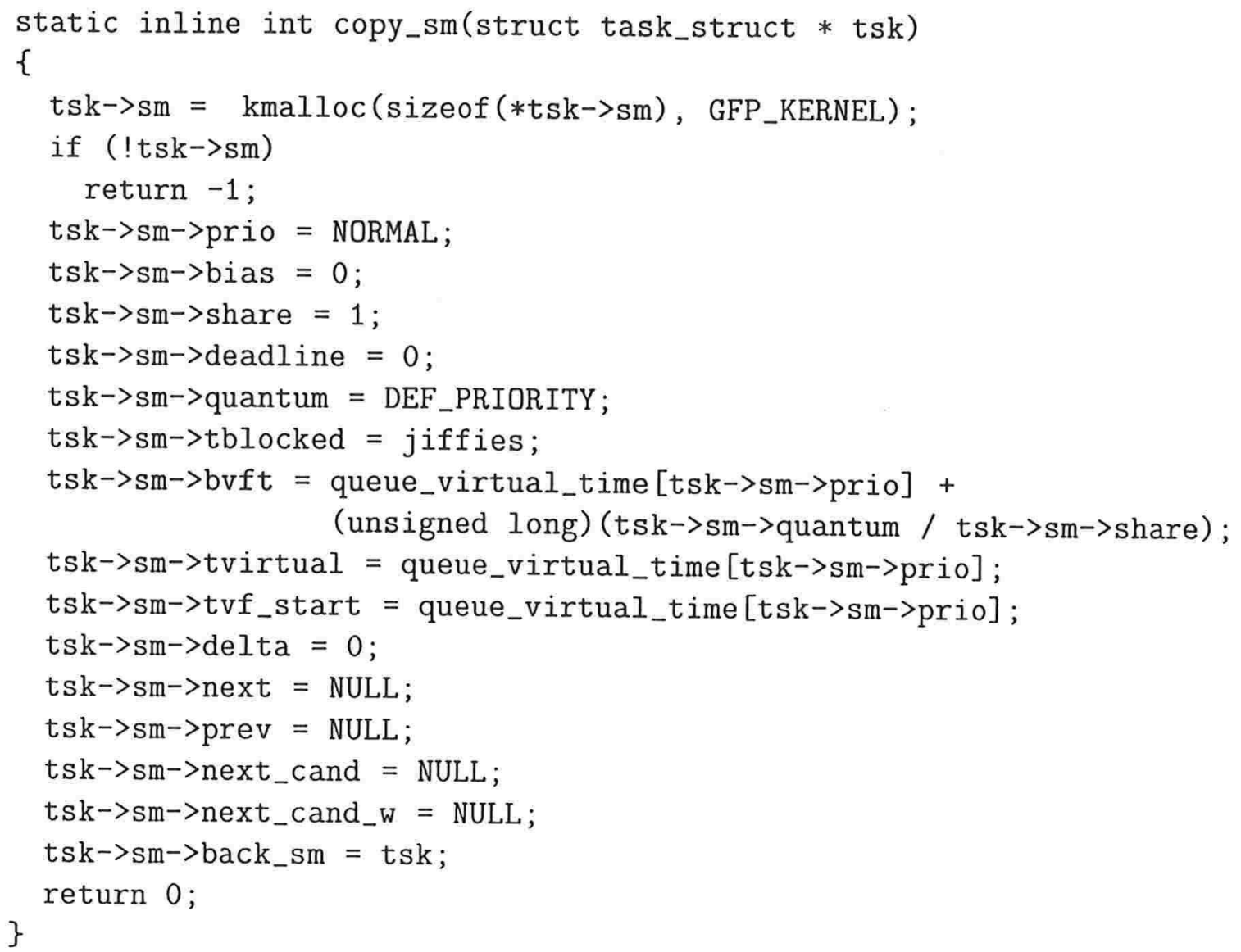

Figura 3.2: Implementação da Função copy_sm 
Os processos são inicializados com prioridade NORMAL e a função add_queue adiciona a estrutura criada no array smart. É importante observar que as inserções são efetuadas no início da fila.

Também foi adicionada no arquivo exit.c a função _-_exit_sm para liberar o espaço de memória de estruturas smart_struct e retirá-las das suas respectivas filas de prioridade, conforme exibido na Fig. 3.3. Ressalta-se que esta função é chamada sempre que um processo de desalocação de memória de uma struct task_struct é iniciado.

O ambiente SMART suporta uma interface de programação da aplicação que permite ao usuário e ao desenvolvedor da aplicação informar ao sistema os seguintes valores determinates para um processo: prioridade, share, deadline e quantum.

Os valores mencionados são passados através de chamadas ao sistema que foram implementadas no arquivo sys.c e são entituladas: setprio, getprio, setshare, setdeadline, setquantum e getquantum.

Dentre estas chamadas exibe-se nas Fig. 3.4 e 3.5 aquelas diretamente utilizadas nos testes de performance da aplicação principal juntamente com a chamada ao sistema setquantum. Antes de comentar as chamadas citadas, destaca-se que as condições de erro utilizadas são definidas no arquivo include/asm/errno.h.

A função setdeadline tem como parâmetro as variáveis which, who e deadline. $\mathrm{O}$ parâmetro which pode assumir os valores 0,1 e 2, os quais especificam se o campo who possui um valor de PID, PGRP ou UID respectivamente. Nos testes efetuados neste trabalho, utilizou-se sempre o valor 0 para which.

Descrevendo o procedimento da chamada ao sistema setdeadline tem-se que inicialmente efetua-se testes para verificar se as variáveis which e deadline estão dentro dos limites esperados. Caso contrário o erro EINVAL é retornado.

Posteriormente, percorre-se a tabela de processos em busca da tarefa com PID igual ao parâmetro who. Neste instante, também é verificado se o usuário solicitando a modificação é o owner do processo ou possui permissão para acessá-lo. Se o processo não for encontrado ou o usuário solicitando a modificação não se qualifica para a mesma, setdeadline retorna um erro, o qual é respectivamente ESRCH e EPERM. Caso contrário, o valor do campo deadline do processo encontrado é alterado.

Analogamente à função setdeadline, a chamada ao sistema setprio verifica se seus parâmetros respeitam os limites esperados para os mesmos. Também de maneira similar efetua a busca do processo a ser modificado no seu campo prio. No caso da função setprio é necessário além da alteração do campo mencionado, alocar o processo na sua nova fila de prioridade. 


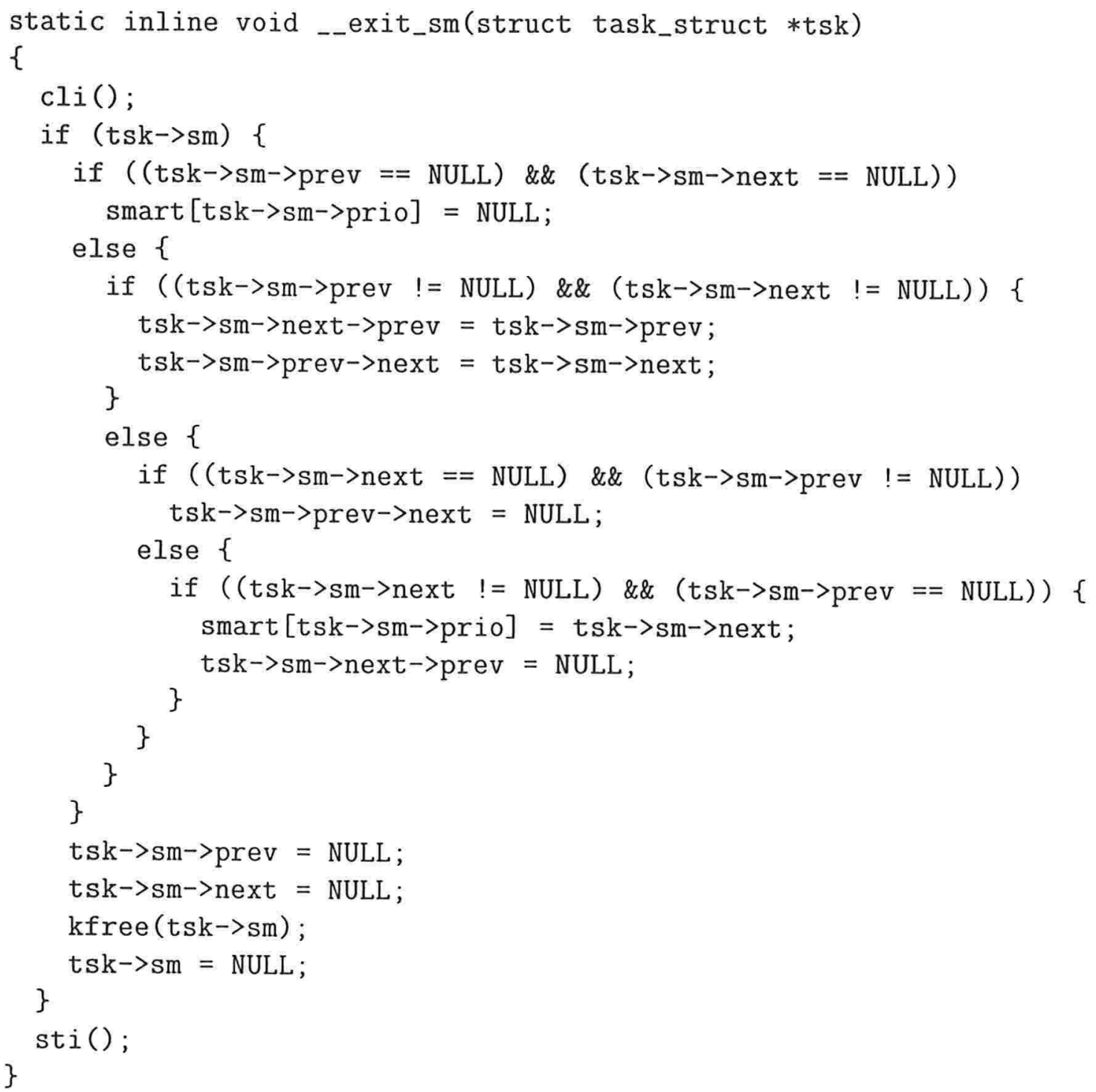

Figura 3.3: Implementação da Função _-exit_sm 


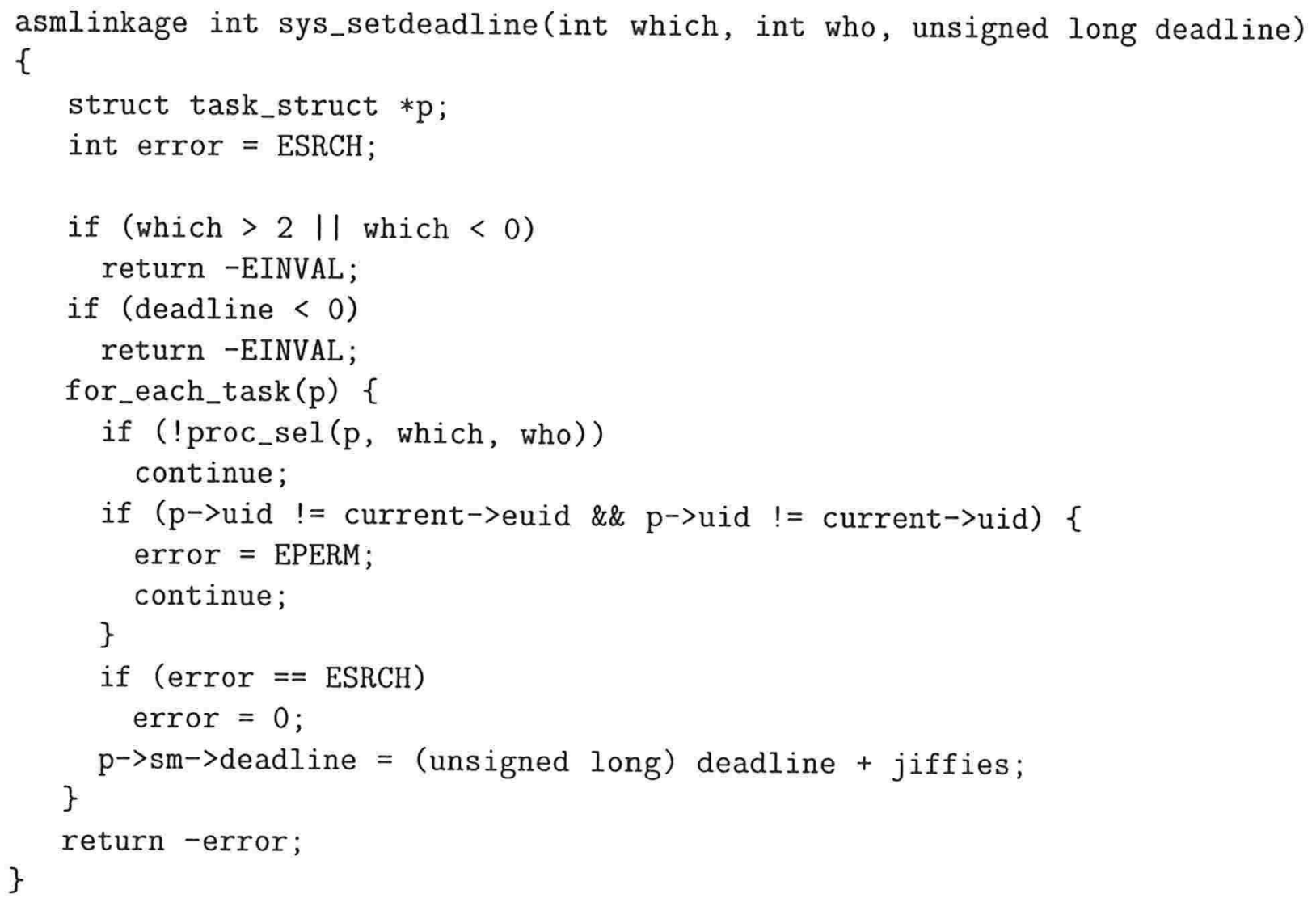

Figura 3.4: Implementação da Chamada ao Sistema setdeadline 


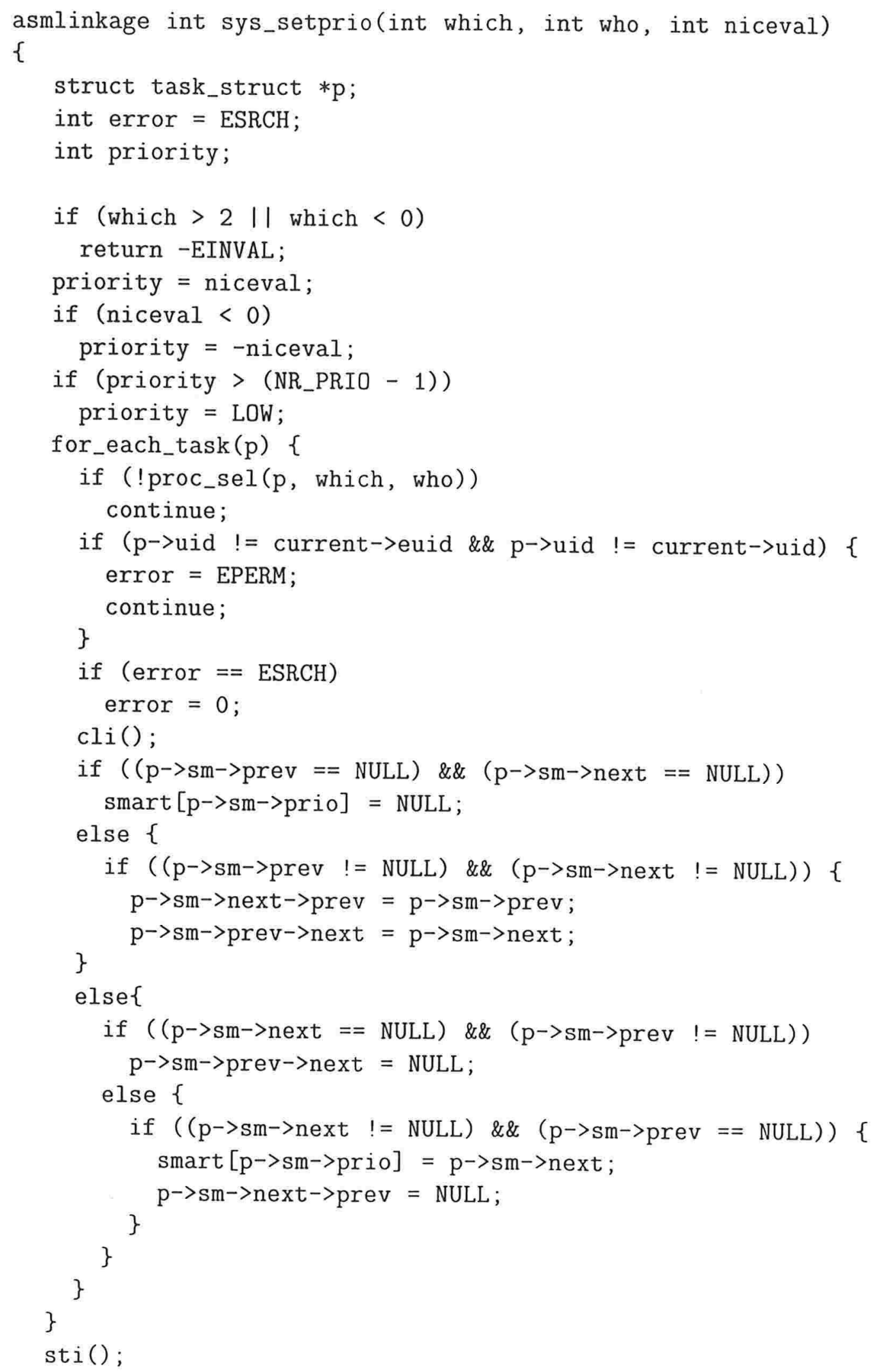




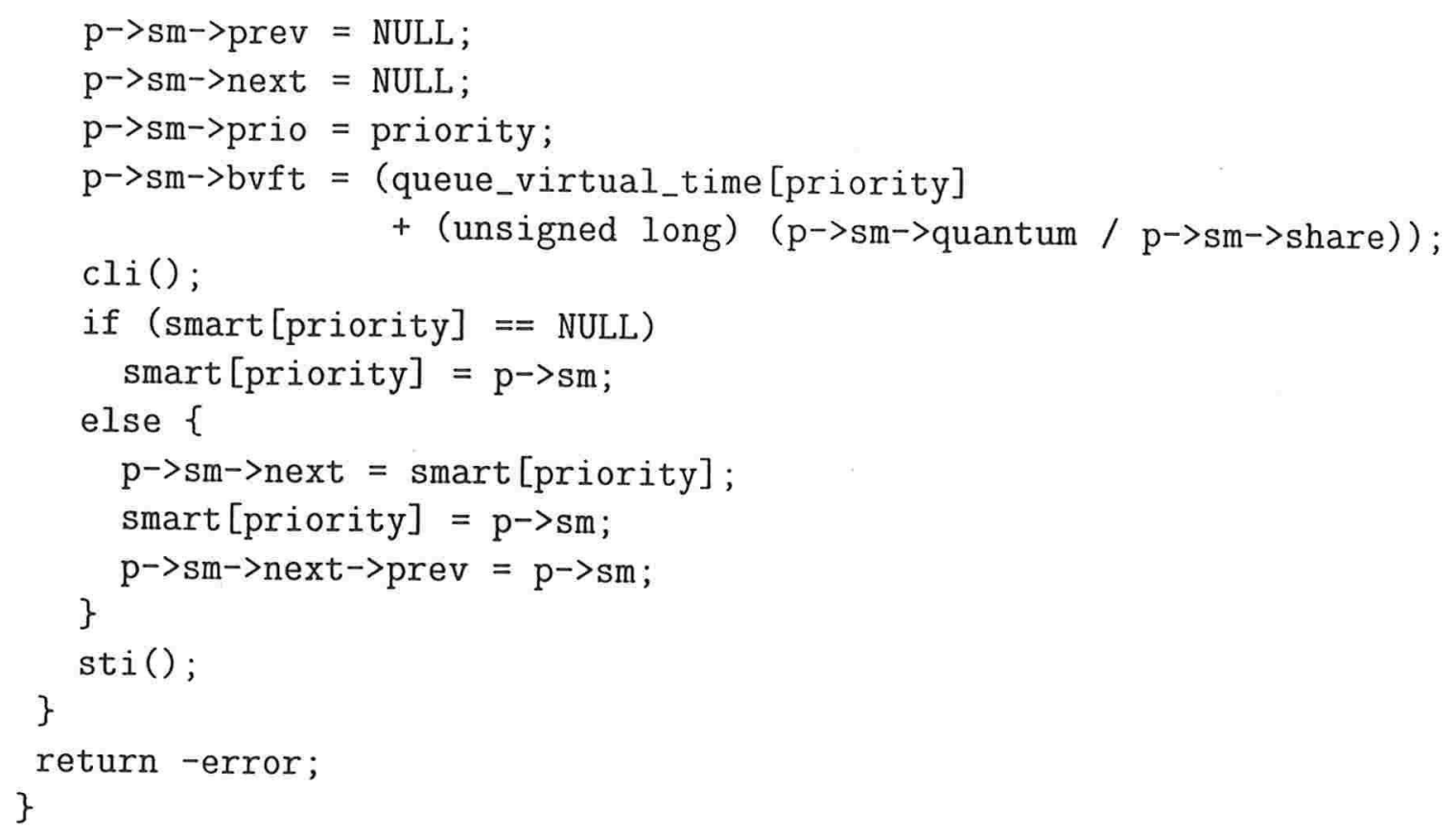

Figura 3.5: Implementação da Chamada ao Sistema setprio

A chamada ao sistema setquantum também possui um procedimento similar a aquele da função setdeadline, distinguindo-se apenas no campo a ser alterado. No caso, o campo quantum.

Seguindo o procedimento natural para definições de chamadas ao sistema no LINLXPADRÃO [CDM97, BBD ${ }^{+} 98$ ], as modificações necessárias nos arquivos entry.S e unistd.h foram efetuadas ${ }^{8}$. Nos arquivos unistd.h e entry.S foram declaradas as novas chamadas ao sistema e associou-se a cada uma delas um número, como exibido nas Fig. 3.6 e 3.7.

Outro fator importante a ser observado é que o limite no número de chamadas de sistemas no sistema operacional é dado pelo valor da constante $N R_{-}$syscalls que é definida no arquivo include/linux/sys.h. Este limite pode ser aumentado até o valor de 0x40000000. Este número é dado pelo número máximo de memória para um sistema de 32 bits (4GB) dividido pelo tamanho de cada entrada. Obviamente, este é um limite que na prática não é alcançado.

Posteriormente, adicionou-se os códigos relativos às novas chamadas ao sistema no arquivo sys.c. Para testar as chamadas ao sistema implementadas foi necessário recompilar o kernel e reinicializar a máquina. Além disto, declarou-se as funções que as executam utilizando macro instruções definidas no arquivo syscall.h.

No arquivo vmscan.c do LINUX-PADRÃO é dada uma prioridade de tempo real no

\footnotetext{
${ }^{8}$ Toda chamada ao sistema deve possuir um nome e um número únicos, isto é definido no arquivo unistd.h. (O arquivo entry.S contém a tabela de inicialização das chamadas.
} 


$\begin{array}{ll}\text { \#define _-NR_setprio } & 164 \\ \text { \#define _-NR_getprio } & 165 \\ \text { \#define _-NR_setdeadline } & 166 \\ \text { \#define _-NR_getjiffies } & 167 \\ \text { \#define _-NR_setshare } & 168 \\ \text { \#define -_NR_setquantum } & 169 \\ \text { \#define -_NR_getquantum } & 170 \\ \text { \#define _-NR_getqueue } & 171\end{array}$

Figura 3.6: Alterações no arquivo unistd.h

.long SYMBOL_NAME(sys_setprio)

.long SYMBOL_NAME (sys_getprio)

.long SYMBOL_NAME (sys_setdeadline)

/* $165 * /$

.long SYMBOL_NAME(sys_getjiffies)

.long SYMBOL_NAME (sys_setshare)

.long SYMBOL_NAME (sys_setquantum)

.long SYMBOL_NAME (sys_getquantum)

.long SYMBOL_NAME (sys_getqueue)

.long 0,0

.long SYMBOL_NAME (sys_vm86)

. space (NR_syscalls-174)*4

Figura 3.7: Alterações no arquivo entry. $S$ 
escalonador SCHED_FIFO para a thread do kernel kswapd, que é ativado todas as vezes que o número de páginas livres fica abaixo de um nível crítico. Para emular este contexto no LINUX-SMART foi dada à thread mencionada a maior prioridade, HIGH. Também no LINUX-SMART foi diminuído o intervalo de swap out, isto buscando um melhor gerenciamento da memória.

A modificação do valor da variável swapout_interval ${ }^{9}$ de $\frac{H Z}{4}$ para 50 , resultou em um melhor desempenho do sistema nos testes efetuados por determinar uma freqüência de verificação da necessidade de page out mais uniforme. Ressalta-se que no LINLXPADRÃO esta verificação era realizada 4 vezes em um segundo e no LINUX-SMART a freqüência passou a ser de 20 vezes em um segundo.

As alterações efetuadas no vmscan.c foram provocadas pelo fraco desempenho da aplicação principal nos cenários que exigiam uma grande utilização de memória virtual. Por exemplo, no cenário com 10 processos gráficos executando concorrentemente com a aplicação principal.

As mais importantes modificações nos arquivos do LINUX-PADRÃO ocorreram no arquivo sched.c. Devido à importância das alterações efetuadas optou-se por descrevê-las em uma seção particular. E antes de exibi-la, discute-se o escalonamento no LINLXPADRÃO na próxima seção.

\subsubsection{O escalonamento no LINUX-PADRÃO}

Existem três classes de escalonamento do sistema operacional LINUX-PADRÃO, as quais são definidas abaixo e seguem o padrão POSIX 1003.4:

- SCHED_FIFO - Nesta classe o escalonador escolhe o processo de mais alta prioridade para executar. O sistema não interrompe a sua execução exceto por três situações: um outro processo da mesma classe e de maior prioridade esta na fila de prontos, o processo ficou suspenso na espera de um evento ou o processo chama a primitiva sched_yield e vai para a fila de prontos [CDM97].

- SCHED_RR - esta classe é similar à anterior com uma exceção: uma fatia de tempo é atribuída ao processo que está executando. Quando seu tempo acaba processos dos tipos SCHED_FIFO e SCHED_RR com igual ou maior prioridade podem ser selecionados e executados.

- SCHED_OTHER - os processos nesta classe somente podem ser executados quando nenhum processo das classes de tempo real estiverem na fila de prontos. A seleção do processo que irá executar é baseada na prioridade dinâmica.

O arquivo sched.c contém de fato o escalonador do LINUX-PADRÃO e este é especificamente descrito pela função schedule. Esta função consiste de três partes. A primeira

\footnotetext{
${ }^{9}$ Onde $\mathrm{HZ}$ é uma constante que define a frequiència do clock.
} 
delas contém aquelas rotinas que devem ser chamadas regularmente no início. Estas funções poderiam pertencer a interrupt timer, mas por razões de eficiência foram colocadas neste arquivo. Na segunda, o processo com mais alta prioridade é determinado. É importante observar que processos de tempo real têm sempre maior prioridade que os convencionais. E finalizando, o novo processo torna-se o current.

Ainda no LINUX-PADRÃO e descrevendo mais detalhadamente o mecanismo de escalonamento utilizado, tem-se que a função schedule começa movendo o processo atual para o final da lista de processos prontos chamando a função move_last_runqueue, se este processo consumiu todos seus ciclos de clock.

Se o processo está no estado PROCESS_INTERRUPTIBLE, a função schedule verifica se o processo recebeu uma mensagem de unmasked. Se esta foi recebida o estado do atual processo retorna para PROCESS_RUNNING. Em seguida para cada processo a função goodness é chamada para determinar se este deve ser escolhido. A função goodness no LINUX-PADRÃO é usada para selecionar o processo com mais alta prioridade. No caso de processos de tempo real esta função retorna a prioridade estática do processo (campo rt.priority da struct task_struct acrescido ${ }^{10}$ de 1000). No caso de um processo convencional retorna o valor do campo counter, que representa o número de ciclos de clock durante o qual o processo deve ser executado.

Ao final deste procedimento o processo escolhido torna-se o processo current. Em conseqüência, a função get_mmu_context é chamada para rearmazenar o contexto da memória do processo e a mudança de contexto é efetuada pela função switch_to.

O valor do campo counter é o critério usado pelo escalonador. Este campo é modificado por várias funções:

- update_process_times: esta função é chamada periodicamente por timer_bh que é ativada pelo gerenciador de interrupção de clock. O campo counter é decrementado pela função update_process_times a qual atribui à variável need_resched o valor 1, se o atual processo consumiu o seu quantum.

- schedule: quando o campo counter é zero para todos os processos, o escalonador executa um loop sobre todos os descritores da tabela de processos para reinicializar o campo counter. O valor de referência utilizada é o campo priority.

- add_to_runqueue: esta função adiciona um processo para a fila de processos prontos e verifica o campo counter. Se este valor é maior do que aquele do atual processo, a variável need_resched recebe o valor 1 para forçar a mudança do atual processo.

Após uma breve explanação sobre os mecanismos de escalonamento do LINUX-PADRÃO, apresenta-se, na próxima seção. as alterações que caracterizam a implementação do escalonador LINUX-SMART sendo relatada.

\footnotetext{
${ }^{10}$ Adiciona-se o valor 1000 ao campo rt.priority para garantir que processos de tempo real sejam priorizados diante daqueles convencionais.
} 


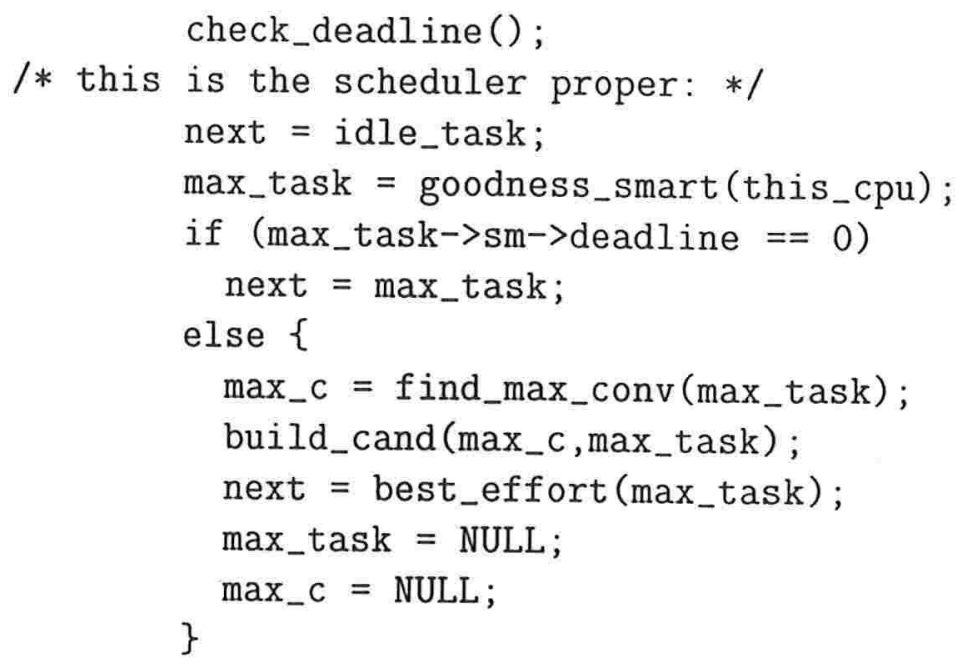

Figura 3.8: Core do Escalonador LINUX-SMART

\subsubsection{As modificações do LINUX-SMART}

A função schedule() no LINUX-SMART também possui três segmentos. O primeiro contém as mesmas rotinas do LINUX-PADRÃO. No segundo, o processo com maior par ordenado (Seção 2.1) é escolhido. Se o processo for convencional é imediatamente executado, senão efetua-se todo o procedimento proposto pela política SMART para tratar processos de tempo real e determinar qual processo será escolhido. A implementação deste segmento é exibida na Fig. 3.8 e representa o escalonador LINUX-SMART propriamente dito. As funções referenciadas e que caracterizam o escalonador são detalhadas posteriormente. O terceiro segmento da função schedule efetua as computações necessárias para que o processo escolhido torne-se o current.

A função check_deadline verifica se algum deadline de uma aplicação de tempo real foi perdido. Em caso positivo, envia um sinal SIGUSR1 para a aplicação.

Em substituição à função goodness descrita na Seção 3.1.1, foi implementada a função goodness_smart, a qual é exibida na Fig. 3.9. No LINUX-SMART esta função é usada para selecionar o processo com maior valor de par ordenado. Para isto percorre a estrutura smart em ordem crescente das filas de prioridade até encontrar um processo pronto para executar. Na respectiva fila de prioridade, verifica-se a existência de outros processos prontos para executar que possuam um valor de bvft menor. Não existindo nenhum processo nas condições mencionadas, retorna-se o primeiro processo encontrado. Caso contrário, retorna-se o processo com um valor de bvft menor do que aquele do processo inicial. Se não existe nenhum processo pronto para executar, a função goodness_smart retorna a tarefa init_task.

Se o processo encontrado pela goodness_smart e armazenado na variável max_task tiver 


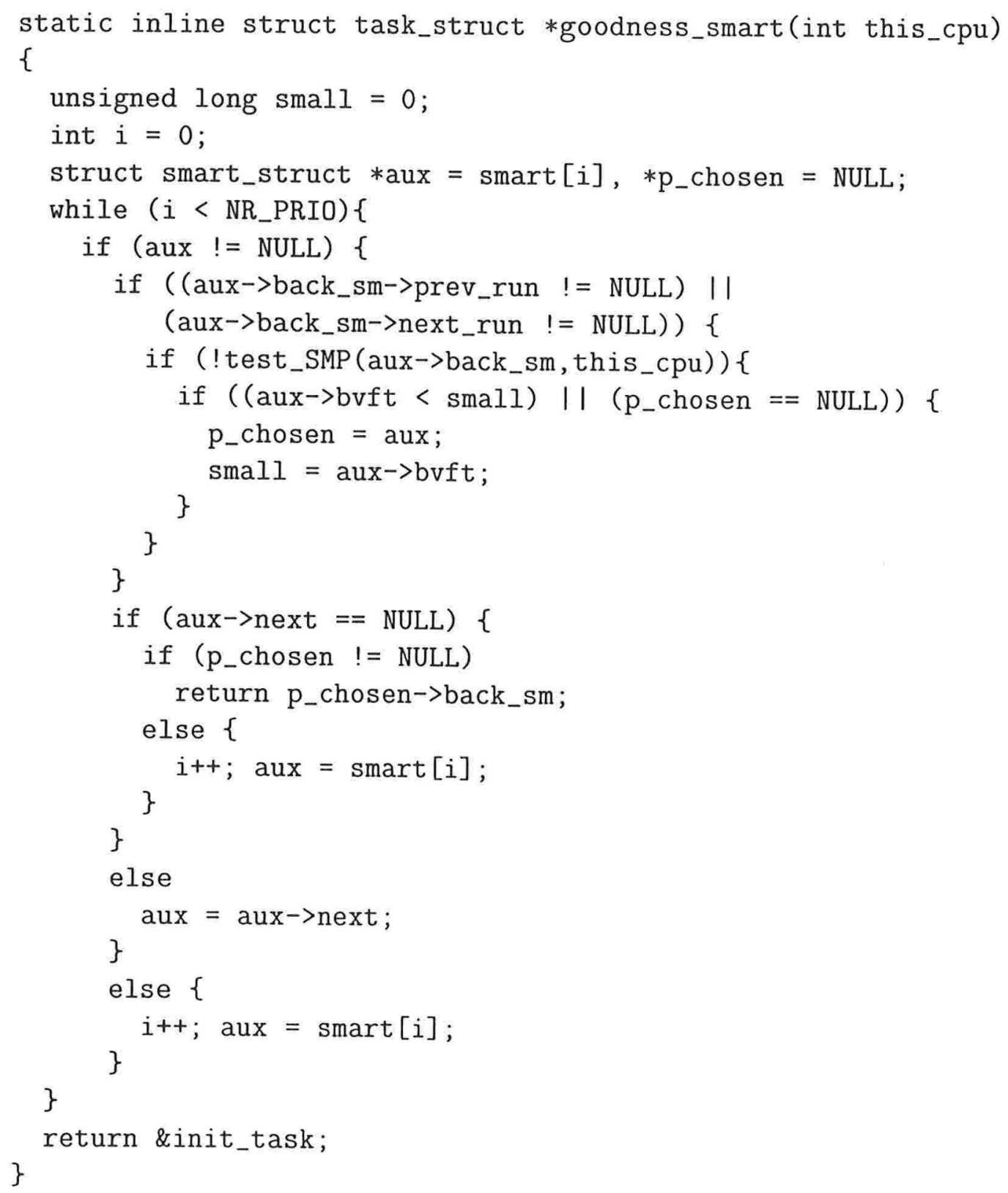

Figura 3.9: Implementação da Função goodness_smart 
o campo deadline igual a zero, sendo então convencional, será definido como o próximo processo a executar. Caso contrário, o classificamos como um processo de tempo real e neste caso realiza-se o seguinte procedimento:

- Determina-se o processo convencional, $\max _{-} c$, com maior valor de par ordenado através da função find_max_conv. Utiliza-se como parâmetro da chamada desta função a variável max_task que é o processo de tempo real com maior valor de par ordenado. Para obter o processo desejado, a função find_max_conv segue um procedimento similar a aquele descrito para goodness_smart possuindo apenas as seguintes restrições: a busca é iniciada a partir da fila de prioridade do processo max_task e verifica-se apenas os processos convencionais prontos para executar. Não existindo nenhum processo nas condições estipuladas retorna-se a tarefa init_task.

- Cria-se uma lista, Cand, que contém todos os processos de tempo real com valor de par ordenado maior do que aquele par de $m a x_{-} c$, os quais são candidatos a ser o próximo processo a executar. Esta lista é construída pela função build_cand que utiliza como parâmetros as variáveis max_c e max_task, definidas no item anterior, conforme exibido na Fig. 3.10.

Na função build_cand, o primeiro elemento da lista Cand é o next_task_smart->sm, que é o processo de tempo real com maior valor de par ordenado (max_task). Os processos que possuem o valor do campo prioridade menor do que aquele valor do processo convencional com maior valor de par ordenado $(c)$ são diretamente inseridos na lista Cand. Isto porque todos estes processos são de tempo real. Para aqueles processos pertencentes a mesma fila de prioridade da tarefa $c$, verifica-se se estes são de tempo real e se possuem um valor de buft menor do que aquele exibido pelo processo convencional $c$ com maior valor de par ordenado. Satisfeitas as condições anteriores, acrescenta-se o respectivo processo na lista Cand.

- Executa-se a função best-effort, utilizando-se como parâmetro a variável max_task. Esta função utiliza-se de rotinas como feasibility e insertion_do_not_loose_deadline para construir uma classificação de trabalho W. conforme exibido na Fig. 3.11. O primeiro elemento a ser testado pelas funções feasibility e insertion_do_not_loose_deadline é max_task, o qual aparece localmente como max_task_rt. Posteriormente, todos os processos da lista Cand têm sua inserção na classificação de trabalho W também verificada. Através desta classificação é escolhido o próximo processo a executar.

Usando o deadline dado e estimativas de tempo de serviço, testa-se através da função feasibility, exibida na Fig. 3.12, para cada processo existente na atual classificação de trabalho $\mathrm{IV}$ mais o processo a ser inserido. se os processos neste conjunto com menor ou igual deadline podem ser executados antes dos seus respectivos deadlines.

Para isto, considera-se cada candidato. comesando com aquele de maior par ordenado. Adotou-se como avaliador da estimativa de recursos o campo counter da struct task_struct porque ele representa a quantidade de recurso (tempo de CPL) 


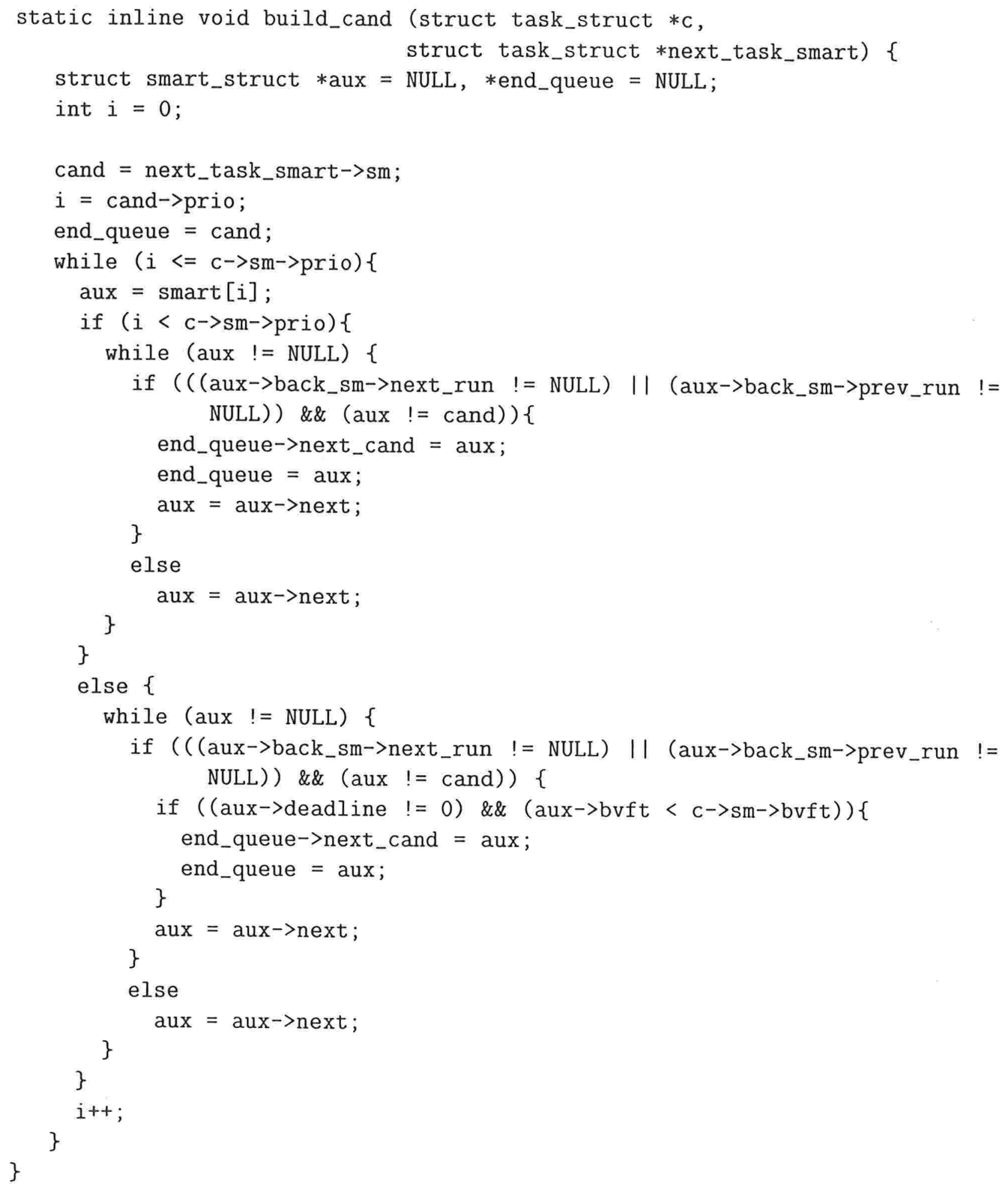

Figura 3.10: Implementação da Função build_cand 


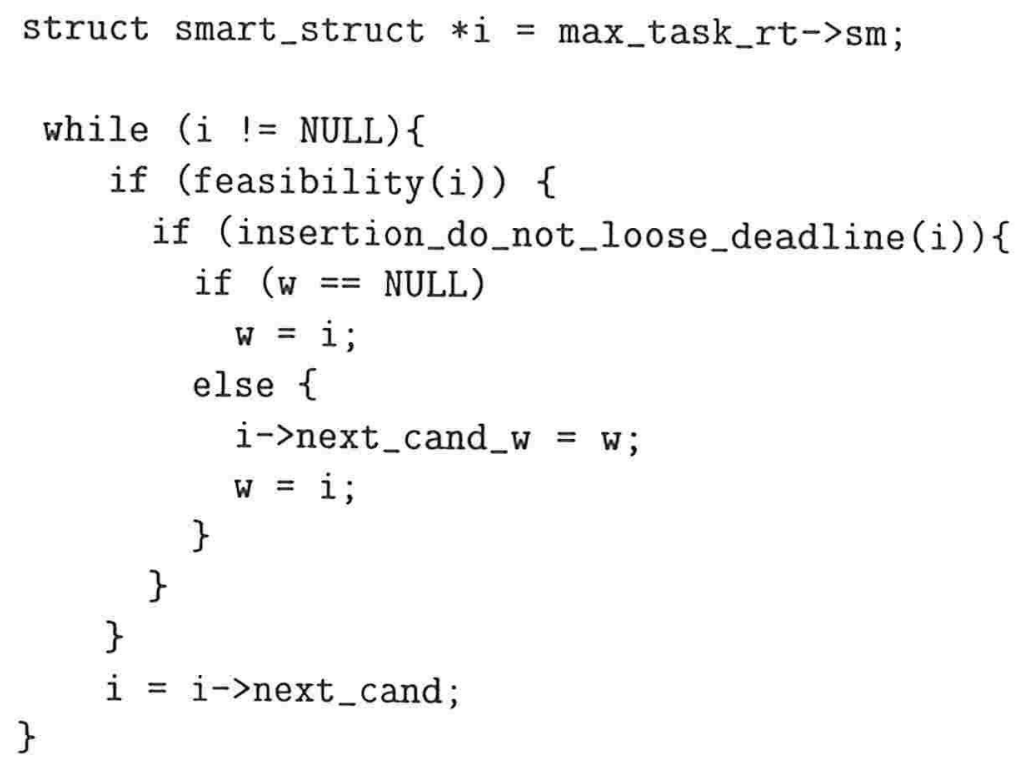

Figura 3.11: Código da Construção de W na Função Best-effort

necessária para cada aplicação. Isto é, tem-se que a requisição $R_{j}(t)$ de recurso estimada do processo $j$ no tempo t, $t \geq D_{j}$, definida na Sec. 2.1 foi implementada como: $R_{j}(t)=Q_{j}-E_{j}+F_{j} \times\left(t-D_{j}\right)=$ counter. $Q_{j}-E_{j}$ é exatamente o valor do campo counter de um processo e $F_{j} \times\left(t-D_{j}\right)=0$ porque não se distinguiu tarefas periódicas daquelas não periódicas, pois utilizou-se o tempo total de processamento da aplicação. Para o calculo $D_{j} \geq t+\sum_{k \in W, D_{k} \leq D_{j}} R_{k}\left(D_{j}\right)$ foi considerada a soma dos valores de counter de todos os processos com deadline $D_{k}$ menor ou igual a $D_{j}$ uma vez que este somatório expressa a quantidade de recursos necessários até o instante $D_{j}$.

A função feasibility retorna 1 se o teste valida a inserção do processo sendo analisado na classificação W. Caso contrário, retorna 0 .

Ocorrendo a validação o candidato é inserido na ordem do deadline nesta classificação. Se o candidato possui um par ordenado menor do que algum elemento em W, este é inserido somente se sua execução não fizer nenhum processo na classificação com maior valor de par ordenado perder seu deadline. Caso contrário, o candidato é diretamente inserido. Esta verificação é realizada pela função insertion_do_not_loose_deadline, a qual é mostrada na Fig. 3.13.

O processo escolhido como o próximo a executar é retornado pela função best-effort $\mathrm{e}$ armazenado na variável next. Este processo é aquele com menor deadline encontrado em W. Ressalta-se que se ao final a lista $W$ for vazia, a função best-effort retorna o processo de tempo real executável com maior valor de par ordenado. A Fig. 3.14 exibe a implementação deste passo do algoritmo. 


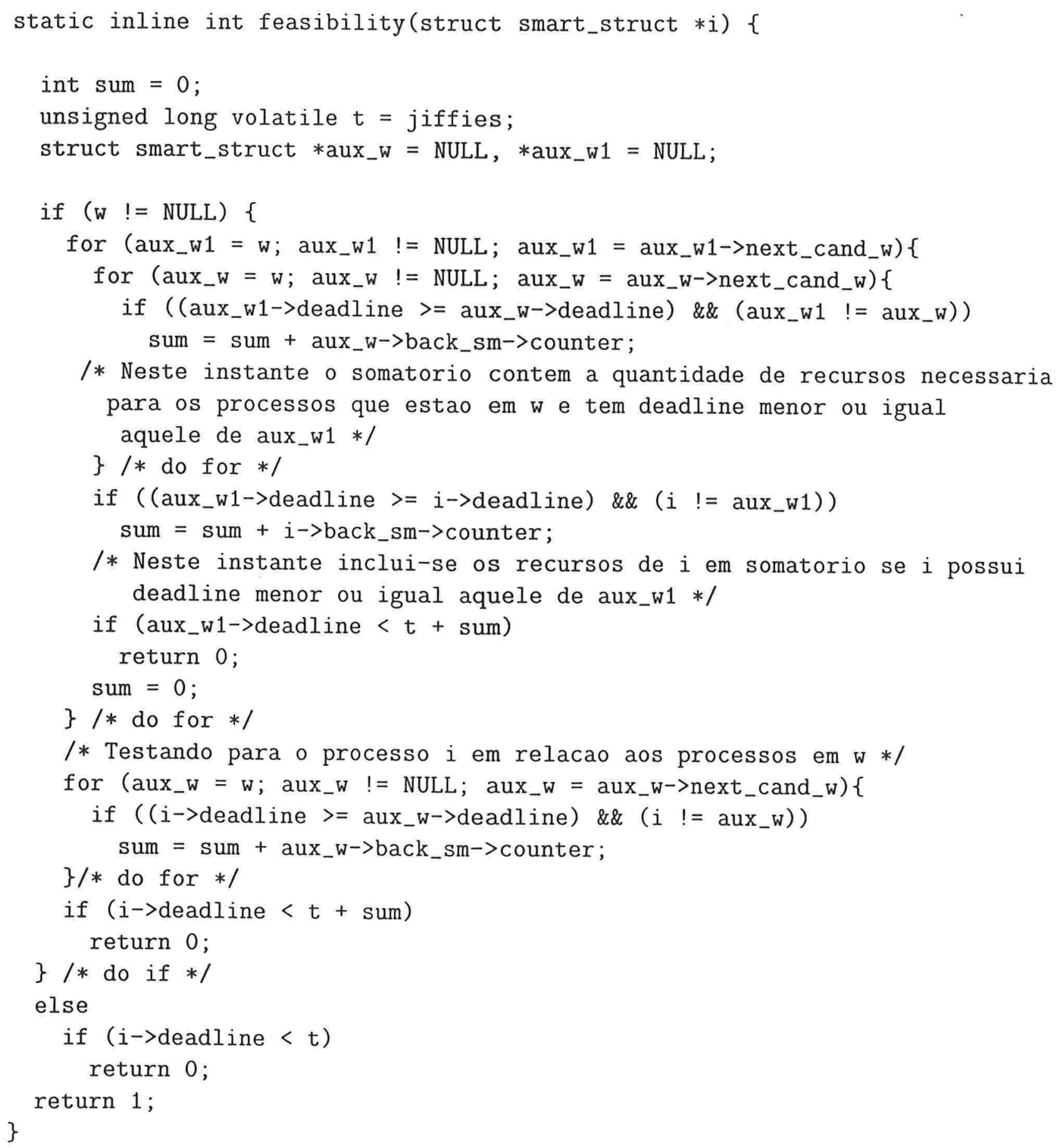

Figura 3.12: Implementação da Função feasibility 


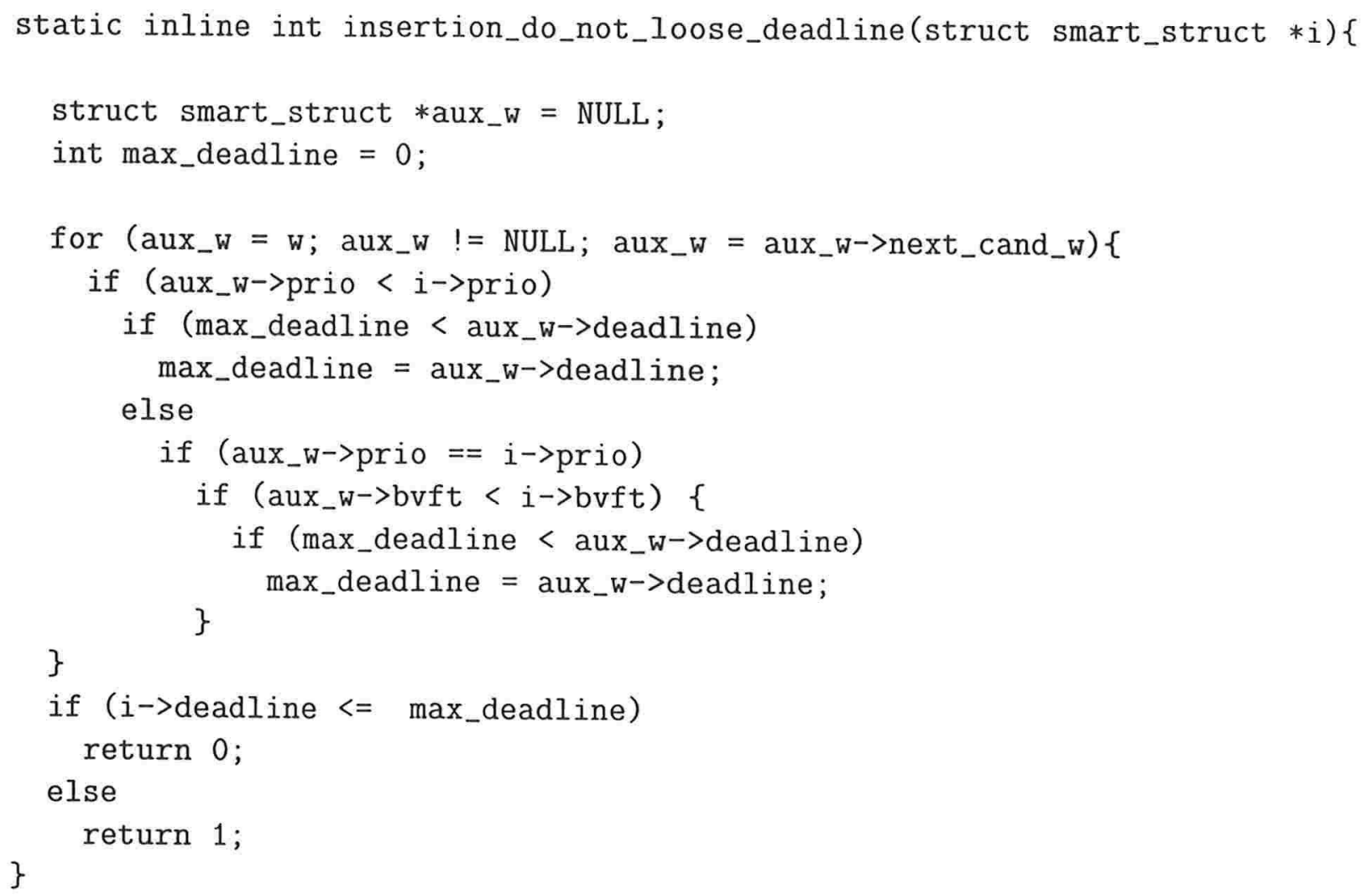

Figura 3.13: Implementação da Função insertion_do_not_loose_deadline

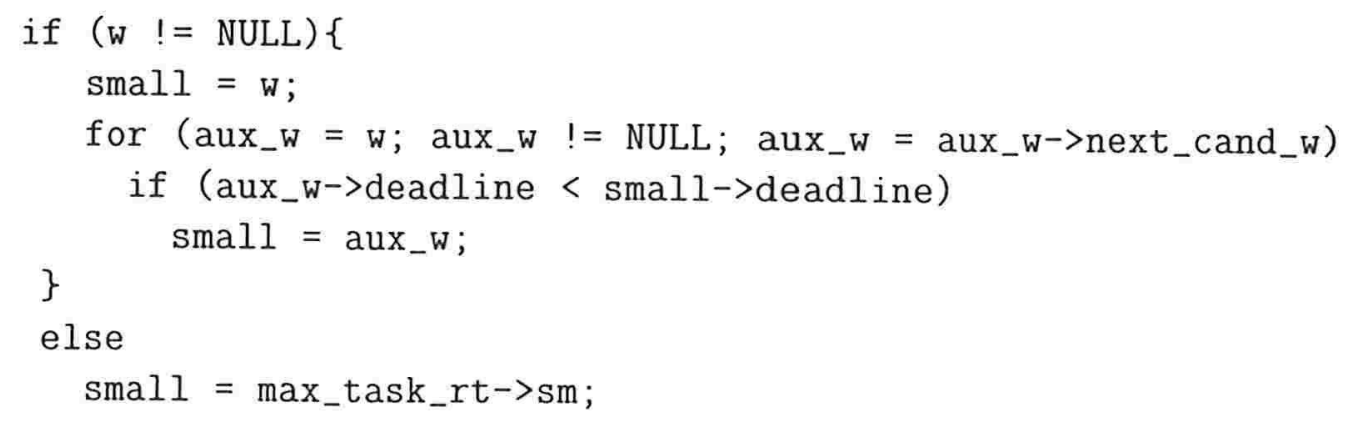

Figura 3.14: Instante da Escolha do Processo a Executar 
Para melhor entendimento das listas Cand e $W$ exemplifica-se na Fig. 3.15 estas estruturas.

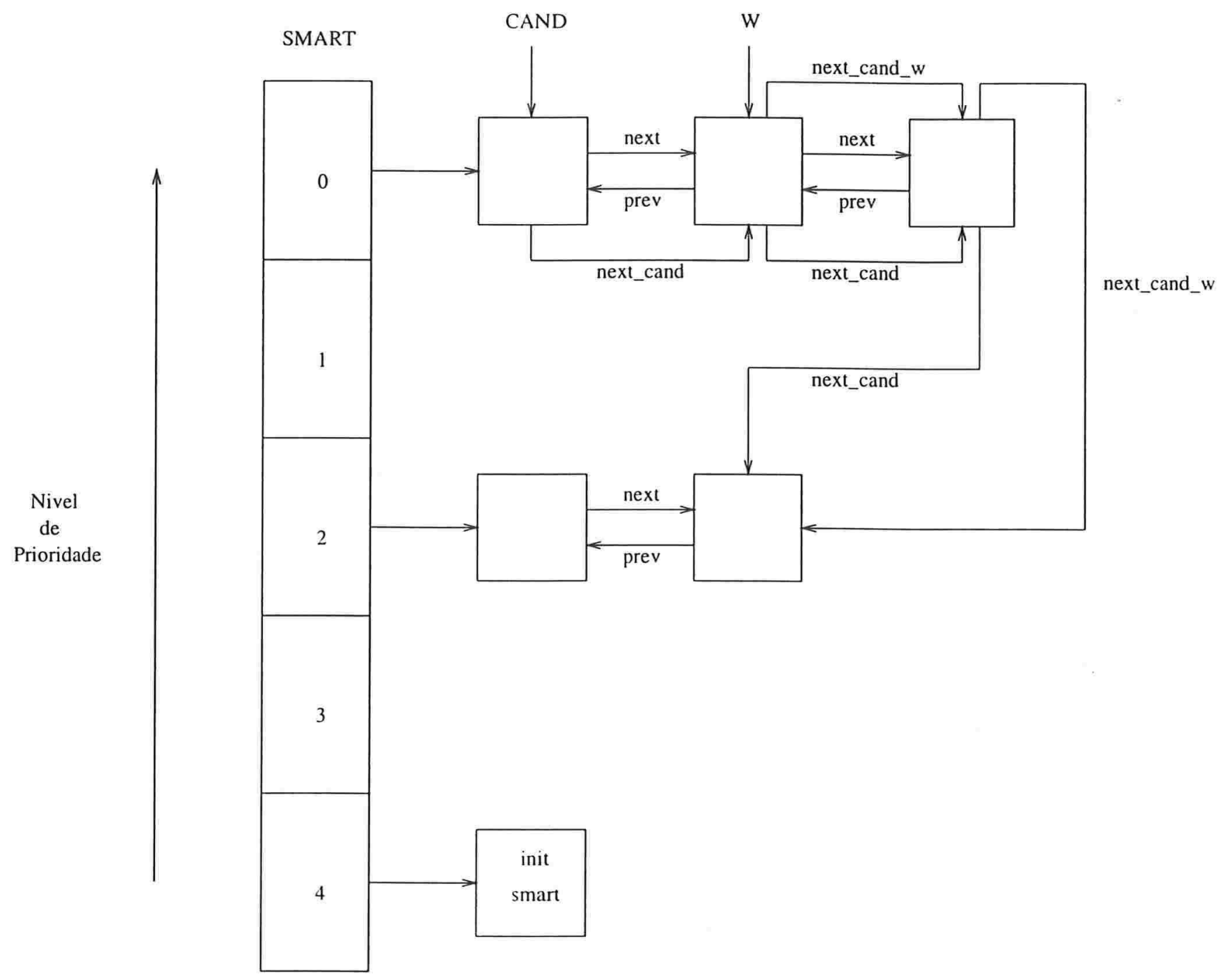

Figura 3.15: As listas CAND e W

Outro aspecto relevante dentro da política de escalonamento LINUX-SMART é a atualização dos parâmetros que caracterizam este escalonador. Estes valores são: bvft, bias, queue_virtual_time, quantum, share e prio.

A estrutura queue_virtual_time é um array onde para cada fila de prioridade armazenase o valor do parâmetro tempo virtual da fila. Inicialmente cada fila é inicializada com valor zero. O valor do tempo virtual de um dada fila é atualizado sempre que algum membro da respectiva fila de prioridade está executando. Esta atualização é efetuada pela função evaluate_virtual_time exibida na Fig. 3.16. Na implementação do LINUXSMART o momento de atualização é aquele onde o campo counter após atingir um valor 


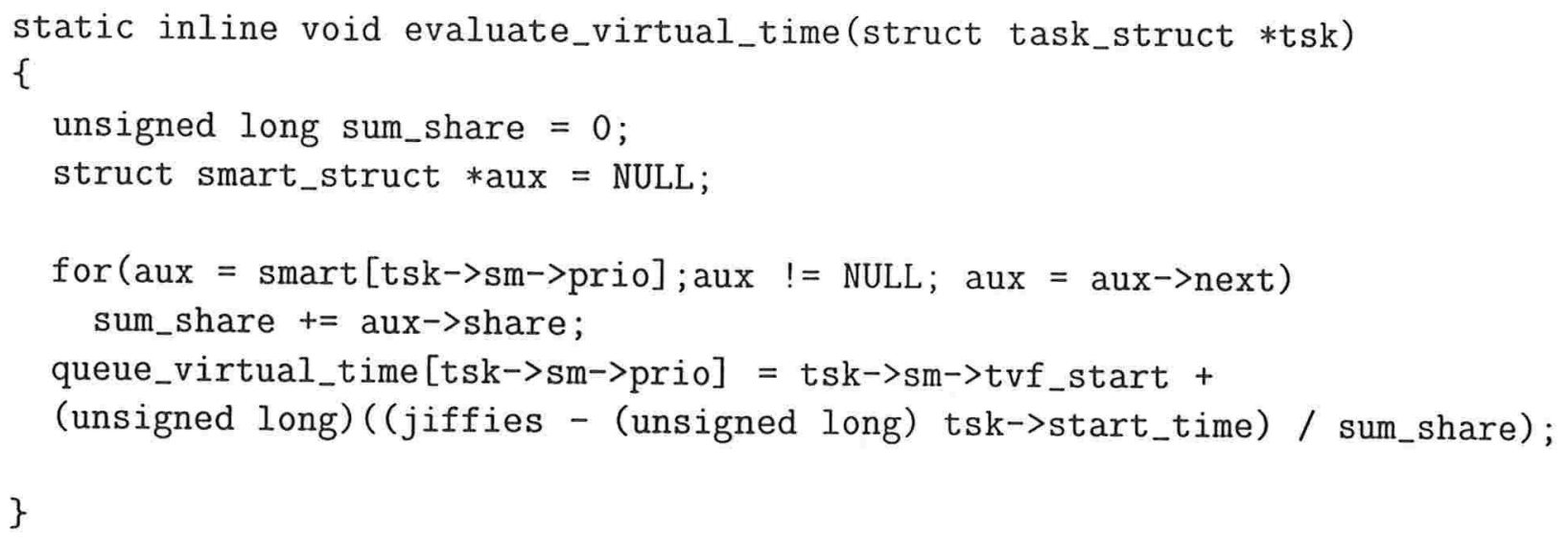

Figura 3.16: Implementação da Função evaluate_virtual_time

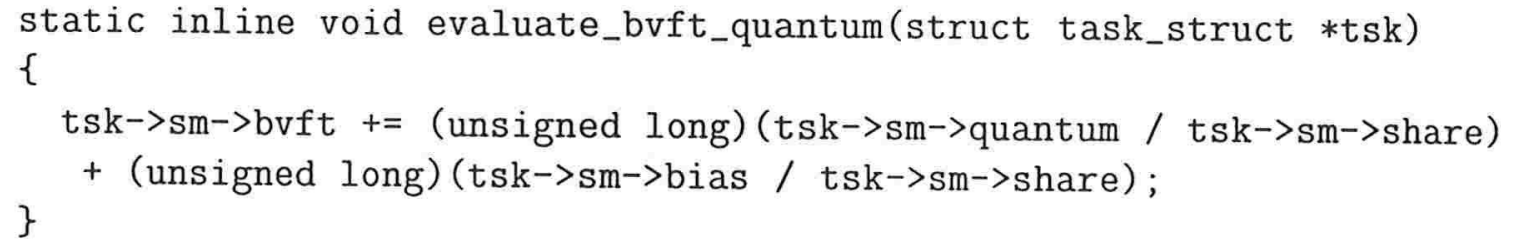

Figura 3.17: Implementação da Função evaluate_bvft_quantum

menor ou igual a zero é reinicializado com o quantum do respectivo processo que finalizou sua execução.

O parâmetro bvft tem sido constantemente referenciado, principalmente por ser um dos fatores que define a ordenação entre os processos do LINUX_SMART. Conseqüentemente, um aspecto importante a se discutir são os instantes e os procedimentos de atualização deste valor.

Inicialmente o campo bvft tem valor:

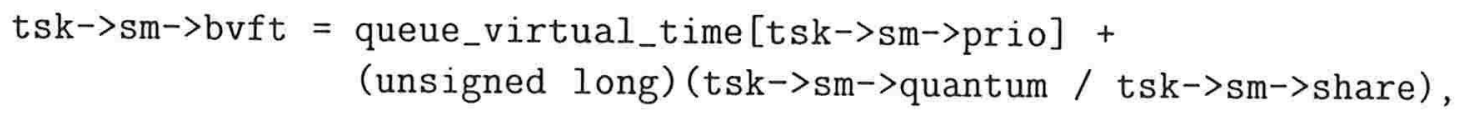

o qual encontra-se no arquivo fork.c e tsk é o processo sendo criado.

Também quando um processo adquire uma nova prioridade através da chamada ao sistema setprio, o valor do bvft é modificado como na equação acima.

Um momento de atualização do bvft é quando um novo quantum é atribuído a um processo. Esta modificação ocorre como apresentado na Fig. 3.17.

O buft também é modificado quando um processo deixa o estado bloqueado e tornase executável. Esta alteração ocorre através da chamada da função evaluate_buft_blocked 


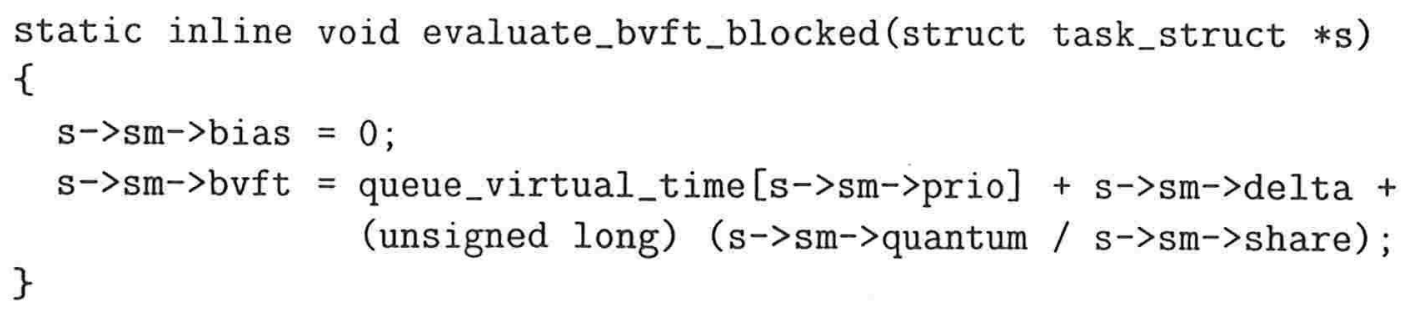

Figura 3.18: Implementação da Função evaluate_bvft_blocked

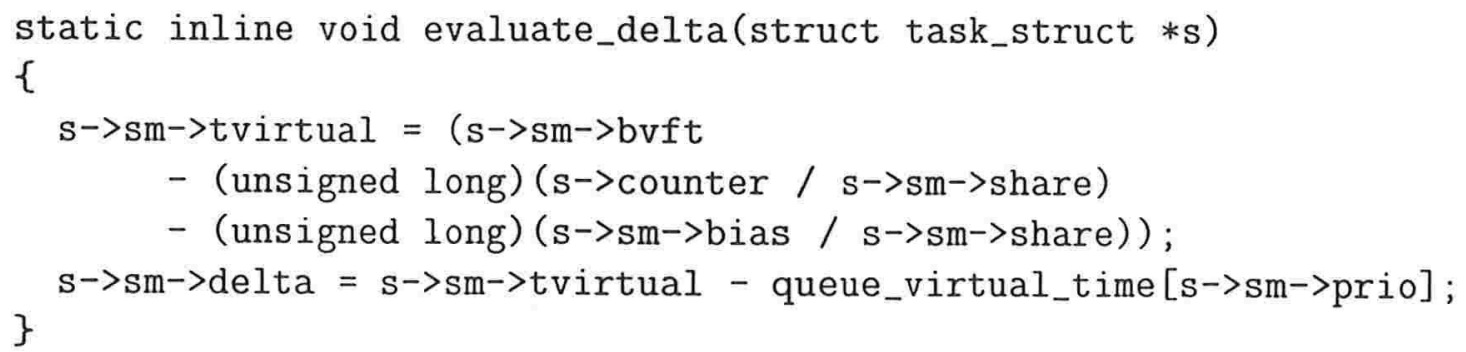

Figura 3.19: Implementação da Função evaluate_delta

mostrada na Fig. 3.18.

O valor delta é definido na Seção 2.2 e implementado como exibido na Fig. 3.19. Este valor é computado toda vez que um processo é bloqueado. Neste momento, também é armazenado o instante atual do sistema, jiffies, no campo tblocked do processo sendo bloqueado.

No retorno à fila de prontos verifica-se se a diferença entre este instante, valor atual de jiffies, e o valor do campo tblocked é superior a constante BOUND definida como $90000 \mathrm{~ms}$. Apenas para os processos que satisfazem esta condição a função evaluate_buft_blocked é chamada. O critério de escolha do valor da constante BOUND é o menor deadline entre as tarefas de tempo real existentes. No nosso caso, como existe apenas a aplicação "Controle de Aproximação de Aeronaves em Aeroportos", utilizamos o seu deadline.

A política de escalonamento SMART permite que uma tarefa permaneça em sua fila de prioridade por um período limitado pelo menor deadline entre as tarefas existentes ou algum valor default do sistema, mesmo após ser bloqueado. Na implementação do LINUX-SMART, o processo assim que é bloqueado deixa de ser considerado na sua fila de prioridade. Mas, quando retorna à mesma e a diferença entre jiffies e o campo tblocked é maior que BOUND, calcula-se como anteriormente o novo valor do bvft.

Este mesmo procedimento de atualização do bvft quando um processo é bloqueado aplica-se para modificação deste valor quando um processo tem o seu valor do campo share alterado através da chamada ao sistema setshare. 
Ainda discutindo as atualizações de parâmetros da política LINUX-SMART, ressaltase que um novo quantum é atribuído a um processo sempre que seu campo counter tem se exaurido e através da chamada ao sistema setquantum. Também no instante em que o counter é reinicializado com um novo quantum, incrementa-se o campo bias nos processos convencionais.

É importante destacar que como optou-se pela especificação do tempo de processamento (quantum) e do deadline para toda a aplicação e não para blocos de códigos da mesma, o cálculo de estimativas de requisições para processamentos futuros de processos de tempo real periódicos não foi necessário, visto que em qualquer instante o campo counter da struct task_struct possui o valor da estimativa de recurso (tempo de CPU) para processamentos futuros.

Um aspecto importante para ser analisado é a interrupção de clock, a qual é o mecanismo que o kernel usa para gerenciar os intervalos de tempo. A interrupção de clock é determinada por uma freqüência default de HZ, que é um valor dependente da arquitetura utilizada e é definida no arquivo param. $h$. Na versão 2.0.34, Linux define $\mathrm{HZ}$ com um valor de 1024 para arquitetura Alpha e 100 para as outras plataformas.

Quando uma interrupção de clock ocorre, o valor de jiffies é incrementado. Assim jiffies representa o número de ticks desde quando o sistema operacional foi inicializado. Se o valor de HZ é modificado e o kernel é recompilado não há qualquer diferença na execução em modo usuário. A única distinção é que jiffies incrementa em um intervalo diferente. Quanto maior o número de interrupções, maior a sobrecarga do sistema, mas o processador será escalonado mais freqüentemente se mantivermos o mesmo quantum.

Assumindo uma máquina de 32 bits com uma resolução de 10 milisegundos, tem-se que o contador jiffies sofreria um overflow depois de aproximadamente 498 dias. Se a resolução é modificada para 1 milisegundo, o overflow ocorre em aproximadamente 50 dias.

Uma observação importante é a necessidade da recompilação e reinstalação dos módulos em uso. Isto porque tudo no kernel depende de $\mathrm{HZ}$, incluindo os módulos. Além disto, todos os programas de usuários que acessam alguma variável do tipo $c l o c k_{-} t$, após a modificação do valor de HZ. possuirão um comportamento diferente do esperado. Neste caso deve-se recompilar estes programas dos usuários.

Para permitir uma resolução mais fina para os eventos de escalonamento, propiciando uma alta resolução do mecanismo de timeout para o kernel e reduzindo a escala de tempo na qual as interrupções do timer ocorrem, especificou-se uma resolução de $1 \mathrm{~ms}$, ao invés daquela de $10 \mathrm{~ms}$ utilizada no LINUX-PADRÃO. Esta modificação também objetivou a comparação dos nossos resultados com aqueles apresentados por Nieh et. al (Seção 2.6), os quais foram obtidos com uma mesma resolução. Operacionalizou-se a resolução de $1 \mathrm{~ms}$ modificando o valor de $\mathrm{HZ}$ de 100 para 1000 no arquivo param.h.

Após a mudança do valor de $\mathrm{HZ}$ e da recompilação do kernel o sistema é interrompido a cada $1 \mathrm{~ms}$ e a função ret_from_sys_call verifica se há necessidade de reescalonar baseando- 
se no valor da variável need_resched. Caso esta variável possua valor 1, a função schedule() é chamada.

A rotina ret_from_sys_call é definida no arquivo arch/i386/kernel/entry.S para a arquitetura x86, escrita em assembly e é chamada depois de cada chamada ao sistema e interrupção lenta. Este tipo de interrupção permite que outras interrupções ocorram durante o seu tratamento. Depois de uma interrupção lenta ter sido processada, atividades adicionais regulares são executadas pelo sistema, por exemplo o escalonador é chamado como e quando solicitado. Interrupções lentas são aquelas que usualmente acontecem nos sistemas operacionais, um exemplo típico é aquela recebida pelo clock. Em contraste com as interrupções rápidas usadas para tarefas curtas e menos complexas. Neste tipo de interrupções, durante o seu tratamento, outras interrupções são bloqueadas, a menos que a rotina de tratamento envolvida explicitamente as habilite. Um exemplo típico é uma interrupção de teclado.

Efetuadas as modificações discutidas nesta seção, tentou-se remover partes do código do LINUX-PADRÃO que se apresentavam aparentemente fora de contexto na implementação do LINUX-SMART. Por exemplo, a função sys_sched_setscheduler do arquivo sched.c que mudava o tipo de escalonamento (SCHED_OTHER,RT-FF,RT-RR). Neste caso, observou-se que vários processos importantes e necessários como $k s w a p d^{11}$, xntpd $^{12}$, isapnp ${ }^{13}$ referenciavam esta chamada ao sistema. Em conseqüência, precisava ser mantida a definição de sys_sched_setscheduler. A opção foi emular os tipos de escalonadores do LINUX-PADRÃO acrescentando-se nesta função as alterações necessárias.

Para emular RT-FF determinou-se que o processo requisitando este escalonador obtivesse a prioridade $H I G H$. No caso do RT-RR, os processos solicitantes obtiveram a prioridade MIDDLE1. Para SCHED-OTHER a prioridade atribuída aos processos foi NORMAL e adotou-se o valor default do campo share que é igual a 1. A Fig. 3.20 mostra como esta emulação foi implementada. Inicialmente, retira-se o processo da atual fila de prioridade. Posteriormente, atribui-se a nova prioridade ao processo, localizando-o na nova fila. Neste momento, atualiza-se o valor do campo bvft porque uma nova prioridade foi obtida.

O problema mencionado acima ocorreu com todas as chamadas ao sistema que referenciavam de alguma maneira os escalonadores do LINUX-PADRÃO. Por exemplo, sys_sched_getscheduler, sys_sched_get_priority_max, sys_sched_getparam, sys_sched_setparam e sys_sched_get_priority_min. No caso destas funções, os códigos não foram alterados.

O próximo capítulo apresenta os testes realizados com o LINUX-SMART, assim como uma comparação com o LINUX-PADRÃO.

\footnotetext{
${ }^{11} \mathrm{O}$ processo kswapd é responsável por manter uma quantidade mínima de páginas livres na memória.

${ }^{12}$ A sincronização do clock de um computador com os demais é realizada pelo processo xntpd.

${ }^{13} \mathrm{O}$ isapnp é responsável por configurar certos hardware ISA automaticamente.
} 


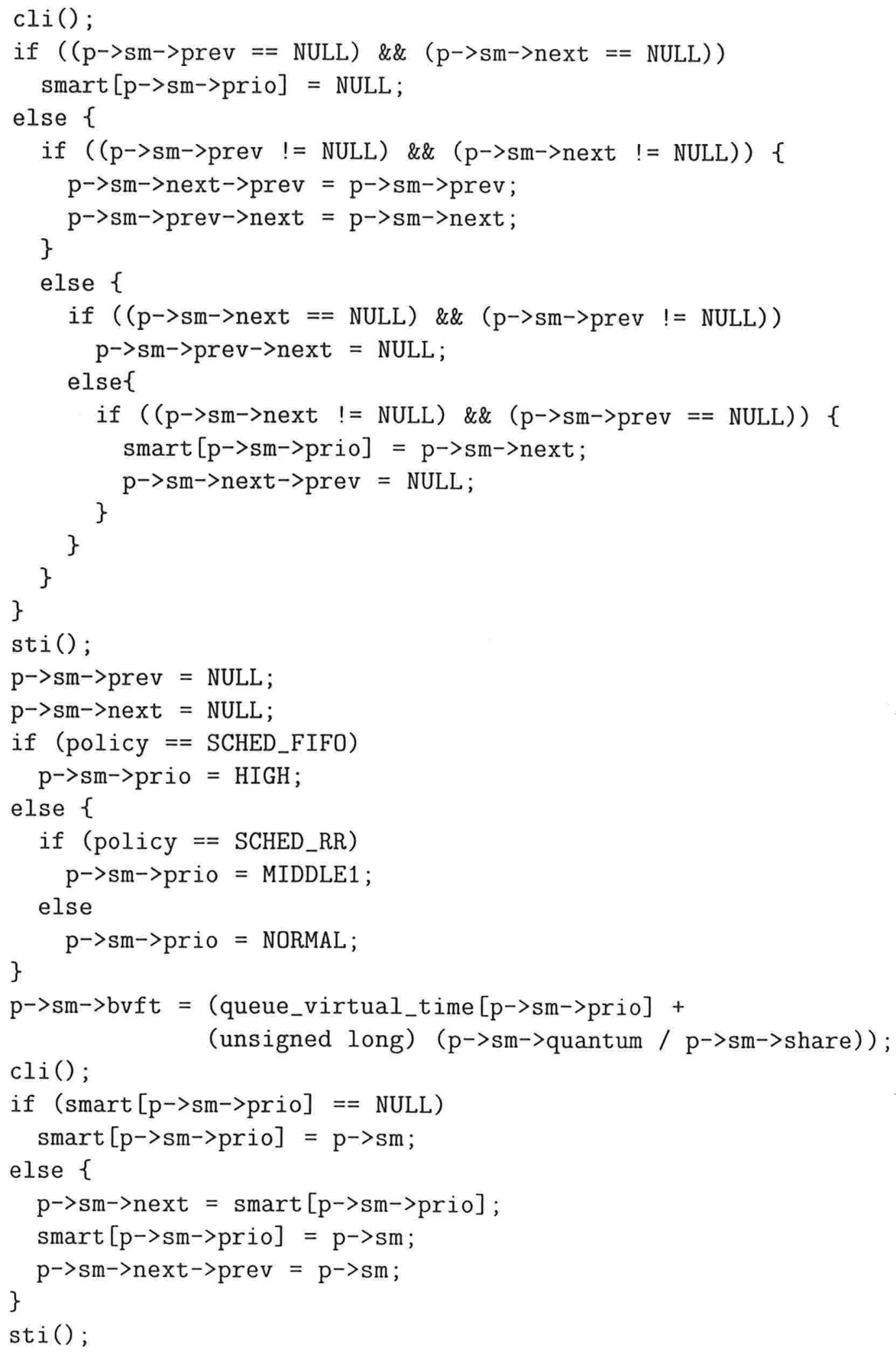

Figura 3.20: Emulando os Escalonadores do LINLX-PADR.̃̄O 


\section{Capítulo 4}

\section{Análise Comparativa entre LINUX-SMART e LINUX-PADRÃO}

Os experimentos com o novo ambiente desenvolvido (LINUX-SMART, Cap. 3) foram realizados no contexto da aplicação "Controle de Aproximação de Aeronaves em Aeroportos". Estes testes de desempenho foram realizados nos mesmos cenários aplicados no LINUX-PADRÃO [VNdS99b], a saber: a aplicação sem processos concorrentes, a aplicação concorrendo com 10 processos gráficos; a aplicação executando com 41 processos concorrentes (20 deles consumindo memória, outros 20 processos utilizando bastante CPU e um processo gráfico também consumindo os recursos da máquina); e finalmente a aplicação concorrendo com a compilação do emacs.

Para avaliação dos testes efetuados, utilizou-se ferramentas como vmstat, strace, readprofile [MoEUoT96] e os parâmetros tempo e iteração representados graficamente através da ferramenta xmaple. No caso em questão, o termo tempo significa o intervalo do início ao final de uma iteração, sob o ponto de vista do usuário da aplicação, e não o tempo de uso de $C P U$. Analisou-se, também, os custos de escalonamento. É importante destacar que todas as ferramentas foram executadas como processos convencionais.

Na Seção 4.1 exibe-se uma descrição da aplicação desenvolvida. O ambiente utilizado para o desenvolvimento da implementação é apresentado na Seção 4.2 e os testes relativos a mesma são apresentados na Seção 4.3. As considerações finais são exibidas na Seção 4.5

\subsection{Descrição da Aplicação Principal}

A aplicação para Controle de Aproximação de Aeronaves em Aeroportos foi implementada em Tcl/Tk[Ous94, Joh97]. Tclé uma linguagem de script e Tk é um construtor de janelas gráficas, que trabalham em conjunto.

O objetivo da aplicação é simular, em um ambiente gráfico, a trajetória de um avião 


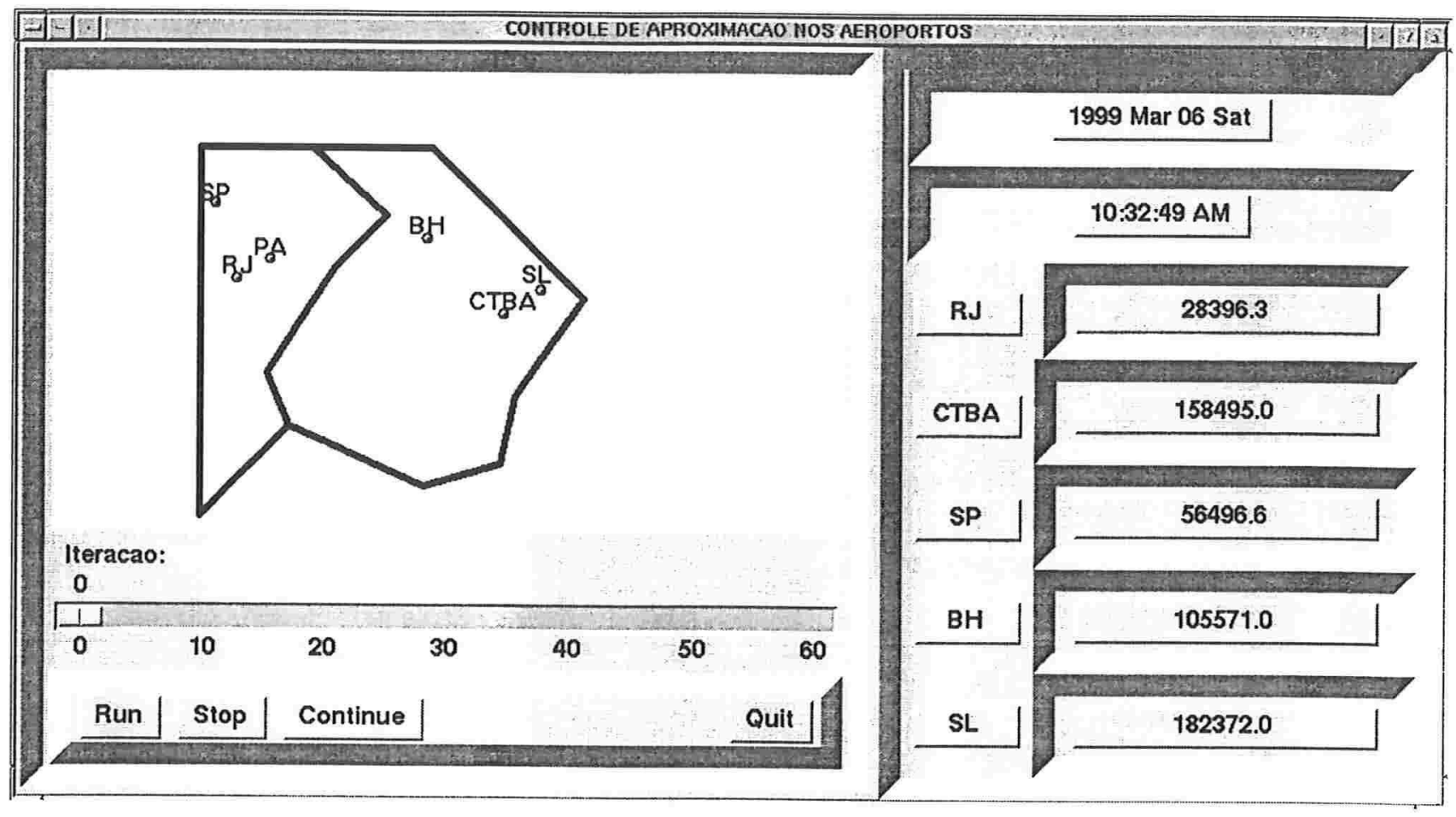

Figura 4.1: Tela da aplicação principal

partindo de uma determinada cidade-origem até uma cidade-destino. A cada iteração, a posição da aeronave é mostrada na tela juntamente com sua distância relativa a cada uma das cidades principais.

O tempo de captura do sinal pelo radar e de seu envio para o computador é de aproximadamente $500 \mathrm{~ms}$. A nossa implementação simula este tempo de captura de dados através de um bloqueio.

A aplicação gera um mapa fictício com algumas cidades indicadas. A Fig. 4.1 retrata a tela principal da aplicação. Há um campo contendo a data e a hora atualizado em tempo-real. Uma barra com 60 iteraçōes é mostrada para indicar o número de iterações realizadas. No rodapé da aplicação há 4 botões: run, stop, continue e quit. No momento em que o botão run é pressionado, inicia-se a execução. A partir de uma cidade prédefinida, a trajetória do avião é indicada graficamente na tela. A função da trajetória da aeronave é simulada pela função $\ln (x)$. A cada 4 (quatro) iterações, é calculada a distância da aeronave com as principais cidades e os campos relacionados são atualizados. Os valores da coordenada x e y, bem como o tempo gasto para computar a iteração, são armazenados em um arquivo. O botão stop pára a execução da aplicação e o continue reinicia a execução da aplicação a partir do ponto de parada. O botão quit aborta a aplicação em execução.

Descrita a aplicação principal, apresenta-se na próxima seção o ambiente utilizado na 
análise comparativa entre o LINUX-PADRÃO e o LINUX-SMART.

\subsection{Ambiente}

Utilizou-se um $P C$ Pentium 266MHz, 32MB de Memória primária e SO LINUX Debian, Versão 2.0, Kernel 2.0.34, para os testes com a máquina sendo desconectada da rede. Denominou-se este ambiente A.

Para testes adicionais, utilizou-se um novo ambiente que se caracteriza como um Pentium $400 \mathrm{MHz}, 130 \mathrm{Mb}$ de memória primária e as demais características idênticas a aquelas mencionadas no ambiente anterior. Referencia-se este novo ambiente como B.

Nas Seções 4.3.1, 4.3.2 e 4.3.3, exibem-se análises comparativas entre os dois ambientes citados. Ressalta-se que quando especificações do ambiente utilizado estiverem ausentes. referencia-se o ambiente $A$.

\subsection{Testes}

Os experimentos efetuados registraram o desempenho da aplicação escolhida, Controle de Aproximação de Aeronaves em Aeroportos, em cenários que representavam o sistema em situações de ausência e presença de sobrecarga.

Estes testes foram realizados colocando essa aplicação no escalonador LINUX-SMART e seus resultados foram comparados com os obtidos em [VNdS99b], que se utilizavam das três classes de escalonamento disponíveis no LINUX-PADRÃO (SCHED-FF, SCHED-RR e SCHED-OTHER descritas na Seção 3.1.1). Os novos testes foram efetuados nos mesmos cenários e os dados coletados com os mesmos parâmetros, tempo e iteração.

Para realizar o experimento mencionado no LINUX-SMART, implementou-se os seguintes programas em linguagem $C$ : setprio.c, setquantum.c, setdead.c e setshare.c. Estes programas informam ao sistema os valores desejados para prioridade, quantum, deadline e share, respectivamente. Isto para um processo específico determinado pelo pid passado pelo usuário. Os programas citados utilizam as chamadas ao sistema mencionadas na Seção 3.1 para efetuar a operação desejada.

Objetivando que os vários testes pudessem ser reapresentados com os mesmos dados da aplicação principal, a trajetória de uma aeronave foi simulada através da mesma função e do mesmo dado inicial, ou seja, uma mesma entrada em todos experimentos. Além disto, foi aplicado o mesmo número de iterações para todos os testes.

A aplicação mencionada é simples, sua função é apenas monitorar o percurso de um avião e, regularmente, informar a distância da aeronave até os principais aeroportos. É importante salientar que a aplicação é apenas um protótipo onde esta monitoração não é real. 
O tempo gasto para completar cada iteração foi armazenado em um arquivo, de maneira que, além da comparação visual de cada experimento, tivemos vários conjuntos de dados para analisar.

Além da aplicação principal, foram utilizados quatro processos secundários que disputavam os recursos do sistema:

- bomba.c-que consumia fortemente os ciclos de $C P U$;

- bomba0.c - que consumia memória;

- isin.tcl [Kim] - que interagia com o Servidor de Janelas e também consumia bastante recursos do sistema (CPU e memória);

- processo de compilação do emacs versão 20.2 .

Ainda no LINUX-SMART, colocou-se a aplicação principal com prioridade HIGH, tempo de processamento igual a $900 \mathrm{~ms}$ e deadline igual a $90000 \mathrm{~ms}$. É importante observar que estes tempos foram utilizados em todos os cenários e que o deadline é da aplicação e não de um bloco de código da mesma. Os demais processos continuaram a ser executados com prioridade NORMAL. Destaca-se que o valor do deadline da aplicação principal foi determinado pelo tempo mínimo necessário para executá-la em qualquer um dos cenários testados. Esta escolha não afeta os resultados apresentados porque a aplicação de tempo real é única nos testes efetuados.

Para os testes, utilizou-se os cenários descritos a seguir:

- A aplicação principal sem processo disputando a CPU.

- A aplicação principal disputando os recursos do sistema com dez processos gráficos.

- A aplicação principal disputando os recursos do sistema com 41 processos, sendo que 20 deles consumiam fortemente a CPU (bomba.c), 20 outros consumiam memória (bomba0.c)e 1 deles consumia CPU e memória (isin.tcl).

- A aplicação principal disputando os recursos de CPU com a compilação do emacs.

Posteriormente, comparou-se os gráficos de comportamento da aplicação principal obtidos em [VNdS99b] nas classes timesharing (TS), Real-Time Round Robin (RT-RR) e Real-Time FIFO $(R T-F F)$ com as funções da aplicação principal obtidas no LINUXSMART sob os cenários mencionados anteriormente, os quais eram os mesmos utilizados nos testes com o LINUX-PADRÃO.

É importante ressaltar que nos gráficos apresentados neste capítulo, o comportamento da aplicação no LINUX-PADR.ÃO corresponde à função representada em linha pontilhada, 
enquanto o comportamento no LINUX-SMART é exibido por uma função representada por linha contínua.

Buscando análises estatísticas sobre o desempenho do sistema nos cenários mencionados, utilizou-se a ferramenta vmstat. Através deste comando foi possível obter informações sobre processos, memória, paginação, entrada e saída, interrupções e atividades da CPU.

A ferramenta vmstat[NSSH95], versão 1.2.9, registra os seguintes parâmetros:

- Processos:

- r: O número de processos esperando para executar.

- b: O número de processos no estado uninterruptable.

- w: O número de processos swapped out mas ainda em estado executável.

- Memory:

- swpd: a quantidade de memória virtual usada(kB).

- free: a quantidade de memória livre (kB).

- buff: a quantidade de memória usada como buffers (kB).

- Swap:

- si: quantidade de memória swapped in do disco $(\mathrm{kB} / \mathrm{s})$.

- so: quantidade de memória swapped out para o disco $(\mathrm{kB} / \mathrm{s})$.

- IO:

- bi: blocos enviados para um dispositivo de bloco (blocks/s).

- bo: blocos recebidos de um dispositivo de bloco (blocks/s).

- System:

- in: O número de interrupções por segundo, incluindo o clock.

- cs: O número de trocas de contexto por segundo.

- CPU (estes são percentuais do tempo total de CPU):

- us: tempo no modo usuário.

- sy: tempo no modo kernel.

- id: tempo sem processamento. 


\begin{tabular}{|c|c|c|c|c|c|c|c|c|c|c|c|c|c|c|}
\hline \multicolumn{4}{|c|}{ procs } & \multicolumn{2}{|c|}{ memory } & \multicolumn{2}{|c|}{ swap } & & io & \multicolumn{2}{|c|}{ system } & \multicolumn{3}{|c|}{$\mathrm{cpu}$} \\
\hline$r \mathrm{~b}$ & & swpd & free & buff & cache & si & so & bi & bo & in & $\mathrm{cs}$ & us & sy & id \\
\hline 00 & 0 & 0 & 15804 & 1348 & 7492 & 0 & 0 & 0 & 0 & 1018 & 4 & 1 & 1 & 98 \\
\hline 0 & 0 & 0 & 15804 & 1348 & 7492 & 0 & 0 & 0 & 0 & 1017 & 4 & 1 & 1 & 98 \\
\hline 0 & 0 & 0 & 15804 & 1348 & 7492 & 0 & 0 & 0 & 0 & 1017 & 8 & 1 & 1 & 98 \\
\hline 00 & 0 & 0 & 15804 & 1348 & 7492 & 0 & 0 & 0 & 0 & 1017 & 6 & 0 & 1 & 98 \\
\hline
\end{tabular}

Figura 4.2: Análise Estatística com vmstat na inicialização do LINUX-SMART

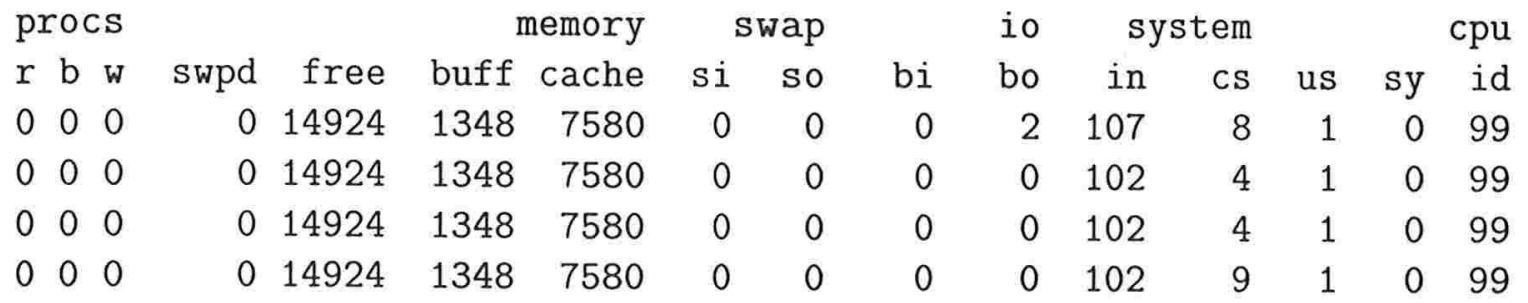

Figura 4.3: Análise Estatística com vmstat na inicialização do LINUX-PADRÃO

Inicialmente, registrou-se uma fatia do comportamento do sistema quando inicializado e não estando em nenhum dos cenários testados. Os resultados foram obtidos no LINUXSMART e no LINUX-PADRÃO, como exibido nas Fig. 4.2 e 4.3 respectivamente.

Um aspecto observado foi o número de interrupções por segundo, in. Esta quantidade mostrou-se bem maior no LINUX-SMART devido a resolução de $1 \mathrm{~ms}$ adotada nesta implementação em relação aquela de 10ms utilizada no LINUX-PADRÃO. O tempo consumido no modo kernel também aumentou, visto que a função schedule é chamada mais freqüentemente.

As seções seguintes exibem os resultados obtidos com os testes no LINUX-SMART e os compara com aqueles registrados no LINUX-PADRÃO com as classes timesharing (TS), Real-Time FIFO(RT-FF) e Real-Time Round Robin (RT-RR). Ressaltamos que nos gráficos comparativos o intervalo entre as funções representa o delay registrado.

\subsubsection{Cenário com a Aplicação Principal sem Processos Concor- rentes}

Nos testes efetuados no LINLX-PADR.̃̃ [VNdS99b], constatou-se que nos escalonadores RT-RR e RT-FF a aplicação possuiu um comportamento pior do que aquele apresentado no SCHED_OTHER. Isto se verificou com a aplicação executando sem nenhum proces- 


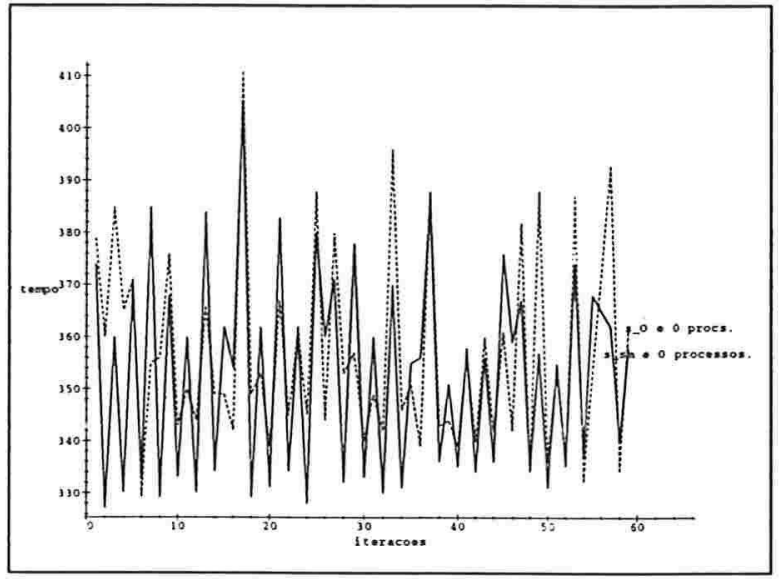

Figura 4.4: Gráfico smart e linux TS com 0 processos.

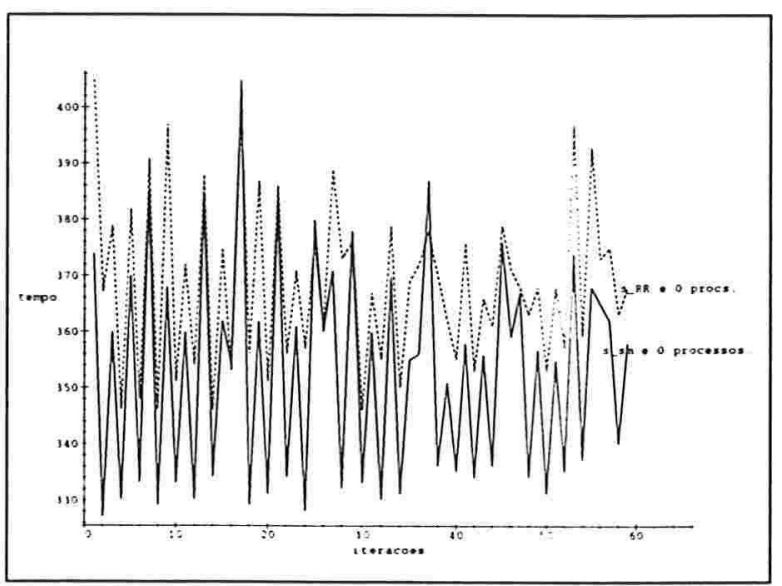

Figura 4.5: Gráfico smart e linux RR com 0 processos. 


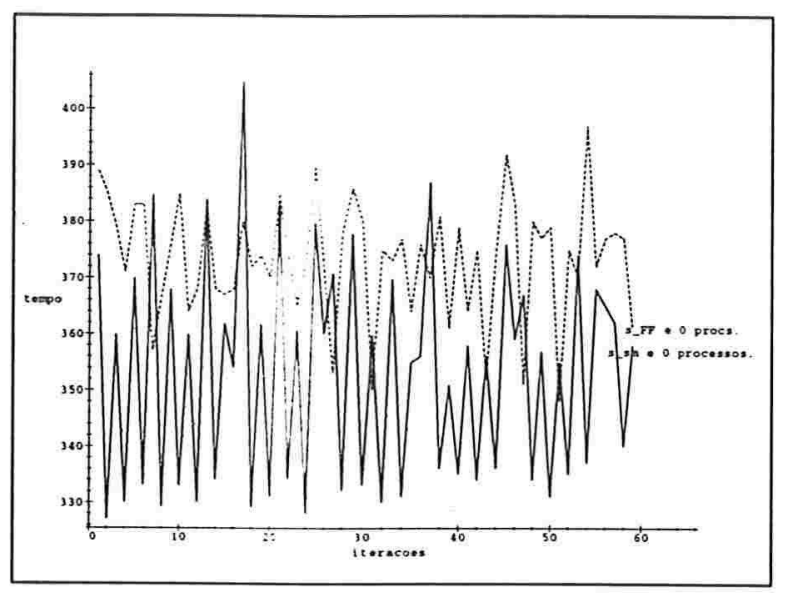

Figura 4.6: Gráfico smart e linux FF com 0 processos.

so concorrente. Neste mesmo cenário. a aplicação no LINUX-SMART apresentou um desempenho semelhante aquele obtido no SCHED_OTHER e conseqüentemente performance melhor com relação ao RT-RR e RT-FF. Esta análise pode ser observada nas Fig. 4.4, 4.5 e 4.6 .

Ressalta-se que o tempo gasto em cada iteração pelo LINUX-SMART não difere em grande proporção daquele obtido nos escalonadores RT-RR e RT-FF. Em nenhum dos escalonadores analisados ocorreu um comprometimento do tempo de resposta da aplicação principal, visto que o consumo de CPL' e memória era mínimo em relação as quantidades disponíveis.

O mesmo teste foi realizado em conjunto com alguns processos iterativos (ls,ps,top). Visualmente não houve piora no tempo de resposta da aplicação e nem dos processos iterativos.

Um fato adicional foram os testes da aplicação nos ambientes A e B, conforme exibido na Fig. 4.7. Observou-se que o desempenho no ambiente $B$ foi bem superior a aquele apresentado no ambiente $\mathrm{A}$. Isto naturalmente devido a maior quantidade de recursos disponíveis, mais memória e mais $\mathrm{CPL}^{-}$.

Na próxima seção exibe-se os resultados no ambiente com 10 processos gráficos.

\subsubsection{Cenário com a Aplicação Principal e 10 Processos Gráficos Concorrentes}

Neste ambiente, observou-se uma sobrecarga do sistema e verificou-se que a aplicação principal no LINUX-SMART possuiu um desempenho semelhante aqueles obtidos nos escalonadores RT-RR e SCHED_OTHER utilizando o mesmo cenário no LINUX-PADR.̃̃O. 


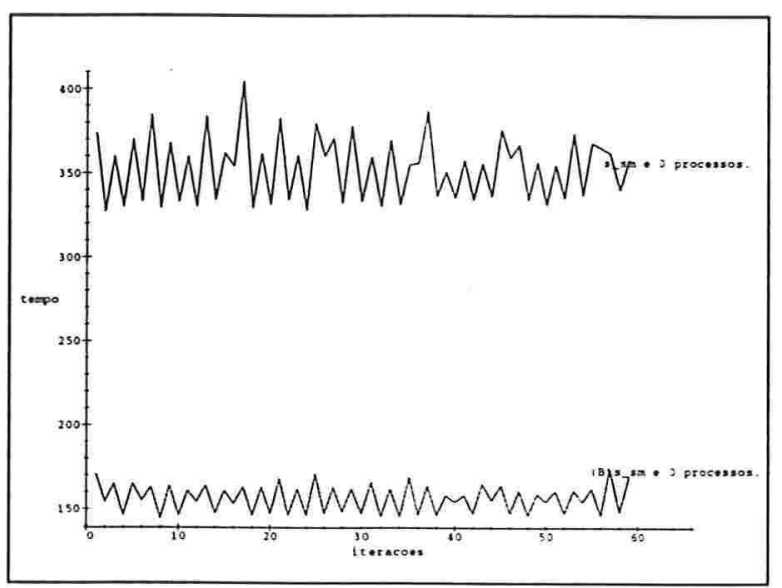

Figura 4.7: Gráficos do smart com 0 processos nos ambientes A e B.

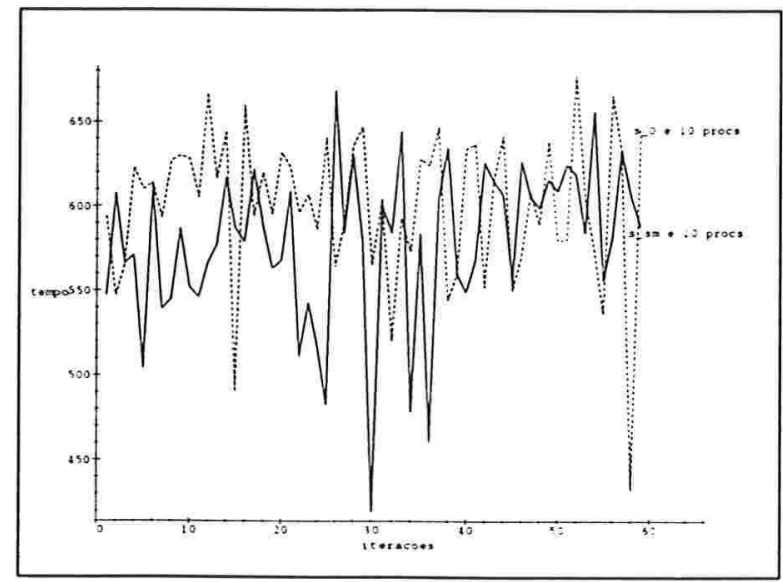

Figura 4.8: Gráfico smart e linux-Other com 10 processos. 


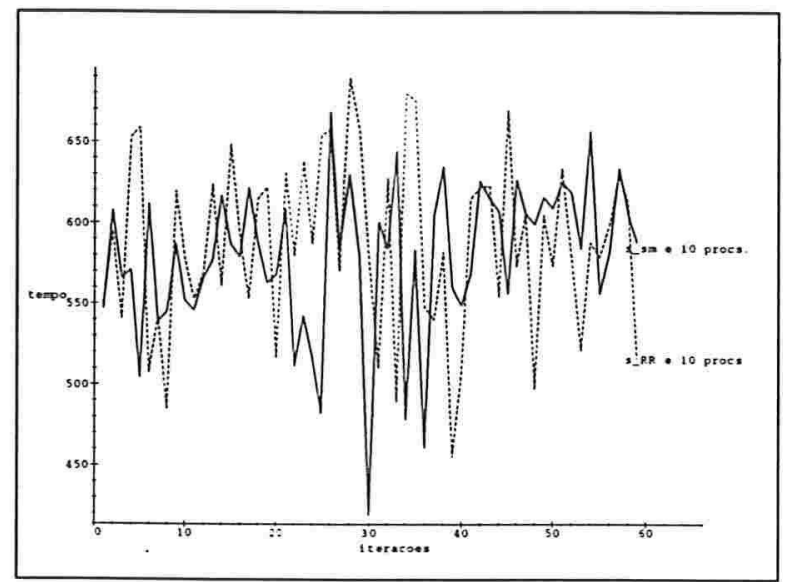

Figura 4.9: Gráfico smart e linux-RR com 10 processos.

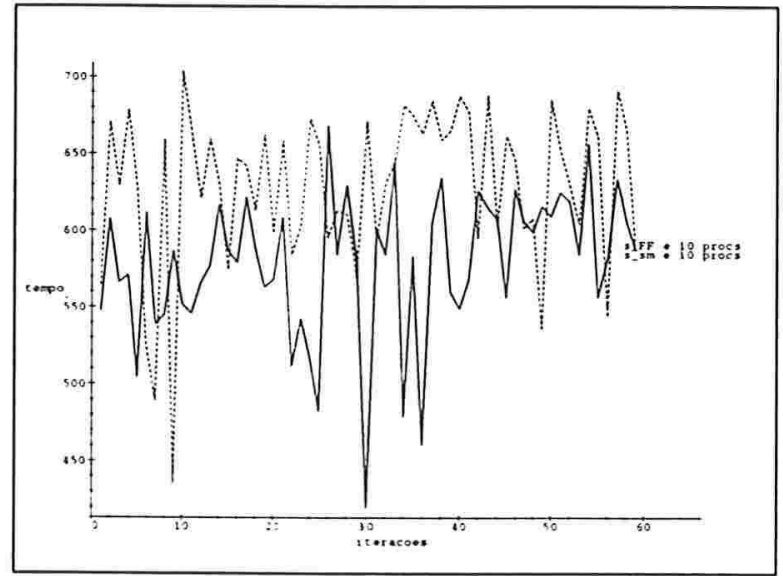

Figura 4.10: Gráfico smart e linux-FIFO com 10 processos. 
Contudo o desempenho da aplicação principal foi melhor no LINUX-SMART do que no escalonador RT-FF do LINUX-PADRÃO. As Fig. 4.8, 4.9 e 4.10 comparam os comportamentos mencionados.

Constatou-se que as ações com o mouse e os processos iterativos tinham um bom tempo de resposta. Já o Servidor de Janelas (XF86_SVGA) mostrou estar consumindo um grande percentual da $\mathrm{CPU}$, provavelmente devido às requisições dos processos gráficos e da própria aplicação principal que também é uma ferramenta gráfica. Isto visualmente gerou uma pequena degradação da aplicação principal. Esta sobrecarga do Servidor de Janelas foi observada através do comando "top". Outro aspecto observado visualmente foi um menor tempo de latência dos 10 processos gráficos e da aplicação principal no LINUX-SMART.

Visando uma análise mais detalhada dos resultados obtidos utilizou-se a ferramenta strace. Este comando mostra todas as chamadas ao sistema efetuadas por alguma aplicação no modo usuário. Além disto, exibe todos os argumentos e valores retornados por estas chamadas.

No caso em questão, a aplicação estudada foi "Controle de Aproximação de Aeronaves em Aeroportos". Comparando os resultados estatísticos apresentados nas Fig. 4.11 e 4.12, verificou-se que no LINUX-PADRÃO ocorreram 957 erros de execução da chamada read e no LINUX-SMART estes erros totalizaram 827. Cada erro da chamada read é devido a falta temporária de recurso disponível. Observou-se então que uma chamada select era realizada com valor de timeout NULL para permitir que o processo seja suspenso enquanto espera a disponibilidade do recurso requisitado. O processo fica bloqueado em uma wait queue, relativa ao descritor do recurso aguardado, até que uma função wake_up ou wake_up_interruptible seja acionada para acordá-lo. Este evento indica que a chamada read pode ser completada. A soma de tempo gasto esperando por um recurso é um dos pontos de degradação do sistema.

Novamente utilizando a ferramenta vmstat, verificou-se que toda a CPU foi usada nas duas implementações: LINUX-SMART e LINUX-PADRÃO. Quanto à troca de contexto observou-se que o LINUX-SMART apresentou um menor número, isto devido provavelmente ao fato da aplicação principal executar com maior prioridade do que os demais processos. Outro aspecto registrado foi que o LINUX-PADRÃO utilizou mais memória virtual, conforme exibido no campo swapd das Figs. 4.13 e 4.14. Para analisar esta situação seria necessário um maior aprofundamento sobre gerenciamento de memória, o que não é o enfoque deste trabalho. Outro fato é que o número de interrupções do LINUX-SMART permaneceu maior do que aquele do LINUX-PADRÃO, igualmente a situação comentada sobre os dados do sistema quando inicializado e não estando em nenhum dos cenários testados (Figs. 4.2 e 4.3). Os dados comentados podem ser encontrados nas Fig. 4.13 e 4.14 .

Outro enfoque comparativo possível é uma análise do desempenho da aplicação principal nos ambientes A e B, conforme exibida na Fig. 4.15. Constatou-se que a aplicação no ambiente $\mathrm{B}$ consumiu menos tempo em cada iteração, provavelmente por existir mais 


\begin{tabular}{|c|c|c|c|c|c|}
\hline$\%$ time & seconds & usecs/call & calls & errors & syscall \\
\hline 55.96 & 0.364972 & 101 & 3621 & & select \\
\hline 16.87 & 0.109996 & 51 & 2138 & & write \\
\hline 15.46 & 0.100791 & 21 & 4902 & 957 & read \\
\hline 7.42 & 0.048374 & 7 & 7084 & & gettimeofday \\
\hline 1.65 & 0.010789 & 1199 & 9 & & writev \\
\hline 0.57 & 0.003745 & 6 & 593 & & time \\
\hline 0.49 & 0.003222 & 8 & 408 & 11 & ioctl \\
\hline 0.38 & 0.002497 & 81 & 31 & 1 & open \\
\hline 0.32 & 0.002062 & 28 & 73 & & brk \\
\hline 0.22 & 0.001404 & 108 & 13 & 1 & stat \\
\hline 0.14 & 0.000883 & 23 & 39 & & mmap \\
\hline 0.12 & 0.000757 & 108 & 7 & & readv \\
\hline 0.09 & 0.000616 & 21 & 30 & & close \\
\hline 0.08 & 0.000551 & 50 & 11 & 4 & access \\
\hline 0.08 & 0.000534 & 534 & 1 & & connect \\
\hline 0.05 & 0.000306 & 19 & 16 & & munmap \\
\hline 0.03 & 0.000177 & 177 & 1 & & socket \\
\hline 0.02 & 0.000149 & 6 & 25 & & fcntl \\
\hline 0.02 & 0.000119 & 15 & 8 & & mprotect \\
\hline 0.01 & 0.000076 & 8 & 9 & & fstat \\
\hline 0.01 & 0.000075 & 13 & 6 & & uname \\
\hline 0.00 & 0.000023 & 8 & 3 & 3 & lseek \\
\hline 0.00 & 0.000015 & 15 & 1 & & personality \\
\hline 0.00 & 0.000010 & 10 & 1 & & sigaction \\
\hline 0.00 & 0.000005 & 5 & 1 & & getpid \\
\hline 100.00 & 0.652148 & & 19031 & 977 & total \\
\hline
\end{tabular}

Figura 4.11: Análise Estatística utilizando strace - $C$ no cenário com 10 processos no LINUX-PADRÃO 


\begin{tabular}{rrrrc} 
\% time & seconds & usecs/call & calls & errors syscall \\
\hline 69.14 & 1.140853 & 358 & 3185 & select \\
10.87 & 0.179354 & 96 & 1877 & write \\
10.05 & 0.165857 & 37 & 4524 & 827 read \\
7.28 & 0.120145 & 19 & 6179 & gettimeofday \\
0.68 & 0.011169 & 1241 & 9 & writev \\
0.57 & 0.009480 & 20 & 483 & time \\
0.41 & 0.006842 & 18 & 370 & 11 ioctl \\
0.22 & 0.003551 & 115 & 31 & 1 open \\
0.19 & 0.003135 & 43 & 73 & brk \\
0.10 & 0.001685 & 153 & 11 & 4 access \\
0.10 & 0.001633 & 126 & 13 & 1 stat \\
0.09 & 0.001565 & 40 & 39 & mmap \\
0.07 & 0.001098 & 122 & 9 & readv \\
0.06 & 0.001072 & 36 & 30 & close \\
0.04 & 0.000614 & 25 & 25 & fcntl \\
0.04 & 0.000604 & 38 & 16 & munmap \\
0.03 & 0.000488 & 488 & 1 & connect \\
0.01 & 0.000235 & 29 & 8 & mprotect \\
0.01 & 0.000201 & 22 & 9 & fstat \\
0.01 & 0.000175 & 29 & 6 & uname \\
0.00 & 0.000065 & 65 & 1 & socket \\
0.00 & 0.000061 & 20 & 3 & 3 lseek \\
0.00 & 0.000030 & 30 & 1 & personality \\
0.00 & 0.000026 & 26 & 1 & sigaction \\
0.00 & 0.000019 & 19 & 1 & getpid \\
----- & $-----19---10$ & total \\
100.00 & 1.649957 & & 16905 &
\end{tabular}

Figura 4.12: Análise Estatística utilizando strace - $C$ no cenário com 10 processos no LINUX-SMART 


\begin{tabular}{rrrrrrrrrrrrrrrr}
\multicolumn{1}{c}{ procs } & \multicolumn{1}{c}{ r memory } & \multicolumn{1}{c}{ swap } & \multicolumn{1}{c}{ io } & system & \multicolumn{4}{c}{ cpu } \\
r & b & w & swpd & free & buff & cache & si & so & bi & bo & in & cs & us & sy & id \\
11 & 0 & 0 & 268 & 2000 & 136 & 4800 & 0 & 0 & 0 & 0 & 1041 & 109 & 92 & 8 & 0 \\
7 & 0 & 0 & 268 & 1752 & 136 & 4800 & 0 & 0 & 0 & 0 & 1023 & 125 & 94 & 6 & 0 \\
1 & 0 & 0 & 268 & 1520 & 136 & 4800 & 0 & 0 & 0 & 0 & 1058 & 170 & 92 & 8 & 0 \\
11 & 0 & 0 & 268 & 1588 & 136 & 4800 & 0 & 0 & 0 & 0 & 1145 & 100 & 94 & 6 & 0 \\
11 & 0 & 0 & 268 & 2220 & 136 & 4800 & 0 & 0 & 0 & 2 & 1120 & 125 & 93 & 7 & 0 \\
11 & 0 & 0 & 268 & 1916 & 136 & 4800 & 0 & 0 & 0 & 0 & 1174 & 135 & 93 & 7 & 0
\end{tabular}

Figura 4.13: Análise Estatística utilizando vmstat no cenário com 10 processos no LINUXSMART

\begin{tabular}{rrrrrrrrrrrrrrrr} 
procs & \multicolumn{1}{c}{ r } & \multicolumn{1}{c}{ memory } & \multicolumn{1}{c}{ swap } & \multicolumn{1}{c}{ io } & \multicolumn{3}{c}{ system } & & cpu \\
r & $\mathrm{b}$ & w & swpd & free & buff & cache & si & so & bi & bo & in & cs & us & sy & id \\
1 & 0 & 0 & 1532 & 2792 & 136 & 4220 & 0 & 0 & 0 & 0 & 103 & 265 & 89 & 11 & 0 \\
1 & 0 & 0 & 1532 & 2628 & 136 & 4220 & 0 & 0 & 0 & 1 & 105 & 272 & 92 & 8 & 0 \\
1 & 0 & 0 & 1532 & 2908 & 136 & 4220 & 0 & 0 & 0 & 0 & 103 & 271 & 93 & 7 & 0 \\
1 & 0 & 0 & 1532 & 2796 & 136 & 4220 & 0 & 0 & 0 & 0 & 103 & 278 & 95 & 5 & 0 \\
1 & 0 & 0 & 1532 & 2764 & 136 & 4220 & 0 & 0 & 0 & 0 & 103 & 272 & 91 & 9 & 0 \\
1 & 0 & 0 & 1532 & 2768 & 136 & 4220 & 0 & 0 & 0 & 0 & 103 & 274 & 90 & 10 & 0
\end{tabular}

Figura 4.14: Análise Estatística utilizando vmstat no cenário com 10 processos no LINUXPADRÃO com escalonador Time-sharing 


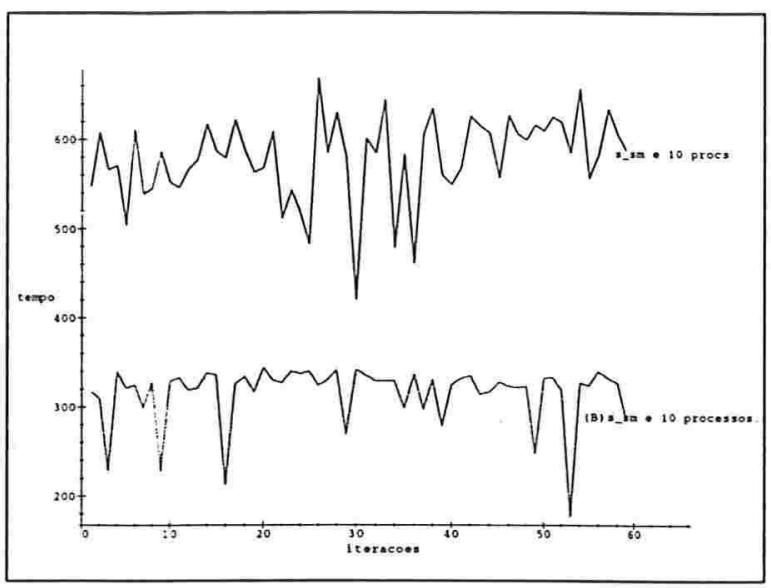

Figura 4.15: Gráficos do smart com 10 processos nos Ambientes A e B.

memória disponível e um processador mais potente (400 MHZ).

Os resultados obtidos na presença de 41 processos concorrentes com a aplicação principal são apresentados na próxima seção.

\subsubsection{Cenário com a Aplicação Principal Concorrente com 41 Processos}

Analisando, neste cenário, o comportamento da aplicação "Controle de Aproximação de Aeronaves em Aeroportos", verificou-se um melhor desempenho na política de escalonamento LINUX-SMART em relação aos resultados obtidos nos escalonadores RT-RR, RT-FF e SCHED_OTHER. Em cerca de metade das iterações a aplicação principal atingiu um desempenho similar a aquele registrado no cenário onde executava sozinha. Nas demais iterações o seu comportamento foi similar a aqueles obtidos no LINUX-PADRÃO com 41 processos concorrentes. Isto para todos os escalonadores analisados (RT-RR, RTFF e SCHED_OTHER). A situação descrita pode ser acompanhada nas Fig. 4.16, 4.17 e 4.18 .

Utilizando a ferramenta strace, apresenta-se na Fig. 4.19 os resultados estatísticos obtidos no LINLX-S.MART. Comparando o desempenho do LINUX-SMART nas Fig. 4.19 e 4.12, observou-se que ocorrem a mais cerca de 175 chamadas read, onde o recurso encontra-se indisponível, no cenário da aplicação com 10 processos. Sabendo que cada chamada read com erro na aplicação principal provoca o bloqueio da mesma e a coloca em alguma wait queue, provavelmente a diferença mencionada é um dos fatores que propiciam um desempenho melhor da aplicação no cenário com 41 processos concorrentes.

Um fato interessante ocorrido com a aplicação no LINUX-SMART foi seu comporta- 


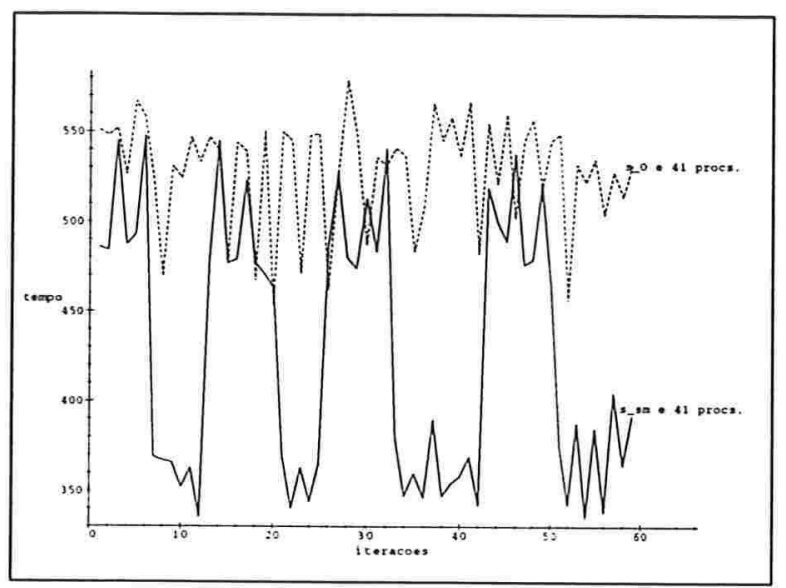

Figura 4.16: Gráfico smart e linux-Other com 41 processos.

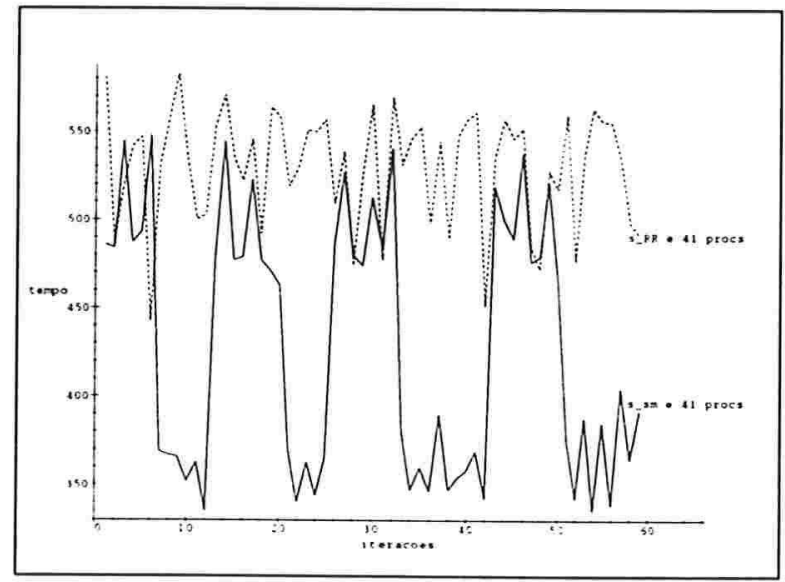

Figura 4.17: Gráfico smart e linux-RR com 41 processos. 


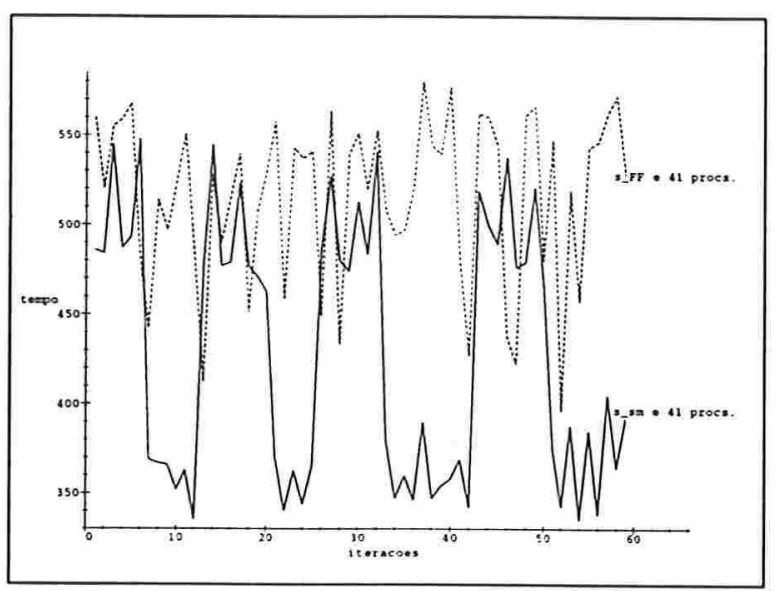

Figura 4.18: Gráfico smart e linux-FIFO com 41 processos.

mento periódico. O principal fator que explica a periodicidade constatada é provavelmente por existirem dois processos, aplicação principal (tempo real) e kswapd (convencional), localizados na fila de prioridade 0. Como a política SMART baseia-se na prioridade em primeiro lugar e para processos em mesma condição de escolha (maior par ordenado) prioriza aquele convencional, tem-se que o processo kswapd consegue executar sempre que não está no estado SLEEP e possui maior valor de par ordenado, fato que ocorre em intervalos de tempo periódicos. Assim os picos de tempo de execução registrados nos gráficos das Fig. 4.16, 4.17 e 4.18 refletem a disputa pela CPU entre os processos mencionados.

Justificando o argumento acima exibe-se, na Fig. 4.20, uma comparação entre o desempenho da aplicação principal nos ambientes A e B. Observou-se que não foi constatada a periodicidade no gráfico do ambiente $\mathrm{B}$. Isto provavelmente porque não foi necessária a execução do kswapd, devido a uma maior quantidade de memória disponível.

Um outro aspecto para analisar são os dados apresentados na Fig. 4.21. Estes foram registrados com o comando:

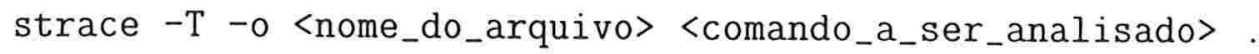

Os dados coletados representam uma pequena fatia do comportamento da aplicação principal e destaca-se que o procedimento mostrado repete-se periodicamente. O fato relevante é o comportamento da chamada ao sistema select, a qual verifica se os dispositivos solicitados estão prontos para utilização. É sabido que enquanto aguarda a prontidão do recurso, a aplicação chamadora fica bloqueada por um intervalo de tempo especificado no campo timeout. Este pode ter um valor específico ou possuir o valor NULL. No segundo caso, o bloqueio é permitido pelo tempo necessário para obter o recurso. Constatou-se que ocorriam chamadas sucessivas da select, estas várias tentativas com insucesso pela expiração do tempo timeout. Após esta situação muitas vezes tentava-se executar um 


\begin{tabular}{|c|c|c|c|c|c|}
\hline$\%$ time & seconds & usecs/call & calls & errors & syscall \\
\hline 61.50 & 0.998123 & 383 & 2609 & & select \\
\hline 12.78 & 0.207444 & 57 & 3646 & 652 & read \\
\hline 12.30 & 0.199655 & 133 & 1505 & & write \\
\hline 10.45 & 0.169567 & 34 & 5002 & & gettimeofday \\
\hline 0.68 & 0.011034 & 31 & 359 & & time \\
\hline 0.68 & 0.010960 & 1370 & 8 & & writev \\
\hline 0.60 & 0.009736 & 29 & 331 & 11 & ioctl \\
\hline 0.22 & 0.003588 & 51 & 71 & & brk \\
\hline 0.19 & 0.003113 & 100 & 31 & 1 & open \\
\hline 0.13 & 0.002127 & 164 & 13 & 1 & stat \\
\hline 0.11 & 0.001729 & 44 & 39 & & mmap \\
\hline 0.07 & 0.001185 & 40 & 30 & & close \\
\hline 0.06 & 0.000988 & 141 & 7 & & readv \\
\hline 0.06 & 0.000955 & 38 & 25 & & fcntl \\
\hline 0.05 & 0.000739 & 67 & 11 & 4 & access \\
\hline 0.04 & 0.000627 & 39 & 16 & & munmap \\
\hline 0.03 & 0.000508 & 508 & 1 & & connect \\
\hline 0.02 & 0.000303 & 38 & 8 & & mprotect \\
\hline 0.01 & 0.000236 & 26 & 9 & & fstat \\
\hline 0.01 & 0.000194 & 32 & 6 & & uname \\
\hline 0.00 & 0.000071 & 71 & 1 & & socket \\
\hline 0.00 & 0.000069 & 23 & 3 & 3 & lseek \\
\hline 0.00 & 0.000031 & 31 & 1 & & personality \\
\hline 0.00 & 0.000027 & 27 & 1 & & sigaction \\
\hline 0.00 & 0.000021 & 21 & 1 & & getpid \\
\hline 100.00 & 1.623030 & & 13734 & 672 & total \\
\hline
\end{tabular}

Figura 4.19: Análise Estatística utilizando strace - $C$ no cenário com 41 processos no LINUX-SMART 


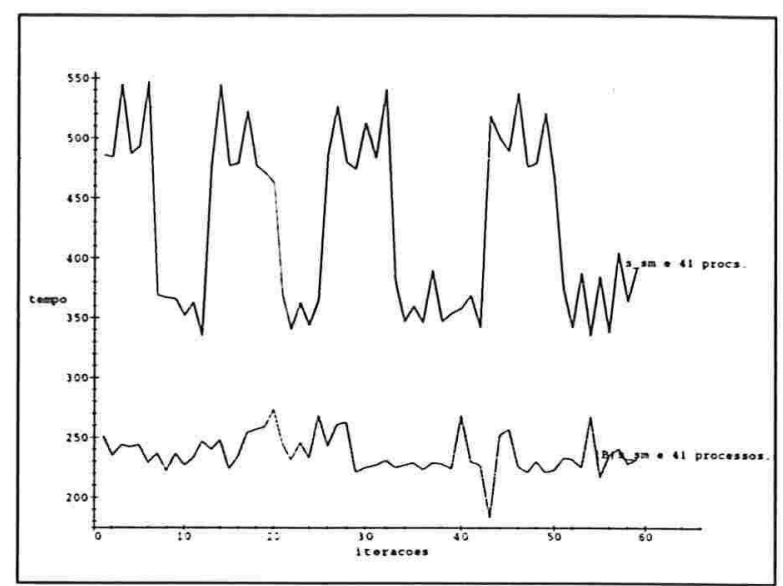

Figura 4.20: Gráficos do smart com 41 processos nos ambientes A e B.

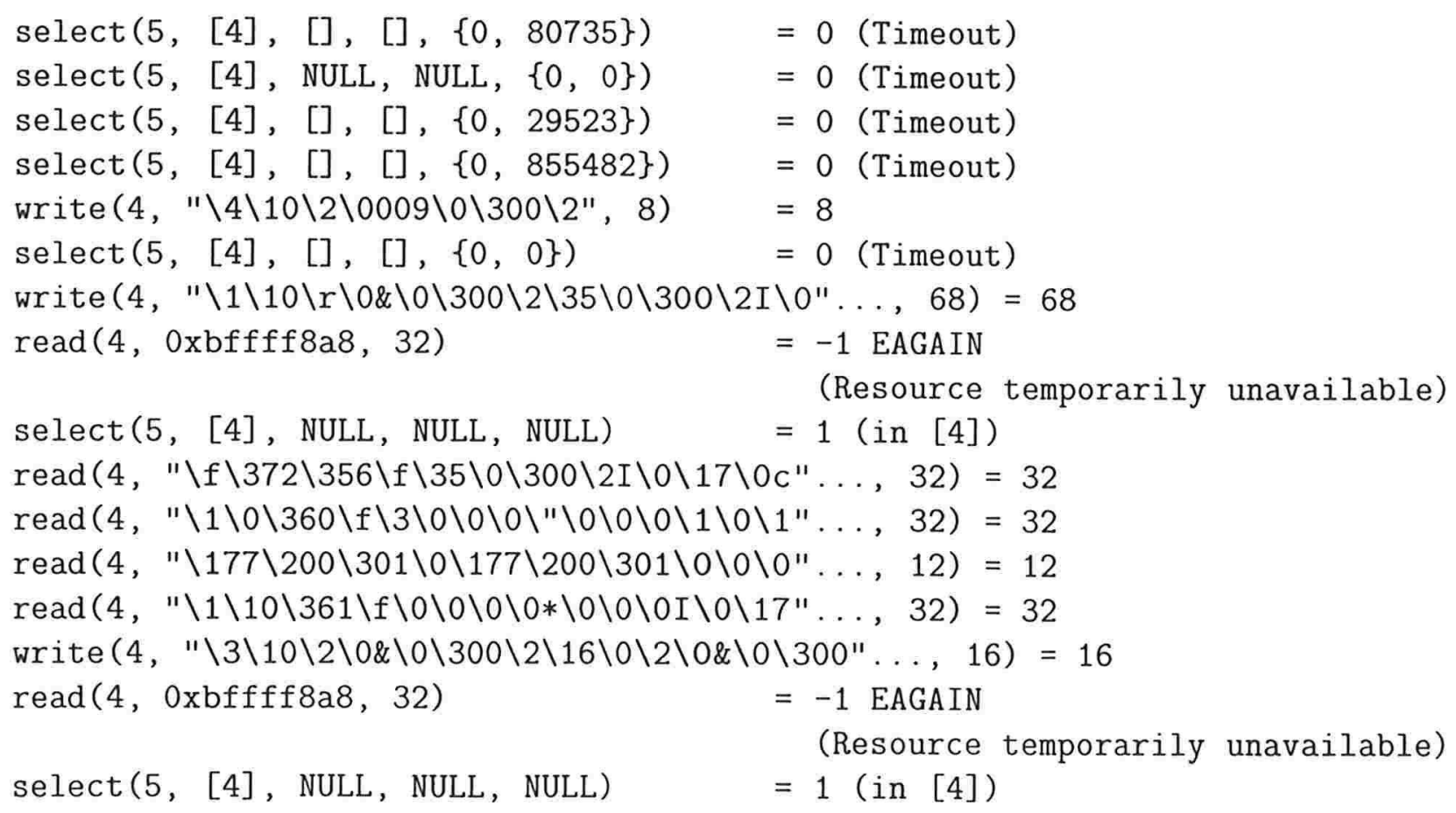

Figura 4.21: Análise de Tempo das Chamadas ao Sistema utilizando strace - $T$ no cenário com 41 processos no LINUX-SMART 


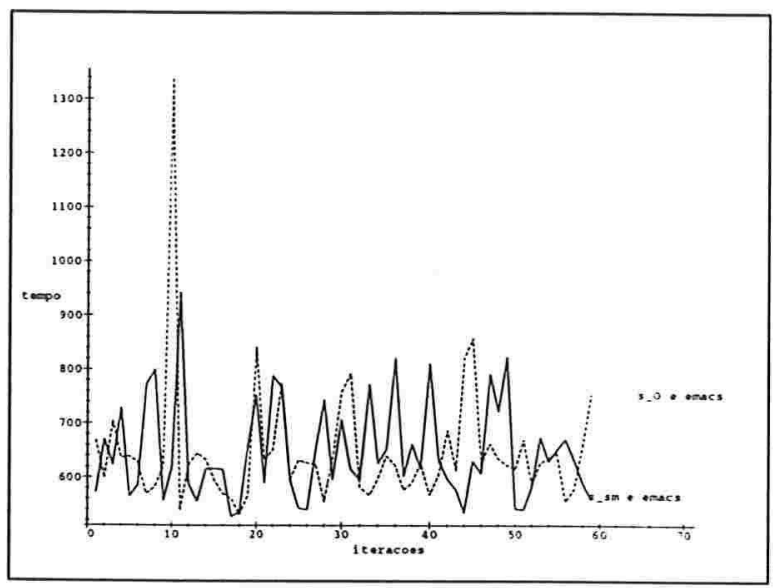

Figura 4.22: Gráfico smart e linux-Other com emacs.

read também sem sucesso pela indisponibilidade temporária do recurso solicitado. Como solução efetuava-se uma nova chamada select desta vez com tempo de timeout não especificado (NULL). Este contexto é provavelmente um dos fatores causadores dos picos de tempo de execução registrados periodicamente nas Fig. 4.16, 4.17 e 4.18.

O desempenho da aplicação principal com a compilação do emacs é discutido na seção seguinte.

\subsubsection{Cenário com a Aplicação Principal e a Compilação do emacs}

Neste cenário observou-se que o comportamento da aplicação principal no LINUX-SMART foi similar a aqueles obtidos nos escalonadores do LINUX-PADRÃO, a saber o RT-RR, RT-FF e o SCHED_OTHER, conforme exibido nas Fig. 4.22, 4.23 e 4.24.

É possível efetuar uma análise comparativa entre os desempenhos mencionados, através da ferramenta vmstat. Observando o comportamento da aplicação no LINUX-SMART e no LINUX-PADRÃO, exibidos nas Fig. 4.25 e 4.26, constatou-se que no LINUX-SMART ocorreu um maior consumo de memória e um número de interrupções muito superior. Este último fato já foi observado em outros cenários e a justificativa está, novamente, na mudança de resolução para $1 \mathrm{~ms}$ no LINUX-SMART.

O desempenho semelhante entre os escalonadores SCHED_OTHER, RT-RR, RT-FF e o LINUX-SMART é provavelmente justificada pelas inúmeras operações de I/O detectadas durante a compilação do emacs, como pode ser observado nos campos bi e bo das Figs. 4.25 e 4.26. E como é sabido, operações de I/O contribuem enormemente para degradação de desempenho. Visto que os custos de operações sobre o disco são altos. 


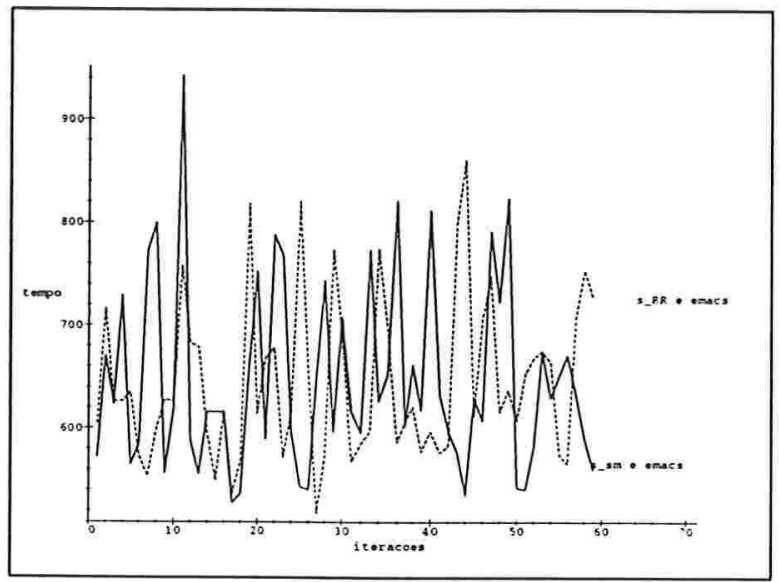

Figura 4.23: Gráfico smart e linux-RR com emacs.

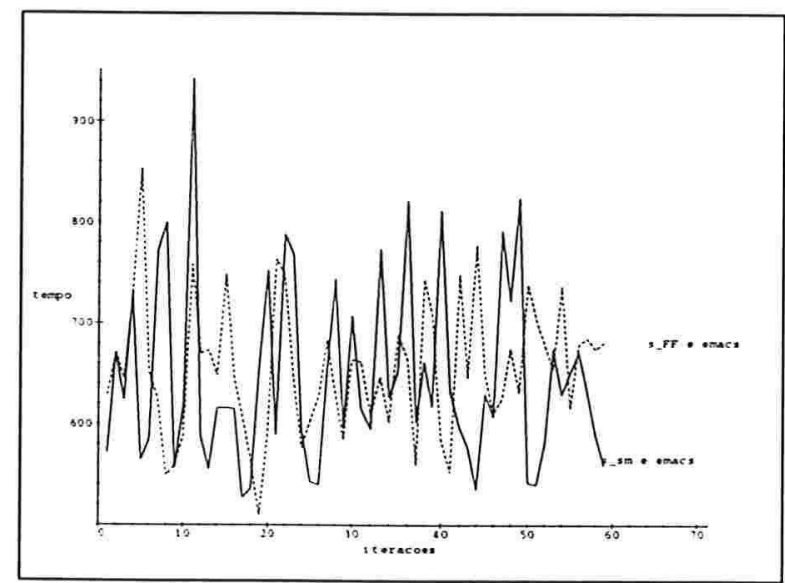

Figura 4.24: Gráfico smart e linux-FIFO com emacs. 


\begin{tabular}{|c|c|c|c|c|c|c|c|c|c|c|c|c|c|c|}
\hline \multicolumn{3}{|c|}{ procs } & \multirow[b]{2}{*}{ free } & \multirow[b]{2}{*}{ buff } & \multicolumn{2}{|l|}{ memory } & \multicolumn{2}{|c|}{ swap } & io & \multicolumn{3}{|c|}{ system } & \multirow[b]{2}{*}{ sy } & \multirow{2}{*}{$\begin{array}{l}\text { cpu } \\
\text { id }\end{array}$} \\
\hline$r \mathrm{~b}$ & $\mathrm{~W}$ & swpd & & & cache & si & so & bi & bo & in & $\mathrm{Cs}$ & us & & \\
\hline 20 & 0 & 0 & 704 & 6660 & 13284 & 0 & 0 & 29 & 0 & 1161 & 48 & 90 & 7 & 3 \\
\hline 10 & 0 & 0 & 1100 & 6624 & 13328 & 0 & 0 & 145 & 0 & 1447 & 134 & 85 & 11 & 4 \\
\hline 20 & 0 & 0 & 620 & 6448 & 13300 & 0 & 0 & 0 & 0 & 1109 & 159 & 93 & 7 & $v$ \\
\hline 10 & 0 & 0 & 704 & 6172 & 13308 & 0 & 0 & 8 & 181 & 1476 & 148 & 96 & 4 & 0 \\
\hline
\end{tabular}

Figura 4.25: Análise Estatística utilizando vmstat no cenário com a compilação do emacs no LINUX-SMART

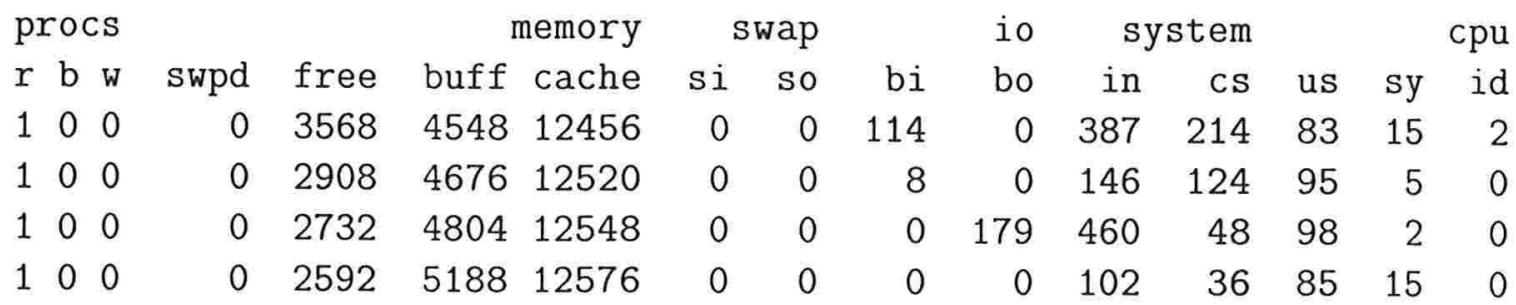

Figura 4.26: Análise Estatística utilizando vmstat no cenário com a compilação do emacs no LINUX-PADRÃO 
Igualmente aos testes efetuados nos escalonadores do LINUX-PADRÃO, a movimentação do mouse e os processos iterativos tiveram um bom desempenho. Também risualmente não houve degradação da aplicação principal.

Discutidos os resultados dos experimentos nos cenários descritos, apresenta-se na próxima seção uma comparação entre os custos de escalonamento no LINUX-PADRÃO e no LINUX-SMART.

\subsection{Custos de Escalonamento}

Um aspecto de interesse é a análise de custo das funções schedule implementadas no LINUX-PADRÃO e no LINUX-SMART, estas comentadas nas Seções 3.1.1 e 3.1.2 respectivamente.

O custo considerado foi o número de ticks gastos com a função schedule em um determinado intervalo de tempo. O intervalo de tempo considerado foi desde o boot do sistema até a inicialização do XWindows.

A ferramenta utilizada nas medidas mencionadas foi a readprofile, a qual lê informações produzidas pelo kernel. As informações utilizadas encontram-se no arquivo / proc/profile e a readprofile as imprime em código ASCII na saída padrão (standard output).

Os dados coletados pela ferramenta utilizada são organizados em três colunas: a primeira é o número de ticks, a segunda é o nome da função em $\mathrm{C}$ no kernel onde aqueles ticks foram gastos, e a terceira é a razão entre o número de ticks e o tamanho da função.

Para habilitar o kernel profiling foi necessário recompilar o kernel e no instante da execução do make xconfig escolheu-se a opção kernel hacking e utilizou-se o valor default 2 para o campo profile shift count. Finalizando a habilitação do kernel profiling especificouse profile $=2$ na linha de comando, isto para determinar o espaçamento entre os passos de profiling.

Antes de obter as medidas, utilizou-se o comando readprofile - $r$ para apagar o buffer de profiling. Posteriormente, realizou-se um shutdown para reinicializar o sistema. Os resultados obtidos registram os dados desde este instante até a inicialização do $X$ Windows como mencionado anteriormente.

Um fato importante para ser comentado é que profiling fica disabilitado quando interrupções são também disabilitadas, e isto interfere diretamente nas medidas do escalonador porque parte dele executa com interrupções disabilitadas. Sendo este aspecto comum em ambos sistemas operacionais, qualquer penalidade sofrida é computada em ambos os casos.

Analisando os resultados da ferramenta readprofile no LINUX-PADRÃO e no LINUXSMART (Capítulo A), localizadas no Apêndice A, observou-se que o gasto com a função schedule no LINUX-PADRÃO foi aproximadamente $50 \mathrm{~ms}$ ( 5 ticks com resolução de $10 \mathrm{~ms}$ ) e no LINUX-SMART o custo obtido foi aproximadamente de $90 \mathrm{~ms}$ (90 ticks com resolução 
de $1 \mathrm{~ms})$. Isto indica que o escalonador do LINUX-SMART gasta em média 1.8 vezes do LINUX-PADRÃO, enquanto que a implementação do SMART no UNIX SRV4 custava 1.74 a mais que o custo do escalonamento do UNIX SRV4.

O maior número de ticks obtidos no LINUX-SMART era esperado devido a maior complexidade da política de escalonamento adotada neste sistema operacional.

Analisados os custos de escalonamentos nos sistemas operacionais sendo estudados, exibe-se algumas considerações sobre a política de escalonamento LINUX-SMART na próxima seção.

\subsection{Considerações Finais}

Deseja-se em um Sistema Operacional bem projetado que as aplicações concorrentes obtenham algum progresso em sua computação, seja a disputa pelo processamento com processos de tempo real ou com convencionais.

Embora o LINUX-PADRÃO apresente as políticas de escalonamento RT-RR e RTFF para tratar aplicações de tempo real, estes escalonadores podem gerar resultados insatisfatórios por poderem propiciar uma situação onde uma única aplicação de tempo real pode dominar o processador. Em conseqüência, as demais aplicações concorrentes não conseguem obter progresso algum.

Um aspecto importante é que o problema acima não está presente nos cenários de testes realizados nos escalonadores de tempo real do LINUX-PADRÃO devido a própria característica da aplicação principal, a qual possui um intervalo de $500 \mathrm{~ms}$ em cada iteração onde fica bloqueada propiciando que os outros processos possam ser executados. Mas o cenário dos testes pode ser trivialmente adaptado de forma a evidenciar esta anomalia. Destaca-se que a anomalia não ocorre no LINUX-SMART, isto por sua política ser baseada no par ordenado prioridade e BVFT.

Analisando os testes efetuados no LINUX-PADRÃO e no LINUX-SMART verificouse um melhor comportamento da aplicação principal no LINUX-SMART na perspectiva tempo versus iteração.

Um ponto de melhoria nesta política de escalonamento foi um melhor gerenciamento, por parte do usuário, sobre o controle do sistema através de system calls que permitem informar o sistema a prioridade, o quantum, o share e o deadline de uma aplicação em relação às demais.

Outro aspecto vantajoso foi o processo de notificação do sistema para a aplicação suportado pelo LINUX-SMART. Através deste procedimento uma aplicação é informada sobre a perda de seu deadline possibilitando um ajuste da mesma neste ambiente de sobrecarga. É importante relatar que no caso estudado, a opção de implementação foi o envio de um SIGKILL para a aplicação afetada. Existem muitas outras maneiras de implemen- 


\begin{tabular}{rrrrrrrrrrrrrrrr}
\multicolumn{1}{c}{ procs } & \multicolumn{1}{c}{ memory } & \multicolumn{1}{c}{ swap } & \multicolumn{1}{c}{ io } & \multicolumn{3}{c}{ system } & \multicolumn{1}{c}{ cpu } \\
r & b & w & swpd & free & buff & cache & si & so & bi & bo & in & cs & us & sy & id \\
1 & 0 & 0 & 0 & 364 & 9184 & 10960 & 0 & 0 & 1036 & 0 & 3115 & 194 & 18 & 23 & 59 \\
1 & 0 & 0 & 0 & 364 & 6712 & 11700 & 0 & 0 & 849 & 0 & 2724 & 181 & 41 & 36 & 23 \\
0 & 1 & 0 & 0 & 3984 & 5756 & 12044 & 0 & 0 & 490 & 500 & 2998 & 77 & 19 & 22 & 59 \\
1 & 0 & 0 & 0 & 3820 & 5820 & 12060 & 0 & 0 & 79 & 0 & 1185 & 139 & 4 & 4 & 92 \\
1 & 0 & 0 & 0 & 2264 & 5948 & 13284 & 0 & 0 & 1225 & 0 & 3495 & 47 & 47 & 22 & 30 \\
0 & 1 & 0 & 0 & 844 & 6076 & 14580 & 0 & 0 & 1287 & 500 & 4635 & 30 & 59 & 23 & 19 \\
1 & 0 & 0 & 0 & 532 & 6032 & 14928 & 0 & 0 & 761 & 0 & 2546 & 138 & 52 & 14 & 34 \\
1 & 0 & 0 & 0 & 392 & 6032 & 15264 & 0 & 0 & 919 & 1761 & 4668 & 137 & 44 & 19 & 36 \\
1 & 0 & 0 & 0 & 388 & 5960 & 15340 & 0 & 0 & 447 & 0 & 3666 & 133 & 22 & 11 & 67
\end{tabular}

Figura 4.27: Análise Estatística com vmstat no cenário com a compilação do emacs.

tar o ajuste devido à perda do deadline, contudo todas incluiriam alguma modificação no código da aplicação principal. Isto afetaria nossa comparação com os resultados obtidos no LINUX-PADRÃO [VNdS99b]. Neste caso, optamos por manter a aplicação com seu código inalterado.

Apesar dos bons resultados obtidos, ressalta-se que melhorias podem ainda ser conquistadas. Por exemplo, no pior caso a complexidade de gerenciamento da classificação de trabalho é $O\left(N_{R}^{2}\right)$, onde $N_{R}$ é o número de tarefas de tempo real ativas de valor maior do que o mais alto valor de par ordenado de uma tarefa convencional. Este pior caso ocorre se cada tarefa de tempo real precisa ser selecionada e testada quanto à possibilidade de sua junção à atual classificação (feasibility test), contra todas as outras tarefas no ato da reconstrução da classificação de trabalho [NL97b].

Os testes efetuados revelaram que a velocidade da CPU não é o fator mais importante que afeta a performance do sistema, como pode ser observado na Fig. 4.27 onde existe CPU disponível mas nem por isto a performance é melhor. Em alguns tipos de aplicação, como por exemplo simuladores, uma CPU muito rápida faria uma grande diferença. Contudo para aplicações onde a interface com o usuário é gráfica a velocidade da CPU já não é tão significante [NSSH95].

No sistema operacional LINUX um aspecto que de fato afeta o desempenho é a largura de banda do disco. Isto porque discos rígidos são sistemas mecânicos e tomam dezenas de milisegundos para localizar o bloco no disco, fazer o fetch do conteúdo e acordar o processo que aguarda o resultado desta operação. Atrasos desta magnitude sobrepõem qualquer outra fonte de degradação de performance do sistema. A cada acesso ao disco milhões de instruções deixam de ser executadas [NSSH95]. Assim para algumas aplicações a grande quantidade de operações de I/O geradas torna-se um aspecto de degradação do sistema. Esta é uma situação detectada na Fig. 4.27.

Esta dissertação objetivou um aumento no desempenho do sistema a partir de me- 
lhorias no gerenciamento dos ciclos de CPU para as aplicações. Contudo, pelo exposto anteriormente, este não é o único e principal fator a ser tratado visando melhoria de performance. Assim os resultados obtidos refletem os esforços de pesquisa em uma direção possível, sendo fatores como o gerenciamento de memória e o tratamento de entrada/saída outros caminhos para serem explorados.

No próximo capítulo apresenta-se o estado da arte dos escalonadores de tempo real e destaca-se os esforços atuais na comunidade LINUX. 


\section{Capítulo 5}

\section{Trabalhos Relacionados}

Neste capítulo descrevemos enfoques recentes presentes na literatura para gerenciamento de recursos de aplicações de tempo real soft, classificando-os em paradigmas. Apresentamos também, os projetos baseados no LINUX que propiciam escalonamento para tempo real.

\subsection{Técnicas Empregadas}

No âmbito da solicitação e aquisição de recursos por parte de uma aplicação, uma questão primordial é a garantia de qualidade de serviço [Bur94]. Este conceito surgiu em redes onde existe a pressuposição que os recursos são limitados e há necessidade explícita de gerenciá-los para que os deadlines das aplicações possam ser satisfeitos. No tratamento deste tópico destacam-se duas abordagens. Uma corrente garante qualidade de serviço para as aplicações, enquanto a outra não vê garantia de qualidade de serviço como uma ferramenta de gerenciamento dos recursos do sistema e projeta as suas aplicações de forma a adaptarem-se à carga do sistema.

Qualidade comumente denota uma característica particular, bem como, o grau em que uma dada característica está presente [Hyd94]. Dentro do contexto de sistemas operacionais, sendo este um fornecedor de serviços tais como ciclos de CPU, memória, operações de I/O entre outros, qualidade de serviço é usada para referenciar o tipo de serviço sendo fornecido e para medir quanto daquele serviço é disponibilizado para uma aplicação. Esta medição é quantificada pela quantidade e pelo número de vezes em que um serviço é fornecido.

Em um sistema baseado em garantia de serviço, a aplicação solicita ao sistema os recursos e este, baseado na disponibilidade dos mesmos, decide se pode aceitar aquela solicitação sem afetar as requisições anteriores. Não sendo possível, a aplicação não executará e o usuário decidirá se espera para submeter novamente a sua aplicação, se a cancela ou se a modifica. 
Na outra abordagem, criam-se mecanismos de comunicação entre a aplicação e o gerenciador de recursos de maneira que a aplicação possa expressar as suas necessidades e suas restrições de tempo. O gerenciador de recursos, através de monitoramento. pode dar feedback para a aplicação sobre a possibilidade de satisfação das restrições de tempo e sobre a sua disponibilidade de recursos. Desta maneira as aplicações tentam se adaptar à carga do sistema.

Uma outra forma de distinguir estas abordagens é considerar uma fornecendo garantia determinística e a outra estatística. Em um ambiente determinístico, as solicitações de recursos não podem deixar de serem cumpridas e em um ambiente estatístico há uma probabilidade de as solicitações não serem cumpridas totalmente.

Neste contexto temos alguns paradigmas como: os baseados em prioridade [Bet94, But97, BW96, LL73], os baseados em qualidade de serviço [Hyd94, $\mathrm{LMB}^{+}$95, BH99], os de reserva de recursos [JLDJSB95, $\mathrm{JJSBF}^{+}$96, JRR97, BGOS97, MST94a, MST94b], os de alocação de recursos proporcional ao seu share [SAWJ+96, Mah95, KL88], os de enfileiramento justo [SAWJ97, BZ96, DKS89, PG93, Wal95, WW95],os hierárquicos [GGV96] e os baseados em feedback $\left[\mathrm{SGG}^{+} 99\right]$.

Nas próximas seções as tendências atuais são explanadas através dos paradigmas mencionados, os quais são descritos e exemplificados.

\subsubsection{Paradigma Baseado em Prioridade}

O paradigma dominante em sistemas operacionais é aquele baseado em prioridade. Apesar do tratamento ad-hoc em muitos sistemas operacionais, prioridades são usadas de uma maneira clara e consistente no domínio de sistemas de tempo real. Os escalonadores utilizados garantem que os deadlines das aplicações não são perdidos, para manter a corretude e evitar falhas catastróficas.

Dentre os algoritmos baseados em prioridade, destacam-se o Rate Monotonic e o Earliest Deadline First.

O algoritmo de escalonamento Rate Monotonic (RM) [Bet94, But97, BW96, LSD89] foi projetado para escalonar tarefas periódicas sem ordenação ou restrições de exclusão mútua em um único processador. Neste algoritmo, inicialmente, a cada tarefa é atribuída uma prioridade igual a sua freqüência de requisição e ao menor período é associado a mais alta prioridade. Por exemplo, para uma tarefa que executa a cada 20 ms é atribuída uma prioridade com valor igual a 50, enquanto para uma tarefa que executa a cada $100 \mathrm{~ms}$ atribui-se uma prioridade com valor 10. Visto que períodos são constantes. R.M tem atribuição de prioridade estática: prioridades são associadas para tarefas antes da execução e não são modificadas posteriormente. Além do mais, RM é intrinsicamente preemptivo: a tarefa atualmente executando é interrompida por uma tarefa recentemente chegada com menor período.

Liu e Layland [LL73] mostraram que R.II c ótimo entre todos os algoritmos que fixam 
prioridades, no sentido que nenhum outro algoritmo de prioridade estática pode escalonar um conjunto de tarefas que não pode ser escalonado pelo RM. Neste mesmo trabalho, mostrou-se o menor limite superior do fator de utilização do processador para um conjunto genérico de $n$ tarefas periódicas.

O algoritmo Earliest Deadline First (EDF) é um escalonador dinâmico [LL73, But97, BW96] onde os processos são selecionados de acordo com os seus deadlines absolutos. Processos com deadlines menores são executados com altas prioridades. A atribuição de prioridades é feita dinamicamente.

Observe que o EDF não faz qualquer suposição específica sobre a periodicidade das tarefas, assim pode ser utilizado para escalonar tarefas periódicas e não periódicas. A desvantagem do EDF é que durante períodos de sobrecarga momentâneos, deadlines podem ser imprevisivelmente perdidos e não é possível prever totalmente se a carga atual pode ser escalonada.

\subsubsection{Paradigma Baseado em Qualidade de Serviço}

O paradigma baseado em qualidade de serviço abrange aqueles escalonadores que utilizam em suas políticas algum tipo de gerenciador de qualidade de serviço. Um exemplo desta classe de escalonadores é o desenvolvido por Eoin Hyden [Hyd94], que propôs um novo ambiente para dar suporte à classe de tempo real soft utilizando um gerenciador de Qualidade de Serviço (QoS). A proposta de um gerenciador de QoS é fazer um acordo com os processos sobre as suas respectivas qualidades de serviços. Uma aplicação apresenta para o gerenciador de QoS uma descrição de seus requisitos e este a converte em um conjunto de parâmetros. O gerenciador de QoS decide se pode ou não aceitar esta requisição. Se a QoS não pode ser provida, a aplicação e o usuário são informados. Se o gerenciador de QoS puder fornecer os recursos solicitados, a aplicação também é informada desta disponibilidade. Então um contrato é gerado entre a aplicação e o sistema. O gerenciador de QoS comunica os parâmetros da solicitação da aplicação para o Run-Time Resource Allocator (RTRA), este toma apenas decisões simples (por exemplo, qual é o próximo processo a executar) baseando-se em regras como a mais alta prioridade e o menor deadline. No mais baixo nível, podemos dizer que o RTRA multiplexa os recursos disponíveis entre aquelas aplicações solicitantes. No caso do processador, a alocação de tempo é feita pelo dispatcher. Este interpreta as requisições de recursos das aplicações como uma série de tarefas que são colocadas em filas para esperar até que o processador possa ser alocado para as mesmas.

Assegurar que uma aplicação recebe a QoS solicitada requer uma contabilização dos recursos usados pela aplicação. Uma proposta para resolver este problema é via um sistema de créditos. A aplicação recebe um número de créditos, os quais são debitados na conta da aplicação e depositados na conta do sistema. Um aspecto negativo deste procedimento é o aumento da sobrecarga na interaçào entre a aplicação e o sistema. 
Existe também um policiamento que ocorre em dois níveis. No nível mais baixo, assegura que uma aplicação não exceda sua alocação e consuma recursos que são reservados para outra aplicação. No nível mais alto, impede que as aplicações não requisitem recursos excessivos para garantir sua execução.

Um importante parâmetro do sistema é o tempo em que qualquer contrato de QoS permanece válido. Um sistema em que contratos permanecem válidos indefinidamente não são convenientes. Por exemplo, para uma estação de trabalho a inconveniência está na variedade de tarefas existentes.

Considerando uma situação em que $90 \%$ do processador já foi reservado e o usuário deseja executar uma aplicação que requer $15 \%$ do processador, podem ocorrer duas ações. O gerenciador de QoS informa a aplicação que não pode ser concedido os $15 \%$ solicitados, mas pode ser fornecido $10 \%$. Então, a aplicação opta por alguma decisão default ou consulta o usuário, o qual aceita ou rejeita o contrato oferecido.

No sistema desenvolvido por Eoin Hyden [Hyd94], o escalonamento ocorre em vários níveis, o gerenciador de QoS toma decisões de escalonamento tais como: admitir ou não um novo processo e retirar recursos de um processo para fornecê-los a outro. O sistema RTRA é responsável por apresentar recursos para um processo respeitando as restrições de tempo. E entre os processos que utilizam os recursos, os escalonadores de threads no nível de usuário são responsáveis por alocar recursos para as aplicações.

A outra abordagem discutida ainda no paradigma de QoS apresenta um gerenciador e um escalonador para gerenciar recursos no processador MAP1000 [BGKO99]. Este processador de multimídia é do tipo VLIW (Very Long Instruction Word) e possui as seguintes características: um conjunto de instruções como do RISC, uma UFF (multi-element Fixed Function Unit) e uma DMA portável e programável chamada Data Streamer. O sistema operacional utilizado é o MMLite [HF98] projetado pela Microsoft. Este sistema suporta um subconjunto das características do escalonador Rialto [JLDJSB95, JJSBF+ 96, JRR97], discutido na Seção 5.1.3. A idéia de Baker-Harvey [BH99] foi implementar o distribuidor de recursos Equator Technologies, Inc. (ETI RD) em substituição às características presentes do escalonador Rialto.

Implementando o ETI RD objetivou-se dar garantias de tempo real mais rígidas do que aquelas garantias de tempo real soft convencionais, além de permitir que tarefas convencionais sejam executadas concorrentemente. As aplicações de tempo real têm os recursos estimados garantidos mesmo quando o sistema está sobrecarregado. Decisões políticas são feitas mas as garantias de escalonamento são mantidas. Embora o ETI RD tenha sido concebido para ambientes onde se exija garantias de tempo real mais rígidas, mostra-se também apropriado para muitos sistemas que combinam aplicações de tempo real soft e convencionais.

Descrevendo detalhadamente o ETI RD, inicia-se caracterizando as aplicações que executam sobre o MAP1000.

As aplicaçōes que executam sobre o MAP 1000 compartilham as seguintes características: 
- são períodicas com períodos definidos naturalmente, assim como aplicações $M P E G$ ou externamente quando têm um período definido por ações que ocorrem somente em pontos específicos;

- são capazes de mudar $^{1}$ a sua carga quando o sistema está sobrecarregado;

- os recursos solicitados são discretos e não contínuos, ou seja, o trabalho que uma aplicação deve fazer é previsível²;

- o desempenho é extremamente bem caracterizado.

Conhecidas as características das aplicações suportadas pelo ETI RD, discutem-se os três requisitos de projeto extraídos da natureza das aplicações de multimídia e das solicitações dos usuários:

- O RD não deve causar anomalias de desempenho em tarefas inicializadas pelo usuário. Em outras palavras, uma vez que uma tarefa foi inicializada com sucesso pelo usuário, o término da aplicação ocorre naturalmente ou somente este pode finalizá-la.

- O escalonador deve procurar alocar quase totalmente os recursos disponíveis para as tarefas prontas para execução. Isto significa que se uma tarefa requisita um recurso anteriormente solicitado por outra tarefa mas ainda não utilizado, o recurso é concedido para a última tarefa solicitante.

- A política de qualidade de serviço (QoS) é determinada pelas preferências do usuário. Estas definem, em uma situação de sobrecarga, quais tarefas mudam suas requisições de recursos e qual degradação de serviço é permitida.

Outro aspecto importante para entedimento do ETI RD são os componentes que o constituem e os algoritmos que caracterizam suas respectivas implementações.

O gerenciador de recursos aloca os recursos do sistema para as tarefas solicitantes, com estas decisões sendo tomadas em duas partes. Primeiramente, determina-se se uma thread pode ser admitida no sistema (controle de admissão). Posteriormente, determina-se a quantidade de recursos destinada a cada thread (controle de permissão). Uma permissão consiste de um período de tempo e uma quantidade de recursos que podem ser consumidos naquele período por uma thread. Por exemplo, uma permissão pode alocar $10 \mathrm{~ms}$ de CPU em um período de $30 \mathrm{~ms}$. Uma permissão é uma garantia para a thread que a quantidade de recursos prevista será alocada para ela a cada período. Uma aplicação que busca garantias de tempo real deve acessar o gerenciador de recursos para ser admitida. Uma lista dos recursos deve ser enviada para o gerenciador pela aplicação onde cada entrada

\footnotetext{
${ }^{1}$ Por exemplo, mudando a sua resolução ou descartando alguns frames.

2Processar um frame MPEG em uma resolução conhecida requer uma conhecida quantidade de $C P U$.
} 
da lista ordenada corresponde a um nível de qualidade de serviço com que a aplicação está preparada para trabalhar.

Cada entrada contém um período e uma solicitação de CPU. Ambos especificados em unidades de ticks de $27 \mathrm{MHz}$. O período mínimo é 500 microsegundos e o máximo é 159 segundos. Cada entrada também contém uma função de retorno associada com cada nível de QoS.

O período ocorre naturalmente ou é definido por algum padrão ou determinado por eventos externos. Por exemplo, MPEG necessita gerar 30 frames por segundo, assim um período de $1 / 30$ segundos é necessário. O período define os instantes inicial e final de cada unidade de tempo na qual os recursos são alocados para uma aplicação. A solicitação de CPU é uma medida da quantidade de CPU que a aplicação requer durante cada período.

Outros campos fornecidos pela lista de recursos são: razão e função de retorno. A razão é computada pela divisão entre a solicitação de CPU e o período, representando a razão na qual a entrada da lista de recurso consome CPU. O campo função é o endereço de uma rotina que implementa a funcionalidade da aplicação no nível de QoS apropriado para uma dada entrada na lista. Uma aplicação pode ter diferentes funções para entradas diferentes e o escalonador chama uma função apropriada quando a aplicação consegue os recursos associados com a entrada correspondente.

Quando uma tarefa solicita admissão, o gerenciador de recursos realiza duas tarefas distintas. A primeira, controle de admissão, determina se a aplicação é admitida para o domínio do ETI RD. Se a tarefa é admitida, o gerenciador executa a segunda tarefa que consiste em determinar o novo conjunto de permissão. O conjunto de permissão especifica quais recursos estão disponíveis para cada tarefa admitida.

Uma nova thread entra no sistema se e somente se a soma das permissões mínimas para todas as threads do sistema podem ser simultaneamente acomodadas quando a nova thread for admitida. Este teste de controle de admissão é expresso como:

$$
\sum_{i=0}^{\text {runnable }} \operatorname{Rate}(\min )_{i}+\sum_{j=0}^{q u i e s c e n t} \operatorname{Rate}(\min )_{j} \leq 100 \%,
$$

onde uma tarefa quiescent é aquela que apesar de não estar usando recursos atualmente, não pode ter sua admissão negada em qualquer instante futuro. Um exemplo é a tarefa responsável pelo resfriamento do processador. Enquanto o processador não está superaquecido não se reserva recursos para esta tarefa.

Quando uma thread entra ou sai do sistema ou quando uma thread quiescent muda de estado, o gerenciador de recursos gera um novo conjunto de permissōes para todos as threads. As permissões para uma thread podem aumentar ou diminuir neste instante. Para o gerenciador de recursos garantir que a soma das permissões não exceda $100 \%$, o escalonador necessita somente dar suporte para que as permissões estejam aptas para usar um esquema EDF (Earliest Deadline First) com sucesso. O cálculo utilizado para determinar o novo conjunto de permissões é:

$$
\sum_{i=0}^{\text {runnable }} \text { Rate(permissão) }_{i} \leq 100 \% .
$$


Porque o ETI RD admite uma tarefa somente se a soma das entradas mínimas da lista de recursos é menor do que o total de recursos disponíveis na máquina, garante-se que existe um legítimo conjunto de permissões ${ }^{3}$.

O gerenciador de recursos trabalha no contexto das requisições das aplicações. O controle de admissão é executado somente quando uma nova tarefa tenta entrar no sistema. Um novo conjunto de permissões é computado somente quando uma tarefa entra, sai, muda sua lista de recursos ou quando entra ou sai do estado quiescent.

Outro componente do ETI RD é o escalonador, o qual preocupa-se apenas com os mecanismos de escalonamento, não com as decisões políticas. Isto significa que o escalonador apenas ordena o conjunto de threads determinado pelo processo de controle de permissão e garante as alocações de recursos estimadas. O escalonador implementa o algoritmo EDF (Earliest Deadline First) [LL73] (Seção 5.1.1) na escolha da próxima tarefa a executar, a qual é extraída do conjunto especificado pelo gerenciador de recursos. Só existe comunicação com o gerenciador de recursos, nenhuma informação é trocada com a caixa de políticas (descrita a seguir), usuários ou aplicações.

O escalonador implementa um algoritmo EDF (Earliest Deadline First). Este tipo de algoritmo tem um custo reduzido e é capaz de escalonar qualquer conjunto de tarefas para o qual exista uma classificação. Uma implicação do EDF é que máxima latência garantida para uma tarefa é duas vezes seu período menos duas vezes suas solicitações de CPU. Isto ocorre quando a permissão é entregue para uma aplicação no início de um período e no final do período subseqüente.

O gerenciador de recursos notifica ao escalonador que uma nova permissão está disponível. Da próxima vez que um tempo de CPU não for alocado, o escalonador faz uma chamada de retorno ao gerenciador para obter informações sobre o novo permissionamento.

O escalonador mantém todas as tarefas com permissões em duas filas: (1) a fila TempoRestante, a qual contém todas as tarefas que possuem ciclos de CPU não usados alocados neste período, ou (2) fila de TempoConsumido que contém as demais tarefas. Ambas as filas são ordenadas por deadline. Uma thread na fila TempoConsumido utilizou seu tempo de CPU para o período ou indica que realizou seu trabalho naquele período. Uma thread na fila TempoConsumido pode também estar sobre uma fila PedidoAlemdoTempo se expirou seu tempo e ainda resta trabalho para fazer.

Em uma troca de contexto, o escalonador escolhe a primeira thread da fila TempoRestante, se existe alguma. Caso contrário, se existem novas permissões, o escalonador faz uma chamada de retorno ao gerenciador de recursos para obter informaçōes sobre a nova permissão. Finalmente, o escalonador executa a primeira thread da fila PedidoAlémdoTempo. O ETI RD sempre mantém pelo menos uma thread nesta lista. A próxima troca de contexto é causada por uma interrupção de clock determinada pelo escalonador ou pela liberação do processador pela tarefa em execução.

\footnotetext{
${ }^{3}$ Pelo menos, todas as tarefas recebem suas permissōes mínimas.
} 
O ETI RD concede as seguintes garantias de escalonamento para as tarefas admitidas:

1. A tarefa receberá uma permissão da lista de recursos fornecida pela aplicação;

2. A permissão será concedida em cada período;

3. A menos que a tarefa tenha o menor requisito de CPU do sistema, esta pode ser interrompida em cada período;

4. A permissão não muda no meio do período;

5. Uma tarefa não terminará involuntariamente.

Estas garantias são ignoradas em qualquer período onde a tarefa é bloqueada, mas continuarão no primeiro período completo no qual a thread não está bloqueada.

A Caixa de Políticas é um repositório de informações sobre como tomar decisões entre as possibilidades de QoS para as diferentes aplicações em execução. A caixa de políticas é solicitada pelo gerenciador de recursos sempre que acontece algum conflito na concessão de recursos para uma dada aplicação ou os requisitos do sistema mudam.

As decisões políticas nunca são tomadas localmente, pois a caixa de políticas é sempre consultada quando o sistema entra em sobrecarga. Além disto, como decisões são feitas no contexto de uma tarefa ainda não admitida, estas não são tomadas quando um deadline está para ser perdido. A política não é afetada nem mesmo pela ordem na qual um conjunto de threads é inicializado. O custo de consulta da caixa de políticas é pago pela tarefa solicitando admissão. Assim nenhuma tarefa terá um serviço negado ou perderá um deadline em consequência de uma situação de sobrecarga do sistema.

A Caixa de Políticas possui políticas padrões oferecidas pelo projetista do sistema, as quais podem ser omitidas ou modificadas pelo usuário segundo suas necessidades. Por exemplo, vídeo deveria ser degradado antes de áudio porque muitos usuários são mais sensíveis a qualidade do áudio. Contudo, esta situação pode ser revertida em prol de uma necessidade de vídeo superior.

Cada política contém uma ordenação relativa às threads em uso. Estas ordenações são utilizadas para computar qual entrada da lista de recursos cada thread deverá receber.

Utilizando os requisitos descritos anteriormente, o ETI RD oferece as seguintes vantagens em comparação com outros escalonadores de tempo real soft:

- Melhor controle de admissões.

Toda tarefa admitida tem a garantia que seu deadline não será perdido. Entre os muitos sistemas que não respeitam este fato, cita-se o SMART (Cap. 2), que efetua um escalonamento com compartilhamento justo em situação de sobrecarga. O ETI RD não reserva recursos para uma tarefa que não está efetivamente utilizando-os e provê suporte para que tarefas especiais não tenham admissão negada posteriormente. 
- Melhor alocação de recursos.

As alocações de recursos são especificamente realizadas para atender às necessidades das aplicações que estão prontas para executar (estado READY) e estas alocações são baseados em unidades de quantum.

- Separação clara entre as decisões do escalonamento e qualidade de serviço (QoS).

Decisões sobre QoS são sempre feitas em um contexto global, baseando-se na caixa de políticas definida pelo usuário. As decisões políticas não são tomadas no contexto de uma única aplicação ou quando uma thread está para perder um deadline. Já as tarefas de escalonamento restringem-se aos mecanismos.

A maioria das tarefas no ETI RD são periódicas e têm características de tempo real. Algumas tarefas não possuem estas características e são chamadas tarefas esporádicas. Tarefas esporádicas são gerenciadas por um servidor esporádico, o qual é uma tarefa periódica [SSL89]. O ETI RD fornece uma interface onde qualquer tarefa periódica pode atribuir sua permissão em um período de tempo específico para outra tarefa não-periódica. O servidor esporádico mantém uma fila round robin de tarefas esporádicas no sistema e quando este é escalonado busca tarefas para executar nesta fila. Se existem tarefas esporádicas prontas para executar, o servidor esporádico atribui sua permissão em alguma quantidade fixa de tempo (geralmente $10 \mathrm{~ms}$ ) para estas tarefas e retorna para o escalonador.

Tarefas esporádicas podem executar as mesmas funções que as tarefas periódicas. A única distinção é que não existem garantias de escalonamento para uma tarefa esporádica. O desempenho de uma tarefa esporádica é uma função da quantidade de tempo ${ }^{4}$ de CPU alocado para o servidor esporádico e do número de tarefas esporádicas.

O modelo periódico não suporta adequadamente tarefas com alta freqüência e baixa latência. Requisitos de latência menores que $1 \mathrm{~ms}$ não podem ser atendidos por tarefas periódicas executando sob o ETI RD. Geralmente, estas tarefas são disparadas por uma interrupção e devem ser gerenciadas por um tratador de interrupções. O ETI RD reserva um pequeno percentual do processador para tratar interrupções. Limites devem ser impostos para manter este número pequeno para evitar o desperdício de recursos e grande o bastante para que interrupções não conflitem com os deadlines das tarefas admitidas.

Quando uma tarefa recebe uma permissão faz-se uma chamada de retorno para a função nomeada na entrada da lista de recursos. O conteúdo da pilha é removido antes da chamada, e os argumentos da chamada incluem se a chamada anterior foi completada, a soma dos recursos usados na chamada anterior e um indicador de qual permissão tem sido atribuída para este período. Este procedimento explica como a permissão inicial para uma tarefa admitida é sempre liberada.

Visto que tarefas do sistema tèm diferentes períodos e requisitos de CPU, torna-se necessário interromper as tarefas com maiores requisitos de CPU e períodos. Preempções

\footnotetext{
${ }^{4}$ Fatia de tempo que pode ser modificada através da caixa de políticas.
} 
são caras. Além da sobrecarga de trocas de contexto, o estado da cache pode também ser perdido. Para minimizar o custo de preempções é fornecido um mecanismo com o qual uma tarefa com comportamento previsível pode executar preempções controladas.

O ETI RD diferencia entre preempções voluntárias e involutárias. Uma preempção involutária ocorre em uma troca de contexto normal, quando o processador está sendo dado a uma outra tarefa. Uma preempção voluntária ocorre quando uma tarefa bloqueia, por exemplo, nas operações de I/O. A preempção voluntária também ocorre quando uma tarefa voluntariamente libera o processador porque o escalonador deve fazer uma troca de contexto.

Para executar preempções controladas, a tarefa notifica o gerenciador de recursos da sua intenção, e este avisa o escalonador. Quando o escalonador precisa interromper a tarefa, define-se um marcador indicando que uma troca de contexto é necessária, a tarefa é notificada e determina-se uma interrupção de clock para um período adicional concedido a mesma. Antes deste período adicional terminar, a tarefa deve notar que está neste tipo de período e voluntariamente se interromper liberando o processador. Se o período adicional termina antes da liberação do processador pela tarefa, esta é involuntariamente interrompida.

O período adicional efetivamente deixa uma tarefa executar em um tempo alocado para outra tarefa, a qual é adiada. Além disto, a tarefa executando em um período adicional é penalizada pelos recursos usados. Por isto é essencial manter um período adicional tão curto quanto possível. Por outro lado, mais freqüentemente as aplicações devem checar por preempções, mais restrições são impostas aos seus códigos, isto para que possam estar preparadas para liberar o processador. Permanece em aberto a determinação do tamanho ótimo para um período adicional.

O ETI RD é o único que fornece garantias de escalonamento para um conjunto dinâmico de aplicações sem disperdiçar recursos. Como outros sistemas de tempo real soft, o ETI RD suporta criação dinâmica de tarefas e a possibilidade de overload. Como sistemas de tempo real hard o ETI RD fornece garantias considerando os recursos que estarão disponíveis para uma tarefa e os momentos nos quais estes recursos serão fornecidos.

Além disto, um controle prático de decisões políticas de QoS, mesmo no tratamento de um conjunto de tarefas dinâmico com rígidos requisitos de tempo real, é também unicamente fornecido pelo ETI RD. Segundo os seus autores, este sistema tem um baixo custo de tempo de execução.

Alguns aspectos do ETI RD permanecem em aberto para pesquisas adicionais, entre eles cita-se:

- Melhor integração de mais recursos.

A implementação atual do ETI RD suporta CPU, FFL • Data Streamer, mas não gerencia especificamente a largura de banda como um recurso nem a memória. Isto 
porque todo recurso adicional aumenta a complexidade dos algoritmos.

- Caminhos para modificações de políticas.

Determinar quando é razoável mudar a caixa de políticas e quando deveriam ocorrer modificações sem afetar as atuais garantias de escalonamento.

\subsubsection{Paradigma Baseado em Reserva de Recursos}

O paradigma de reserva de recursos garante a alocação para as aplicações antes delas executarem e não há participação da aplicação na decisão do escalonador. Caso alguma aplicação deseje executar e não haja recursos suficientes disponíveis, esta não será executada mesmo que o usuário esteja disposto a aceitar a degradação de desempenho.

Michael Jones et. al [JRR97] descreve um escalonador de tempo real implementado como parte do sistema operacional Rialto da Microsoft, o qual permite que múltiplas aplicações de tempo real independentes executem eficientemente e de maneira previsível na mesma máquina, juntamente com aplicações timesharing tradicionais. Três abstrações são fundamentais para este objetivo:

- Atividades

- Reserva de CPU

- Restrição de Tempo

Um objeto atividade [JLDJSB95] é a abstração para qual recursos são alocados e contra a qual o uso de recursos é cobrado. Normalmente, cada programa ou aplicação é associado com uma atividade separada.

Reservas de CPU são realizadas por atividades para assegurar granularidade e uma taxa de execução mínima. Solicitações de reserva de CPU são da forma: reserve $X$ unidades de tempo em cada $Y$ unidades para atividade $A$. Reservas no Rialto são garantidas continuamente. Se A tem uma reserva de $\mathrm{X}$ unidades em cada $\mathrm{Y}$, então para todo tempo $T$, A será executada pelo menos $\mathrm{X}$ unidades de tempo no intervalo $[T, T+Y]$, desde que esteja pronta para executar.

Uma restrição de tempo é uma solicitação dinâmica gerada por uma thread para o escalonador para que o código associado com aquela restrição seja executado no intervalo entre o instante inicial e o deadline. A solicitação também possui um limite superior do tempo de execução do código.

A análise de viabilidade (feasibility) é realizada para todas restrições de tempo quando são submetidas, incluindo aquelas com um instante inicial posterior. Para a thread solicitante garante-se o tempo suficiente para a realização do trabalho desejado ou informa-se 
que a solicitação é inviável, permitindo que a thread tenha ações alternativas para a restrição não satisfeita.

Quando uma thread efetua uma chamada indicando que completou uma restrição de tempo, o escalonador retorna a quantidade real de tempo de execução que o código consumiu como um resultado para aquela chamada. Isto fornece uma base para computar estimativas apuradas do tempo de execução para subsequentes solicitações.

O escalonador desenvolvido por Jones et. al objetiva executar concorrentemente diversos conjuntos de aplicações na mesma máquina, satisfazendo os requisitos de tempo real para aquelas em que isto é possível, enquanto fornecendo garantias de execução para aplicações convencionais. Outros objetivos ainda não mencionados são:

- Baixa sobrecarga de escalonamento - O tempo para realizar decisões de escalonamentos deve ser pequeno e previsível, preferencialmente não aumentando quando cresce o número de threads.

- Compartilhamento justo do tempo disponível - O tempo de CPU não reservado ou não utilizado por uma atividade de tempo real deve ser compartilhado entre todas as atividades (tempo real ou convencional).

- Justiça para threads dentro de uma atividade - Em uma atividade, threads executáveis e que não usam restrições de tempo devem receber quantidades semelhantes de CPU.

- Melhor esforço para garantir reservas de CPU para atividades brevemente bloqueadas - Enquanto reservas de CPU são somente garantidas para atividades que não bloqueiam, muitas aplicações bloqueiam inevitavelmente por pequenos períodos devido à sincronização e I/O. Se possível, atividades brevemente bloqueadas e com risco de não obter suas reservas de CPU devem receber a CPU quando estiverem prontas para executar.

- Melhor esforço para satisfazer as restrições de tempo negadas - Em algumas situações, existe tempo insuficiente para garantir a execução de uma restrição de tempo, mas na verdade, tempo suficiente existirá para executá-las. Se possível, threads com restrições de tempo negadas devem preferencialmente serem escalonadas para aumentar suas chances de sucesso.

- Melhor esforço para finalizar uma restrição de tempo subestimada - Em alguns casos, aplicações subestimam a quantidade de tempo necessária por uma restrição de tempo. Se possível, threads com restrições que ultrapassam suas estimativas devem ser preferencialmente escalonadas para finalizarem tào cedo quanto possível.

Aplicações de tempo real em um ambiente dinâmico não podem confiar em análise de escalonamento off-line porque a disponibilidade de recursos pode mudar durante a execução e devido ao desconhecimento de fatores como velocidade da CPU, memória, caches entre outros. Assim. um dos requisitos deste modelo foi que as aplicações de tempo 


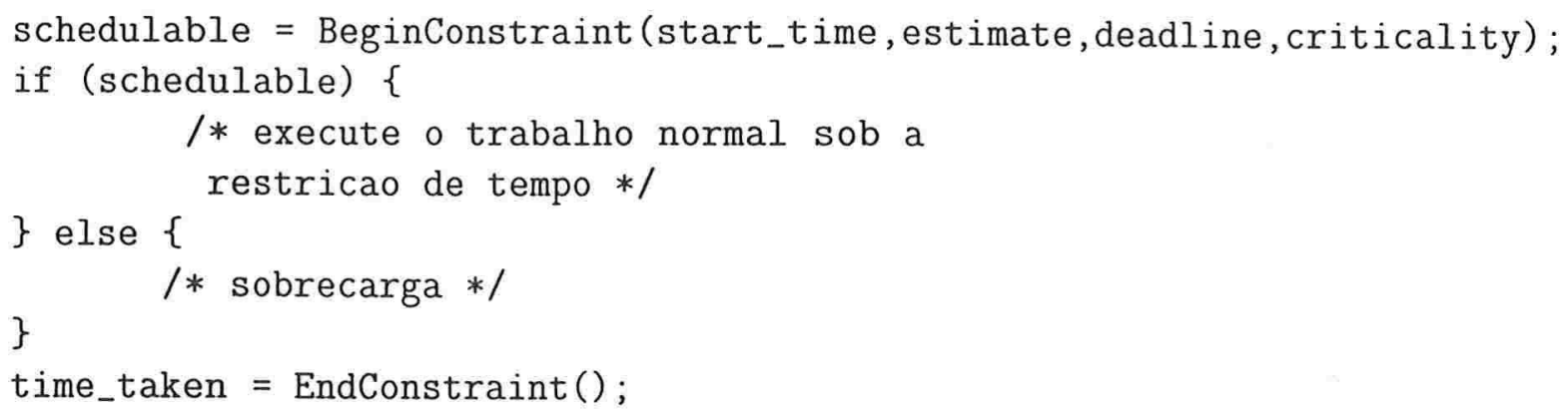

Figura 5.1: Programação com restrição de tempo

real conheçam as suas restrições e possam adaptar-se ao ambiente que estão executando. Conseqüentemente, aplicações de tempo real devem monitorar seu próprio desempenho e consumo de recursos modificando o seu procedimento e requisições de recursos até que obtenha um desempenho satisfatório. Deste modo, o sistema permite que as aplicações monitorem seu próprio uso de recursos e reservem recursos que elas necessitam para um desempenho previsível.

Aplicações por default executam dentro de suas próprias atividades permitindo que os recursos destinados para cada atividade sejam gerenciados independentemente. É importante observar que uma aplicação pode alocar múltiplas atividades com diferentes quantidade de CPU. O próprio sistema operacional Rialto é um processo que utiliza duas atividades com distintas reservas de CPU.

As threads dentro de cada atividade são escalonadas por round-robin a menos que exista uma restrição de tempo ou uma primitiva de sincronização de threads alterando este comportamento padrão. Além disto, é importante ressaltar que quando não há mais threads para executar, a atividade é bloqueada e estas atividades não acumulam créditos pelo tempo reservado mas não usado. Este tempo não usado é fornecido para outros processos que estão executando. As atividades podem solicitar, a qualquer instante, a quantidade total de CPU que ela consumiu deste sua criação (time_taken). Isto fornece uma base de consumo de CPL para as aplicações, possibilitando que estas possam adaptar suas requisições de reserva de CPU.

A figura 5.1 ilustra como uma aplicação pode requisitar que um pedaço de código seja executado em um deadline específico. Os parâmetros desta solicitação são comentados a seguir.

Os parâmetros start_time e deadline são diretamente calculados uma vez que dependem de como o código foi implementado e do que a aplicação executa. O parâmetro estimate (estimativa do tempo de execução) é mais difícil. Uma superestimativa deste valor aumenta o risco das restriçōes serem negadas. Este campo é calculado baseando-se em feedback de execuçōes anteriores deste código. Em particular, a variável time_taken 


\begin{tabular}{|c|c|c|c|c|c|c|}
\hline \hline Atividade & A & B & C & D & E & F \\
\hline \hline Quantidade & $4 \mathrm{~ms}$ & $3 \mathrm{~ms}$ & $2 \mathrm{~ms}$ & $1 \mathrm{~ms}$ & $1 \mathrm{~ms}$ & $5 \mathrm{~ms}$ \\
\hline Período & $20 \mathrm{~ms}$ & $10 \mathrm{~ms}$ & $40 \mathrm{~ms}$ & $20 \mathrm{~ms}$ & $10 \mathrm{~ms}$ & $40 \mathrm{~ms}$ \\
\hline \hline
\end{tabular}

Tabela 5.1: Tabela de Atividades

provê a base para este feedback.

O parâmetro criticality é usado para fazer a distinção entre threads dentro de cada atividade e assume dois valores: CRITICAL e NONCRITICAL. Este campo existe porque podem ocorrer algumas situações onde nem todas as restrições requisitadas possam ser satisfeitas e a aplicação pode utilizar-se deste campo para informar ao escalonador as restrições mais importantes.

A chave para que aplicações independentes sejam executadas concorrentemente é que nenhuma coordenação global deve existir entre elas. No Rialto, nenhuma coordenação é necessária porque os requisitos de tempo real são especificados usando apenas informações da aplicação. A quantidade de tempo de CPU que uma aplicação necessita é uma propriedade da aplicação em particular e não de todo o sistema. É esta propriedade que permite que o sistema operacional Rialto execute aplicações de tempo real e convencionais juntas, sem nenhuma mudança global ou coordenação.

Os aspectos principais da implementação do escalonador são discutidos a seguir:

- Grafo de escalonamento pré-computado - O fundamento básico deste escalonamento é a habilidade de pré-computar uma classificação repetitiva de maneira que todas as reservas de CPU aceitas possam ser atendidas continuamente e análises corretas de viabilidade das restrições de tempo possam ser realizadas. Esta classificação deve ser representada em uma estrutura de dados que possa ser usada em tempo de execução para decidir, em tempo limitado por uma constante, qual a próxima atividade a executar. No Rialto, esta classsificação é representada por uma árvore binária, ainda que mais geralmente esta classificação poderia ser um grafo dirigido. A Fig. 5.2 exibe um grafo de escalonamento para seis atividades com as reservas apresentadas na Tab. 5.1.

Cada nó do grafo representa um intervalo de tempo periódico que é dedicado a execução de uma atividade específica ou que está livre. Por exemplo, o nó mais a esquerda dedica $3 \mathrm{~ms}$ para a execução da atividade B. Cada caminho da esquerda para a direita no grafo tem o mesmo comprimento, isto é, 10ms. Este comprimento é o período base do grafo de escalonamento e corresponde ao período mínimo de reserva ativo.

O escalonador repetidamente percorre o grafo da esquerda para a direita, alternando escolhas cada vez que um ponto de ramificação é alcançado. Quando o lado direito 


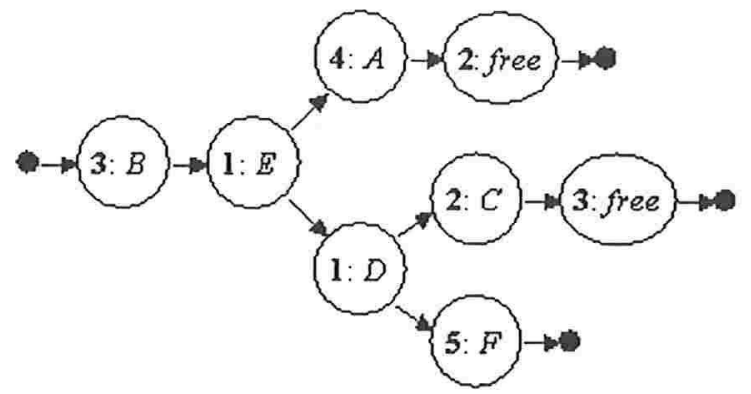

Figura 5.2: Grafo de Escalonamento com um Período Base de $10 \mathrm{~ms}$

do grafo é alcançado, o percurso segue retornando-se ao lado esquerdo do grafo. Neste exemplo a ordem de execução do escalonador é:

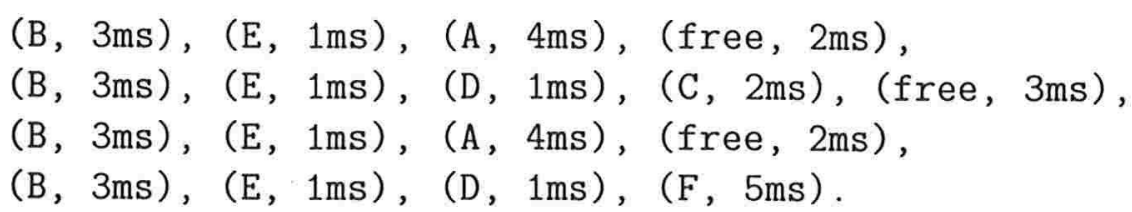

O procedimento acima é sempre repetido pelo escalonador.

Os tempos de execução associados com os nós do grafo são periódicos e fixos durante toda a existência do grafo. Por exemplo, se a atividade D é escalonada primeiro para executar durante o intervalo de tempo $[T, T+1 \mathrm{~ms}]$, esta também executará durante os intervalos $[T+20 m s, T+21 m s],[T+40 m s, T+41 m s]$ e assim por diante. É claro que quando uma interrupção ocorre, a atividade recebe menos tempo do que o planejado.

Cada nó depois de um ponto de ramificação no grafo é escalonado somente metade das vezes do que aquele que o precede. Por exemplo, a atividade A é apenas escalonada a cada $20 \mathrm{~ms}$, metade da atividade E. Diferentemente, a atividade C é escalonada a cada $40 \mathrm{~ms}$, metade da atividade D. Isto possibilita o escalonamento de reservas com períodos diferentes usando o mesmo grafo, desde que cada período de reserva seja um múltiplo potência de dois do período base. As reservas cujos períodos não são um múltiplo deste tipo são normalizadas e escalonadas para o próximo menor múltiplo potência de dois do período base. Por exemplo, a atividade A pode ter originalmente solicitado $6 \mathrm{~ms}$ a cada $30 \mathrm{~ms}$ mas porque o período base do grafo é $10 \mathrm{~ms}$, sua reserva foi garantida para $4 \mathrm{~ms}$ em cada $20 \mathrm{~ms}$, o mesmo percentual de CPU mas com uma freqüencia maior.

O grafo de escalonamento deve ser atualizado de acordo com as mudanças das reservas de CPU. O critério usado na construção do grafo inclui minimizar o número de trocas de contexto entre atividades e maximizar as fatias de tempo. O grafo é construído para permitir um tempo suficiente para as trocas de contexto entre os nós. 


\begin{tabular}{|l|c|c|c|c|c|}
\hline \hline & Atividade & Instante de Geração & Estimativa & Tempo Inicial & Deadline \\
\hline \hline$C_{1}$ & $\mathrm{~A}$ & $205 \mathrm{~ms}$ & $11 \mathrm{~ms}$ & $230 \mathrm{~ms}$ & $270 \mathrm{~ms}$ \\
\hline$C_{2}$ & $\mathrm{E}$ & $213 \mathrm{~ms}$ & $11 \mathrm{~ms}$ & $215 \mathrm{~ms}$ & $265 \mathrm{~ms}$ \\
\hline$C_{3}$ & $\mathrm{~A}$ & $225 \mathrm{~ms}$ & $10 \mathrm{~ms}$ & $225 \mathrm{~ms}$ & $270 \mathrm{~ms}$ \\
\hline \hline
\end{tabular}

Tabela 5.2: Restrições de Tempo

\begin{tabular}{|c|c|c|c|}
\hline \hline Intervalo do Nó & Atividade & 205ms & 213ms \\
\hline \hline $204-208$ & $\mathrm{~A}$ & & \\
\hline $208-210$ & free & & \\
\hline $213-214$ & $\mathrm{E}$ & & \\
\hline $217-220$ & free & & $C_{2}(3)$ \\
\hline $223-224$ & $\mathrm{E}$ & & $C_{2}(1)$ \\
\hline $224-228$ & $\mathrm{~A}$ & & \\
\hline $228-230$ & free & & $C_{2}(2)$ \\
\hline $233-234$ & $\mathrm{E}$ & & $C_{2}(1)$ \\
\hline $243-244$ & $\mathrm{E}$ & & $C_{2}(1)$ \\
\hline $244-248$ & $\mathrm{~A}$ & $C_{1}(4)$ & $C_{1}(4)$ \\
\hline $248-250$ & free & $C_{1}(2)$ & $C_{1}(2)$ \\
\hline $253-254$ & $\mathrm{E}$ & & $C_{2}(1)$ \\
\hline $257-260$ & free & $C_{1}(1)$ & $C_{1}(1), C_{2}(1)$ \\
\hline $263-264$ & $\mathrm{E}$ & & $C_{2}(1)$ \\
\hline $264-268$ & $\mathrm{~A}$ & $C_{1}(4)$ & $C_{1}(4)$ \\
\hline $268-270$ & free & & \\
\hline \hline
\end{tabular}

Tabela 5.3: Atribuições de Intervalos

- Atribuição de intervalo de tempo - O escalonador analisa a viabilidade de cada restrição de tempo quando uma thread a submete. Se a restrição é viável, a chamada BeginConstraint() retorna um status de sucesso e o escalonador promete que pelo menos a quantidade estimada de tempo foi reservada para a execução da restrição entre o instante inicial e o deadline especificados. Caso contrário, um status diferente é retornado e nenhum tempo é reservado. Análises de viabilidade de restrições e reservas de tempo para restrições aceitas são realizadas usando estruturas de dados para atribuição de intervalo de tempo.

Associada a cada nó no grafo de escalonamento tem-se uma lista (possivelmente vazia) de registros de atribuição de intervalo, ordenados pelo instante inicial. Atribuições de intervalo são realizadas adicionando-se referências nos registros de atribuição de intervalo dos nós do grafo de escalonamento cobrindo o período de tempo do intervalo. Estes registros contêm os instantes inicial e final do intervalo atribuído 
dentro do nó, e uma referência para a restrição que está recebendo a atribuição.

Como um exemplo, suponha que as restrições de tempo da Tab. 5.2 são geradas pelas threads das atividades listadas nos tempos dados, com reservas de CPU como no exemplo da Tab. 5.1. Os próximos nós do grafo de escalonamento que são dedicados as atividades A, E ou são livres aparecem listados nas primeiras duas colunas da Tab. 5.3.

Assumindo que nenhuma atribuição de intervalo anterior foi feita para estes intervalos, a análise de viabilidade para as restrições $C_{1}$ e $C_{2}$ acontecerá, resultando nas atribuições de intervalo listadas nas últimas duas colunas, e a análise de viabilidade para $C_{3}$ não ocorrerá.

O procedimento de atribuição de intervalos primeiro determina os intervalos já dedicados às atividades solicitantes, atribuindo intervalos de nós livres somente se necessário. Esta regra explica porque para $C_{1}$ é atribuído $4 \mathrm{~ms}$ no intervalo (264 $268 \mathrm{~ms}$ ) e somente $1 \mathrm{~ms}$ do intervalo livre anterior (257 - 260ms).

A restrição $C_{3}$ não pode ser garantida, visto que esta poderia obter somente os intervalos (225 - 228ms), (259 - 260ms) e (268 - 270ms), conseguindo 6ms daqueles $10 \mathrm{~ms}$ que necessita. Quando uma análise falha, qualquer atribuição de intervalos tentada são desconsideradas.

- Execução das restrições EDF - Quando durante um percurso no grafo de escalonamento se encontra um registro de atribuição de intervalo para o instante atual, uma thread com uma restrição de tempo ativa é selecionada para executar. A thread com menor deadline entre aquelas com restrições ativas é escolhida, resultando em uma política de escalonamento EDF (Earliest Deadline First) para restrições de tempo aceitas.

Além de ser executada a partir da fila EDF, uma thread com uma restrição de tempo pode também ser executada se sua atividade é escalonada por políticas de escalonamento de atividades normais, por exemplo, durante o tempo reservado para a atividade da thread, tempo livre, ou quando outra atividade é bloqueada. Isto pode resultar em restrições finalizando mais cedo ou tendo mais tempo para terminar do que teriam com a execução EDF simplesmente.

- Política Round-Robin para threads dentro da atividade - Quando um escalonador seleciona uma atividade para executar e esta não tem restrições ativas, a próxima thread a executar é selecionada através da política Round-Robin. A thread selecionada executa até bloquear ou o tempo restante no nó do grafo ser consumido.

- Quando em um percurso no grafo de escalonamento se encontra um nó livre sem atribuição de intervalo ou com um intervalo dedicado a uma atividade bloqueada, o escalonador deve decidir que atividade escolher. Como no caso anterior, o Rialto escolhe a atividade através de uma política Round-Robin, agora entre atividades. Threads são executadas usando um quantum fixo de $10 \mathrm{~ms}$. 
Quando restrições ou reservas de CPU não são usadas, as políticas mencionadas resultam em simples timesharing, fornecendo um compartilhamento justo entre atividades e threads de cada atividade.

Segundo os autores, o sistema operacional Rialto demonstra a eficiência e praticidade de usar um grafo de escalonamento pré-computado para implementar reservas de CPU garantidas com períodos definidos pela aplicação e restrições de tempo garantidas com análise de viabilidade correta a priori. Os resultados obtidos mostram que não é necessário sacrificar eficiência para ganhar os benefícios previsíveis das reservas de CPU e restrições de tempo.

Uma vantagem destas abstrações é que a utilização correta das mesmas não exige coordenação antecipada entre aplicações que podem ser executadas concorrentemente. Porque os parâmetros para restrições de tempo e reservas de CPU são derivados somente das propriedades das aplicações, estas abstrações podem ser usadas para desenvolver aplicações de tempo real independentes que podem ser executadas concorrentemente com outra aplicação de tempo real ou com aplicações convencionais (enquanto ainda garantindo as restrições de tempo de todas as aplicações de tempo real, desde que haja recursos suficientes para isto).

Alguns sistemas têm optado pela mistura de cargas de trabalho de tempo real e $t i$ mesharing, dando suporte à execução de aplicações de tempo real através de mecanismos de alocação de CPU proporcional ao share [GGV96, Wal95] ou através de reservas de recurso [MST94a]. Entretanto, estes sistemas não oferecem meios para garantir antecipadamente que tarefas específicas respeitarão seus deadlines quando as tarefas exigem mais tempo de CPU do que seus respectivos shares podem assegurar, ou quando são postergadas por algum tempo. O Rialto combina os benefícios de sistemas operacionais atuais com a previsibilidade dos melhores sistemas de tempo real soft e trata a situação mencionada.

Comparando o Rialto com o ETI RD, este suporta períodos de qualquer tamanho, enquanto o Rialto para reduzir o número de trocas impõe que todas as aplicações tenham períodos que são múltiplos uns dos outros. O ETI RD consegue reduzir o número de trocas através de preempções gerenciadas. O custo de uma preempção gerenciada é bem menor do que uma troca de contexto involuntária, mas existe dois encargos adicionais. $\mathrm{O}$ primeiro é que uma thread deve periodicamente verificar se está em um período adicional, isto em uma freqüência suficiente para obter um estado seguro e liberar o processador antes que este período adicional termine. O segundo encargo, e de maior custo, é atribuído ao sistema operacional, o qual deve notificar a thread que está executando em um período adicional:

\subsubsection{Paradigma Baseado em Fatias (shares) Proporcionais}

No paradigma de alocação de recursos proporcional ao share, os clientes recebem recursos de acordo com seu share. o qual é uma abstração utilizada para expressar a fração dos 
recursos destinados a cada aplicação.

Ion Stoica et. al em [SAWJ+96] propõem e analisam um algoritmo de alocação de recursos proporcional ao share para obter melhoria de desempenho nas aplicações de tempo real em sistemas time-sharing. Em um sistema de alocação proporcional ao seu share a todo processo no sistema é garantido fảzer alguma computação a uma taxa bem definida e uniforme. Formalmente, a cada processo é associado um share do processador (um percentual da capacidade total do processador). Se um share de um processo é $s$ então em qualquer intervalo de tempo de tamanho $t$ é garantido ao processo receber entre $(s \cdot t)-\epsilon$ e $(s \cdot t)+\epsilon$ unidades de tempo do processador onde $0 \leq \epsilon \leq \delta$, para alguma constante $\delta$. A alocação de recursos sob o paradigma de share proporcional é flexível e o share recebido por um processo pode ser modificado dinamicamente. Desta maneira, a razão de progresso de tempo real de um processo pode ser explicitamente controlada.

Esta proposta de alocação de recursos proporcional ao share difere daqueles métodos tradicionais de integração de processos de tempo real e convencionais, pois estas tarefas são tratadas de maneira idêntica. Assim, em termos do modelo de processos, nenhum suporte especial é exigido para a computação de tempo real (existe somente um tipo de processo). O algoritmo proposto aloca recursos em unidades discretas ou quanta, como muitos algoritmos de escalonamento em sistema timesharing. Isto facilita a implementação, pois políticas de tempo real tradicionais são geralmente orientadas a eventos e exigem suporte para interromper processos de maneira arbitrária. Adicionalmente, algoritmos de share proporcional fornecem um meio natural de degradar o sistema uniformemente em situações de sobrecarga.

O escalonador de alocação de recursos proporcional ao share projetado por Ion Stoica e seus colaboradores, fornece uma abordagem unificada para aplicações batch, interativas e de tempo real. Isto é alcançado atendendo uniformemente as solicitações sem considerar os tipos das aplicações em uma seqüência de requisições para um recurso. O algoritmo desenvolvido garante que a diferença entre o tempo de serviço que um cliente deveria receber em um sistema idealizado e o tempo de serviço que este realmente recebe em um sistema de tempo real é limitado por um quantum de tempo, o qual é um limite ótimo.

Este sistema consiste de um conjunto de processos, de tempo real e convencional, que competem por recursos de tempo compartilhado tal como uma CPU ou um canal de comunicação. Neste modelo, processos são entitulados clientes. Um cliente é dito ativo enquanto está competindo pelo recurso, e passivo caso contrário. Supõe-se que o recurso é alocado em quanta de tempo de tamanho no máximo q. No início de cada quantum de tempo, um cliente é selecionado para usar o recurso. Desde que o cliente adquira o processador, pode utilizá-lo por todo o quantum de tempo ou liberá-lo antes deste tempo acabar.

Ainda explicando os conceitos utilizados no sistema sendo comentado, tem-se que a cada cliente é associado um peso que determina o share de recursos que deve ser recebido. Define-se $w_{i}$ como o peso associado ao cliente $i, A(t)$ o conjunto de todos os clientes ativos no instante $t$ e $f_{i}(t)$ como: 


$$
f_{i}(t)=\frac{w_{i}}{\sum_{j \in A(t)} w_{j}}
$$

o qual é o share instantâneo de um cliente ativo $i$ no instante $t$.

Se o share do cliente permanece constante durante um intervalo de tempo $[t, t+\Delta t]$, então este é designado para usar o recurso por $f_{i}(t) \Delta t$ unidades de tempo. Em geral, quando o share do cliente varia com o tempo, o tempo de serviço em unidades de tempo que o cliente $i$ deveria receber em um sistema de justiça perfeita é:

$$
S_{i}\left(t_{0}, t_{1}\right)=\int_{t_{0}}^{t_{1}} f_{i}(\tau) d \tau,
$$

enquanto ativo por um intervalo de tempo $\left[t_{0}, t_{1}\right]$.

A equação acima corresponde a um sistema de fluxo ideal no qual o recurso pode ser garantido em intervalos de tempo arbitrariamente pequenos. Infelizmente, em muitas situações práticas isto não é possível. Uma das razões é a sobrecarga introduzida pelo próprio algoritmo de escalonamento e pela troca de contexto entre clientes. Outro motivo é que algumas operações não podem ser interrompidas, isto é, uma vez inicializadas devem completar no mesmo quantum de tempo. Por exemplo, em alguns cenários, um processo não pode ser interrompido enquanto está em uma seção crítica e neste caso pode-se escolher o tamanho de um quantum $q$ como sendo a duração máxima de um processo em uma seção crítica.

Devido a quantização, em um sistema no qual o recurso é alocado em quanta de tempo discretos não é possível para um cliente sempre receber exatamente o tempo de serviço designado para o mesmo. A diferença entre o tempo de serviço que deve receber em um instante $t$, e o tempo de serviço que o cliente realmente recebe é chamado tempo de serviço lag.

Sejam $t_{0}^{i}$ o tempo no qual o cliente $i$ torna-se ativo e $s_{i}\left(t_{0}^{i}, t\right)$ o tempo de serviço que o cliente recebe no intervalo $\left[t_{0}^{i}, t\right]$. Então o lag do cliente $i$ no instante $t$ é

$$
\operatorname{lag}_{i}(t)=S_{i}\left(t_{0}^{i}, t\right)-s_{i}\left(t_{0}^{i}, t\right)
$$

Visto que lag quantifica a corretude de alocação, utiliza-se este dado como o principal parâmetro na caracterização do algoritmo proporcional ao share proposto por Ion Stoica et. al, o EEVDF (Earliest Eligible Virtual Deadline First).

No algoritmo EEVDF um cliente deve especificar a duração do tempo de serviço quando solicitar um recurso. Atendida a solicitação efetuada, o cliente pode fazer um novo pedido ou tornar-se passivo. O algoritmo de escalonamento foi formulado baseado no procedimento de um sistema de fluxo ideal que executa clientes em um domínio de tempo virtual. Abstratamente, o sistema de fluxo virtual executa cada cliente por $w_{i}$ unidades 
de tempo real durante cada unidade de tempo virtual. Formalmente, tempo virtual é definido pela seguinte função de tempo real

$$
V(t)=\int_{0}^{t} \frac{1}{\sum_{j \in A(\tau)} w_{j}} d \tau .
$$

Observe que o tempo virtual aumenta a uma razão inversamente proporcional a soma dos pesos de todos os clientes ativos. Quando a competição aumenta o tempo virtual decresce lentamente e quando a competição diminui o tempo virtual aumenta. Intuitivamente, o fluxo de tempo virtual muda para alocar todos os clientes ativos em uma unidade de tempo virtual. Em outras palavras, o tamanho de uma unidade de tempo virtual é modificado tal que no sistema de fluxo correspondente cada cliente ativo $i$ recebe $w_{i}$ unidades de tempo real durante uma unidade de tempo virtual. Por exemplo, considere dois clientes com pesos $w_{1}=2$ e $w_{2}=3$. Então, relativo ao tempo real, a razão na qual o tempo virtual aumenta é $\frac{1}{w_{1}+w_{2}}=0.2$. E assim uma unidade de tempo virtual é igual a cinco unidades de tempo real. Desta maneira, em cada unidade de tempo virtual os dois clientes devem receber $w_{1}=2$ e $w_{2}=3$ unidades de tempo.

Combinando as Eq. 5.1 e 5.2 pode-se expressar o tempo de serviço que um cliente ativo $i$ deveria receber no intervalo $\left[t_{1}, t_{2}\right)$ como:

$$
S_{i}\left(t_{1}, t_{2}\right)=w_{i} \int_{t_{1}}^{t_{2}} \frac{1}{\sum_{j \in A(\tau)} w_{j}} d \tau .
$$

Através da integral na Eq. 5.5, pode-se facilmente determinar o tempo de serviço que qualquer cliente $i$ deveria receber durante um intervalo $\left[t_{1}, t_{2}\right)$, simplesmente multiplicando o peso do cliente pelo valor da integral. Formalmente, das Eq. 5.4 e 5.5 tem-se que:

$$
S_{i}\left(t_{1}, t_{2}\right)=\left(V\left(t_{2}\right)-V\left(t_{1}\right)\right) w_{i}
$$

O algoritmo EEVDF usa medidas realizadas no domínio do tempo virtual para fazer decisões de escalonamento. Para cada solicitação de um cliente, define-se um instante elegível $e$ e um deadline $d$ que representa os instantes inicial e final para o serviço requisitado no sistema, respectivamente.

Sejam $t_{0}^{i}$ o instante no qual o cliente $i$ torna-se ativo e $t$ o instante em que este inicia uma nova solicitação. Então uma solicitação torna-se elegível no instante $e$ quando o tempo de serviço que o cliente deveria receber no sistema de fluxo $S_{i}\left(t^{0}, e\right)$ é igual ao tempo de serviço que o cliente já recebeu no sistema real $s_{i}\left(t^{0}, t\right)$. Observe que se no instante $t$ o cliente $i$ tem recebido mais tempo de serviço do que deveria receber $\left(\operatorname{lag}_{i}(t)<0\right)$, entào este é o caso em que $e>t$ e assim o cliente deve esperar até o instante $e$ antes que a nova solicitação torne-se elegível. Desta maneira, um cliente que tem recebido mais tempo de serviço do que seu share é atrasado lentamente, enquanto concede aos outros clientes ativos a oportunidade de executar. Por outro lado, se no instante $t$ o cliente $i$ 
tem recebido menos tempo de serviço do que foi determinado receber $\left(\operatorname{lag}_{i}(t)>0\right)$, então é o caso em que $e<t$ e assim a nova solicitação é imediatamente elegível no instante $t$. Se o cliente $i$ no instante $t$ tem um tempo de serviço igual ao que deveria receber então $\operatorname{lag}_{i}(t)=0$. Pela Eq. 5.6 o instante elegível virtual $V(e)$ é

$$
V(e)=V\left(t_{0}^{i}\right)+\frac{s_{i}\left(t_{0}^{i}, t\right)}{w_{i}}
$$

Similarmente, o deadline da solicitação é escolhido tal que o tempo de serviço que o cliente deveria receber entre o tempo elegível $e$ e o deadline $d$ é igual ao tempo de serviço da nova solicitação. Ou seja, $S_{i}(e, d)=r$ onde $r$ representa o tamanho da nova requisição. Novamente utilizando a Eq. 5.6, deriva-se o deadline virtual $V(d)$ como segue:

$$
V(d)=V(e)+\frac{r}{w_{i}} .
$$

Observe que embora as Eq. 5.7 e 5.8 dêem o tempo virtual elegível e o deadline virtual, não necessariamente fornecem os valores $e$ e $d$ de tempo real. Em conseqüência, o algoritmo EEVDF é formulado em termos do tempo elegível e do deadline virtuais. Desta maneira, este algoritmo pode ser simplesmente definido como: um novo quantum é alocado para o cliente que tem a solicitação elegivel com o menor deadline virtual.

Waldspurger and Weihl [Wa195], apresentam uma proposta onde os direitos aos recursos são estipulados intuitivamente usando tickets de loteria que podem até ser compartilhados. A flexibilidade desta proposta permite que as políticas de gerenciamento dos recursos possam ser definidas em vários níveis de abstração (threads, aplicações, usuários e grupos). Esta abordagem utiliza dois escalonadores: lotérico e stride. O lotérico por ser baseado na alocação proporcional ao share é descrito a seguir, enquanto o stride será comentado sob o paradigma de enfileiramento justo abordado posteriormente.

O escalonamento lotérico [WW94] é um mecanismo de alocação de recursos aleatório. Os direitos aos recursos são representados por tickets de loteria. Uma alocação é realizada após o resultado de uma loteria e os recursos são garantidos ao cliente que tem o ticket vencedor. Isto efetivamente aloca recursos para clientes competidores proporcionalmente ao número de tickets que estes possuem. Os tickets de loteria encapsulam direitos de recursos que são abstratos, relativos e uniformes.

Os direitos são abstratos porque quantificam os direitos de recursos independentemente dos detalhes da máquina, são relativos porque a fração de um recurso que representam varia dinamicamente em proporção à disputa para aquele recurso e são uniformes porque os direitos para diferentes recursos podem ser homogeniamente representados como tickets.

O escalonamento lotérico é probabilisticamente justo. A alocação de recursos esperada por um cliente é proporcional ao número de tickets que possui. Visto que o algoritmo de escalonamento é randômico, a real alocação implementada nem sempre corresponde à alocação esperada. Contudo. a disparidade entre elas decresce quando o número de 
alocações aumenta.

O número de loterias vencidas por um cliente possui uma distribuição binomial. A probabilidade $p$ que um cliente possuido $t$ tickets vencerá uma dada loteria com um total de $T$ tickets é $p=\frac{t}{T}$. Depois de $n$ loterias idênticas, o número esperado de vencedores $w$ é $E[w]=n p$, com variância $\sigma_{w}^{2}=n p(1-p)$. O coeficiente de variação para a proporção observada de vencedores é $\frac{\sigma_{w}}{E[w]}=\sqrt{(1-p) / n p}$. Assim, um throughput do cliente é proporcional a sua alocação de tickets, como corretude que aumenta com $\sqrt{n}$.

O número de loterias exigidas para uma primeira vitória do cliente tem uma distribuição geométrica. O número esperado de loterias $n$ que um cliente deve esperar antes de sua primeira vitória é $E[n]=1 / p$, com variância $\sigma_{n}^{2}=(1-p) / p^{2}$. Assim, o tempo médio de resposta de um cliente é inversamente proporcional à sua alocação de tickets.

Visto que qualquer cliente com um número de tickets diferentes de zero eventualmente vencerá uma loteria, o problema de starvation não existe. O mecanismo de loteria também opera corretamente quando o número de clientes ou tickets varia dinamicamente. Para cada alocação, a todo cliente é dada uma chance justa de vencer proporcional ao seu share do número total de tickets.

A representação explícita de direitos de recursos como tickets de loteria favorece um gerenciamento de recursos modular. Tickets podem ser usados para separar as políticas de gerenciamento de recursos de módulos independentes, porque cada ticket probabilisticamente garante ao seu proprietário o direito de consumo de um recurso mesmo no pior caso.

Uma maneira direta de implementar uma escalonador lotérico centralizado é randomicamente selecionar um ticket vencedor e então buscar em uma lista de clientes aquele que possui o ticket vencedor. Isto exige uma geração de números randômicos e $O(n)$ operações para percorrer uma lista de clientes de tamanho $n$, acumulando uma soma de tickets até encontrar o valor vencedor. Um exemplo é apresentado na Fig. 5.3; neste cinco clientes competem em uma loteria baseada em lista com um total de 20 tickets. O décimo-quinto ticket é randomicamente selecionado, e procura-se na lista de clientes o vencedor. Uma soma de tickets é acumulada até o valor do ticket vencedor ser encontrado. Neste exemplo, o terceiro cliente é o vencedor.

Para valores grandes de $n$, uma implementação mais eficiente é utilizar uma árvore de somas de tickets parcial, com clientes nas folhas. Para localizar o cliente com um ticket vencedor, caminha-se na árvore a partir da raiz até o nó folha com apenas $O(\log (n))$ operações.

Ainda no contexto da alocação de recursos proporcional ao seu share, Umesh [Mah95] propõe que para cada thread sejam alocados alguns shares e este seja executado em taxas proporcionais ao seu share. O escalonador não muda o share de cada thread mas manipula outro valor associado as mesmas, chamado de contas. O escalonador inicializa o valor da conta de cada thread com o seu share. Posteriormente, escalona as threads em round robin e cada vez que a thread recebe um quantum é deduzida uma taxa de sua conta. Durante o 


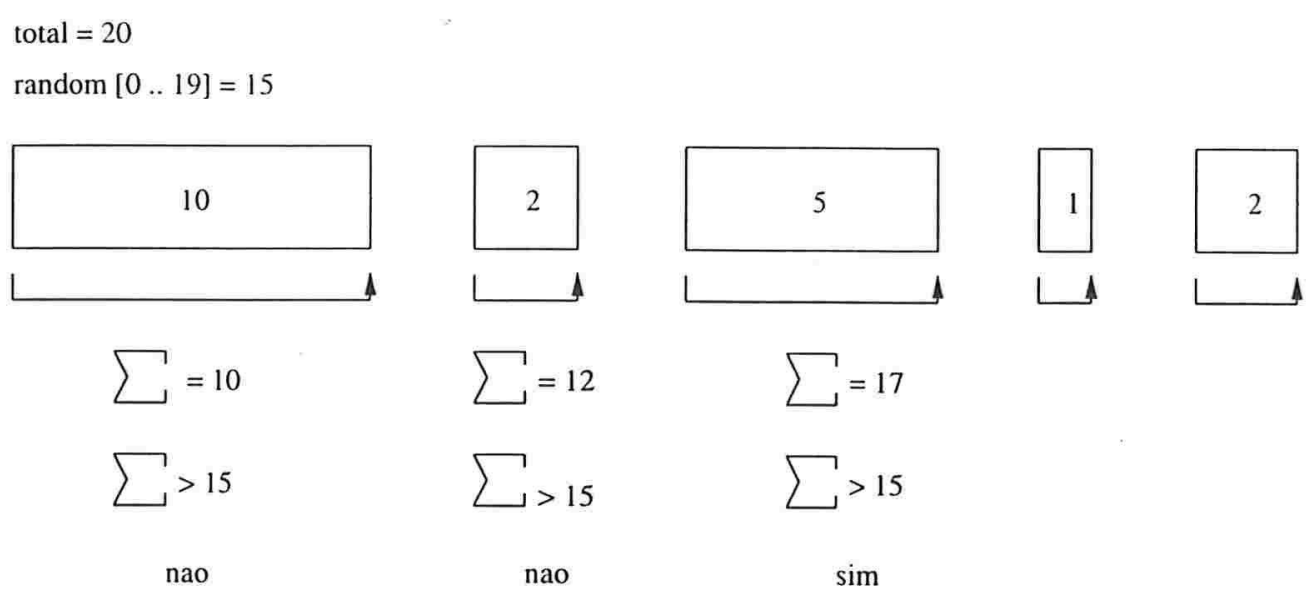

Figura 5.3: Exemplo da Loteria.

processo de escalonamento qualquer thread com uma conta negativa é descartada. Quando não há mais threads com conta positiva, o escalonador reinicializa as contas com os seus respectivos números de share.

É importante ressaltar que o LINUX-SMART (Cap. 3) tem um escalonador baseado em alocação proporcional ao share, pois quando não há recursos suficientes para atender todas as solicitações de recursos, o sistema atende todos os pedidos menores do que a quantia de share proporcional e os recursos disponíveis após esta alocação são distribuídos entre as tarefas que podem usar este excesso.

\subsubsection{Paradigma do Enfileiramento Justo}

O paradigma de enfileiramento justo também fornece um mecanismo de alocação proporcional ao share, mas neste caso utilizando adicionalmente uma política de enfileiramento justo, o qual pode ser determinado de acordo com as alocações desejadas pelo usuário [WW95] ou baseado nos requisitos de recursos das tarefas para fornecer reserva de recursos [SAWJ97]. Quando usado para fornecer reservas, uma política de controle de admissão é também usada. Ao contrário de escalonadores de reservas de recurso, o enfileiramento justo pode integrar suporte de reservas para tarefas de tempo real com share proporcional para tarefas convencionais [SAWJ97].

O escalonamento stride [Wal95, WW95] é um mecanismo de alocação determinística para recursos de tempo compartilhado. Este escalonador implementa um controle proporcional ao share sobre o tempo do processador e outros recursos. Trata-se de uma generalização dos algoritmos de rede [DKS89, Zha91, ZK91, PG93]. Nesta proposta novas técnicas são introduzidas para dar suporte eficientemente operaçōes dinâmicas, tais como modificações de alocações de tickets e mudanças no número de clientes competindo por um recurso. 


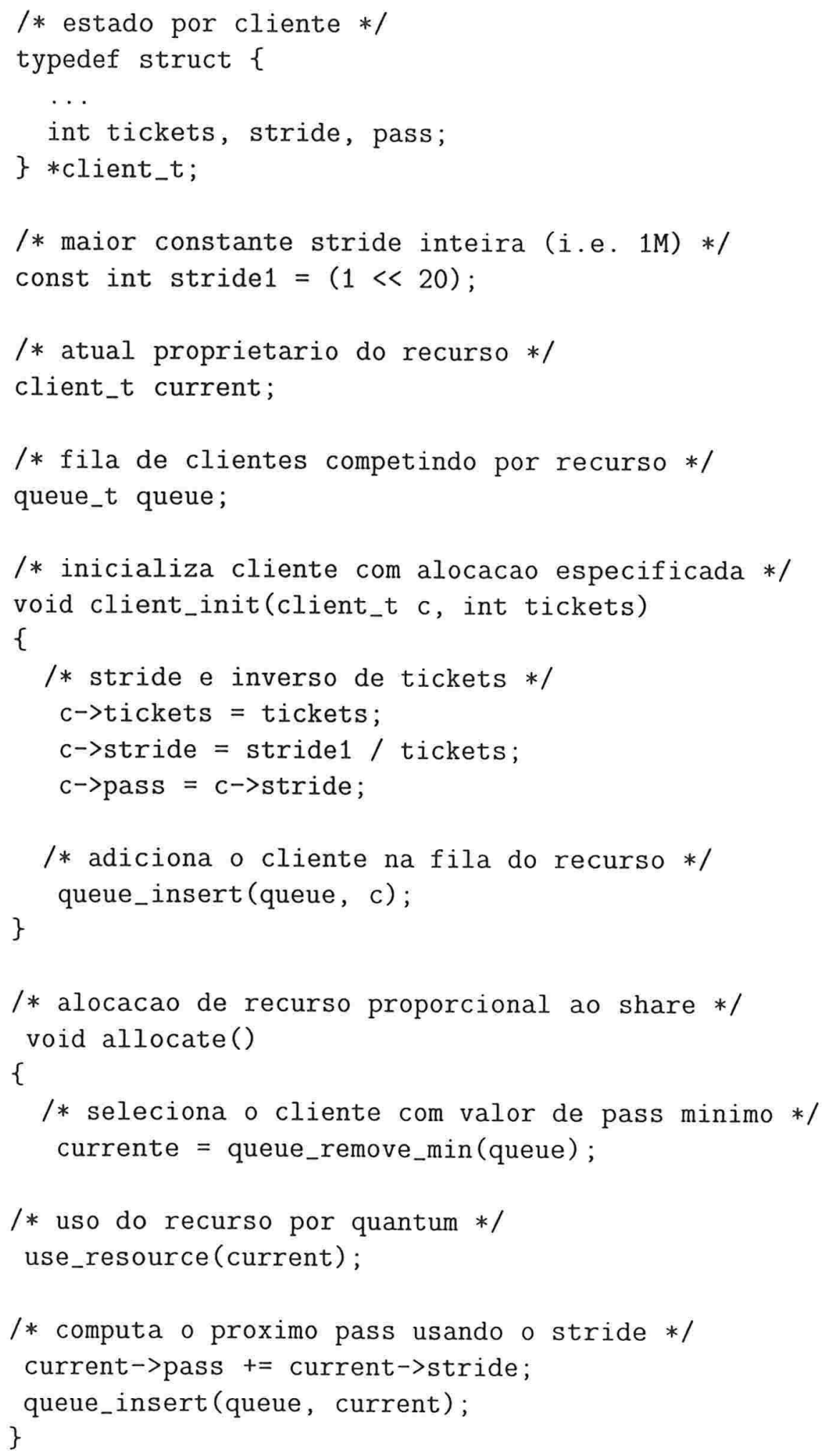

Figura 5.4: Algoritmo de Escalonamento Stride Básico. Código ANSI C para escalonar um conjunto estático de clientes. 
A idéia central do algoritmo stride é computar uma representação de intervalo de tempo, ou stride, que um cliente deve esperar entre sucessivas alocações. O cliente com o menor stride é escalonado. Um cliente com metade do stride de outro, executa duas vezes mais do que aquele cliente. Strides são representados em unidades de tempo virtual chamadas passes, ao invés de unidades de tempo real tais como segundos.

Três variáveis de estado são associadas com cada cliente: ticket, stride e pass. O campo ticket especifica a alocação de recursos do cliente, relativa a outros clientes. O campo stride é inversamente proporcional ao ticket e representa o intervalo de tempo entre seleções, medido em passes. O campo pass representa o índice de tempo virtual para próxima seleção do cliente. Executar uma alocação de recurso é simples: o cliente que possui o campo pass com o menor valor é selecionado, e seu pass é incrementado com o seu stride. Se mais do que um cliente tem um valor de pass mínimo, qualquer deles pode ser selecionado. Uma abordagem determinística razoável é usar uma ordenação consistente para solucionar os empates.

A Fig. 5.4 lista o código em ANSI C para o algoritmo de escalonamento stride básico. Por simplicidade, um conjunto estático de clientes com tickets fixos atribuídos é assumido. Estas restrições são relaxadas posteriormente para permitir um ambiente dinâmico. O estado de cada cliente deve ser inicializado através da função client_init antes de qualquer alocação efetuada pela função allocate.

O Algoritmo da Fig. 5.4 não suporta mudanças dinâmicas no número de clientes competindo por um recurso. Quando permite-se que clientes entrem e saiam da fila em qualquer instante, seus estados devem ser modificados apropriadamente. A Fig. 5.5 estende o algoritmo básico para tratar eficientemente mudanças dinâmicas em um conjunto de clientes ativos. Este algoritmo também suporta quanta não uniforme. Uma extensão chave é a adição de variáveis globais que mantêm informação agregada sobre o conjunto de clientes ativos. A variável global_tickets contém a soma total de ticket de todos os clientes ativos. A variável global_pass mantém o pass atual para o escalonador. A variável global_pass avança na razão de global_stride por quantum, onde global_stride $=$ stride $1 /$ global_tickets. A constante stride1 é um inteiro grande utilizado pelo escalonador stride para ajustar a representação em ponto fixo do campo global_stride. Para isto, além desta constante precisa-se da razão de alocação de tickets dos clientes.

Por exemplo, três clientes A, B e C estão competindo por um recurso compartilhado no tempo com uma razão de tickets igual a 3:2:1. Por simplicidade, uma constante stride $1=6$ conveniente é usada ao invés de um inteiro grande, produzindo respectivamente strides de 2,3 e 6 respectivamente.

Uma variável de estado é também associada com cada cliente para armazenar a porção restante do seu stride quando uma mudança dinâmica ocorre. O campo remain representa o número de passes que ocorrem antes da próxima seleção do cliente. Quando um cliente deixa o sistema, remain é computado como a diferença entre o pass do cliente e a variável global_pass. 


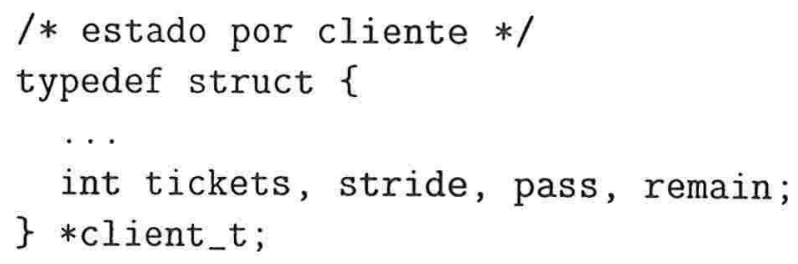




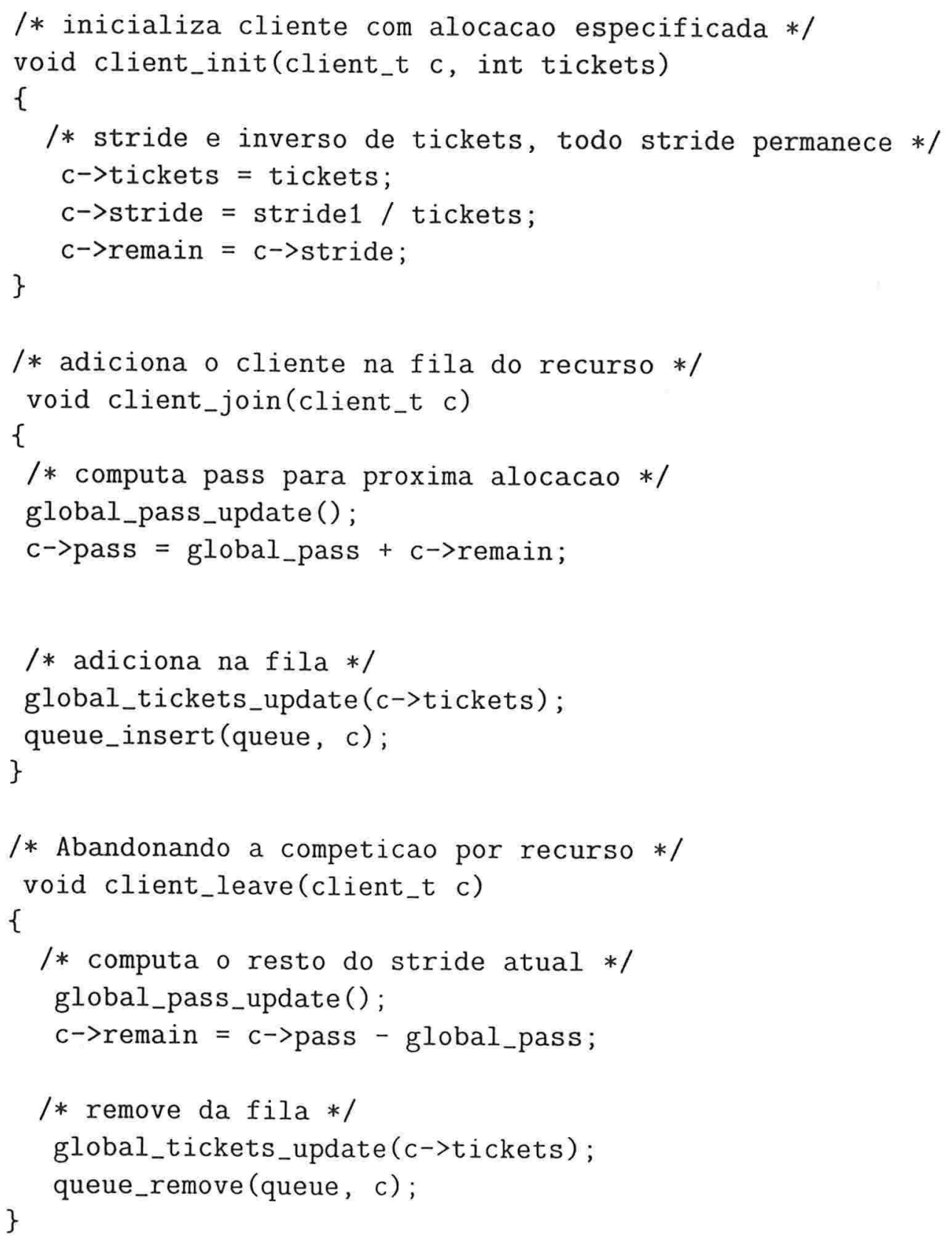




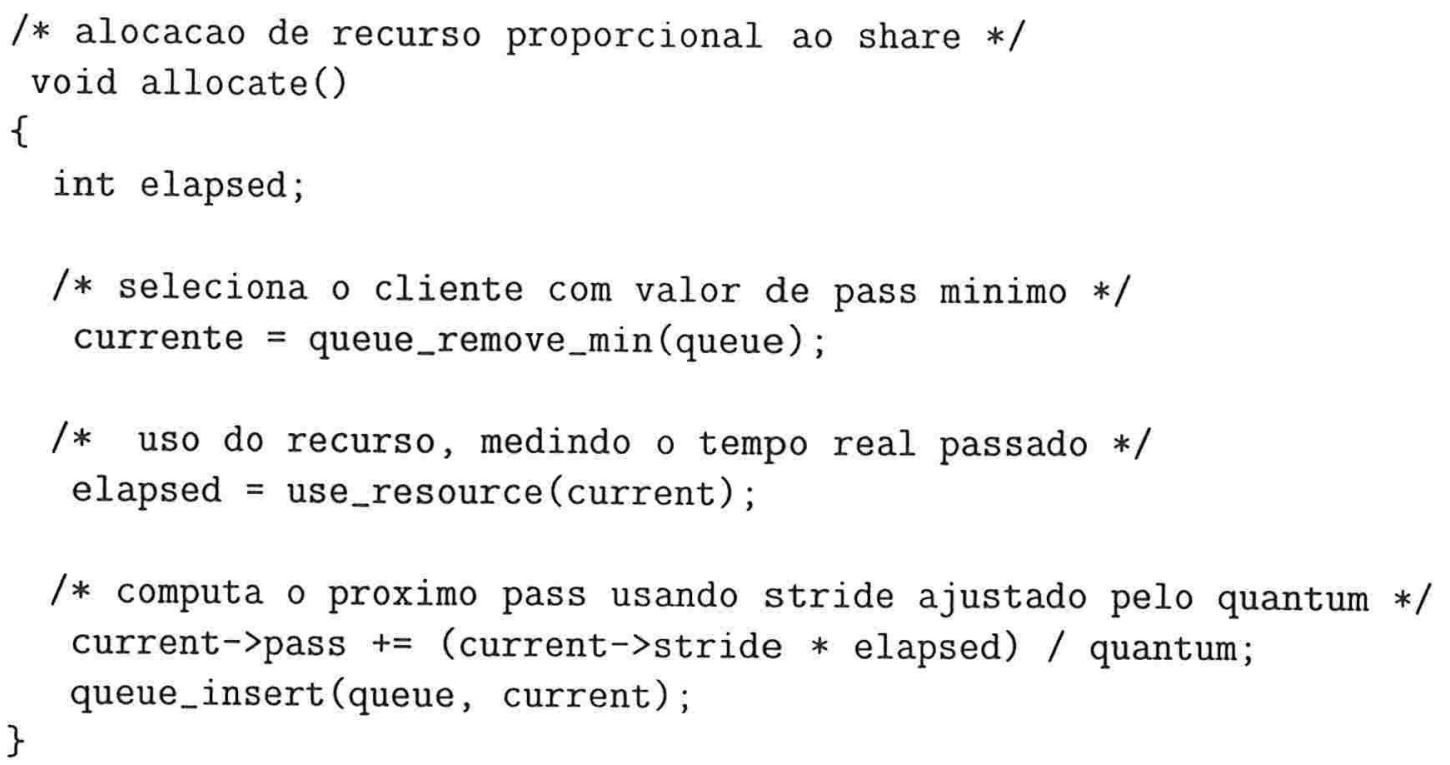

Figura 5.5: Algoritmo de Escalonamento Stride Dinâmico. Código ANSI C para operações de escalonamento stride.

Este mecanismo trata situações envolvendo erro positivo ou negativo entre o número de alocação real e aquele especificado. Se remain < stride, então o cliente recebe crédito quando junta-se novamente à fila de clientes por ter previamente esperado por parte de seu stride sem um quantum. Se remain $>$ stride, então o cliente é penalizado quando junta-se novamente à fila de clientes por ter anteriormente recebido um quantum sem esperar por todo o seu stride.

Um suporte adicional é necessário para modificar dinamicamente alocações de tickets de clientes. Quando uma alocação de cliente é dinamicamente modificada de ticket para ticket' seus valores de stride e pass devem ser recomputados. O novo stride' é calculado como antes, inversamente proporcional a ticket'. Para calcular o novo pass' a porção restante do stride do cliente atual, denotado por remain é ajustado para refletir o novo stride'. Isto é realizado normalizando remain por stride'/stride. A Fig. 5.6 apresenta o código em ANSI C que modifica dinamicamente uma alocação de tickets de um cliente.

Ainda sob a perspectiva do enfileiramento justo, desta vez utilizando pesos ${ }^{5}$, tem-se a proposta de Stoica et. al [SAW.J97]. Neste trabalho, existe também a exploração dos paradigmas de alocação de recursos proporcional ao seu share e baseados em reserva. Para expressar o share do cliente é usada a noção de peso ao invés de tickets. Usa-se dois níveis hierárquicos para classificar os processos. No mais alto nível, os processos são divididos entre as classes de share proporcional e de reserva de recursos. A idéia básica de integrar

\footnotetext{
${ }^{5}$ Neste caso, estamos tratando o Enfileiramento Justo com Pesos ou $W F Q$.
} 


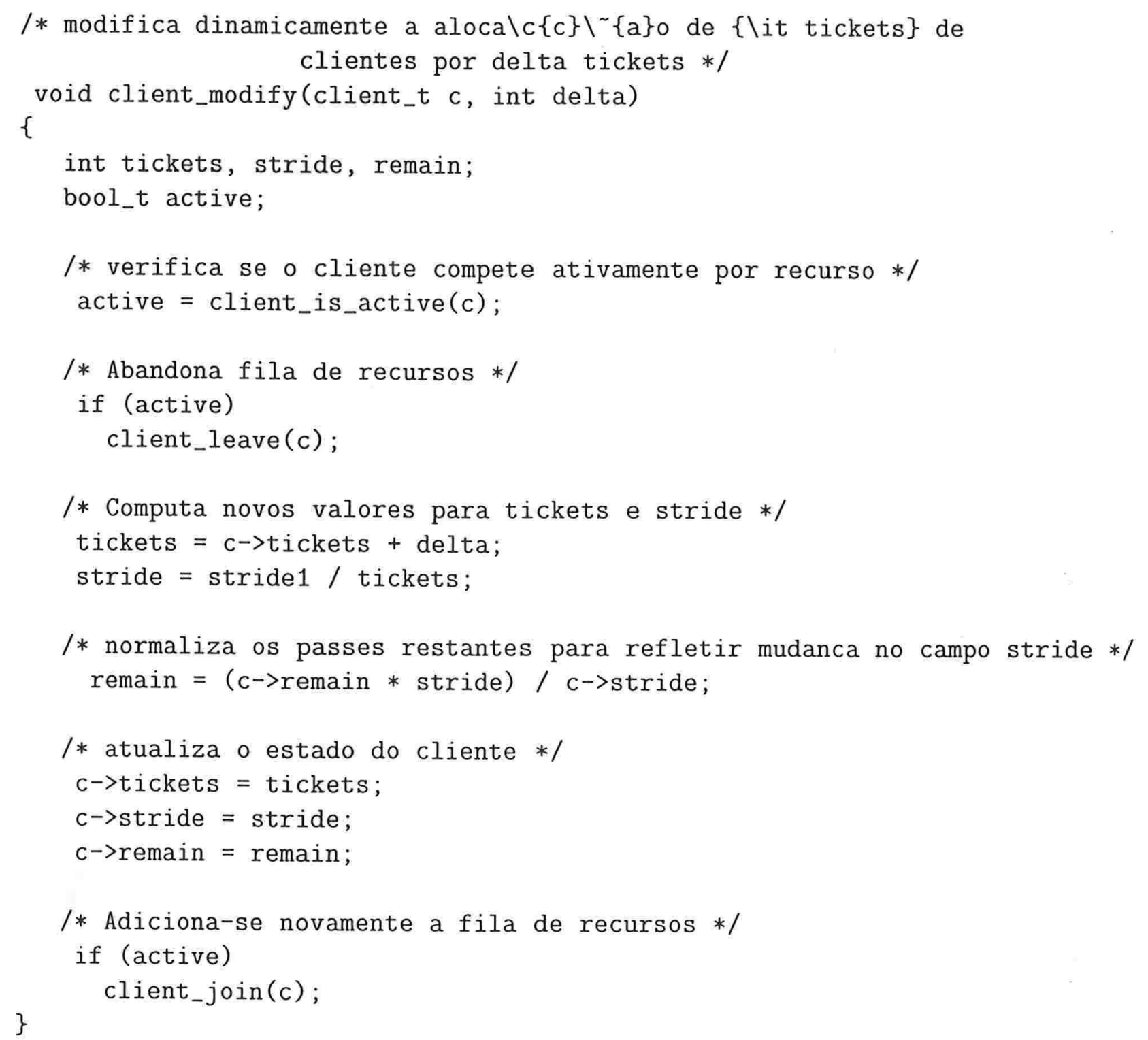

Figura 5.6: Modificação Dinâmica de tickets 
os dois paradigmas é muito simples. Ao invés de caracterizar o cliente exclusivamente pelo seu peso ou share, utiliza-se ambos simultaneamente. Em outras palavras, associa-se um par $(w, f)$ para cada cliente onde $w$ representa o peso do cliente e $f$ representa o real share de recursos que o cliente deve receber. Além do mais:

$$
f=\frac{w}{W}
$$

onde $W$ representa a soma dos pesos de todos os clientes ativos. A partir disto, se fixarmos o peso do cliente o seu share é dado pela Eq. (1). Alternativamente, se o cliente pedir por uma fração $f$ de recursos, usando a mesma equação, o peso do cliente pode ser facilmente computado por:

$$
w=\frac{W^{\prime} f}{1-f},
$$

onde W' representa a soma de todos os pesos dos outros clientes. Desta maneira por explorar o dualismo entre $w$ e $f$ pode-se alcançar alocação de share proporcional (fixando $w$ ) ou reserva (fixando $f$ ).

\subsubsection{Paradigma Baseado em Hierarquia}

Sob a perspectiva do paradigma hierárquico a banda de CPU é dividida entre classes de aplicações e estas dividem a sua fatia de recursos entre os seus componentes.

P.Goyal [GGV96], analisando os requisitos impostos pelas várias classes de aplicações suportadas por um sistema de multimídia, concluiu que:

- Aplicações de tempo real hard - Exigem um sistema operacional que garanta deterministicamente o atraso que pode ser suportado por várias tarefas. Exemplos de algoritmos que tratam estas aplicações convenientemente são Earliest Deadline First (EDF) e o Rate Monotonic Algorithm (RMA) (Seção 5.1.1).

- Aplicações de tempo real soft - Estas aplicações exigem que o sistema operacional garanta estatisticamente alguns parâmetros de QoS como delay máximo e throughput. Os algoritmos citados no item anterior não fornecem qualquer garantia de QoS quando a largura de banda da CPU está saturada. Além disto, o período e os requisitos de computação de cada thread devem ser conhecidos a priori.

Como para aplicações de tempo real soft há dificuldade em se prever os requisitos de computação necessários, estes algoritmos não são adequados para esta classe de aplicação. Um exemplo desta classe são as aplicações de vídeo. Devido ao uso de técnicas de compressão intra e inter-frames a largura de banda exigida para compressão e descompressão de frames varia bastante. Em conseqüência, um novo algoritmo de escalonamento que atenda as necessidades desta classe de aplicações precisa ser desenvolvido. 
- Aplicações best-effort - Muitas aplicações convencionais não necessitam de garantias de desempenho, mas exigem que a CPU seja alocada de maneira que o tempo médio de resposta seja baixo enquanto throughput executado seja alto. Algoritmos de escalonamento timesharing são adequados para esta classe de aplicações.

Baseando-se nas análises mencionadas, observou-se que diferentes algoritmos de escalonamento são adequados para diferentes classes de aplicações. Deste modo há a necessidade que o sistema operacional utilize diferentes escalonadores para diferentes aplicações. Adicionalmente, para viabilizar uma co-existência entre as várias classes de aplicações um mecanismo de proteção deve ser fornecido. Por exemplo, deve-se assegurar que o excesso de requisições de CPU para aplicações de tempo real soft não viole as garantias de aplicações de tempo real hard. De maneira similar, um erro de execução de aplicações hard ou soft não deve causar starvation em aplicações best-effort.

Diante da necessidade de co-existência de diferentes algoritmos de escalonamento para diferentes aplicações, Goyal et. al sugerem um particionamento da largura de banda da CPU. Especificamente, um sistema operacional deveria estar apto a particionar a largura de banda da CPU entre as várias classes de aplicações e cada uma destas por sua vez entre as suas diversas subclasses ou aplicações.

No ambiente proposto por Goyal e seus colaboradores, o particionamento hierárquico é especificado por uma árvore. Cada thread no sistema pertence a exatamente um nó folha e cada nó intermediário na árvore representa uma classe de aplicações ou uma agregação de classes de aplicações. Enquanto as threads são escalonadas de acordo com os requisitos da classe a qual pertencem, os nós intermediários são escalonados por um algoritmo que executa particionamento hierárquico. Este algoritmo deve: (1) efetuar uma distribuição justa da capacidade do processador entre os nós competidores, (2) não exigir a priori conhecimento dos requisitos computacionais das threads, (3) fornecer garantias de throughput, e (4) ser eficiente computacionalmente. Baseando-se nestas características foi desenvolvido o algoritmo Start-time Fair Queuing (SFQ), o qual atende todos os requisitos mencionados. A Fig. 5.7 ilustra a estrutura de escalonamento comentada. Neste exemplo, a classe raiz tem três subclasses: tempo real hard, tempo real soft e best-effort com pesos iguais a 1, 3 e 6 respectivamente. A largura de banda da classe best-effort foi dividida igualmente entre as classes usuário 1 e usuário 2.

Antes de comentar o algoritmo SFQ é necessário formalizar o conceito de alocação justa. Sejam $r_{f}$ o peso de uma thread $f$ e $W_{f}\left(t_{1}, t_{2}\right)$ o trabalho agregado realizado no intervalo $\left[t_{1}, t_{2}\right]$ pela CPU para a thread $f$. Por simplicidade, determinou-se que o trabalho realizado pela $\mathrm{CPU}$ para uma thread é medido em número de instruções executadas pela thread $f$. Neste contexto, uma alocação de CPU é considerada justa se, para todos os intervalos $\left[t_{1}, t_{2}\right]$ nos quais duas threads $f$ e $m$ são executáveis, o trabalho normalizado (pelo peso) recebido por elas é idêntico. Em outras palavras,

$$
\frac{W_{f}\left(t_{1}, t_{2}\right)}{r_{f}}-\frac{W_{m}\left(t_{1}, t_{2}\right)}{r_{m}}=0 .
$$




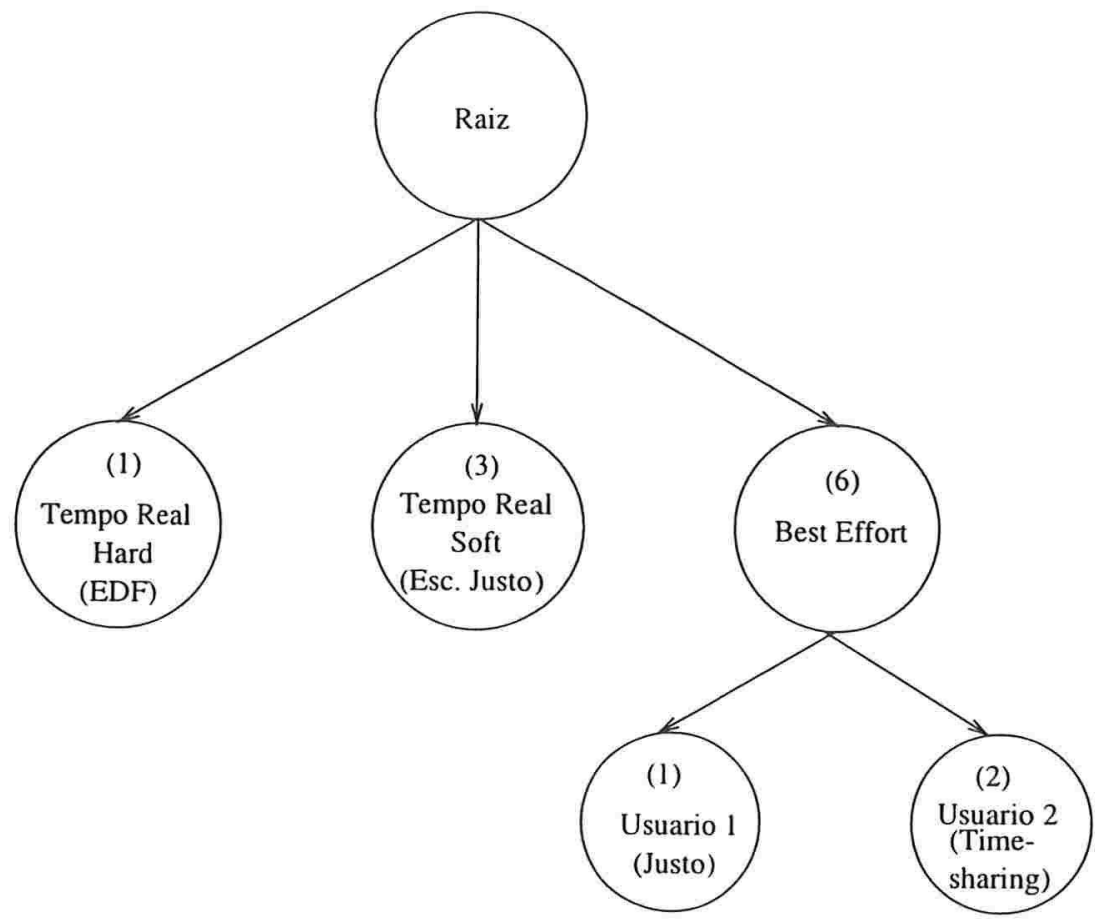

Figura 5.7: Um Exemplo da Estrutura de Escalonamento

Esta é uma definição idealizada de justiça, pois como a cada thread é concedido um quantum por vez, injustiças ainda podem ocorrer. Contudo, o objetivo do SFQ é minimizar o grau de injustiça que possa ocorrer. Formalmente, garantir que

$$
\left|\frac{W_{f}\left(t_{1}, t_{2}\right)}{r_{f}}-\frac{W_{m}\left(t_{1}, t_{2}\right)}{r_{m}}\right|
$$

seja tão próximo de 0 quanto possível.

Para alcançar este objetivo, o SFQ associa um valor inicial para cada thread e as escalona na ordem crescente destes valores. Para definir o valor inicial, suponha que o quantum destinado a cada thread tenha um tamanho variável a cada instante. Defina $q_{f}^{j}$ e $l_{f}^{j}$ como o $j$-ésimo quantum da thread $f$ e seu tamanho (em unidade de instruções), respectivamente. Também denote $A\left(q_{f}^{j}\right)$, o tempo no qual o $j$-ésimo quantum é requisitado. Se a thread está fazendo uma transição do estado bloqueada para em execução, então $A\left(q_{f}^{j}\right)$ é o instante em que esta transição é realizada. Caso contrário, este valor é o instante no qual o quantum anterior finalizou.

Uma descrição formal do algoritmo SFQ é apresentada a seguir:

1. Quando o quantum $q_{f}^{j}$ é solicitado pela thread $f$, esta é marcada com um valor inicial $S_{f}$, computado como:

$$
S_{f}=\max \left\{v\left(A\left(q_{f}^{j}\right)\right), F_{f}\right\}
$$


onde $v(t)$ é o tempo virtual no instante $t$ e $F_{f}$ é o valor final da thread $f . F_{f}$ é inicialmente 0 , e quando $j$-ésimo quantum finaliza é incrementado como:

$$
F_{f}=S_{f}+\frac{l_{f}^{j}}{r_{f}},
$$

onde $r_{f}$ é o peso da thread $f$.

2. Inicialmente o tempo virtual é 0. Quando a CPU está ocupada, o tempo virtual no instante $t, v(t)$, é definido como o valor inicial da thread em serviço no instante $t$. Por outro lado, quando a CPU está inativa, para $v(t)$ é determinado o máximo do valor final atribuído a qualquer thread.

3. Threads têm seus serviços atendidos na ordem crescente dos seus valores iniciais. Empates são decididos arbitrariamente.

O algoritmo SFQ mostrou-se adequado para aplicações de vídeo e os resultados obtidos demostraram que: (1) suporta a co-existência de escalonadores heterogêneos, (2) protege as classes de aplicações entre si, e (3) não impõe uma sobrecarga maior do que aquela apresentada por escalonadores timesharing convencionais.

O ambiente de particionamento hierárquico proposto facilita a utilização de um gerenciador de QoS que aloca os recursos dependendo dos requisitos da aplicação. Para exemplificar este gerenciador, suponha que uma aplicação requisite serviço de tempo real hard (soft). O gerenciador de QoS pode usar um algoritmo determinístico (estatístico) de controle de admissão que utiliza a capacidade alocada à classe hard (soft) e determina se a requisição pode ser satisfeita. Neste caso, atribui a aplicação a uma partição apropriada.

Um gerente de QoS pode trocar dinamicamente as proporções do particionamento hierárquico para refletir a importância relativa das várias aplicações. Por exemplo, inicialmente para a classe de aplicações de tempo real soft pode ter sido alocada uma pequena fração de CPU, mas quando aumenta o número de requisições para serviços de tempo real soft, a alocação desta classe pode ser aumentada significativamente.

\subsubsection{Paradigma Baseado em Feedback}

O último paradigma abordado é aquele baseado em feedback, o qual caracteriza-se pela alocação dinâmica de recursos baseada nas necessidades das aplicações.

D. Steere et. al [SGG+99] apresentam uma técnica para estimar dinamicamente a proporção e o período exigido por uma tarefa particular baseando-se em seu progresso. Em conseqüência, o sistema pode oferecer os benefícios de escalonamento proporcional sem o uso de reservas de recursos. Com estas estimativas. o sistema pode atribuir a proporção de recurso e o período para as threads de uma tarefa. sem a necessidade de entrada destes parâmetros pelos usuários ou projetistas do sistema. 
Esta técnica é baseada em feedback. Deste modo as proporções e os períodos são mudados dinamicamente de acordo com as modificações dos requisitos de recursos de uma thread.

O problema fundamental com o escalonamento baseado em prioridade é que o conhecimento da prioridade de uma tarefa não é suficiente para alocar recursos propriamente. Por exemplo, não há como expressar dependências entre tarefas usando prioridades ou especificar como compartilhar recursos entre tarefas com diferentes prioridades. Conseqüentemente, técnicas baseadas em prioridades têm vários problemas, incluido starvation, inversão de prioridade e falta de alocação com fina granularidade. O uso de mecanismos adaptativos como escalonadores feedback multinível ameniza alguns aspectos.

A abordagem desenvolvida evita as desvantagens anteriormente citadas usando um controlador que atribui proporção e período baseando-se em estimativas do progresso da thread. Evita-se também starvation por assegurar que a toda thread no sistema é atribuído um percentual não nulo da CPU. Outro aspecto solucionado é a inversão de prioridade, isto é realizado pela alocação da CPU baseada na necessidade medida pelo progresso e não pela prioridade. O sistema proposto também provê uma fina granularidade visto que threads podem solicitar porções específicas da CPU, por exemplo, atribuindo $60 \%$ da CPU para thread X e $40 \%$ para a thread $\mathrm{Y}$.

Os problemas de inversão de prioridade e starvation ocorrem porque apenas o parâmetro prioridade não captura todos os relacionamentos desejados entre tarefas. Como resultado, esquemas baseados em prioridade são forçados a usar alguns artifícios para compensar, tais como passagem de prioridades por mutexes ou decrementação da prioridade de tarefas $C P U$-bound. Antes estes mecanismos foram suficientes, mas atualmente têm gerado alguns efeitos colaterais.

Por exemplo, para garantir que o kernel aloque CPU suficiente para uma importante tarefa CPU-bound executando no UNIX, pode-se utilizar o comando nice. Entretanto, como a tarefa continua utilizando sua fatia de tempo, o kernel automaticamente reduzirá sua prioridade até que esta execute com uma prioridade inferior a aquela das tarefas menos importantes. Alternativamente, poderia se associar uma prioridade de tempo real fixa, a qual é maior do que todas as prioridades normais, garantindo então a execução. Infelizmente, isto acarreta a exclusão de todas as tarefas com menor prioridade, enquanto o processo com prioridade de tempo real fixa estiver executando.

Para ilustrar esta situação, considere uma tarefa com uma prioridade de tempo real fixa que executa esperando (spin-waits) por uma determinada entrada do usuário. Como o servidor de janelas tipicamente executa com menor prioridade do que uma thread de tempo real, não é possivel gerar a entrada que a thread de tempo real aguarda, e assim ocorre livelock no sistema.

A solução adotada é baseada na noção de progresso. Essencialmente, monitora o progresso de tarefas, incrementando ou decrementando a alocação de CPU para estas tarefas quando necessário. Neste ambiente, uma tarefa é uma coleção de threads cooperativas que 


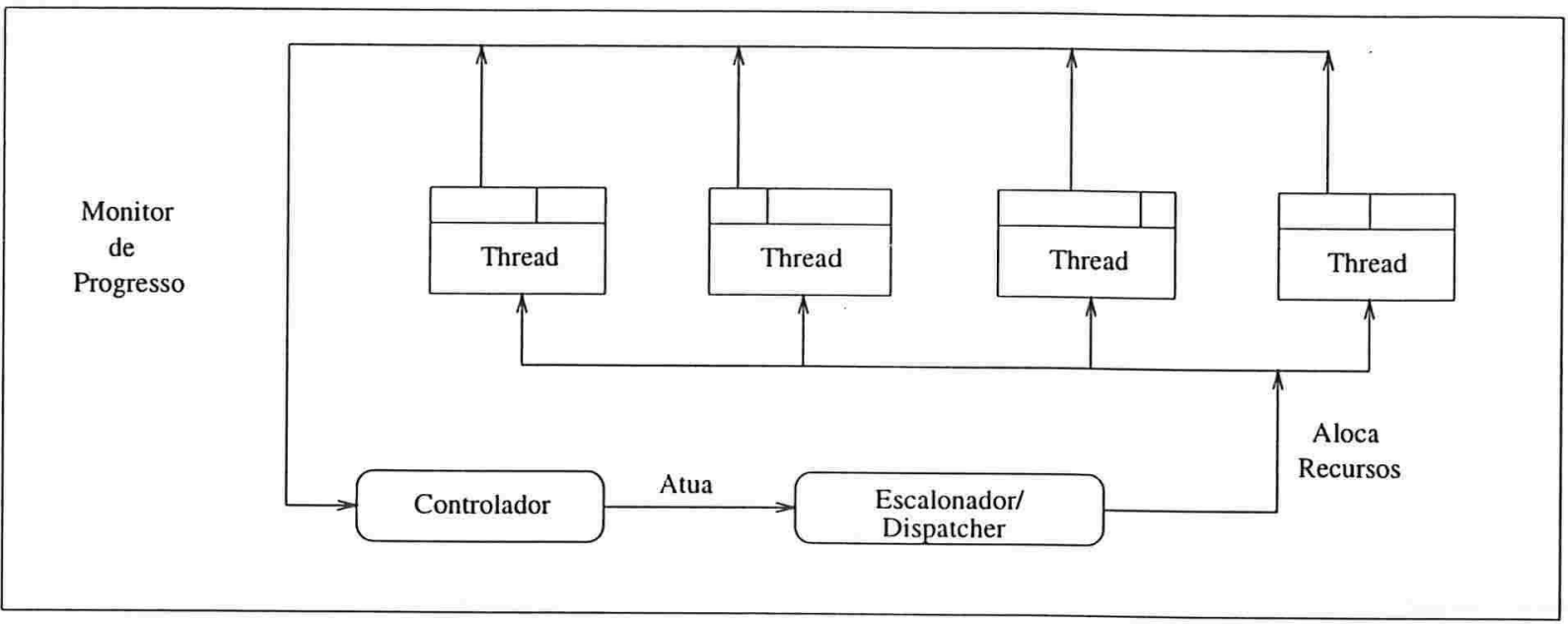

Figura 5.8: Arquitetura em Alto Nível

podem ou não estar contidas no mesmo processo.

A Fig. 5.8 exibe a arquitetura em alto nível do escalonador desenvolvido. O escalonamento das threads é efetuado de maneira que recebam suas respectivas proporções de CPU nos seus períodos. Um controlador periodicamente monitora o progresso da thread ajustando automaticamente sua proporção de CPU. Este ajuste é chamado de adaptação.

Esta adaptação dinâmica controlada por feedback é necessária porque as necessidades das tarefas e a composição das tarefas executando variam com o tempo.

O escalonador utilizado, aloca CPU para threads baseando-se em dois atributos: proporção e período. A proporção é o percentual da duração do período durante o qual a aplicação deve obter a CPU, e o período é o intervalo de tempo especificado em milisegundos no qual a alocação deve ocorrer. Por exemplo, se uma thread tem uma proporção de $5 \%$ e um período de $30 \mathrm{~ms}$, então deve executar $1.5 \mathrm{~ms}$ a cada $30 \mathrm{~ms}$.

Uma vantagem deste escalonador é que se pode facilmente detectar sobrecarga através da soma das proporções: uma soma maior ou igual a 1, indica que a CPU está sobrecarregada. Após detectar uma sobrecarga, o escalonador tem muitas escolhas. Primeiro, pode realizar um controle de admissão rejeitando ou cancelando tarefas de forma que a carga resultante seja menor do que 1. Segundo, pode gerar exceções de qualidade para notificar as tarefas da sobrecarga e renegociar as proporçōes. Terceiro, pode automaticamente normalizar a alocação usando políticas como compartilhamento justo com e sem pesos. No sistema sendo descrito, estes mecanismos são implementados por um controlador.

O escalonador desenvolvido por Steere et. al foi implementado no kernel do Linux 2.0.35 adicionando-se uma nova política de escalonamento (que utiliza o escalonamento Rate-Monotonic) usando mecanismos básicos do Linux. Neste ambiente, garante-se que a função goodness (Seção 3.1.1) retorna um valor maior do que aquele retornado em outras políticas. Isto para as threads sob controle deste novo escalonador, as demais são 
controladas pelos escalonadores padrões do Linux (Seção 3.1.1). Quando uma thread usou sua alocação durante seu período é bloqueada até seu próximo período começar. Devido as suas características, o escalonador proposto é classificado como de baixo-nível e funciona como o dispatcher do sistema.

A novidade da abordagem de Steere et. al está na estimativa de progresso como meio de controlar a alocação de CPU. Infelizmente, esta estimativa é um procedimento difícil pela pouca transparência entre a aplicação e o sistema operacional.

A solução para este problema baseou-se na noção de interfaces simbióticas, as quais conectam a semântica da aplicação com as métricas do sistema tais como progresso. Por exemplo, considere duas aplicações com um relacionamento de produtor/consumidor utilizando uma fila compartilhada para se comunicar. Uma interface simbiótica que implementa esta fila cria uma conexão com o kernel mostrando o nível de preenchimento do buffer, tamanho, e o procedimento de cada thread (produtor ou consumidor) para o sistema. Com esta informação, o kernel pode estimar o progresso do produtor e do consumidor monitorando o nível de preenchimento da fila. Quando a fila torna-se cheia, o kernel entende que o consumidor precisa de mais CPU e que o produtor necessita menos do processador. Similarmente, quando a fila torna-se vazia, o kernel inverte as necessidades do produtor e do consumidor.

Dada uma interface é possível construir um monitor que periodicamente modela o progresso da aplicação e transmite esta informação ao controlador. No ambiente proposto define-se interfaces simbióticas adequadas para cada uma das classes de aplicações comentadas a seguir:

- Produtor/Consumidor: As aplicações utilizam alguma forma de buffer limitado para se comunicar, assim como fila em memória compartilhada, pipe, ou sockets. Pipes e sockets são efetivamente filas gerenciadas pelo kernel como parte da abstração. Pelo conhecimento do nível de preenchimento, tamanho e funcionalidade da aplicação (produtor/consumidor), o escalonador pode determinar a taxa relativa de progresso da aplicação monitorando o nível de preenchimento.

- Servidor: Servidores são essencialmente consumidores de um buffer limitado, onde o produtor pode ou não estar na mesma máquina.

- Interativas: Tarefas interativas são servidores que aguardam dados do terminal ao invés dos sockets. Visto que tarefas interativas possuem requisitos específicos (períodos relativos à percepção humana), o escalonador somente precisa saber que a tarefa é interativa e os terminais nos quais está interessado.

- I/O Intensivas: Aplicações que processam um grande conjunto de dados podem ser consideradas consumidoras dos dados que são produzidos pelo subsistema de I/O. Como tal, necessitam de bastante CPU para manter o disco ocupado. Utilizando mecanismos como atrasos na escrita dos buffers. permite-se que o sistema monitore 
a taxa de progresso do subsistema de I/O como um produtor/consumidor para uma tarefa particular.

- Outras: Algumas aplicações não são estruturadas e não se adequam a interfaces simbióticas. Nestes casos, onde o escalonador não pode monitorar o progresso, utiliza-se uma heurística simples para atribuir proporção e período, baseando-se na utilização pela aplicação da alocação concedida.

Quando uma aplicação inicializa uma interface simbiótica (abrindo um arquivo ou uma fila compartilhada), a interface cria uma conexão com o kernel usando uma chamada ao sistema meta-interface que registra a fila (ou sockets,etc.) e a utilização daquela fila pela aplicação (produtor ou consumidor).

Dados o dispatcher e os componentes de monitoração, o trabalho do escalonador é atribuir proporção e período para garantir que a aplicação progrida razoavelmente. Os quatro casos considerados pelo controlador são: threads de tempo real, de tempo real não periódicas, real-rate e miscelâneas (descritas a seguir). As threads de tempo real especificam ambos proporção e período, as de tempo real não periódicas especificam somente a proporção, aquelas rate-real não especificam proporção ou período mas fornecem uma métrica de progresso e as threads miscelâneas não fornecem qualquer informação.

Descrevendo melhor as classes de threads existentes no sistema, tem-se que:

- Threads de Tempo Real - Para melhor servir estas aplicações, o controlador determina a proporção e o período da thread e não os modifica na prática. Esta especificação, se aceita pelo sistema, é essencialmente uma reserva de recursos para a aplicação. Entretanto, se ocorre sobrecarga, o controlador pode gerar uma exceção e iniciar uma renegociação da reserva de recursos.

- Threads de Tempo Real não Periódicas - Para tarefas que conhecem a proporção mas não são periódicas ou desconhecem seu período, o controlador deve atribuir um período. Intuitivamente, o período especifica um deadline no qual o escalonador deve fornecer a alocação. Um período muito grande pode introduzir um inaceitável jitter, o qual é a percepção humana da variação do retardo e é detectado via grandes oscilações relativas ao tamanho do buffer, enquanto um período pequeno pode apresentar sobrecarga visto que o escalonamento torna-se mais freqüente.

- Threads Real-Rate - Estas são threads que possuem uma métrica de progresso mas que não conhecem proporção ou período. As threads real-rate não têm um deadline hard mas possuem requisitos de throughput. Exemplos desta classe são pipelines multimídia e servidores. Durante cada intervalo do controlador, este especifica o progresso de cada thread para determinar a "pressão" exercida na thread. A pressão é um número entre $-\frac{1}{2}$ e $\frac{1}{2}$. Os valores negativos indicam que muito progresso está sendo feito e a alocação deve ser reduzida, 0 indica uma alocação ideal e os valores positivos indicam que a thread necessita mais CPU. 
A fórmula usada pelo controlador para determinar os valores de pressão mencionados é:

$$
Q_{t}=G\left(\Sigma_{i} R_{t, i} F_{t, i}\right),
$$

onde $R_{t, i}$ é - 1 se $t$ é um produtor de $i$ e 1 se $t$ é consumidor de $i$.

Para filas compartilhadas, $F_{t, i}$ é calculado dividindo o nível de preenchimento atual pelo tamanho da fila e subtraindo $\frac{1}{2}$. Utiliza-se $\frac{1}{2}\left(F_{t, i}=0\right)$ como o nível de preenchimento ótimo visto que deixa espaço máximo para tratar excessos de ambos produtor e consumidor. $R_{t, i}$ é usado para determinar o sinal da fila, visto que uma fila cheia significa que o consumidor deve ser acelerado (pressão positiva) enquanto o produtor deve ser retardado (pressão negativa).

As pressões dos progressos individuais são somadas e passadas para um controle derivada-integral-proporcional (PID) que calcula a pressão acumulada, $Q_{t}$. Um controlador PID combina a magnitude das somas das pressões (P) com a integral (I) e com a primeira derivada (D) da função descrita pelas pressões dos progressos somadas com o tempo. O controle PID é uma técnica comumente aplicada para construir controladores com uma redução de erro e estabilidade aceitável [FPEN94].

Para threads real-rate não periódicas deve-se também determinar o período. Atualmente, utiliza-se uma heurística simples que aumenta o período para reduzir o erro de quantização quando a proporção é pequena, visto que o dispatcher pode alocar somente múltiplos do intervalo dispatcher, o qual é o tempo entre duas ações do dispatcher. O controlador diminui o período para reduzir o jitter. O controlador determina a magnitude da oscilação através da monitoração da quantidade de mudanças no nível de preenchimento sobre o curso de um período, tirando-se a média sobre muitos períodos.

- Threads Miscelâneas - O controlador usa uma heurística para tratar threads que não foram classificadas nas categorias anteriores. Para proporção, o controlador aproxima o progresso das threads com uma constante positiva. Desta maneira, existe pressão constante para alocar mais CPU para uma thread miscelânea, até que esta seja satisfeita ou a CPU torne-se sobrecarregada.

Depois do cálculo da pressão para uma thread, o controlador deve computar a nova alocação para a thread. A equação usada pelo controlador para estimar proporção é igual a :

$$
P_{t}^{\prime}= \begin{cases}k Q_{t} & \text { para } P_{t} \text { adequada. } \\ -C & \text { para } P_{t} \text { muito generosa. }\end{cases}
$$

Onde $P_{t}$ é a alocação anterior para a thread $t$ e $Q_{t}$ é a pressão do progresso.

Em circunstâncias normais, multiplica-se a pressão da fila por um fator de normalização constante para determinar a alocação desejada. Contudo, o aumento da alocação 
pode não aumentar o progresso da thread, como pode acontecer por exemplo se outro recurso é o gargalo para esta aplicação.

Para confirmar a alocação não usada, o controlador compara a CPU usada por uma thread com a quantidade alocada para a mesma. Se a diferença é maior do que o limite, o controlador assume que a pressão está superestimada em face da real necessidade e a alocação deve ser reduzida.

Quando a soma dos limites desejados é maior do que a soma de CPU disponível, o controlador deve reduzir a alocação para as threads. Este aumento pode resultar da entrada de uma nova thread de tempo real ou de uma estimativa periódica do controlador das necessidades de threads real-rate ou miscelâneas.

No primeiro caso, o controlador efetua um controle de admissão rejeitando a nova tarefa de tempo real que requer mais CPU do que existe disponível. Nos demais casos, o controlador restringe as alocações da tarefa atual para liberar capacidade para as novas solicitações. Depois que as novas alocações são calculadas o controlador soma estas alocações e as compara com o limite da sobrecarga. Se as alocações ultrapassam o limite da CPU, cada tarefa miscelânea ou real-rate tem suas alocações propostas reduzidas por uma quantidade proporcional à alocação. Na ausência de outras informações (tais como métricas de progresso), esta política resulta na mesma alocação da CPU para todas as tarefas competidoras.

Uma extensão desta política simples de compartilhamento justo foi realizada através da associação do conceito de importância a cada thread. O resultado é um compartilhamento justo com pesos, onde a importância é o peso associado. O uso da noção de importância é diferente do conceito de prioridade, visto que uma tarefa mais importante não pode causar starvation em outra menos importante. Ao invés disto, importância determina a probabilidade que uma thread conseguirá a alocação desejada. Para duas tarefas que desejam mais do que a quantidade de CPU disponível, a mais importante tarefa executará com o maior percentual.

Aplicações real-rate (servidores web, pipelines multimídia), que devem atingir uma taxa externa de throughput, e aplicações de tempo real são fracamente servidas pelos sistemas operacionais atuais de propósito geral. Um motivo é que no escalonamemto baseado em prioridade, amplamente utilizado nos sistemas operacionais existentes, falta controle suficiente para acomodar as mudanças necessárias para estas aplicações dinamicamente.

Ainda comentando o estado da arte de escalonadores de tempo real, desta vez não sob a perspectiva de paradigmas mas das implementações existentes no LINUX, exibe-se na próxima seção os sistemas operacionais RT-LINLX e KU RT-LINUX. 


\subsection{Esforços na Comunidade Linux}

Os sistemas operacionais atuais, como o sistema operacional LINUX, são projetados para ter um desempenho médio onde se tenta dar a cada processo um tempo justo de computação. Contudo, para o paradigma de tempo real, mais importante do que ter um desempenho médio é ter a previsibilidade como uma característica. Imaginemos o que deve acontecer, se um processo que interrompe um experimento químico em caso de emergência, tiver que esperar o Netscape redesenhar a sua janela [YB99].

$\mathrm{O}$ algoritmo de escalonamento timesharing do Linux permite que se atribua uma prioridade alta para os processos, mas tenta assegurar que todos tenham um compartilhamento justo do processador. No paradigma de tempo real os processos devem obter o processador sempre que necessário, não se preocupando com um processamento justo entre os processos ativos.

Outro problema que se verifica no tratamento de processos de tempo real pelo Linux é a utilização da memória virtual. Páginas pertencendo a qualquer usuário podem ser enviadas para o disco a qualquer momento. Retornar com a página para a memória leva uma soma de tempo não previsível em Linux.

Em conseqüência, atualmente objetiva-se construir um sistema operacional de tempo real pequeno e simples para ser localizado em uma camada abaixo do Linux. Neste contexto, surgiu o RT-Linux [RL99, Bar98, BY96]. Este é um sistema operacional em que um pequeno kernel de tempo real co-existe com o kernel do Linux. A idéia é aproveitar os serviços sofisticados do ambiente timesharing, onde temos um desempenho ótimo na média, e permitir ainda que funções de tempo real operem em um ambiente previsível e de baixa latência. RT-Linux é uma ferramenta não proprietária que se pode usar para controlar instrumentos científicos e robôs, bem como para pesquisar sistemas operacionais eficientes e confiáveis para aplicações de tempo real e convencionais. Por exemplo, mesmo para sistemas operacionais convencionais gostaríamos de ser capazes de determinar se ele pode garantir o tempo necessário para seus dispositivos de I/O.

Recentes desenvolvimentos em várias áreas, como por exemplo, de multimídia e redes ATM têm criado uma nova classe de aplicações de tempo real que não se enquadram na distinção binária de soft ou hard. Estas aplicações são periódicas e necessitam de serviços do sistema operacional como: um sistema de arquivos, dispositivos de cartão de vídeo, uma mais alta resolução de tempo, entre outros.

Estas novas aplicações têm requisitos de tempo como as aplicações de tempo real hard e necessitam de serviços do sistema operacional disponíveis geralmente, em sistemas soft ou timesharing [Sri95]. Estas ampla faixa de aplicaçōes são classificadas como firm.

Uma importante característica desta nova classe de aplicações é que elas são raramente projetadas para executar em hardware de tempo real dedicado. Por exemplo, uma aplicação de vídeo-conferência geralmente é dirigida para ser usada em um desktop padrão em conjunto com aplicações convencionais, assim como processadores de texto e browsers. 
Por este motivo, um requisito crucial do sistema operacional para suportar aplicaçōes firm é permitir que tarefas de tempo real e convencional co-existam. O KU Real-Time Linux [Sri97] trata adequadamente esta nova classe.

As Seções 5.2.1 e 5.2.2 detalham os mais recentes esforços da comunidade Linux, a saber, o KU RT-LINUX e o RT-LINUX, respectivamente.

\subsubsection{KU Real-Time Linux}

A política de escalonamento SCHED_KURT é implementada adicionalmente a aquelas existentes no Linux. Porém, a política de escalonamento SCHED_KURT é diferente das outras porque só tem efeito quando o kernel está em modo de tempo real. Caso contrário, estes processos são selecionados de acordo com sua política de escalonamento default.

No modo normal, o sistema age como um sistema Linux genérico e quando o kernel está executando em modo de tempo real podem acontecer duas situações: a execução apenas de tarefas de tempo real ou a execução de todas as tarefas priorizando aqueles de tempo real. As tarefas convencionais são escalonadas caso não haja nenhum processo de tempo real para executar. Uma simples chamada de sistema permite que o kernel altere do modo normal para de tempo real e vice-versa.

No KURT, as aplicações necessitam especificar explicitamente os instantes em que os eventos ${ }^{6}$ de tempo real estão para ocorrer. Estes instantes são armazenados em um arquivo de classificação e baseando-se nele os eventos são explicitamente escalonados. O termo explicitamente é propositadamente utilizado pois expressa quando o escalonamento ocorre de acordo com o instante previamente determinado no arquivo de classificação.

O sistema KU Real-Time consiste de módulos de tempo real no kernel que realizam atividades específicas para as aplicações e um sistema base que chama estes módulos em tempos determinados pela aplicação. Estes módulos executam em modo kernel e por este motivo podem acessar dispositivos, bem como outras partes do kernel. Concessão nem sempre permitida para um processo usuário em outros sistemas. A aplicação passa os instantes para o sistema base através de um arquivo de classificação. A Fig. 5.9 ilustra o sistema KURT.

Um exemplo do comportamento mencionado é o sistema ATM Reference Traffic Systems (ARTS) que registra e transmite pacotes ATM. Estes pacotes são transmitidos por um módulo de tempo real. O gerador de tráfego do ARTS simplesmente constrói um arquivo de classificação especificando os instantes das chamadas ao módulo que efetua a transmissão dos pacotes [HSPN98].

Diferente do ARTS, existem aplicações que têm um fluxo de execução periódico. Por exemplo. algumas aplicações de multimídia executam uma seção de código repetidamente em um intervalo de tempo fixo. Neste caso. as aplicaçōes especificam seu período e KLRT

\footnotetext{
${ }^{6}$ Chamadas de módulos de tempo real.
} 


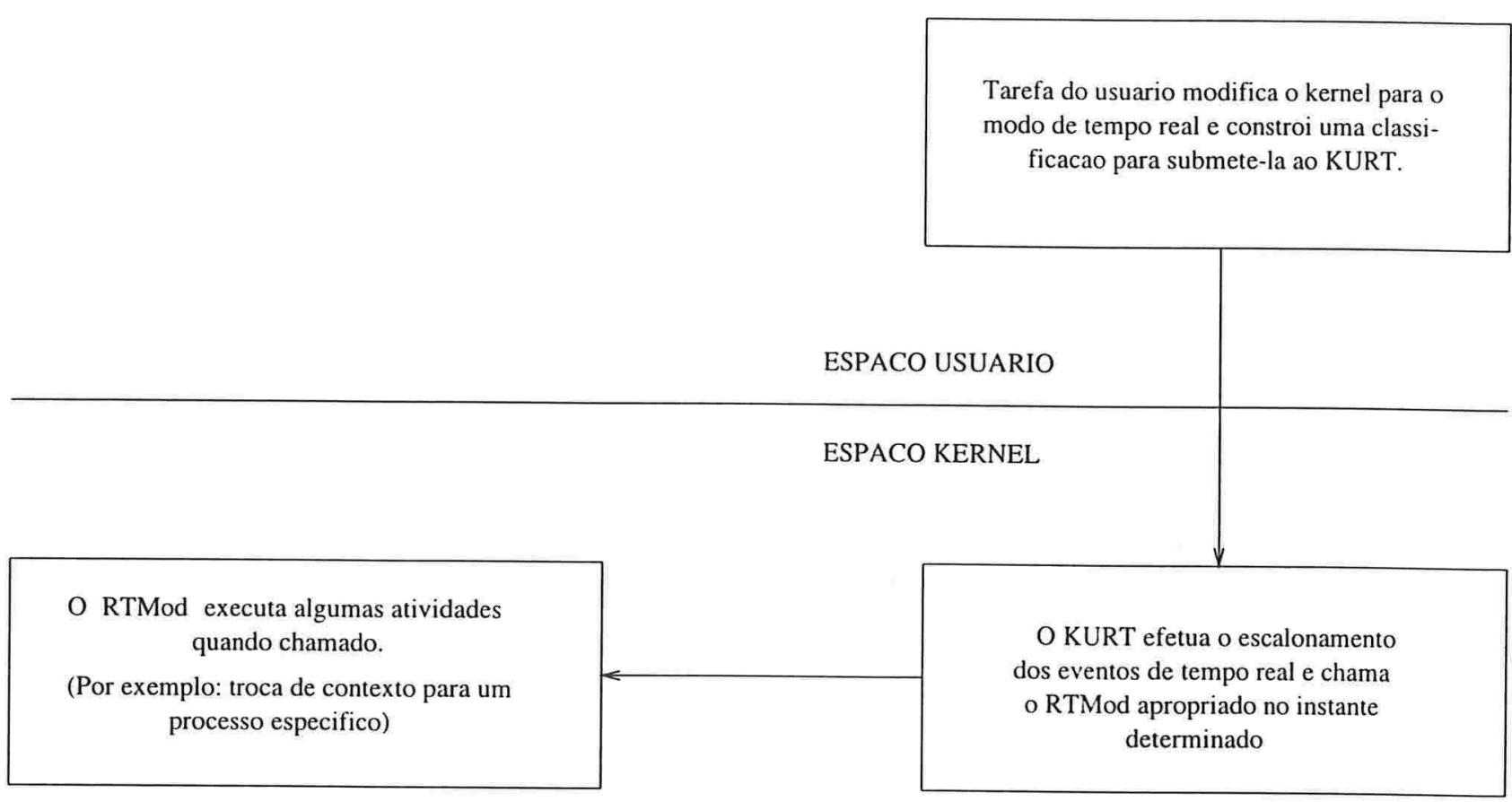

Figura 5.9: Arquitetura do Sistema KURT

executa a seção de código apropriada a cada período. Estas tarefas são escalonadas de acordo com a política Round Robin, baseando-se na prioridade das tarefas. Embora estas tarefas estejam sendo escalonadas usando Round Robin, ainda têm uma prioridade maior do que outras tarefas usando o escalonador Round Robin padrão.

Além dos módulos específicos para uma aplicação, KURT tem um módulo de processos cuja função é efetuar a troca de contextos entre processos. Um arquivo de classificação especifica dois parâmetros: o instante em que o módulo de processo deve ser chamado e para qual processo a troca de contexto deve ser realizada.

Introduzido o sistema KURT, descreve-se na próxima seção a estrutura de execução de um processo de tempo real neste sistema.

\subsubsection{Modelo de Programação}

A maioria dos processos KURT tem a estrutura exibida na Fig. j.10.

Geralmente, um processo de tempo real usa um processo executivo para escalonar eventos para ele. Neste contexto. é importante a breve discussão das características destes processos exibidas a seguir.

- Processos de Tempo Real 


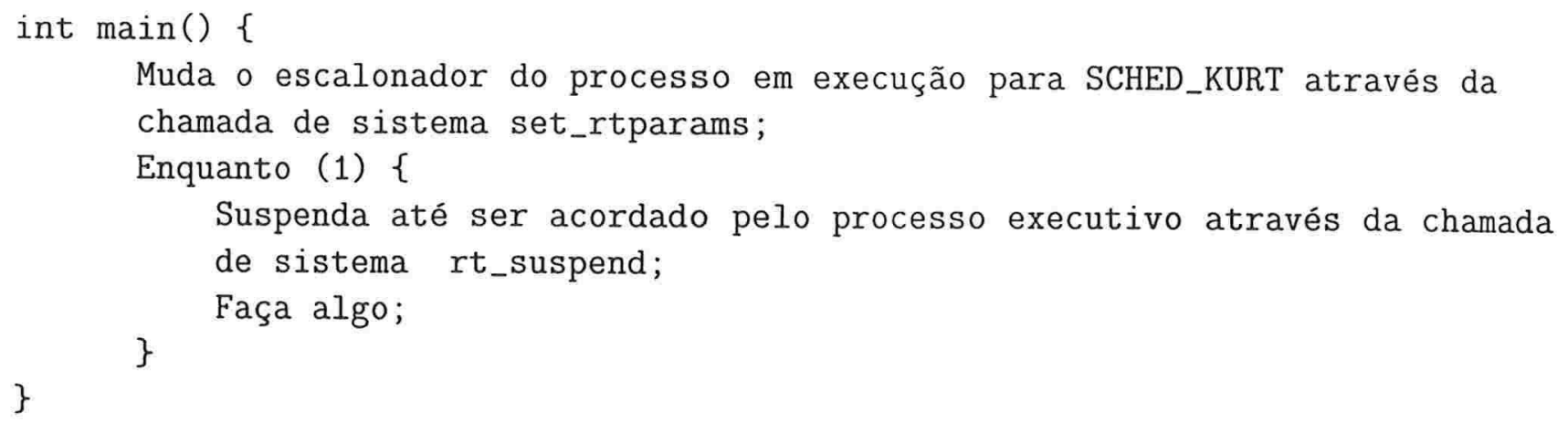

Figura 5.10: Estrutura de um Processo KURT

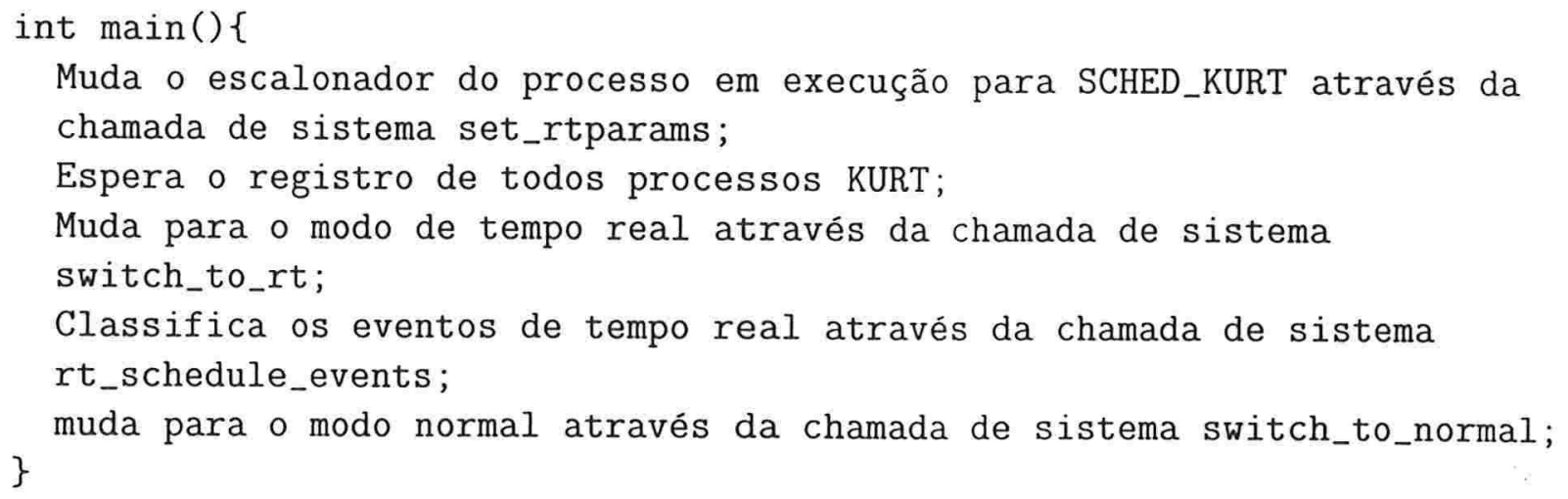

Figura 5.11: Um Processo Executivo no KURT

Processos de tempo real são classificados como periódicos e não periódicos. A diferença entre eles é que processos não periódicos necessitam de um processo executivo para o escalonamento de seus eventos, enquanto que aqueles periódicos utilizam o módulo de processos.

- Processos Executivos

Um processo executivo controla o escalonamento de todos processos KURT e todos RTMods (Módulos de Tempo Real) [Sri9ī]. A principal ação deste processo executivo é mostrada na Fig. 5.11.

Um outro aspecto importante do sistema KURT são os módulos de tempo real. que são primeiramente módulos padrão do kernel Linux. possuindo as funções init_module e cleanup_module. as quais são chamadas para carregar e remover módulos, respectivamente. É importante ressaltar que a parte mais importante de $1 \mathrm{~m}$ módulo de tempo real é o tratador de eventos.

Muitas aplicações de tempo real necessitam de uma resolução da ordem de microsegundos. O sistema KLRT oferece esta resolução através do sistema LTIME que é exibido 
na próxima seção.

\subsubsection{UTIME}

No Linux, qualquer subsistema do kernel que necessita de notificação assíncrona cria um timer e o adiciona a uma lista mantida pelo kernel. Estes timers são colocados em uma lista duplamente ligada, organizada em ordem crescente de tempo. O sistema KURT utiliza-se também dos timers. Neste caso, cada evento possui um timer associado e o módulo de tempo real apropriado é chamado quando este expira.

Ainda comentando sobre timers no Linux, tem-se que o chip do timer é programado para gerar interrupções periódicas a uma taxa fixa. Cada vez que a CPU é interrompida o kernel atualiza a variável global jiffies, que é um contador do número de interrupções do timer desde que o kernel foi inicializado. Estas interrupções periódicas são realizadas a cada 10 milisegundos, o que é inaceitável para a maioria das aplicações da classe firm. O sistema ARTS, por exemplo, requer uma resolução da ordem de 10 microsegundos.

Para resolver este problema KURT usa o sistema UTIME. Este sistema programa o chip do timer para interromper a CPU nos instantes de escalonar os eventos que têm seu timer expirado. Desta maneira a CPU é interrompida somente quando há necessidade de executar algum módulo de tempo real e não mais em intervalos regulares.

Uma vez que interrupções não são periódicas uma função chamada update_time foi adicionada. Esta função calcula o tempo que passou desde a última vez que foi chamada fazendo uso do $\mathrm{TSC}^{7}$ (Time stamp counter) que está disponível na maioria das CPUs modernas.

Como o contador jiffies não é incrementado regularmente, pode ocorrer algum problema em um dos subsistemas do kernel. Para resolver este problema, quando o chip do timer é reprogramado para disparar no instante de executar o próximo evento é feito um teste para verificar se alguma tarefa conhecida a priori ocorre antes da próxima interrupção. Esta ação introduz mais interrupções na qual nenhum evento é processado, porém faz com que todos os subsistemas trabalhem bem.

$\mathrm{Na}$ próxima seção são discutidas as chamadas ao sistema para escalonar eventos de tempo real e efetuar as mudanças entre os modos de tempo real e normal.

\subsubsection{Chamadas de Sistema no Core do KURT}

A chamada ao sistema switch_to_rt muda o kernel para o modo de tempo real e o seu protótipo é:

int switch_to_rt(int timer_mode, unsigned long period, int rt_mode,

\footnotetext{
${ }^{7}$ Em um Pentium, o TSC é um contador de 64 bits que é incrementado a todo ciclo de clock e cada ciclo leva em torno de 5 nanosegundos em uma CPU de $200 \mathrm{MHz}$.
} 
char *cmdline, int length);

Se o parâmetro rt_mode for setado para SCHED_KURT_PROCS, somente os processos que são marcados como $S C H E D_{-} K U R T$ são permitidos executar. Caso rt_mode seja setado para $S C H E D \_A L L_{-} P R O C S$, todos os processos podem ser escalonados.

Para retornar o kernel ao modo normal utiliza-se a chamada switch_to_normal. Este procedimento permite o uso do PC como uma estação de trabalho normal e o protótipo desta chamada ao sistema é:

int switch_to_normal(int force);

Nesta chamada o parâmetro force pode ser setado para forçar a mudança do modo do kernel para normal deletando todos os eventos que já foram escalonados. Se o parâmetro force não é setado então esta chamada bloqueia até que todos os eventos que já foram escalonados terminem a sua execução.

Usando a chamada rtmod_cmd o programa de um usuário pode solicitar ao RTMod que execute uma certa ação. O protótipo desta chamada de sistema é:

int rtmod_cmd(int rtmod_id, int command, void *buf, unsigned long length);

Neste procedimento o RTMod é localizado através do identificador rtmod_id e os parâmetros command, buffer e length são passados para o RTMod identificado.

A chamada ao sistema rt_schedule_events escalona os eventos conforme o arquivo de classificação e seu protótipo é:

int rt_schedule_events (struct timeval *start_time, int sched_mode, int

num_times, char *filename);

Nesta chamada o parâmetro start_time determina o início do escalonamento de eventos de tempo real pelo kernel do KURT. Se este valor é NULL, então a classificação é inicializada imediatamente. Os valores de sched_mode podem ser:

- RT_FROM_MEM - O arquivo de classificação é lido para a memória antes de iniciar a classificação, por este motivo o tamanho deste arquivo é limitado pela quantidade de memória do sistema. Este tipo é bom para classificações cíclicas, nas quais um conjunto de erentos tem que ser repetido um número de vezes.

- RT_FROM_DISK - O arquivo de classificação é lido constantemente do disco. Em conseqüência. não existe limite para o tamanho do arquivo de classificação e há a possibilidade de ocorrer distorções com relação ao instante em que um evento especificado acontece. 
A função get_rtmod_num é uma chamada de biblioteca e permite que um usuário obtenha o RTMod Id de um módulo. O protótipo desta chamada é:

int get_rtmod_num(char *name);

Outra classe de chamadas ao sistema são aquelas utilizadas no módulo processo, as quais são exibidas a seguir.

\subsubsection{Chamadas de Sistema no Módulo Processo}

O módulo processo é responsável pela troca de contexto para um processo específico. Ele modifica algumas chamadas de sistema existentes e adiciona outras mencionadas a seguir.

A chamada ao sistema set_rtparams foi adicionada ao kernel do Linux para definir um processo como SCHED_KURT. Somente os processos com política de escalonamento SCHED_KURT são permitidos executar em modo de tempo real. O protótipo da chamada mencionada é:

int set_rtparams(int pid, int policy, struct rtparams *);

O valor pid é o identificador do processo cujo rtparams está sendo modificado. Se este parâmetro for 0 então a chamada set_rtparams será aplicada ao processo que está executando. A política de escalonamento de um dado processo é especificada por policy. Assim, para marcar um processo como sendo de tempo real deve-se setar este parâmetro para SCHED_KURT. É importante ressaltar que para mudar a política de SCHED_KURT para SCHED_OTHER, SCHED_FIFO ou SCHED_RR não se pode usar a chamada de sistema do Linux sched_setscheduler. Neste caso. deve-se fazer uma nova chamada de set_rtparams. O parâmetro rtparams determina as características do processo SCHED_KURT. Esta estrutura é definida a seguir:

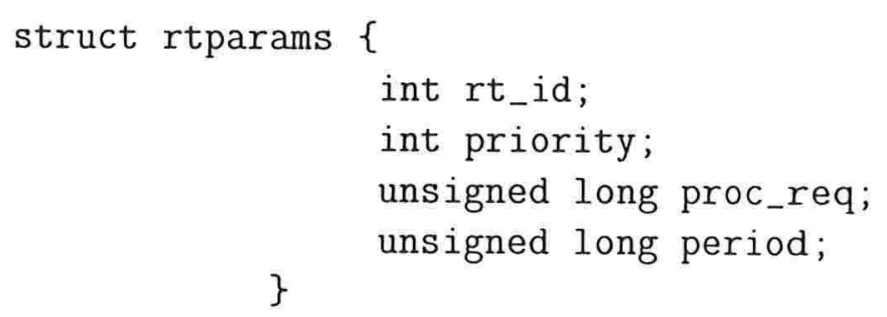

O campo proc_req representa o tempo de processamento que uma tarefa necessita quando é escalonada, sendo útil para processos periódicos. Para processos que são escalonados explicitamente, usando um arquivo de classificação, este parâmetro deve ser 0 .

O período de um processo é armazenado em period. Geralmente, todos os processos KLRT devem ter o mesmo período. Para aqueles processos não periódicos que estão sendo 
escalonados usando a chamada de sistema rt_schedule_events, o campo mencionado deve ser setado para 0 .

Se um processo SCHED_KURT chama fork o processo filho herda esta política e o módulo de processo associa um $r t_{-} i d$ para o mesmo. O valor de $r t_{-} i d$ pode ser modificado através da chamada de sistema set_rtparam.

As informações sobre os requisitos de processamento e o identificador podem ser obtidas através da chamada de sistema get_rtparams.

A chamada ao sistema get_rtmod_num retorna o número de processos SCHED_KURT e o seu protótipo é:

int get_rtmod_num(char *name);

Para suspender um processo SCHED_KURT utiliza-se $r t$ suspend, o qual permanece assim até que seja acordado pelo módulo de processo. O protótipo desta chamada é:

int rt_suspend(int susp_mode);

O parâmetro susp_mode pode ser START_SCHED ou STOP_SCHED. Se o processo é periódico então START_SCHED inicia o escalonamento do processo de acordo com seu período. Já o STOP_SCHED interrompe o escalonamento de um processo periódico. Processos escalonados explicitamente não necessitam usar os flags START_SCHED e STOP_SCHED.

A estrutura rtstats da tarefa é mostrada através da chamada de sistema get_rtstats e sua definição é exibida a seguir:

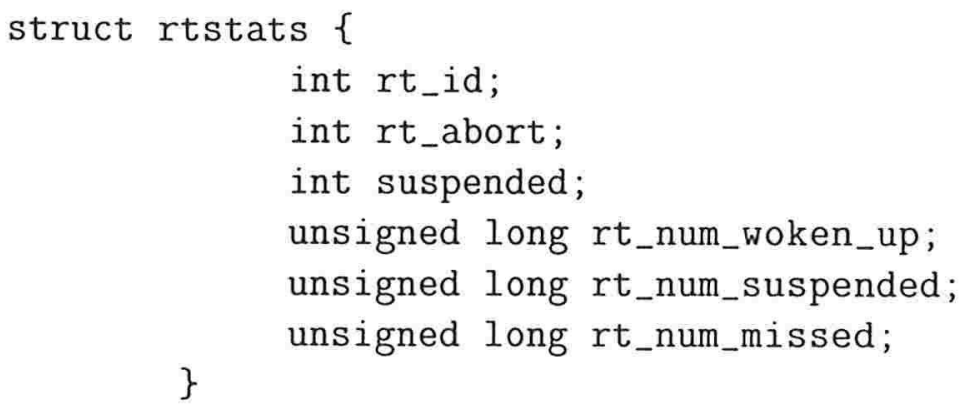

O campo rt_abort é setado quando um processo excede seu tempo de alocação e outro processo é escalonado. Isto significa que um processo necessita abortar e realizar uma chamada ao sistema $r t$ suspend tão breve quanto possível.

Os valores de rt_num_woken_up, rt_num_suspended e $r t_{-} n u m_{-}$missed indicam respectivamente: o número de vezes que o processo corrente foi acordado, o número de vezes que 
o processo corrente realizou um $r t_{-}$suspended e o número de vezes que o processo perdeu seu escalonamento porque não terminou sua iteração prévia.

Discutido o sistema KURT, aborda-se na próxima seção o RT-LINUX. Além disto, a Seção 5.2.3 tece comparações do KURT com o LINLX-SMART.

\subsubsection{RT-LINUX}

Alguns dos problemas mencionados no início da Seção 5.2 possuem solução simples como: mudança do algoritmo de escalonamento ou "lock" das páginas de um processo, idéias que são parte do POSIX.1b-1993 que define um padrão para processos de tempo real [Kuh98]. Contudo, este padrão não resolve todos os problemas e os processos de tempo real hard têm várias desvantagens:

- Os processos em Linux são pesados, além de gerarem uma sobrecarga significativa na troca de processos. Isto pode levar centenas de microsegundos em uma máquina rápida e tornaria impossível a leitura de um sensor a cada 200 microsegundos, por exemplo.

- Linux segue o padrão UNIX de tornar os processos no kernel não-preemptivos. Nesta perspectiva, quando um processo está fazendo uma chamada ao sistema (e executando em modo kernel) ele não pode ser forçado a ceder o processador mesmo que um outro processo tenha maior prioridade. Para projetistas de sistemas operacionais isto é ótimo, pois não há preocupação com muitos possíveis problemas de sincronização. Do ponto de vista de processos de tempo real é ruim, porque ele não pode obter o processador enquanto o kernel estiver trabalhando. Por exemplo, se o Netscape utiliza a chamada de sistema fork, esta executará antes de qualquer outro processo.

- Linux desabilita interrupções em seções críticas do código do kernel. Isto significa que uma interrupção de tempo real pode ser atrasada até que o processo corrente, independente da sua prioridade, termine de executar a sua seção crítica [BY96].

Mudar o kernel do Linux para ser um kernel preemptivo de tempo real com baixa latência no processamento de interrupções, poderia exigir uma reescrita quase completa do código. RT-Linux usa uma solução mais simples e eficiente. A idéia básica é fazer o Linux executar sob o controle de um kernel de tempo real, como apresentado na Fig. 5.12. Existindo processo de tempo real, o sistema operacional RT o seleciona, assim apenas na ausência de processo de tempo real o Linux é escalonado. Desta maneira, Linux é o processo com mais baixa prioridade no RT_Kernel.

O problema da disabilitação de interrupções no Linux é resolvido simulando no kernel de tempo real as interrupções mencionadas, como exibido na Fig. 5.13. Por exemplo. sempre que o kernel do Linux chama a rotina cli(). para disabilitar as interrupçōes, um 


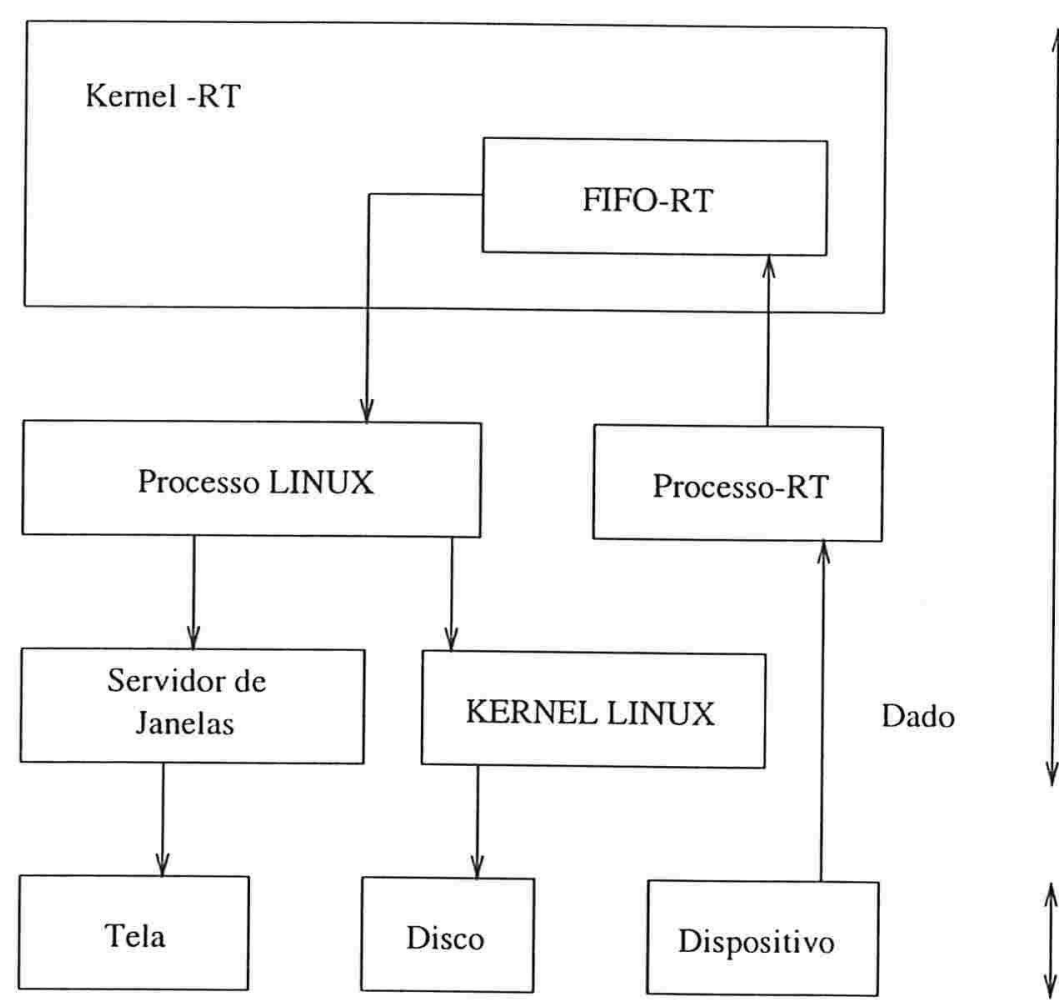

Nivel de Software

Figura 5.12: RT-Linux

flag de interrupção é setado em vez de disabilitar as interrupções. Nesta situação, se uma interrupção ocorre para que um processo de tempo real execute, o RT-Linux salva o estado do Linux e executa o processo de tempo real imediatamente. No caso de interrupção do Linux, o RT-Linux seta um flag mostrando que há uma interrupção pendente. Quando o Linux reabilita as interrupções, o RT-Linux processa todas as interrupções pendentes e faz com que o Linux efetue o tratamento [Bar98]. Este procedimento impõe algumas restrições aos processos de tempo real, os quais, por exemplo, não podem facilmente usar os drivers do Linux.

Processos de tempo real, executam no modo kernel para poder acessar o hardware do computador e têm uma alocação fixa de memória para código e dados. Vão sendo assim, pode ocorrer um atraso não previsível quando um processo requisita memória ou uma página de código. Além disto, processos de tempo real não podem fazer chamadas ao sistema ou acessar estruturas de dados no kernel do Linux, porque isto poderia gerar inconsistència.

O Linux e os processos de tempo real comunicam-se através de filas e memória compartilhada. Do ponto de vista dos programadores de aplicações, as filas parecem com os dispositivos de caracteres, acessados por chamadas ao sistema (padrão POSIX). como por exemplo read, write, open e ioctl. A memória compartilhada é geralmente acessada através da chamada ao sistema mmap. Como acontece com os processos de tempo real, 


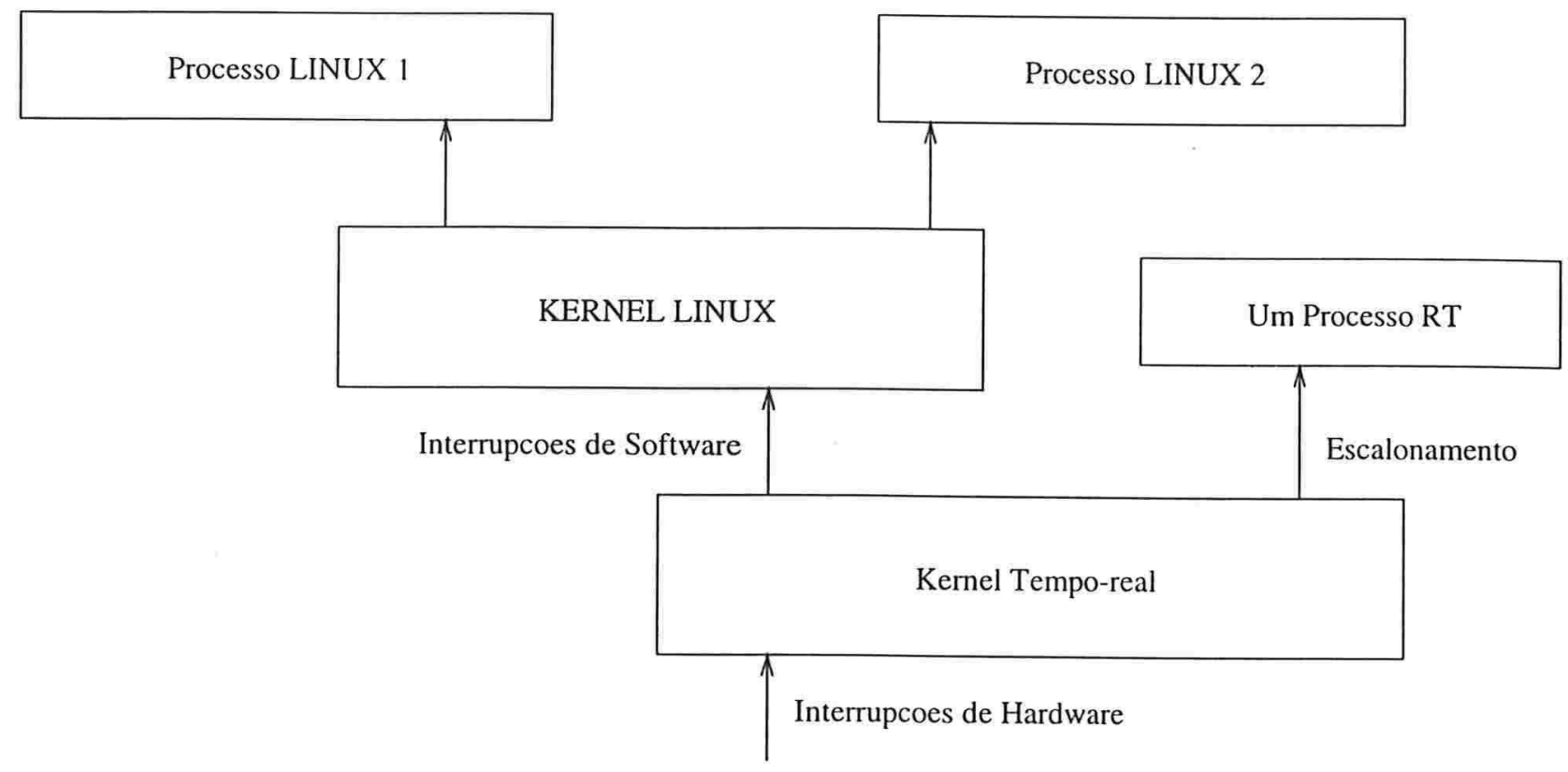

Figura 5.13: Interrupções em RT-Linux

as FIFOs nunca têm suas páginas gravadas no disco, o que elimina o problema de atrasos devido a paginação. Adicionalmente, FIFOs de tempo real ${ }^{8}$ são projetadas para nunca bloquear um processo de tempo real [Bar98].

É possível que processos de tempo real consumam todo os ciclos de CPU provocando uma sobrecarga do sistema. Neste caso, como o kernel do Linux tem a mais baixa prioridade, ele nunca conseguirá executar e o sistema não funcionará corretamente.

Apresentados os problemas de tarefas de tempo real no Linux e uma visão geral do funcionamento do sistema operacional RT-Linux, detalha-se nas próximas seções as interfaces principais, as RT-FIFOs e o escalonador.

\subsubsection{Interfaces}

O módulo kernel do RT-Linux implementa um simples escalonador de tempo real. O escalonador permite criar, executar, suspender e deletar tarefas de tempo real, as quais têm prioridades fixas e são preemptivas. Além disto, o escalonador tem suporte especial para tarefas periódicas.

$\mathrm{O}$ arquivo $r t \_s c h e d . h$, comentado a seguir, contém os protótipos das funções de interface e a declaração de tipo do escalonador [RL99]. Durante o relato deste arquivo, as funções principais e estruturas de dados do RT-Linux são comentadas, apresentando-se também

\footnotetext{
${ }^{8}$ Também denominadas RT-FIFOs, as quais são buffers utilizados como forma de comunicação entre as tarefas de tempo real e o Linux.
} 
os respectivos protótipos.

O rt_sched.h inicia enumerando os valores possíveis para o campo state de uma tarefa de tempo real. Estes valores podem ser: RT_TASK_READY, RT_TASK_DELAYED. RT_TASK_DORMANT, RT_TASK_ACTIVE, RT_TASK_ZOMBIE. Em seguida, determinase como menor prioridade do RT-Linux, RT_LOWEST_PRIORITY, o valor 1000000 . Os aspectos comentados são exibidos no código a seguir.

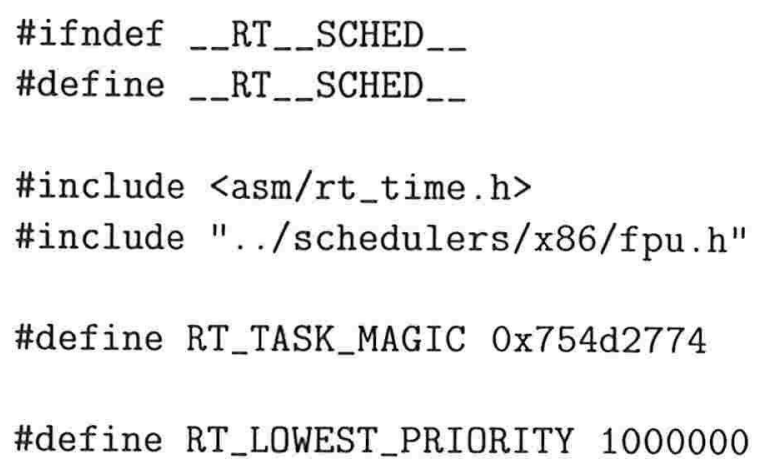

Posteriormente, define-se a estrutura rt_task_struct associada com uma tarefa de tempo real.

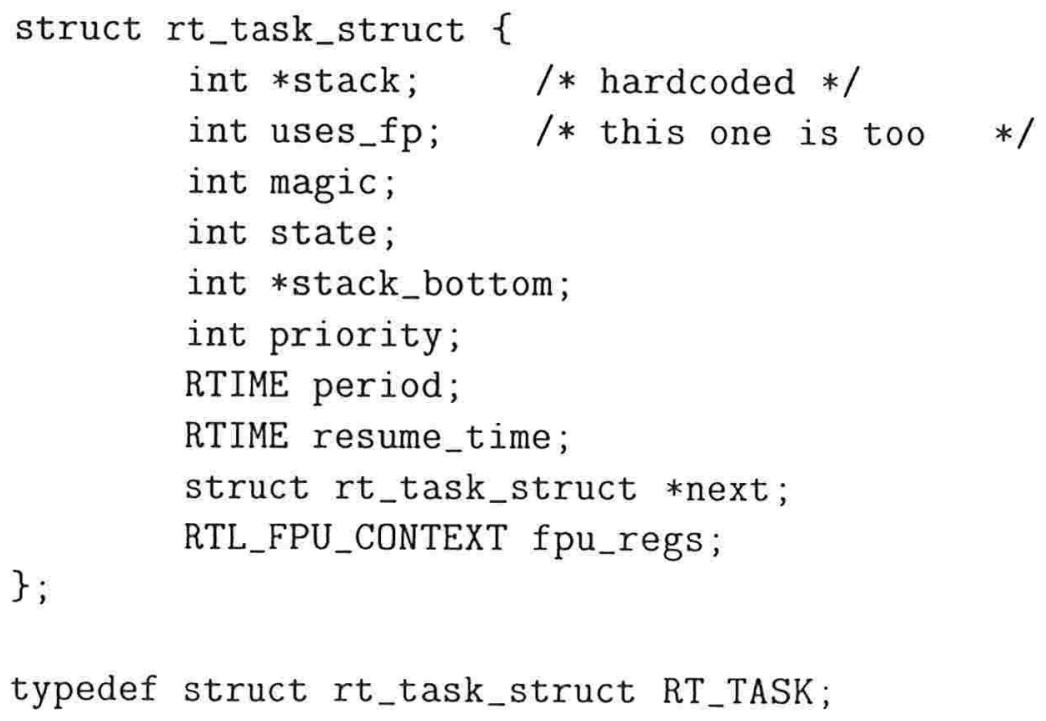


A tarefa de tempo real atualmente executando é acessada pelo ponteiro rtl_current e aquela com valor do campo priority igual a RT_LOWEST_PRIORITY encontra-se em rtl_linux_task. Ambos valores são bastante manipulados na implementação da política do RT-Linux e por isto a necessidade de um acesso imediato. O código a seguir mostra a definição das variáveis rtl_current e rtl_linux_task.

\#include "../schedulers/x86/switch.h"

extern RT_TASK *rtl_current;

extern RT_TASK rtl_linux_task;

No RT-Linux, para efetuar o tratamento de tarefas no estado RT_TASK_ZOMBIE utiliza-se a macro rtl_is_linux_zombies, definida a seguir.

\#define rtl_is_linux_task(a) (a == \&rtl_linux_task)

A função rt_task_init cria e inicializa uma tarefa de tempo real. O parâmetro fn é o ponto de entrada para a nova tarefa, a tarefa que originou a recém-criada tarefa pode passar para a mesma um valor inteiro data. O parâmetro stack_size é o tamanho da pilha para a tarefa criada e priority é a prioridade da nova tarefa, onde a maior prioridade é 1 e a mais baixa prioridade é o valor de RT_Lowest_Priority. A mais nova tarefa de tempo real é inicializada no estado dormant e é geralmente ativada quando se chama rt_task_make_periodic. A função comentada é exibida a seguir.

extern int rt_task_init(RT_TASK *task, void $(* f n)$ (int data), int data, int stack_size, int priority);

\#define rtl_init $(a, b, c, d, e)$ \{rt_task_init $(a, b, c, d, e) ;\}$

\#define rtl_fpinit $(a, b, c, d, e)\left\{r t_{-}\right.$task_init $(a, b, c, d, e)$; rt_task_use_fp $(a, 1) ;\}$

A função $r t_{-} t a s k_{-} u s e_{-} f p$ disponibiliza o uso de operações aritméticas de ponto flutuante em uma tarefa de tempo real. O flag terá valor 0 para disabilitar ou diferente de 0 para permitir o uso das operações mencionadas. O protótipo desta função é:

extern int rt_task_use_fp (RT_TASK *task, int flag);

Para remover uma tarefa task da lista de tarefas de tempo real RT_TASKS, utiliza-se a função rt_task_delete, cujo protótipo é:

extern int rt_task_delete (RT_TASK *task); 
A função rt_task_wait finaliza a execução da tarefa correntemente executando até o início do próximo período. Neste caso, a tarefa não é suspensa e simplesmente passa o controle do processador até o próximo período. O protótipo desta função é exibido a seguir.

extern int rt_task_wait (void);

A suspensão de uma tarefa de tempo real, task, em execução, é efetuada através da função rt_task_suspend. Neste caso, a tarefa foi previamente marcada para execução usando rt_task_make_periodic e diferentemente de rt_task_wait, esta função suspende a execução da tarefa até que uma outra chamada de rt_task_make_periodic seja feita. $\mathrm{O}$. protótipo desta função é:

extern int rt_task_suspend (RT_TASK *task);

A função rt_task_wakeup ativa uma tarefa de tempo real para executar, a qual encontrava-

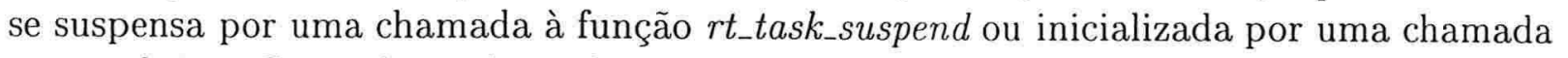
a rt_task_init. O protótipo desta é mostrada em seguida.

extern int rt_task_wakeup (RT_TASK *task);

Para marcar uma tarefa, previamente criada com uma chamada de rt_task_init, como pronta para executar, utiliza-se a função rt_task_make_periodic. A tarefa executará em intervalos especificados em period e o tempo de inicialização desejável é fornecido em start_time. Caso a tarefa deva ser executada imediatamente, usa-se o rt_get_time como valor de parâmetro em start_time. O protótipo da função rt_task_make_periodic é:

extern int rt_task_make_periodic(RT_TASK *task, RTIME start_time, RTIME period);

Para exemplificar o uso da função rt_task_make_periodic na criação de duas tarefas com um período de 993 temos:

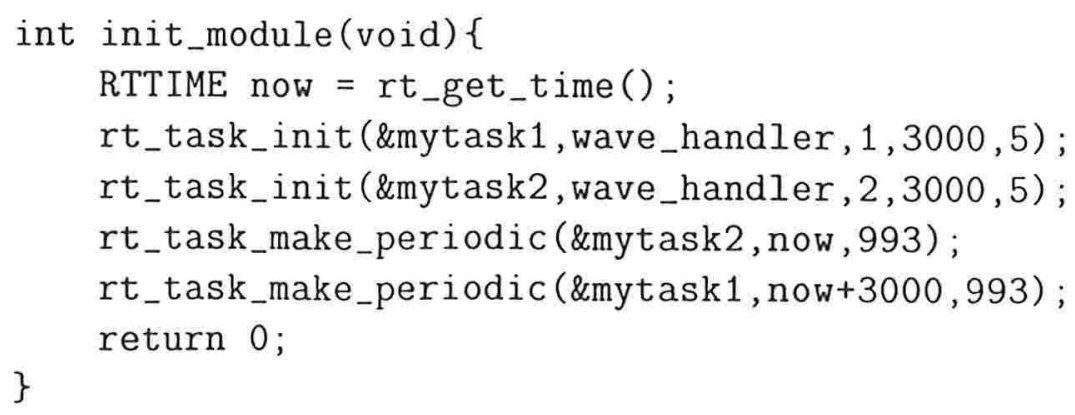


No RT_Linux é possível selecionar o modo de execução do escalonador através das funções $r t l_{-} s e t$ periodic_mode e rtl_set_oneshot_mode, cujos protótipos exibe-se a seguir.

extern RTIME rtl_set_periodic_mode (RTIME period);

extern int rtl_set_oneshot_mode (void);

Descritas as funções e estruturas de dados principais do RT-Linux, exibe-se na próxima seção como tarefas de tempo real e o Linux se comunicam.

\subsubsection{FIFO}

O RT-Linux utiliza-se de buffers FIFO para mover informações entre as tarefas de tempo real e o Linux. Estas estruturas são alocadas no espaço de endereço do kernel e são referenciadas por números inteiros. As interfaces das tarefas de tempo real para RTFIFOs incluem funções de criação, destruição, leitura e escrita, onde as funções de leitura e escrita são atômicas para evitar o problema de inversão de prioridade [YB99].

Os processos de usuários vêem os RT-FIFOs como dispositivos de caracteres. Por exemplo, /dev/rtfo e /dev/rtf1. O arquivo $r t f . h$, comentado a seguir, contém as funções para que as tarefas de tempo real possam ler e escrever em RT-FIFOs. Assim como na Secão 5.2.2.1, as funções são comentadas e posteriormente têm seus protótipos exibidos. É importante ressaltar que as funções $r t f_{-}{ }^{*}$ são usadas pelas tarefas de tempo real, pois as tarefas Linux usam funções de acesso a dispositivos de caracteres, como por exemplo read, write entre outras.

Um uso imediato deste esquema de RT-FIFO é data streaming. Em uma aplicação de aquisição de dados, por exemplo, uma tarefa de tempo real é criada usando rt_task_init e rt_task_make_periodic para adquirir os frames em intervalos regulares. Esta tarefa envia seus dados para uma tarefa Linux usando $r t f_{-} p u t$. A tarefa Linux fica em um loop, lendo dados de uma RT-FIFO, escrevendo dados em disco, enviando pela rede ou exibindo dados através de um servidor de janelas [Epp97].

Uma outra característica do RT-Linux é a existência de um tratador de RT-FIFOs, o qual é executado quando dados são lidos ou escritos em uma RT-FIFO por uma tarefa Linux. O tratador é criado pela função $r t f_{-}$create_handle que recebe como parâmetro o número da RT-FIFO a ser manipulada. O protótipo desta função é:

extern int rtf_create_handler(unsigned int fifo, int (*handler) (unsigned int fifo)

A função rtf_create, cujo protótipo é mostrado a seguir, origina uma RT_FIFO ('om tamanho inicial size e associa a mesma um identificador fifo. Este é um valor único dentro do sistema. Se a função executa com sucesso o valor de retorno é size, caso contrário í-1. 
extern int rtf_create(unsigned int fifo, int size);

Para remover uma RT-FIFO previamente criada com rtf_create, utiliza-se a função $r t f_{-}$destroy e o identificador da fila fifo é então disponibilizada para reutilização. Se executada com sucesso a função retorna 0 e em caso de falha retorna -1. A função $r t f_{-}$create possui o protótipo mostrado a seguir.

extern int rtf_destroy(unsigned int fifo);

O redimensionamento de uma RT-FIFO é efetuado pela função $r$ tf_resize, cujo protótipo é exibido a seguir. Uma observação importante é que qualquer dado presente na RT-FIFO quando rtf_resize executa pode ser perdido.

extern int rtf_resize(unsigned int minor, int size);

A escrita de um bloco de dados para uma RT-FIFO é realizada pela função $r t f_{-} p u t$, cujo protótipo é mostrado a seguir. O parâmetro count é o tamanho do bloco em bytes e o mecanismo citado só é disponível para tarefas de tempo real. As tarefas Linux usam write para colocar dados na RT-FIFO.

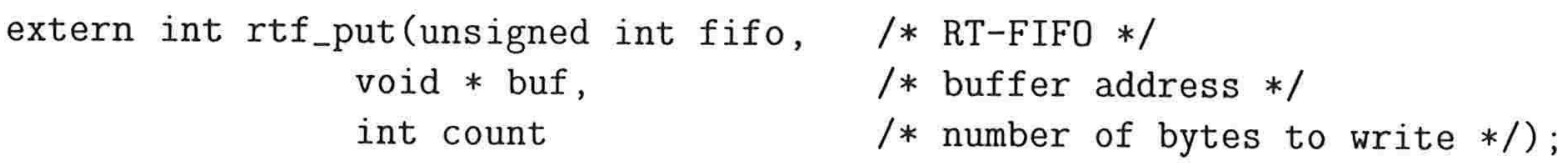

A função rtf_get tenta ler count bytes da RT-FIFO fifo e é freqüentemente usada em conjunto com rtf_create_handler para processar os dados recebidos assincronamente da tarefa Linux. O protótipo desta função é:

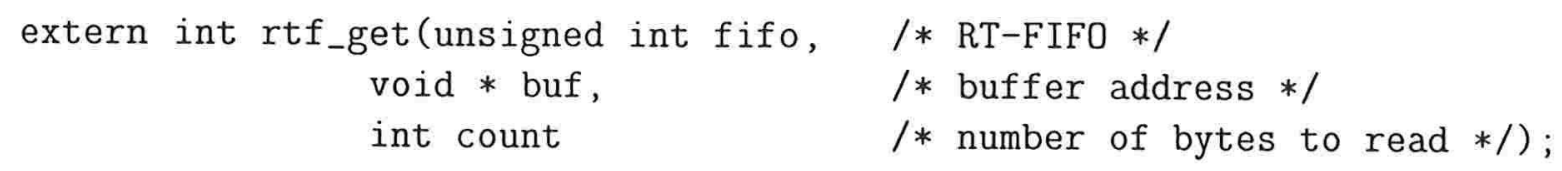

Analisadas as formas de comunicação entre tarefas de tempo real e Linux, descreve-se o escalonador propriamente dito na próxima seção.

\subsubsection{O Escalonador}

A principal função de um escalonador de tempo real é satisfazer as restrições de tempo das tarefas. O RT-Linux usa o escalonamento preemptivo baseado em prioridade. Se existem várias tarefas que estão prontas para executar, a tarefa que tem a mais alta prioridade é 
escalonada. Sempre que uma tarefa se torna pronta para executar e tem prioridade maior do que a tarefa corrente, o escalonador apropria-se do processador e o disponibiliza para aquela tarefa de mais alta prioridade [Bar97].

O escalonador trata o Linux como a tarefa de tempo real com a mais baixa prioridade. Desta maneira, o Linux somente executa quando não existe nenhuma outra tarefa de tempo real para ser escalonada.

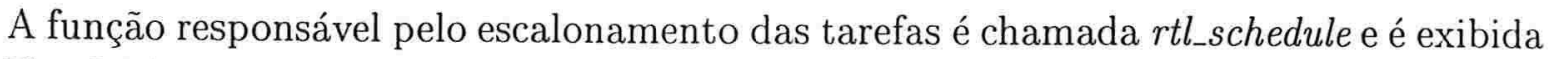
na Fig. 5.14.

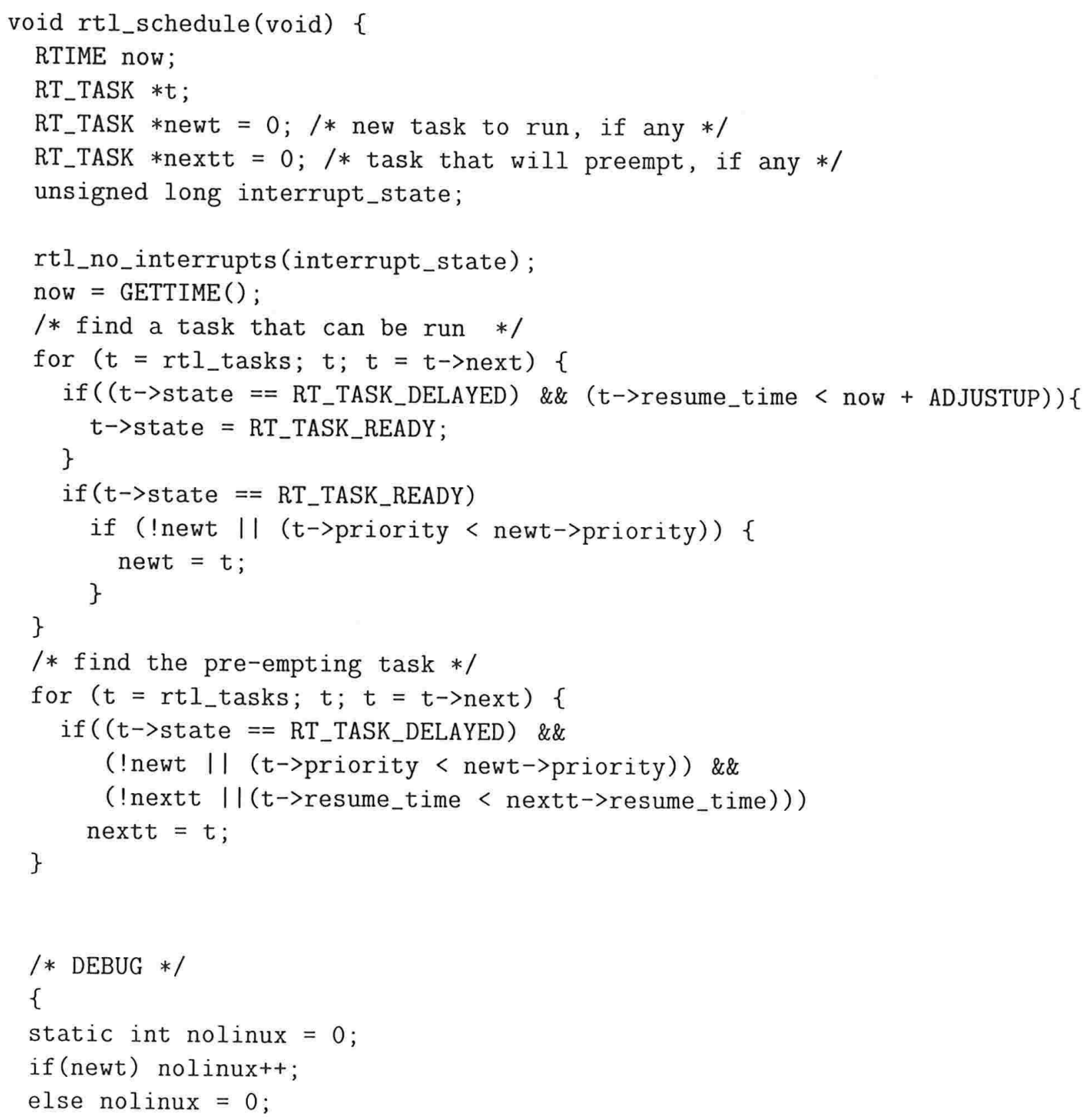




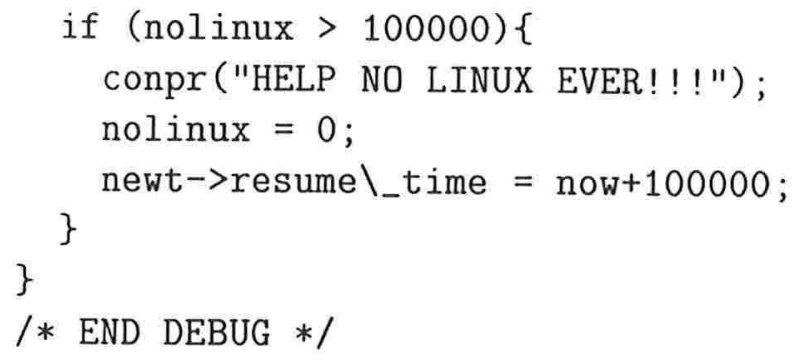




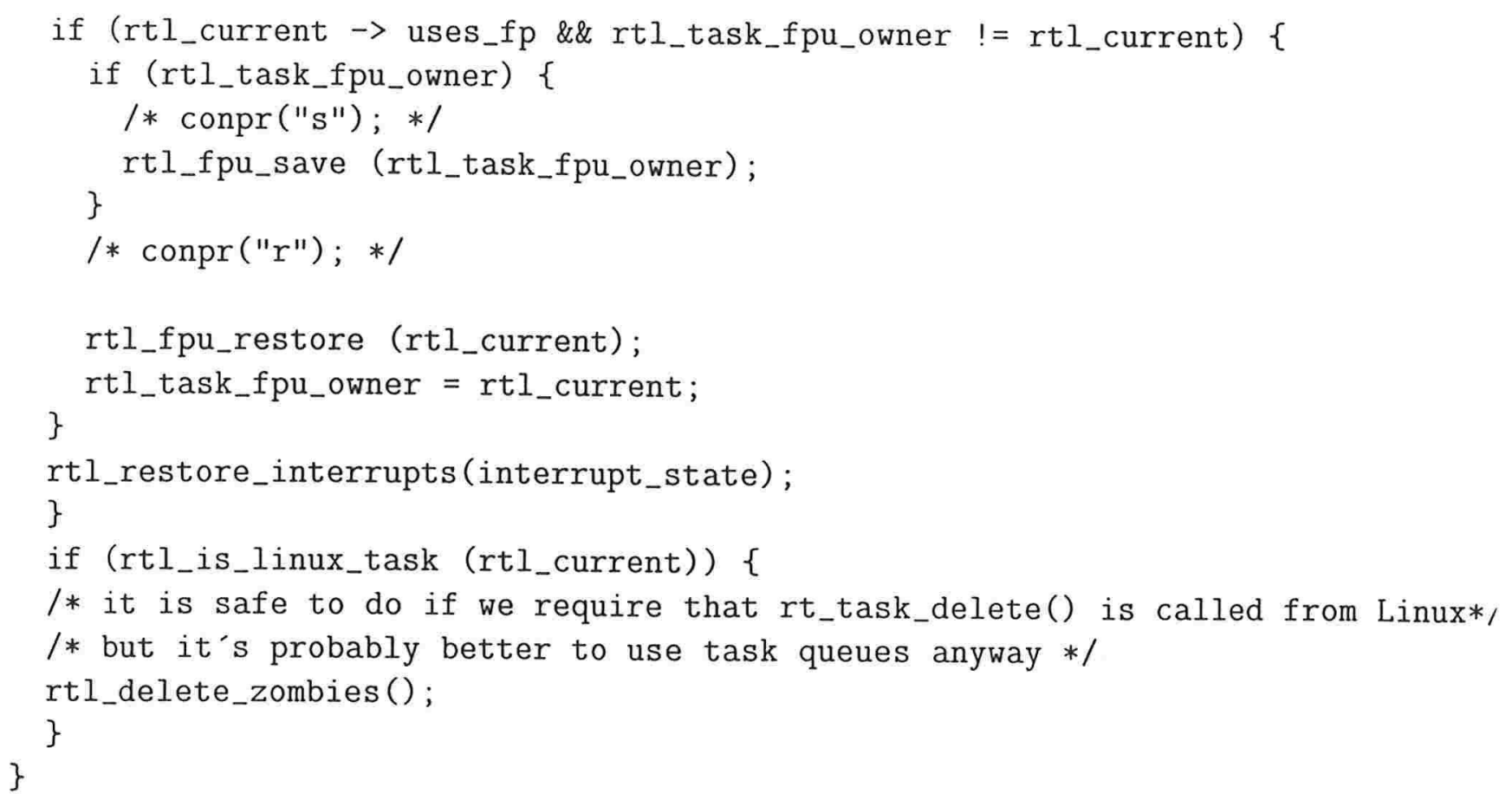

Figura 5.14: Função rtl_schedule do RT-LINUX

Na próxima seção algumas considerações são apresentadas em complementação à visão geral do RT-Linux e do KU RT-LINUX exibidas neste capítulo. Também efetua-se algumas comparações com o LINUX-SMART.

\subsubsection{Considerações Finais}

O sistema KURT define uma nova classe de aplicações de tempo real denominada firm. Além disto, apresenta várias inovações como a idéia de eventos, módulos de tempo real e a utilização do sistema UTIME, por exemplo.

Um aspecto negativo da abordagem descrita é o perigo de se ter um módulo com algum bug e este derrubar o sistema, pois estes módulos são partes do kernel. Outro fato é que embora o KURT permita que tarefas de tempo real e convencionais co-existam, as tarefas convencionais só executam se não houver nenhuma de tempo real para executar. É importante também destacar que o KURT utiliza-se de uma tabela de classificação que pode crescer arbitrariamente. Conforme o tamanho que esta tabela atinja não pode permanecer na memória, causando assim degradação. Este sistema parece ser ideal para tarefas periódicas.

No caso do LINUX-S.MART nenhum destes aspectos negativos do KURT ocorrem. Contudo o KLRT tem a vantagem de possuir uma resolução de microsegundos utilizando- 
se do sistema UTIME que evita que a CPU seja interrompida em intervalos regulares, sendo esta interrompida apenas quando há necessidade de executar algum módulo de tempo real. Este fato não ocorre no LINUX-SMART porque sua resolução é de $1 \mathrm{~ms}$ e a CPU é interrompida em intervalos regulares.

A proposta do RT-Linux tenta tratar convenientemente tarefas de tempo real hard criando uma camada virtual onde as tarefas de tempo real são colocadas em uma lista ligada e um escalonador simples escolhe a tarefa com maior prioridade para executar. Neste contexto, o Linux é visto como uma tarefa de tempo real com a menor prioridade.

Sob esta perspectiva, observa-se uma melhor forma de tratamento para tarefas de tempo real do que as políticas atualmente existentes no Linux. Isto porque o RT-Linux é rápido, tem uma baixa latência, usa um escalonador simples e é previsível o tempo de resposta para tarefas de tempo real. Além disto, utiliza-se de todos os serviços do Linux como por exemplo: GUI, TCP/IP, NFS e compiladores entre outros.

Um aspecto negativo é que as tarefas de tempo real podem utilizar todo o tempo da CPU de maneira que as tarefas básicas do sistema não possam ser processadas, gerando um comportamento incorreto do sistema. Outro fato é que processos de tempo real não podem facilmente usar os drives do LINUX porque o RT-LINUX disabilita as interrupções no LINUX simulando no kernel de tempo real as interrupções mencionadas. No RTLINUX, processos de tempo real têm uma alocação fixa de memória para códigos e dados, além de executar em modo kernel. Adicionalmente, estes processos não podem acessar estruturas de dados no kernel do LINUX porque inconsistências poderiam ser geradas.

Como as interrupções não são disabilitadas no LINUX-SMART o problema mencionado no RT-LINUX não ocorre. Outra diferença é que os processos de tempo real não executam em modo kernel, isto evita que um bug no processo cause uma queda no sistema.

Discutidas as tendências atuais apresenta-se no próximo capítulo as contribuições e as pesquisas futuras que podem decorrer desta dissertação. 


\section{Capítulo 6}

\section{Conclusões e Trabalhos Futuros}

Este capítulo resume os resultados obtidos e discute o direcionamento de trabalhos futuros associados com esta dissertação. Lembrando que a implementação, as análises e os testes do LINUX-SMART foram realizados sob a perspectiva do gerenciamento de CPU, ignorando-se demais recursos como memória e I/O.

Analisando os testes efetuados no LINUX-PADRÃO e no LINUX-SMART verificouse um melhor comportamento da aplicação principal no LINUX-SMART na perspectiva tempo versus iteração.

Um ponto de melhoria na política de escalonamento implementada no LINUX-SMART foi um melhor gerenciamento, por parte do usuário, do controle do sistema através das chamadas ao sistema que permitem informar ao sistema a prioridade, o quantum, o share e o deadline de uma aplicação em relação as demais.

Outro aspecto vantajoso foi o processo de notificação do sistema para a aplicação suportado pelo LINUX-SMART. Através deste procedimento uma aplicação é informada sobre a perda de seu deadline possibilitando um ajuste da mesma neste ambiente de sobrecarga.

No intuito de ressaltar as características do LINUX-SMART, comenta-se a seguir aspectos importantes deste escalonador desta vez comparando-o com outros escalonadores de tempo real.

\subsection{O LINUX-SMART e Outros Escalonadores de Tempo Real}

Escalonadores de tempo real como Rate Monotonic e Earliest Deadline First foram projetados para tratar eficientemente os requisitos de recursos das aplicações de tempo real. Entretanto, não executam bem quando o sistema está sobrecarregado, nem foram proje- 
tados para suportar tarefas convencionais. Em contraste com o SMART estas propostas são mais restritivas, pois este sistema implementa um compartilhamento justo do processador entre tarefas de tempo real e aquelas convencionais. Além distos os testes efetuados com o LINUX-SMART evidenciaram que este sistema executa bem em uma situação de sobrecarga.

O LINUX-SMART tem um escalonador baseado em WFQ e alocação proporcional ao share e como tal, é flexível e garante justiça entre processos competidores. Contudo, este sistema não atende aplicações de tempo real que exijam garantias precisas para respeitarem os seus deadlines. Dentre aqueles sistemas que seguem este mesmo paradigma, alocação proporcional ao share, apenas o escalonamento lotérico trata esta situação. Isto porque o ambiente proposto nesta política, através das apuradas abstrações utilizadas, consegue integrar reserva de recursos com alocação proporcional ao share.

O LINUX-SMART implementou restrições de tempo baseadas em deadline. Dependendo das prioridades e do controle de admissão, novas restrições de tempo podem utilizar um tempo que poderia ter sido necessário para finalizar uma restrição existente em tempo ou manter os requisitos de share proporcional das outras aplicações. Esta situação não ocorre no Rialto porque este sistema fornece garantias mais fortes de independência da aplicação.

Em um cenário de sobrecarga, o SMART utiliza uma política de escalonamento com compartilhamento justo. Comparando com o ETI RD, este só permite que uma nova thread entre no sistema se a soma das permissões mínimas para todas as threads no sistema pode ser simultaneamente acomodada se a nova thread é admitida. Isto mostra que o SMART é flexível, pois suporta grandes variações de carga baseando-se na urgência e na importância das aplicações. O LINUX-SMART também dinamicamente faz o balanço das necessidades das aplicações de tempo real e convencionais. Neste contexto, associa prioridades para ambas as classes, mas adiciona um peso para as tarefas convencionais.

Um outro aspecto a comparar entre o LINUX-SMART e o ETI RD é a periodicidade das aplicações: o LINUX-SMART também trata tarefas não periódicas. Para tarefas não periódicas, o ETI RD necessita de um servidos esporádico, que é uma tarefa periódica, para gerenciá-las, o que não é exigido no LINUX-SMART.

Observe que o uso de reservas baseia-se em políticas de controle de admissão inflexíveis para evitar sobrecarga. Isto é geralmente realizado em uma abordagem FIFO, na qual aplicações inicializadas posteriormente podem ter suas solicitações de recursos negadas mesmo sendo aplicações mais importantes. Alternativamente, estas aplicações renegociam suas requisições através de um mecanismo que no melhor caso é um processo de tentativa e erro. No caso do LINUX-SMART, através de uma política de controle de admissão, esta situação não ocorre.

Fornecendo restrições de tempo e shares, SMART não somente realiza enfileiramento justo, mas pode também mais efetivamente encontrar os requisitos de tempo real, com ou sem reservas. Ao contrário dos escalonadores de enfileiramento justo o SMART pode 
fornecer uma ótima performance de tempo real enquanto permitindo share proporcional baseando-se nas alocações desejadas pelo usuário para aplicações de tempo real e convencionais. Além disto, o SMART suporta alocação de recursos proporcional e baseada em prioridade simultaneamente.

O escalonamento hierárquico separa as políticas de escalonamento para tarefas de tempo real e convencional. Estas políticas são combinadas usando prioridade ou compartilhamento proporcional como base do mecanismo de escalonamento. O problema com esta abordagem é que os requisitos de tempo real não são explicitamente considerados. Outro aspecto negativo destes escalonadores é a incapacidade de propagar decisões para o mais baixo nível de gerenciamento onde o escalonamento propriamente dito é realizado. Comparando com o LINUX-SMART, este procede como um escalonador de tempo real quando tratando e somente solicitações de tempo real e age como um escalonador convencional quando escalona somente requisições convencionais. Contudo, combina estas abordagens em uma maneira integrada que totalmente considera os requisitos de tempo real.

O escalonador LINUX-SMART permite que usuários atribuam prioridade para threads convencionais e de tempo real, mas prioriza aquelas convencionais dentro da mesma classe de equivalência. A solução proposta por Steere et. al, embora ofereça precedência para tarefas de tempo real, espera que muitas tarefas sejam classificadas como real-rate. Isto inclui o que costuma-se classificar como aplicações de tempo real soft tal como multimídia.

O LINUX-SMART garante que tarefas mais importantes obtêm seus requisitos de recursos, independente da classe a qual pertencem, tempo real ou convencional. Além de flexibilidade, não presente em esquemas estáticos, o LINLX-SMART fornece uma utilização mais eficiente dos recursos, adapta-se a variações de cargas de trabalho e provê feedback dinâmico para suportar aplicações de tempo real adaptativas. Características não encontradas nas outras abordagens referenciadas nesta dissertação.

Efetuadas algumas comparações do LINUX-SMART com alguns escolanodores existentes, comenta-se na próxima seção os resultados desta dissertação.

\subsection{Contribuições}

Esta seção enumera as contribuições desta dissertação.

Inicialmente, cita-se a incorporação do SMART ao sistema operacional LINUX, sendo este fato a maior relevância deste trabalho incluindo as fases de análise, projeto, implementação e testes sobre a viabilidade do SMART no LINUX. Acreditamos que o resultado obtido acomode melhor aplicações de tempo real com convencionais do que os outros dois sistemas existentes, conforme discutido na Seção 5.2.3.

Realizou-se um relato dos problemas encontrados durante a implementação com as soluçōes adotadas no Cap. 3. as considerações finais efetuadas no Cap. 4 e as comparações 
deste capítulo entre o LINUX-SMART e alguns escalonadores abordados no Cap. 5.

Posteriormente, menciona-se os testes para medida de desempenho efetuados no ambiente implementado, o LINUX-SMART. Para realização destes testes, criou-se uma aplicação em TK/TCL entitulada Controle de Aproximação de Aeronaves em Aeroportos, cuja descrição encontra-se no Cap. 4.

Também foi realizada uma análise comparativa entre os resultados obtidos com o LINUX-SMART e aqueles registrados no LINUX-PADRÃO [VNdS99b]. Ressalta-se que as medidas de desempenho foram extraídas dos mesmos cenários: a aplicação executando sozinha, aplicação com 10 processos gráficos concorrentes, a aplicação com 41 processos (20 processos CPU bound, 20 consumindo bastante memória e um processo gráfico) executando simultaneamente e a aplicação concorrendo com a compilação do emacs.

Adicionalmente, as atividades de implementação e testes cita-se a elaboração de uma pequena resenha dos trabalhos relacionados com escalonadores de tempo real. Um aspecto interessante também abordado nesta dissertação foram os esforços atuais na comunidade LINUX. Nesta etapa, estudou-se os sistemas RT-LINUX e KU RT-LINUX, os quais foram comparados com o LINUX-SMART em algumas características.

Também é oportuno referenciar os resultados obtidos na etapa inicial da pesquisa onde objetivou-se determinar o grau de tratamento que o LINUX-PADRÃO oferece para as aplicações de tempo real soft. Os resultados mencionados culminaram em trabalho publicado [VNdS99b] no Workshop de Tempo Real da SBRC - Simpósio Brasileiro de Rede de Computadores.

Descritas as contribuições, exibe-se a seguir o direcionamento para pesquisas futuras.

\subsection{Trabalhos Futuros}

Esta seção relata alguns objetivos pretendidos nesta etapa posterior à implementação e aos testes iniciais do LINUX-SMART.

Pretende-se usar mecanismos de feedback da taxa de progresso das aplicações como base para a alocação dos ciclos de CPU. Isto substitui a necessidade das aplicações de tempo real de fornecerem o seu tempo de processamento e deadline. O ajuste passa a ser dinâmico. Nesta abordagem dinàmica, outro fator a ser implementado e que consta dos construtores de programação do SMART é o fornecimento pelo sistema operacional da sua disponibilidade de recursos, o que propicia que uma aplicação de tempo real adaptativa possa ajustar a sua taxa de execução quando seus requisitos de tempo não puderem ser satisfeitos.

Outro aspecto interessante para ser adicionado, seria a simulação de interrupçōes para permitir que uma aplicação com mais alto valor de par ordenado possa interromper o processo atualmente executando. Para isto o LINUX-SMART salvaria o estado do kernel 
e executaria o processo de tempo real imediatamente.

Também pretende-se investir em alguns testes adicionais de performance, desta vez com o sistema em sobrecarga, mas em cenários com várias aplicações multimídia, onde estas tratem a notifição de perda de deadline. Atualmente a aplicação de tempo real soft usada não faz tratamento algum, apenas finaliza sua execução com o recebimento do sinal SIGUSR1.

Adicionalmente, pretende-se incluir uma ferramenta que monitora as atividades do processador em tempo real, lista as principais tarefas CPU bound, visualiza as trocas de contexto entre tarefas causadas por decisões de escalonamento e mostra características de processos como share, prio, pid e outros.

Outros objetivos são: estender a implementação atual para sistemas multi-processador (SMP), analisar o comportamento do LINUX-SMART em sistemas distribuídos e empregar em um ambiente de produção real, por exemplo, redes Linux operando em universidades, os resultados alcançados.

Esta dissertação objetivou um aumento no desempenho do sistema a partir de melhorias no gerenciamento dos ciclos de CPU para as aplicações. Contudo, pelo exposto na Seção 4.5, este não é o único e principal fator a ser tratado visando melhoria de desempenho. Assim os resultados obtidos refletem os esforços de pesquisa em uma direção possível, sendo fatores como o gerenciamento de memória e o tratamento de entrada/saída outros caminhos para serem explorados. 


\section{Referências Bibliográficas}

[Bar97] M. Barabanov. A Linux Real-Time Operating System. Master's thesis, New Mexico Institute of Mining and Technology, Socorro, New Mexico, June 1997.

[Bar98] M. Barabanov. An Introduction to RT-Linux, Mar 1998. Available at http://people.qualcomm.com/btwallac/projects/RTLManual/RTLManualv0.03 /RTLManual-2.html.

[BBD $\left.{ }^{+} 98\right] \quad$ M. Beck, H. Böhme, M. Dziadzka, U. Kunitz, R. Magnus, and D. Verworner. Linux Kernel Internals. Addison-Wesley, second edition, 1998.

[Ben96] R. Bentson. Inside Linux: A Look at Operating System Development. Specialized System Consultants, first edition, 1996.

[Bet94] R. Bettati. End-to-End Scheduling to Meet Deadlines in Distributed Systems. PhD Thesis, University of Illinois, 1994.

[BGKO99] C. Basoglu, R. Gove, K. Kojima, and J. O'Donnell. "Single-Chip Processor Media Applications: The MAP1000". In Int J Imaging Syst Technol, 1999. in press.

[BGOS97] J. Bruno, E. Gabber, B. Özden, and A. Siberschatz. "Move-to-Rear List Scheduling: A New Scheduling Algorithm for Providing QoS Guarantees". In ACM Multimedia'97, November 1997.

[BH99] M. Baker-Harvey. "ETI Resource Distributor: Guaranteed Resource Allocation and Scheduling in .Multimedia Systems". In Proceedings of the Third Symposium on Operating Systems Design and Implementation (OSDI'99), pages 131 - 144, New Orleans, LA, Feb 1999. Usenix Association.

[Bur94] T. M. Burkow. "Operating System Support for Distributed Multimedia Applications: A Survey of Current Research". Technical Report Pegasus 94-8, University of Cambridge Computer Laboratory, 1994.

[But97] G. C. Buttazzo. Hard Scheduling Algorithms and Applications, chapter 4, pages $77-107$. Kluwer Academic Publishers. 1997. 
[BW96] A. Burns and A. Wellings. Real-Time Systems and Programming Languages, chapter 13, pages 399 - 437. Addison-Wesley, 1996. Reprinted 1997.

[BY96] M. Barabanov and V. Yodaiken. "Real-Time Linux". Linux Journal, Mar 1996.

[BZ96] J. Bennett and H. Zhang. "WF2Q: Worst-Case Fair Weighted Fair Queueing". In IEEE INFOCOM 96, pages 120-128, San Francisco, CA, Mar 1996.

[CDM97] R. Card, É. Dumas, and F. Mével. The Linux Kernel Book. John Wiley, 1997.

[DKS89] A. Demers, S. Keshav, and S. Shenker. "Analysis and Simulation of a Fair Queueing Algorithm". In Proceeding of SIGCOMM'89, pages 1-12, Sept 1989.

[Epp97] J. Epplin. "Linux as an Embedded Operating System". Embedded Systems Programming, 10(10), Oct 1997.

[FPEN94] G. F. Franklin, J. D. Powell, and A. Emami-Naeini. Feedback Control of Dynamic Systems. Addison-Wesley, third edition, 1994. Reprinted with corrections June, 1995.

[GGV96] P. Goyal, X. Guo, and H. Vin. "A Hierarchical CPU Scheduler for Multimedia Operating Systems". In Proceedings of the Second Symposium on Operating Systems Design and Implementation, pages 107-122, Seattle,WA, Oct 1996.

[HF98] J. Helander and A. Forin. "MMLite: A Highly Componentized System Architecture". In Proceedings of the Eighth ACM SIGOPS European Workshop on Support for Composing Distributed Applications, Sep. 1998.

[HP96] K. Husain and T. Parker. Linux Unleashed. Sams Publishing, second edition, 1996.

[HSPN98] R. Hill, B. Srinivasan, S. Pather, and D. Niehaus. "Temporal Resolution and Real-Time Extensions to Linux. Technical report, University of Kansas, Jun 1998.

[Hyd94] E. Hyden. Operating System Support for Quality of Service. PhD Thesis, University of Cambridge, February 1994.

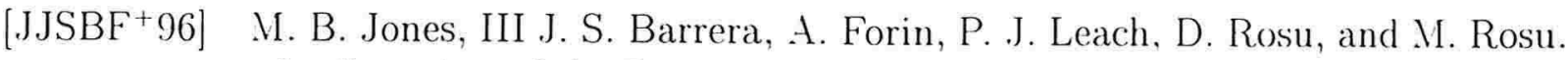
"An Overview of the Rialto Real-Time Architecture". In Proceedings of the Seventh ACM SIGOPS European Workshop, pages 249 256. Sep. 1996. 
[JLDJSB95] M. B. Jones, P. J. Leach, R. P. Draves, and III J. S. Barrera. "Modular Real-Time Resource Management in the Rialto Operating System". In Proceedings of the Fifth Workshop on Hot Topics in Operating Systems, pages 12 - 17. IEEE Computer Society, May 1995.

[Joh97] E. Johnson. Graphical Applications with Tcl and Tk. M\&T Books, second edition, 1997.

[JRR97] M. B. Jones, D. Rosu, and M. Rosu. "CPU Reservations and Time Constraints: Efficient, Predictable Scheduling of Independent Activities". In Proceedings of the 16th ACM Symposium on Operating Systems Principles, Oct. 1997.

[Kao95] B. Kao. Scheduling in Distributed Soft Real-Time Systems with Autonomous Components. $\mathrm{Ph}(\mathrm{d})$ Thesis, Princeton University, November 1995.

[Kim] M. Kim. Ising Model Simulator. http://hana.etri.re.kr/ mgkim/tcltk.html.

[KL88] J. Kay and P. Lauder. "A Fair Share Scheduler". Comunications of the ACM, 31(1):44-55, 1988.

[Kuh98] M. Kuhn. A Vision for Linux 2.2 - POSIX.1b Compatibility and Real-Time Support, Sept 1998. Available at ftp://ftp.informatik.unierlangen.de/local/cip/mskuhn/misc/linux-posix.1.

[Lin98] Revenge of the hackers. The Economist, Jul. 1998. Summary:General information about the success of Linux on a server, but questions its viability as a desktop OS.

[Lin99a] More users are looking at linux. CNN, May 1999. Summary: Although most information technology managers remain aloof to Linux, the free, Unix-like operating system is rapidly gaining enough credibility to merit a look from users at major companies, according to a Computerworld tracking survey.

[Lin99b] More big technology firms embrace broad use of linux operating system. MSNBC / Wall Street Journal, May 1999. Summary: Several more big technology companies are stepping up their commitments to use Linux.

[LL73] C. Liu and J. Layland. "Scheduling Algorithms for Multiprogramming in a Hard Real-Time Enviroment". Journal of the ACM, pages 20(1):46-61, July 1973.

[LMB +95$] \quad$ I. Leslie, D. McAuley, R. Black, T. Roscoe, P. Barham, D. Evers, R. Fairbairns, and E. Hyden. "The Design and Implementation of an Operating System to Support Distributed Multimedia Applications". Journal on Selected Areas in Communications, June 1995. 
[LSD89] J. P. Lehoczky, L. Sha, and Y. Ding. "The Rate Monotonic Scheduling Algorithm: Exact Characterization and Average Case Behavior". In Proceedings of the 10th IEEE Real-Time Systems Symposium, pages 166 - 171, December 1989.

[Mah95] U. Maheshwari. "Charge-Based Proportional Scheduling". Technical Memo MIT/LCS/TM-529 TM-529, M.I.T Laboratory for Computer Science, Cambridge, MA, Jan 1995.

[MoEUoT96] Mathematics and Computing Science Dept. of Eindhoven University of Technology. Readprofile - tool as part of the util-linux package. ftp://ftp.win.tue.nl in /pub/linux-local/utils/util-linux/util-linux2.9u.tar.gz, May 1996. Also available at ftp://ftp.br.kernel.org in /pub/linux/utils/util-linux/util-linux-2.9u.tar.gz.

[MST94a] C. Mercer, S. Savage, and H. Tokuda. "Processor Capacity Reserves: Operating System Support for Multimedia Applications". In Procedings of the IEEE International Conference on Multimedia Computing and Systems, May 1994.

[MST94b] C. W. Mercer, S. Savage, and H. Tokuda. "Processor Capacity Reserves: Operating System Support for Multimedia Applications". In Proceedings of the IEEE International Conference on Multimedia Computing and Systems, May 1994.

[NHNW93] J. Nieh, J. Hanko, J. Northcutt, and G. Wall. "SVR4 UNIX Scheduler Unacceptable for Multimedia Applications". In Proceedings of the Fourth International Workshop on Networkand Operating System Support for Digital Audio and Video, Lancaster,U.K, November 1993.

[NL95] J. Nieh and M. Lam. "Integrated Processor Scheduling for Multimedia". In Proceedings of the Fifth International Workshop on Network and Operating System Support for Digital Audio and Video, Durham, New Hampshire, April 1995.

[NL97a] J. Nieh and M. Lam. "SMART UNIX SVR4 Support Multimedia Applications". In Procedings of the IEEE International Conference on Multimedia Computing, Ottawa,Ontario,Canadá, June 1997.

[NL97b] J. Nieh and M. Lam. "The Design, Implementation and Evaluation of SMART: A Scheduler for Multimedia Applications". In Proceedings of the Sixteenth ACM Symposium on Operating Systems Principles, Saint-Malo, France, October 1997.

[NSSH95] E. Nemeth. G. Snyder, S. Seebass, and T. Hein. Unix System Administration Handbook. Prentice Hall PTR, second edition, 1995. 
[Ous94] J. Ousterhout. Tcl and the Tk Toolkit. Addison-Wesley Publishing Company, 1994.

[PG93] A. K. Parekh and R. G. Gallager. "A Generalized Processor Sharing Approach to Flow Control in Integrated Services Networks: The Single-Node Case". IEEE/ACM Transactions on Networking, 1(3):344 - 357, June 1993.

[RL99] RT-Linux. RT-Linux Version V1.1 for Linux 2.0.36, 1999. Available at ftp://rtlinux.cs.nmt.edu/pub/rtlinux/v1.

[Rus97] D. Rusling. The Linux Kernel. D. A. Rusling, 1997. Available at http://uhp.u-nancy.fr/linux/linuxdoc/LDP/tlk/.

$\left[\mathrm{SAWJ}^{+}\right.$96] I. Stoica, H. Abdel-Wahab, K. Jeffay, S. Baruah, J. Gehrke, and G. Plaxton. "A Proportional Share Resource Allocation Algorithm for Real-Time, TimeShared Systems". In Proceedings of 17th Real-Time Systems Symposium, pages 288-299, December 1996.

[SAWJ97] I. Stoica, H. Abdel-Wahab, and K. Jeffay. "On the Duality between Resource Reservation and Proportional Share Resource Allocation". In Proceedings of Multimedia Computing and Networking, Feb. 1997.

[SGG+99] D. C. Steere, A. Goel, J. Gruenberg, D. McNamee, C. Pu, and J. Walpol. "A Feedback-Driven Proportion Allocator for Real-Rate Scheduling". In Proceedings of the Third Symposium on Operating Systems Design and Implementation - OSDI'99, pages 145 - 158, New Orleans, LA, Feb 1999.

[Shn92] B. Shneiderman. Designing the User Interface: Strategies for Effective Human-Computer Interaction. Addison-Wesley, second edition, 1992.

[Sri95] B. Srinivasan. A Firm Real-Time System Implementation Using Commercial Off-The-Shelf Hardware and Free Software. Master's thesis, University of Kansas, Lawrence, Kansas, 1995.

[Sri97] B. Srinivasan. KURT: The KU Real-Time Linux, 1997. Available at http://hegel.ittc.ukans.edu/projects/kurt/.

[SSL89] B. Sprunt, L. Sha. and J. Lehoczky. "Aperiodic Task Scheduling for HardReal-Time Systems". The Journal of Real Time Systems 1, Nov. 1989.

[SW95] R. Steinmetz and L. Wolf. "Evaluation of a CPU Scheduling Mechanism for Synchronized Multimedia Streams". In Joint Conference: 8th International Conference on Modelling Techniques and Tools for Computer Performance Evaluation and Sth GI/ITG Conference on Measuring, Modelling and Evaluation Computing and Communication System, Heidelberg,Germany, September 1995. 
[SW97] R. Steinmetz and L. Wolf. "Quality of Service: Where are We?". In Proceedings of the IFIP Fifth International Workshop on Quality of Service (IWQOS'97), New York, NY, USA, May 1997.

[SWM95] R. Staehli, J. Walpole, and D. Maier. "Quality of Service Specifications for Multimedia Presentations". Multimedia Systems, 3(5/6):251 - 263, Nor. 1995.

[VNdS99a] J. E. Vieira, M. C. G. Noronha, and Dilma M. da Silva. "Estudo de Caso: Desempenho do Sistema Operacional Linux". Technical report, Departamento de Ciência da Computação, Instituto de Matemática e Estatística, USP, Fevereiro 1999. available at http://www.ime.usp.br/ dil$\mathrm{ma} / \mathrm{smart} / \mathrm{ws} 99$.

[VNdS99b] J. E. Vieira, M. C. G. Noronha, and Dilma M. da Silva. "Estudo de Caso: Desempenho do SO Linux para Aplicações Multimídia em Tempo Real". In Proc. of the Second Symposium of Real Time, pages 88-95, Salvador, B.A. May 1999.

[Wa195] C. Waldspurger. Lottery and Stride Scheduling: Flexible Proportional-Share Resource Management. PhD. Thesis, Massachusetts Institude of Technology, September 1995.

[WBV96] L. Wolf, W. Burke, and C. Vogt. "Evaluation of a CPU Scheduling Mechanism for Multimedia Systems". Software - Practice and Experience. 26(4):375-398, April 1996.

[WW94] C. A. Waldspurger and W. E. Weihl. "Lottery Scheduling: Flexible Proportional-Share Resource Management". In Proceedings of the First USENIX Symposium on Operating Systems Design and Implementation (OSDI), pages 1 - 11, Monterey, California, Nov 1994.

[WW95] C. A. Waldspurger and W. E. Weihl. "Stride Scheduling: Deterministic Proportional-Share Resource Management". Technical Report MIT/LCS/TM-528, Massachusetts Institute of Techno;ogy, MIT Laboratory for Computer Science, Cambridge, Massachusetts, June 1995.

[YB99] V. Yodaiken and M. Barabanov. Real time. In "Linux Applications Development and Deployment Conference. USENIX, Jan 1999.

[Zha91] L. Zhang. "Virtual Clock: A New Traffic Control Algorithm for Packet Switching Networks". ACM Transactions on Computer Systems, 9(2):121 - 124, May 1991.

[ZK91] H. Zhang and S. Keshav. "Comparison of Rate-Based Service Disciplines". In Proceedings of the SIGCOMM'91 Conference: Communications Architectures and Protocols, pages 113 - 121. Zurich. Switzerland, Sep 1991. 


\section{Apêndice A}

\section{Custos de Escalonamento no LINUX-SMART e no LINUX-PADR ÃO}

Neste apêndice, apresenta-se os resultados obtidos com a ferramenta readprofile. O objetivo é fornecer dados para uma comparação dos custos de escalonamento no LINUXPADRÃO e no LINUX-SMART. Ao exibir os dados coletados, utilizamos o termo Consumo para indicar o número de ticks gastos em uma função e a Razão indica a relação entre o tamanho da função e o número de ticks consumidos pela respectiva função.

É importante ressaltar que a resolução no LINUX-SMART é de 1ms e no LINUXPADRÃO é de $10 \mathrm{~ms}$. Portanto, um tick de clock custa $1 \mathrm{~ms}$ no LINUX-SMART e $10 \mathrm{~ms}$ no LINUX-PADRÃO.

\begin{tabular}{|c|c|c|c|c|}
\hline \multirow{2}{*}{ Função } & \multicolumn{2}{|c|}{ LINUX-SMART } & \multicolumn{2}{c|}{ LINUX-PADRÃO } \\
\cline { 2 - 5 } & Consumo & Razão & Consumo & Razão \\
\hline SHATransform & 3 & 0.0004 & - & - \\
\hline _-brelse & 1 & 0.0147 & 1 & 0.0147 \\
\hline _-free_page & 1 & 0.0047 & - & - \\
\hline -_get_fd_set & 1 & 0.0100 & - & - \\
\hline -_get_free_pages & 18 & 0.0405 & 3 & 0.0068 \\
\hline -_iget & 22 & 0.0404 & 1 & 0.0018 \\
\hline _-set_fd_set & 1 & 0.0227 & - & - \\
\hline -_set_origin & 3 & 0.0341 & - & - \\
\hline -_wait_on_buffer & 1 & 0.0054 & - & - \\
\hline -_wait_on_page & 2 & 0.0114 & - & - \\
\hline _namei & 1 & 0.0044 & - & - \\
\hline
\end{tabular}




\begin{tabular}{|c|c|c|c|c|}
\hline \multirow{2}{*}{ Função } & \multicolumn{2}{|c|}{ LINUX-SMART } & \multicolumn{2}{|c|}{ LINUX-PADRÃO } \\
\hline & Consumo & Razão & Consumo & Razão \\
\hline add_request & 3 & 0.0058 & 1 & 0.0019 \\
\hline add_timer & 5 & 0.0144 & - & - \\
\hline alloc_skb & 5 & 0.0151 & 1 & 0.0030 \\
\hline allow_interrupts & 2 & 0.2500 & - & - \\
\hline aux_select & 2 & 0.0161 & - & - \\
\hline bcopy & 4 & 0.1000 & - & - \\
\hline bread & 1 & 0.0081 & - & - \\
\hline breada & 2 & 0.0054 & - & - \\
\hline brw_page & 15 & 0.0167 & - & - \\
\hline build_mmap_avl & 2 & 0.0040 & - & - \\
\hline change_protection & 1 & 0.0033 & - & - \\
\hline change_termios & 1 & 0.0025 & - & - \\
\hline check & 14 & 0.1061 & - & - \\
\hline check_deadline & 34 & 0.3864 & - & - \\
\hline check_tty_count & 4 & 0.0278 & - & - \\
\hline check_wild_interrupts & 202 & 1.3289 & 22 & 0.1447 \\
\hline clear_inode & 4 & 0.0120 & - & - \\
\hline clear_page_tables & 13 & 0.0613 & 1 & 0.0047 \\
\hline close fp & 2 & 0.0217 & 1 & 0.0109 \\
\hline con_write & 11 & 0.0022 & 1 & 0.0002 \\
\hline con_write_room & 2 & 0.0833 & - & - \\
\hline conv_uni_to_pc & 2 & 0.0125 & - & - \\
\hline copy_page_range & 51 & 0.0557 & 5 & 0.0055 \\
\hline copy_strings & 10 & 0.0202 & 2 & 0.0040 \\
\hline copy_thread & 2 & 0.0036 & - & - \\
\hline cp_new_stat & 5 & 0.0174 & - & - \\
\hline create_elf_tables & 4 & 0.0064 & - & - \\
\hline datagram_select & 10 & 0.0263 & 2 & 0.0053 \\
\hline dcache_add & 51 & 0.1262 & 1 & 0.0025 \\
\hline dcache_lookup & 22 & 0.0618 & 4 & 0.0112 \\
\hline def_callback2 & 1 & 0.0227 & - & - \\
\hline del_timer & 1 & 0.0156 & - & - \\
\hline delay_50ms & 2601 & 130.0500 & 306 & 15.3000 \\
\hline dir_namei & 2 & 0.0066 & - & - \\
\hline do_bottom_half & 18 & $0.187 \overline{5}$ & - & - \\
\hline do_execve & 1 & 0.0023 & - & - \\
\hline do_exit & 1 & 0.0020 & - & - \\
\hline do_fork & 26 & 0.0102 & 6 & 0.0030 \\
\hline do_gettimeofday & 2 & 0.0294 & 2 & 0.0294 \\
\hline do_mmap) & 7 & 0.0084 & - & - \\
\hline (o.munmap) & 8 & 0.0061 & - & - \\
\hline do_no_page & 126 & $0.15 \overline{5} 9$ & 9 & 0.0111 \\
\hline do_open & 1 & 0.0034 & - & - \\
\hline
\end{tabular}




\begin{tabular}{|c|c|c|c|c|}
\hline \multirow{2}{*}{ Função } & \multicolumn{2}{|c|}{ LINUX-SMART } & \multicolumn{2}{|c|}{ LINUX-PADRÃO } \\
\hline & Consumo & Razão & Consumo & Razão \\
\hline do_page_fault & 23 & 0.0312 & 3 & 0.0041 \\
\hline do_readv_writev & 2 & 0.0033 & 1 & 0.0016 \\
\hline do_select & 30 & 0.0469 & 3 & 0.0047 \\
\hline do_wp_page & 312 & 0.4906 & 31 & 0.0487 \\
\hline el3_probe & 1 & 0.0008 & - & - \\
\hline error_code & 16 & 0.2222 & 2 & 0.0278 \\
\hline exit_mmap & 3 & 0.0183 & - & - \\
\hline exit_notify & 1 & 0.0021 & - & - \\
\hline ext2_add_entry & 2 & 0.0027 & - & - \\
\hline ext2_alloc_block & 1 & 0.0024 & - & - \\
\hline ext2_bmap & 3 & 0.0051 & - & - \\
\hline ext2_check_blocks_bitmap & 23 & 0.0336 & 2 & 0.0029 \\
\hline ext2_check_dir_entry & 58 & 0.3222 & 2 & 0.0111 \\
\hline ext2_count_free & 28 & 0.3500 & - & - \\
\hline ext2_discard_prealloc & 1 & 0.0208 & - & - \\
\hline ext2_file_write & 1 & 0.0009 & - & - \\
\hline ext2_find_entry & 31 & 0.0433 & 4 & 0.0056 \\
\hline ext2_follow_link & 1 & 0.0028 & 2 & 0.0057 \\
\hline ext2_getblk & 10 & 0.0180 & - & - \\
\hline ext2_lookup & 1 & 0.0027 & - & - \\
\hline ext2_match & 17 & 0.1700 & 4 & 0.0400 \\
\hline ext2_new_block & 1 & 0.0004 & - & - \\
\hline ext2_permission & 2 & 0.0116 & - & - \\
\hline ext2_read_inode & 6 & 0.0070 & - & - \\
\hline ext2_readdir & 8 & 0.0051 & - & - \\
\hline ext2_update_inode & 3 & 0.0041 & 1 & 0.0014 \\
\hline fcntl_setlk & 1 & 0.0026 & - & - \\
\hline filemap_nopage & 182 & 0.2473 & 18 & 0.0245 \\
\hline filldir & 7 & 0.0427 & - & - \\
\hline flush_old_exec & 3 & 0.0090 & - & - \\
\hline follow_link & 1 & 0.0089 & - & - \\
\hline free_page_tables & 11 & 0.0611 & 2 & 0.0111 \\
\hline free_pages & 23 & 0.0858 & 1 & 0.0037 \\
\hline free_wait & 2 & 0.0294 & - & - \\
\hline generic_file_mmap & 2 & 0.0111 & - & - \\
\hline generic_file_read & 34 & 0.0223 & 1 & 0.0007 \\
\hline get_cmd640_reg_pci2 & 1 & 0.0132 & - & - \\
\hline get_empty_filp & 3 & 0.0167 & 1 & 0.0056 \\
\hline get_empty_inode & 15 & 0.0431 & 2 & 0.0057 \\
\hline get_hash_table & 45 & 0.2616 & 8 & 0.0465 \\
\hline
\end{tabular}




\begin{tabular}{|c|c|c|c|c|}
\hline \multirow{2}{*}{ Função } & \multicolumn{2}{|c|}{ LINUX-SMART } & \multicolumn{2}{|c|}{ LINUX-PADRÃO } \\
\hline & Consumo & Razão & Consumo & Razão \\
\hline get_pid & 4 & 0.0417 & - & - \\
\hline get_scrmem & 5 & 0.0357 & - & - \\
\hline get_unused_buffer_head & 2 & 0.0263 & - & - \\
\hline get_unused_fd & 3 & 0.0300 & - & - \\
\hline get_write_access & 2 & 0.0179 & - & - \\
\hline getblk & 19 & 0.0199 & 2 & 0.0021 \\
\hline getname & 7 & 0.0219 & - & - \\
\hline grow_inodes & 2 & 0.0132 & - & - \\
\hline handle_signal & 1 & 0.0069 & - & - \\
\hline ide_do_request & 38 & 0.0232 & 8 & 0.0049 \\
\hline ide_probe_pci & 2 & 0.0192 & - & - \\
\hline ide_wait_stat & 11 & 0.0466 & - & - \\
\hline inet_select & 1 & 0.0227 & 1 & 0.0227 \\
\hline init_dev & 1 & 0.0009 & - & - \\
\hline inode_getblk & 4 & 0.0097 & - & - \\
\hline insert_vm_struct & 9 & 0.0121 & 3 & 0.0040 \\
\hline iput & 7 & 0.0175 & 1 & 0.0025 \\
\hline kfree & 8 & 0.0267 & - & - \\
\hline kfree_skb & 6 & 0.0246 & - & - \\
\hline kfree_skbmem & 1 & 0.0125 & - & - \\
\hline kmalloc & 10 & 0.0194 & - & - \\
\hline ll_rw_block & 4 & 0.0100 & - & - \\
\hline load_elf_binary & 5 & 0.0017 & - & - \\
\hline load_inode_bitmap & 1 & 0.0027 & - & - \\
\hline lookup & 4 & 0.0161 & - & - \\
\hline make_request & 14 & 0.0137 & 1 & 0.0010 \\
\hline memcpy_fromiovec & 6 & 0.0500 & 1 & 0.0083 \\
\hline merge_segments & 4 & 0.0033 & 3 & 0.0025 \\
\hline mlock_fixup & 2 & 0.0033 & - & - \\
\hline mprotect_fixup & 1 & 0.0017 & 1 & 0.0017 \\
\hline n_tty_open & 3 & 0.0127 & - & - \\
\hline n_tty_set_termios & 1 & 0.0017 & - & - \\
\hline namei & 1 & 0.0139 & - & - \\
\hline new_page_tables & 12 & 0.0732 & 1 & 0.0061 \\
\hline normal_select & 5 & 0.0112 & - & - \\
\hline old_mmap & 1 & 0.0078 & - & - \\
\hline old_select & 1 & 0.0125 & - & - \\
\hline open_namei & 2 & 0.0019 & 1 & 0.0010 \\
\hline opost & 1 & 0.0022 & - & - \\
\hline
\end{tabular}




\begin{tabular}{|c|c|c|c|c|}
\hline \multirow{2}{*}{ Função } & \multicolumn{2}{|c|}{ LINUX-SMART } & \multicolumn{2}{|c|}{ LINUX-PADRÃO } \\
\hline & Consumo & Razão & Consumo & Razão \\
\hline padzero & 37 & 0.6167 & 5 & 0.0833 \\
\hline page_fault & 18 & 1.5000 & 1 & 0.0833 \\
\hline permission & 3 & 0.0142 & - & - \\
\hline pipe_read & 2 & 0.0045 & 1 & 0.0022 \\
\hline pipe_write & 1 & 0.0019 & - & - \\
\hline poll_aux_status & 1 & 0.0114 & - & - \\
\hline poll_aux_status_nosleep & 1 & 0.0179 & - & - \\
\hline prepare_binprm & 1 & 0.0024 & - & - \\
\hline printk & 1 & 0.0033 & - & - \\
\hline probe_irq_on & 800 & 8.0000 & 80 & 0.8000 \\
\hline proc_lookup & 1 & 0.0032 & - & - \\
\hline put_dirty_page & 9 & 0.0250 & - & - \\
\hline put_page & 1 & 0.0278 & - & - \\
\hline put_unused_buffer_head & 2 & 0.0179 & 1 & 0.0089 \\
\hline putname & 1 & 0.0625 & 1 & 0.0625 \\
\hline read_exec & 2 & 0.0056 & - & - \\
\hline read_inode_bitmap & 1 & 0.0083 & - & - \\
\hline read_mem & 4 & 0.0192 & - & - \\
\hline read_profile & 11 & 0.0458 & 2 & 0.0083 \\
\hline refile_buffer & 2 & 0.0025 & - & - \\
\hline remove_shared_vm_struct & 1 & 0.0132 & - & - \\
\hline ret_from_sys_call & 25 & 0.1838 & 5 & 0.0368 \\
\hline rs_init & 1 & 0.0010 & - & - \\
\hline save_i387 & 1 & 0.0081 & - & - \\
\hline schedule & 90 & 0.0567 & 5 & 0.0077 \\
\hline scrup & 6 & 0.0106 & 1 & 0.0018 \\
\hline sel_loadlut & 1 & 0.0179 & - & - \\
\hline send_data & 5 & 0.0284 & - & - \\
\hline session_of_pgrp & 1 & 0.0167 & - & - \\
\hline set_cursor & 69 & 0.3594 & 7 & 0.0365 \\
\hline set_writetime & 4 & 0.0625 & 1 & 0.0156 \\
\hline sock_ioctl & 2 & 0.0500 & - & - \\
\hline sock_read & 2 & 0.0104 & - & - \\
\hline sock_readv_writev & 1 & 0.0048 & - & - \\
\hline sock_select & 1 & 0.0208 & 1 & 0.0208 \\
\hline sock_wake_async & 4 & 0.0370 & - & - \\
\hline sock_wmalloc & 2 & 0.0238 & - & - \\
\hline sock_write & 1 & 0.0056 & - & - \\
\hline startup_32 & 4 & 0.0213 & 4 & 0.0213 \\
\hline swap_tick & 1 & 0.0061 & - & - \\
\hline sync_supers & 1 & 0.0086 & - & - \\
\hline sys_brk & 1 & 0.0031 & - & - \\
\hline sys_close & 1 & 0.0125 & - & - \\
\hline
\end{tabular}




\begin{tabular}{|c|c|c|c|c|}
\hline \multirow{2}{*}{ Função } & \multicolumn{2}{|c|}{ LINUX-SMART } & \multicolumn{2}{|c|}{ LINUX-PADRĀO } \\
\hline & Consumo & Razão & Consumo & Razão \\
\hline sys_fcntl & 2 & 0.0024 & - & - \\
\hline sys_get_kernel_syms & 1 & 0.0027 & - & - \\
\hline sys_gettimeofday & 1 & 0.0089 & - & - \\
\hline sys_ioctl & 2 & 0.0074 & - & - \\
\hline sys_lseek & 2 & 0.0088 & - & - \\
\hline sys_newfstat & 1 & 0.0109 & - & - \\
\hline sys_newuname & 2 & 0.0294 & - & - \\
\hline sys_personality & 1 & 0.0093 & - & - \\
\hline sys_read & 3 & 0.0129 & - & - \\
\hline sys_select & 10 & 0.0164 & - & - \\
\hline sys_sgetmask & 1 & 0.0833 & - & - \\
\hline sys_sigaction & 4 & 0.0130 & - & - \\
\hline sys_swapon & 8 & 0.0051 & 1 & 0.0006 \\
\hline sys_wait4 & 6 & 0.0071 & - & - \\
\hline sys_write & 6 & 0.0155 & 1 & 0.0026 \\
\hline sys_writev & 1 & 0.0060 & - & - \\
\hline system_call & 27 & 0.2177 & 3 & 0.0242 \\
\hline tcp_listen_select & 3 & 0.0197 & - & - \\
\hline tcp_select & 3 & 0.0089 & - & - \\
\hline timer_bh & 3 & 0.0037 & - & - \\
\hline truncate_inode_pages & 2 & 0.0063 & 1 & 0.0032 \\
\hline try_to_read_ahead & 5 & 0.0169 & - & - \\
\hline tty_hung_up_p & 1 & 0.0500 & - & - \\
\hline tty_ioctl & 1 & 0.0005 & - & - \\
\hline tty_select & 2 & 0.0122 & - & - \\
\hline unix_gc & 1 & 0.0016 & - & - \\
\hline unix_ioctl & 3 & 0.0192 & - & - \\
\hline unix_recvmsg & 32 & 0.0307 & 2 & 0.0019 \\
\hline unix_select & 7 & 0.2500 & - & - \\
\hline unix_sendmsg & 11 & 0.0111 & - & - \\
\hline unmap_fixup & 4 & 0.0087 & - & - \\
\hline unplug_device & 6 & 0.1364 & - & - \\
\hline update_process_times & 1 & 0.0022 & - & - \\
\hline update_wall_time & 1 & 0.0132 & - & - \\
\hline verify_area & 31 & 0.0705 & 6 & 0.0136 \\
\hline vm_enough_memory & 2 & 0.0333 & 1 & 0.0167 \\
\hline vt_ioctl & 3 & 0.0004 & - & - \\
\hline wait_til_ready & 1 & 0.0068 & - & - \\
\hline wake_up & 2 & 0.0053 & - & - \\
\hline wake_up_interruptible & 4 & 0.0109 & 1 & 0.0043 \\
\hline zap_page_range & 18 & 0.0429 & 1 & 0.0024 \\
\hline total & 5807 & 0.0092 & $61 j$ & 0.0010 \\
\hline
\end{tabular}

